Portland State University

PDXScholar

Fall 11-27-2018

\title{
The Role of the Academic Analyst in Shared Governance
}

Rebecca Ann Mathern

Portland State University

Follow this and additional works at: https://pdxscholar.library.pdx.edu/open_access_etds

Part of the Higher Education Commons, Public Administration Commons, and the Public Affairs Commons

Let us know how access to this document benefits you.

\section{Recommended Citation}

Mathern, Rebecca Ann, "The Role of the Academic Analyst in Shared Governance" (2018). Dissertations and Theses. Paper 4653.

https://doi.org/10.15760/etd.6537

This Dissertation is brought to you for free and open access. It has been accepted for inclusion in Dissertations and Theses by an authorized administrator of PDXScholar. Please contact us if we can make this document more accessible: pdxscholar@pdx.edu. 
The Role of the Academic Analyst in Shared Governance

by

Rebecca Ann Mathern

A dissertation submitted in partial fulfillment of the requirements for the degree of

\author{
Doctor of Philosophy \\ in \\ Public Affairs and Policy \\ Dissertation Committee: \\ Craig Shinn, Chair \\ Christine Cress \\ Kathi Ketcheson \\ Craig Kolins
}

Portland State University

2018 


\section{(C) 2018 Rebecca Ann Mathern}

\section{(c) $(1) \Theta \Theta$}

EY No ND This work is licensed under the Creative Commons Attribution -

Noncommercial - No Derivatives 4.0 International License. View license at

http://creativecommons.org/licenses/by-nc-nd/4.0/ 


\begin{abstract}
This research explores the roles of academic professionals in higher education, specific to how they engage in decision-making processes. Academic professionals provide important functions in higher education work but there is little in the literature about these actors and their contributions to leadership and governance. A literature review triangulated role theory, organization theory, and the shared-governance field of study to bring together actors within higher education and compare their involvement based on the shared-governance model in operation at different institutions. The researcher introduced the hypothesis that when registrars are not involved in curriculum management, there may be negative effects on student success. In the study, a survey was administered to registrars and faculty members representing nearly 200 institutions to ask about the role of the registrar in specific policies and curriculum practices. Results were measured using Fisher's Exact Test but also interpreted through multiple qualitative approaches, including inductive analysis. Outcomes were not significant in the quantitative test results, but respondents overwhelmingly indicated that the role of the registrar in shared governance affected student success. Themes were recorded to articulate the most common reasons respondents offered for how the registrar was involved in academic policy, curriculum management, and supporting student success. Results of the inductive analysis provided several themes that pointed to unique roles for the registrar, such as leading from behind and acting as a compliance authority, even when partners do not appreciate being held to compliance standards. Implications for practice focused on the qualitative outcomes of the survey. Suggestions for future
\end{abstract}


research included further review of quantitative data outcomes and exploring ideas from inductive analysis around leading from behind and acting as a compliance authority. 


\section{Dedication}

I dedicate this dissertation, and its extraordinarily long journey, to my partner, Patrick, my children, Thea and Freya, and to my parents, Ann and Charlie. Without them, I would not have made it to this point. Mom, you gave me the passion for learning; Dad, you taught me to be too stubborn to quit. Thea, Freya, and Pat, you gave me the grace of time, understanding, and love. 


\section{Acknowledgments}

My appreciation begins with my dissertation committee for the support, encouragement, and patience they gave me. Dr. Christine Cress, Dr. Kathi Ketcheson, and Dr. Craig Kolins have been beyond supportive, and I am grateful for all of them. Dr. Kolins’ writing chair was most uncomfortably motivational. My heartfelt, eternal gratitude and admiration goes to my advisor, Dr. Craig Shinn. He sometimes pulled and sometimes pushed me through this long and winding process but was always there with me never giving up on my interests and goals, reminding me to demonstrate my expertise in the field. Thank you, Dr. Shinn, for the never-ending affirmations and positivity you provided while holding me to standards and rigor that demonstrate quality doctoral work.

During my final stages of research and writing, I had the grace of working with amazing colleagues and friends who provided expertise and support. Thanks to Dr. Alix Gitelman for her statistical expertise and guidance as well as her supportive cajoling. Thank you to Cynthia Chapman for her outstanding, any-hour-of-the-day editing services. Thank you to Jennifer Lembach for talking through my research questions and helping me re-center. I am grateful for my Ph.D. study partner and friend, Ally. To all my friends and family, especially DC, WB, JJ, TN, and MM (my neighbor women), thank you for your support!

My family is a perfect, cherished prize. I am grateful for their patience and understanding while I worked, parented, and schooled for so many years. I missed many important moments, but watch out, I will be making up for it now. Pat, Thea, and Freya, you mean the world to me. 


\section{Table of Contents}

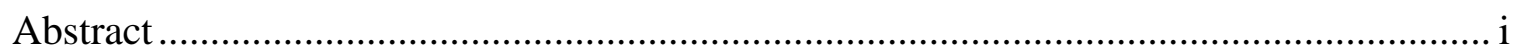

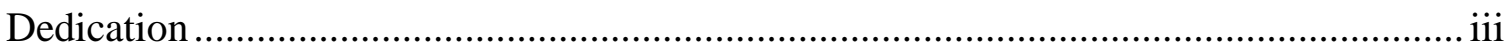

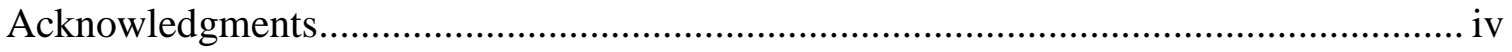

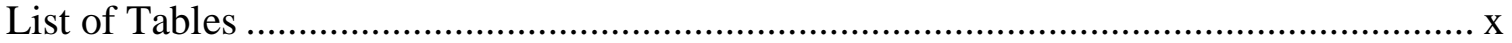

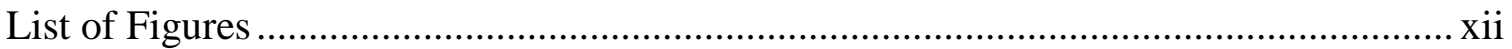

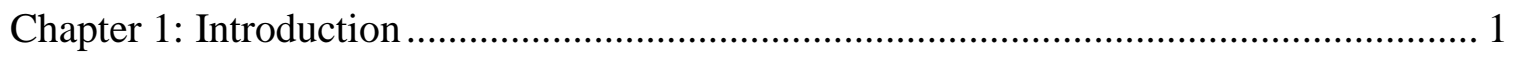

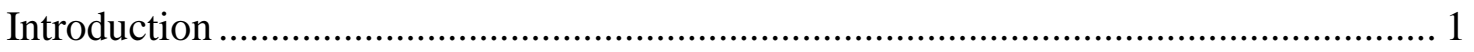

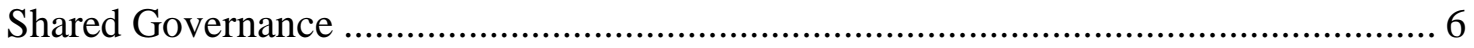

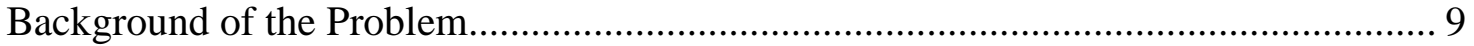

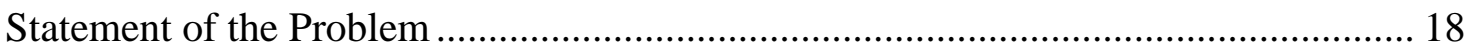

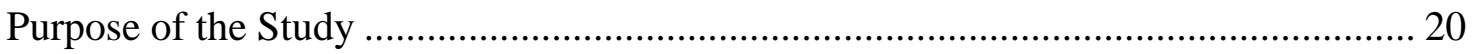

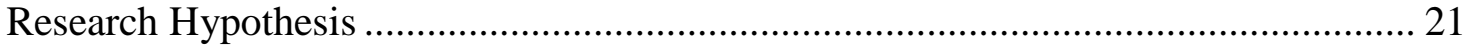

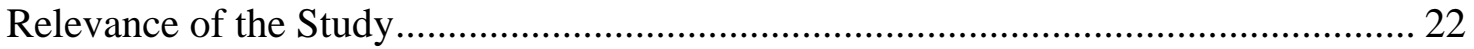

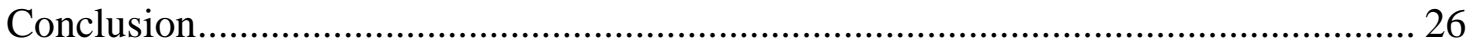

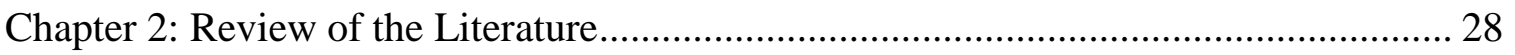

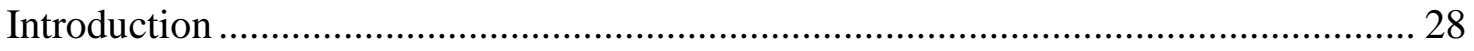

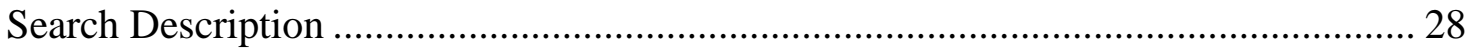




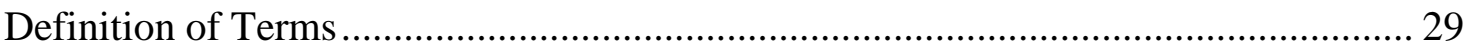

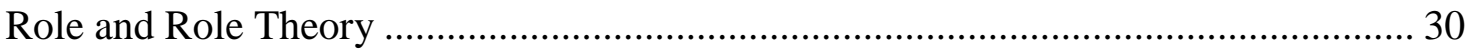

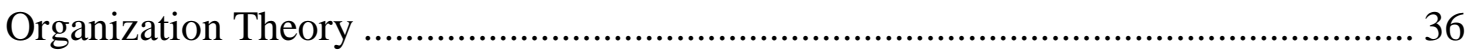

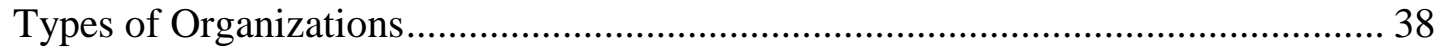

Two Models: The School System and Mintzberg's Bureaucracy ............................ 40

Shared Governance ....................................................................................... 52

Models of Shared Governance ........................................................................ 54

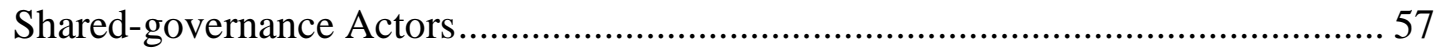

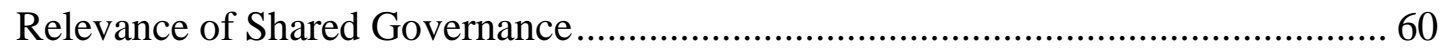

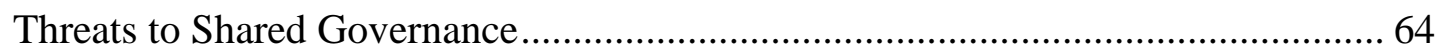

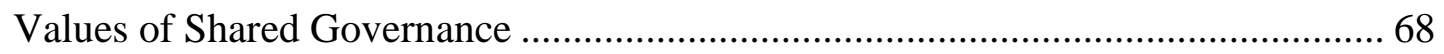

Integration of Role Theory, Organization Theory, and Shared-governance Theory .... 70

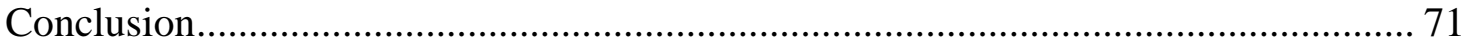

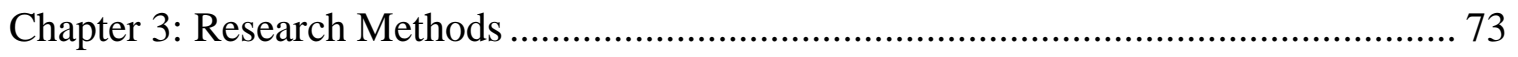

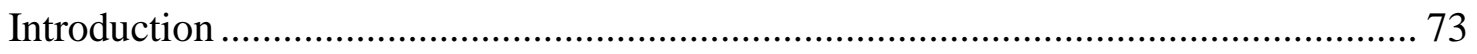

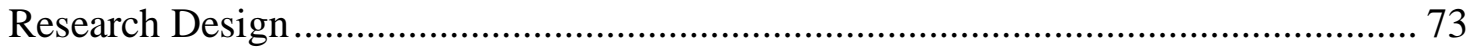

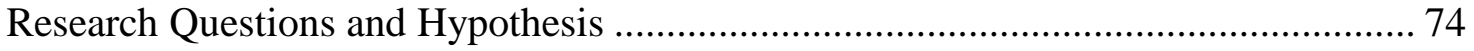

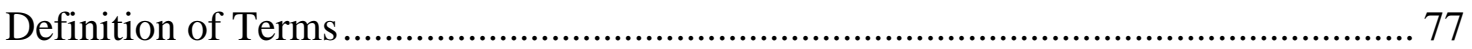

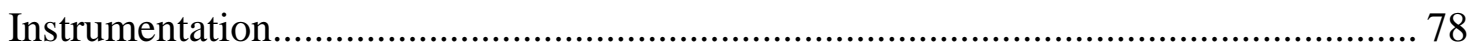




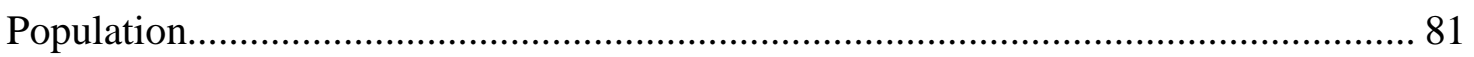

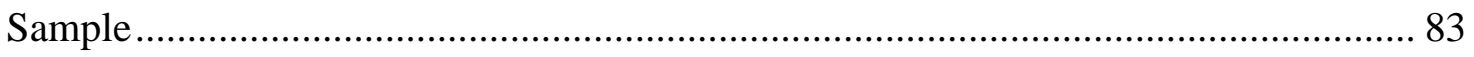

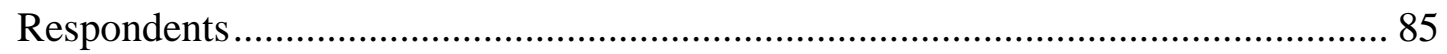

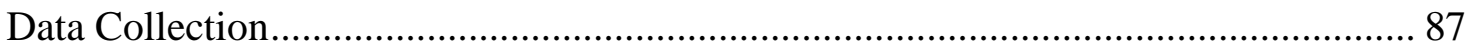

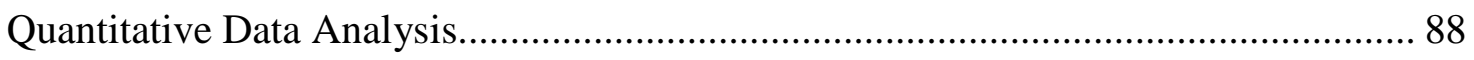

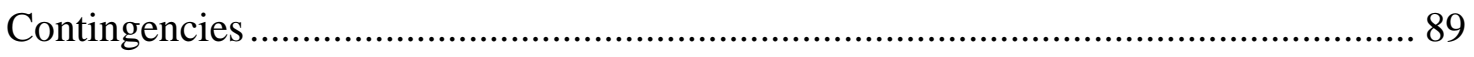

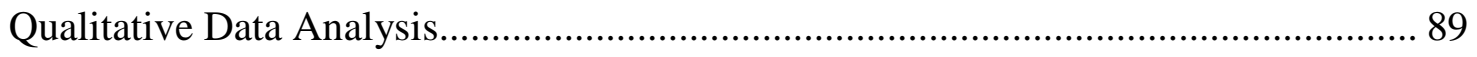

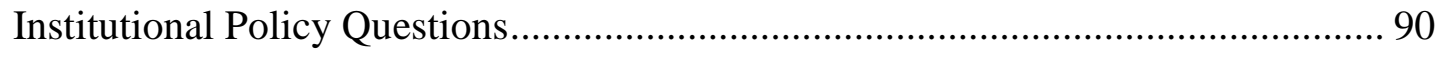

Registrar's Involvement and Impact to Students............................................... 92

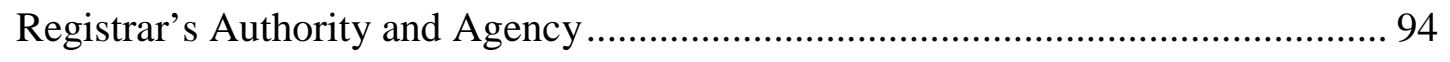

Inductive Review of Qualitative Responses ..................................................... 95

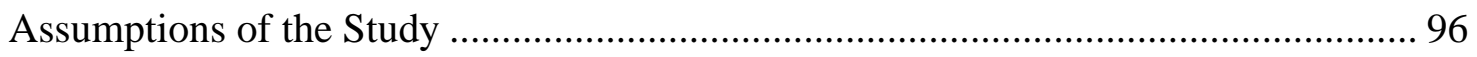

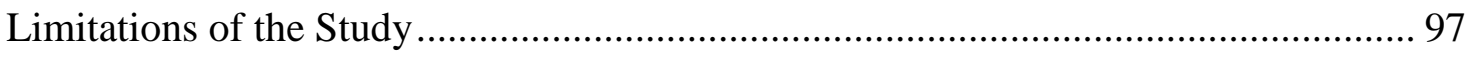

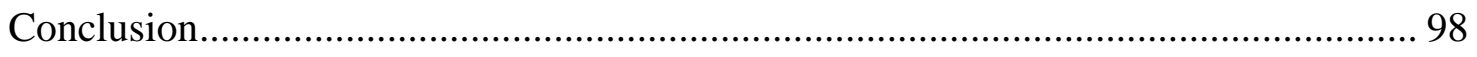

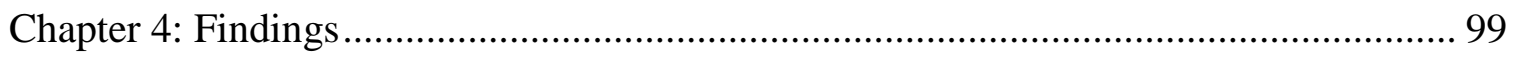

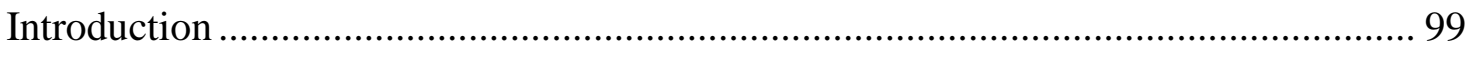

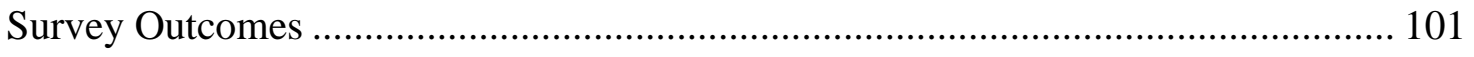

Respondent Demographics.......................................................................... 102

Level of Highest Degree Attainment.............................................................. 102 
Number of Years in Education Field................................................................ 102

Registrars versus Faculty Curriculum Leaders.......................................................... 103

Shared-governance Models ......................................................................................... 104

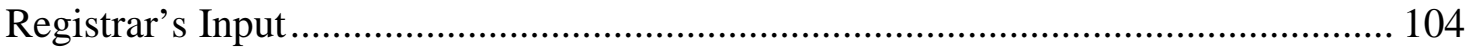

Perceived impact on students ................................................................................ 107

Fisher's Exact Test Findings ................................................................................. 112

Qualitative Research ……................................................................................. 118

Specific Policy Questions........................................................................................... 118

Qualitative and Quantitative Results Compared ..................................................... 125

Registrar Only Feedback .............................................................................. 128

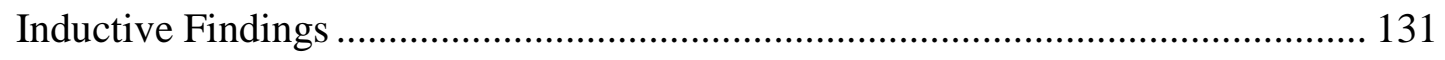

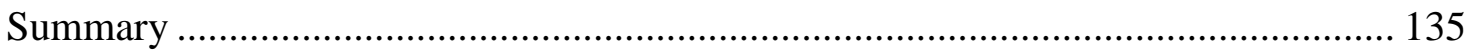

Chapter 5: Discussion \& Conclusions ..................................................................... 138

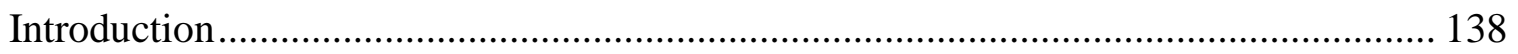

Summary of Research Questions and Methods......................................................... 139

Limitations of the Research......................................................................................... 140

Discussion of Findings and Suggestions for Future Research ..................................... 141

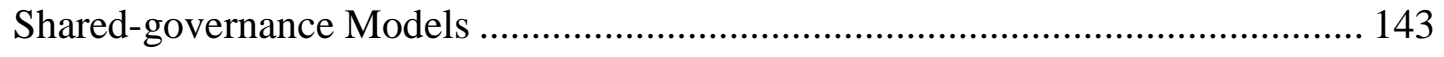

Input from the Registrar .................................................................................. 144 
Perceived Impact on Students.......................................................................... 145

The Qualitative and Quantitative Perspectives Compared ......................................... 150

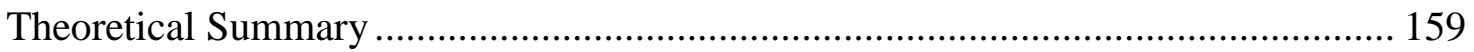

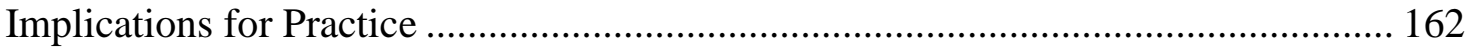

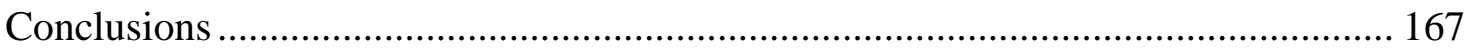

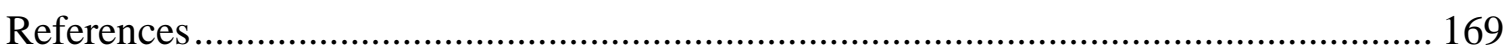

Appendix A: Survey Instrument .................................................................................. 182

Appendix B: Fisher’s Exact Test Results: Analysis of Survey on Shared Governance and

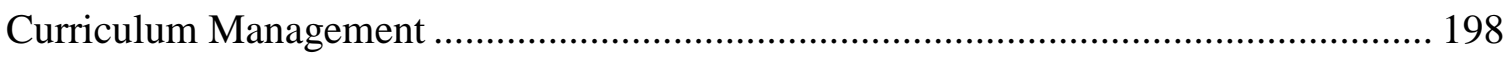

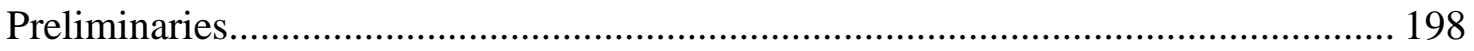

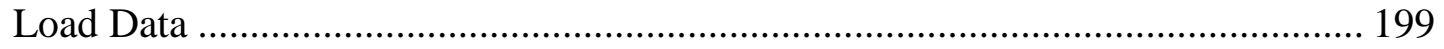

Some Preprocessing................................................................................................ 199

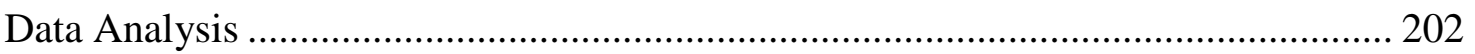

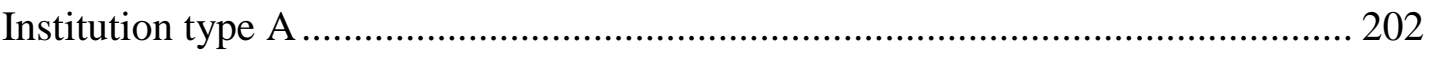

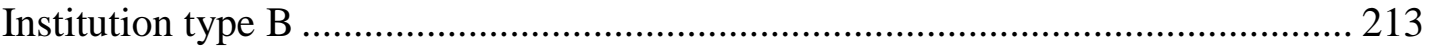

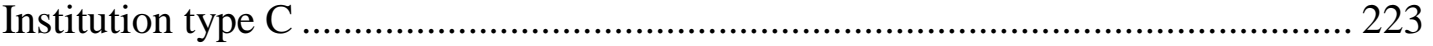

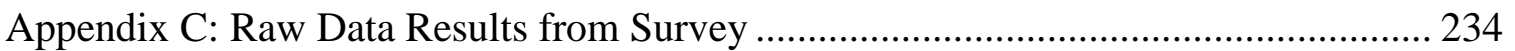

Appendix D: Birnbaum Permission (Figure) ............................................................. 240

Appendix E: Mintzberg Permission (Figure)................................................................. 245 


\section{List of Tables}

Table 1. Actors and their Level of Involvement in Shared Governance ........................... 14

Table 2. Overlay of Literature Review Topics and Research ...................................... 29

Table 3. Definitions of Strength for Shared-governance Models by Decision-making

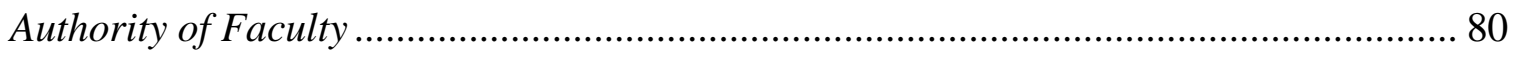

Table 4. Sorting Rubric for Each Shared-governance Model by Behavior of Faculty..... 85

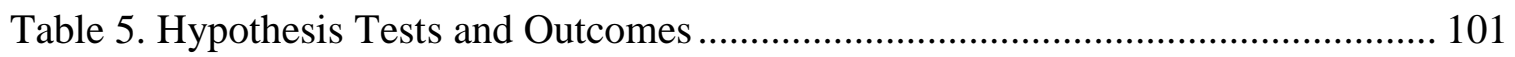

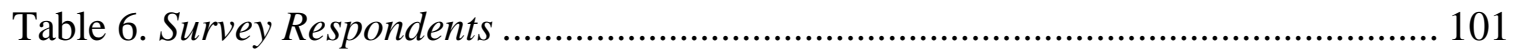

Table 7. Number of Years in the Education Field ...................................................... 103

Table 8. Input from the Registrar ...................................................................... 105

Table 9. Registrars’ Input by Shared-governance Model............................................ 107

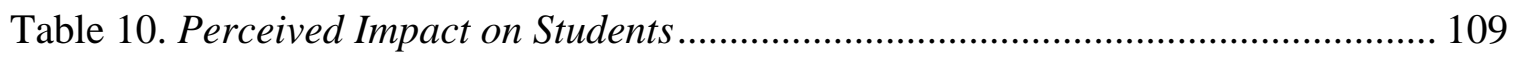

Table 11. Perceived Impact on Students by Shared-governance Model ......................... 111

Table 12. Fisher's Exact Test Distributions ............................................................. 113

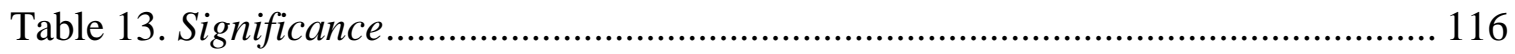

Table 14. Role of the Registrar by Shared-governance Model...................................... 121

Table 15. Role of the Registrar in Defining Course Equivalencies by Shared-governance

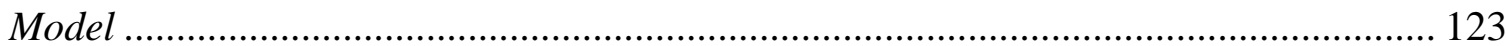

Table 16. Role of the Registrar in Students’ Academic Standing by Shared-governance

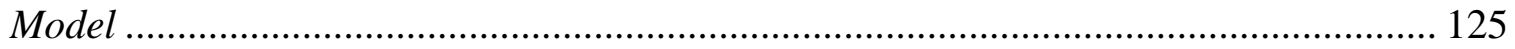

Table 17. Effect of Registrars' Involvement on Students by Shared-governance Model 126 
Table 18. Themes of Registrars' Impact on Students by Shared-governance Model ..... 128

Table 19. Agency Derived from Registrars’ Authority by Shared-governance Model... 130 


\section{List of Figures}

Figure 1. School system by Robert Birnbaum (Birnbaum, 1988, p. 32. Used by permission of John Wiley and Sons and Copyright Clearance Center.)............................ 41

Figure 2. A rendition of the model from Mintzberg that shows the five basic parts of the organization (Mintzberg, 1993, p. 11. Used by permission of the author.)...................... 45 Figure 3. Contrast in importance of types of decentralization by Mintzberg, suggesting an accurate shared-governance model in the professional bureaucracy. (1993, pp. 115, 190. Used by permission of the author.).............................................................................. 51

Figure 4. Sources suggesting a continuum of governance characteristics ....................... 54 Figure 5. Mintzberg’s professional bureaucracy model adaptation (Mintzberg, 1993, p.194. Used by permission of the author.)................................................................... 70 Figure 6. Shared-governance archetype proposed to measure decision-making authority of faculty

Figure 7.Type E: Operating core (Mintzberg 1993, p. 194. Used by permission of the author.) 161

Figure 8. Actors and process in relationship for shared governance within organizations. 162 


\section{Chapter 1: Introduction}

\section{Introduction}

The university registrar at Sunnyside State University works hard to coordinate curriculum issues with academic faculty by sitting on the Curriculum Council of the Faculty Senate. Instructional faculty did a great job of creating the curriculum for their students' majors, minors, and concentrations, but certain areas related to curriculum management are in need of special attention. For instance, course repeatability needs to be determined for all courses, course numbering must be appropriately determined based on number availability and type of course to prevent reuse of course numbers, and new subject codes must be determined judiciously to avoid proliferation of unnecessary codes that only confuse and negatively affect students. The university registrar is called upon to be the conduit between the academic record for the student and the faculty development of the coursework that eventually ends up on an academic record. This challenging role is one that the registrar must harmonize with academic faculty to make decisions in the best interest of consistency on the student record while maintaining the original goal of integrated curriculum development by the teaching faculty.

The registrar at Happy Community College has long attempted to deliver policy directives for leadership but is often faced with the reality that teaching faculty and leadership do not have the same vision for those policies. In an environment where instructional faculty do not vote on academic policies-and are only allowed an opportunity for consultation-this registrar struggles between implementing an action that teaching faculty may not accept and continuing to keep administration satisfied by 
meeting their directives. The navigation of this role is critical to the success of implementing new policy and plans of action. Relationships with academic staff are keys to the success of this registrar's attempt to ensure an equitable implementation of policy that both teaching faculty and administrators want to affect students.

At the University of Blissfulness, a long-standing practice permits teaching faculty to ask administrators to complete their structured curriculum when instructors do not have the release time in their schedule. Department chairs are busy with their teaching assignments, scheduling of courses, and basic curriculum development. Consequently, staff in the curriculum office and in the office of the registrar is left with much instructional design work to complete "on behalf of" the faculty. The registrar and the curriculum office staff struggle with how to make the best decisions on behalf of the teaching faculty without strong feedback and involvement from those instructors.

These fictional examples describe different types of engagement between registrars and instructional faculty as well as different levels of complexity that exists between the two groups. Not only how they interact but also how the cultural construct on each campus affects their interactions combine to shed light on different approaches to the shared-governance models that exists in higher education. The role of the registrar, an academic analyst, working with teaching faculty to accomplish curriculum management is an example of operational, shared governance. This role is part of the administrative branch within a three-tiered approach toward shared governance: teaching faculty, administrators, and trustees. 
The work of an academic analyst, such as the registrar, is performed in an institution of higher education. This particular research focused on the evaluation and study of the academic analyst through the lens of a university registrar in a four-year, public or not-for-profit institution. The context of the research and the empirical setting will influence the outcome and draw comparisons between different types of organizations of higher education. Within a four-year institution in a higher educational setting based on a public or not-for-profit institution, many assumptions were implied. A public school is a public organization, and its impact will be different from that of a private school, especially one that is for profit.

In Understanding and Managing Public Organizations, Hal Rainey (2009) defined organization in such a way that he gave context for the further development of his concept "public organization”. Rainey described organization broadly as a group of people who work together to pursue a goal. Moreover, he characterized organization by the certain elements that serve as a framework for it: environment, tasks, technologies, performance, organizing, leadership, strategies, structures, and processes (Rainey, 2009, pp. 20-22). The definition of public organization has been, over time, hotly debated by organizational theorists as to whether a real difference exists between public and private organizations. In the United States, public organizations (which Rainey defined as supported by government) meet the definition of organization, but Rainey also defined them to include, "providers of services that are not exchanged on economic markets but are justified on the basis of general social values, the public interest, and the politically imposed demands of groups” (Rainey, 2009, p. 68). Dewey’s long-standing definition 
supported this explanation as well when he wrote, “organizations that have a great impact on public interest” (Dewey, 1927, pp. 27-28). Blau and Scott distinguished the public and private as commonweal and business organizations respectively, stating that for commonweals the "prime beneficiary is the public-at-large" and for businesses "owners are the primary beneficiary” (Blau \& Scott, 1962, p. 43). Consequently, the public organization is made of people working together to pursue a goal based on general social values, which benefits the public through positive impact and does so with the elements of an organizational framework as previously defined by Rainey.

While a large number of students seeking higher education attend schools that are publicly funded and supported, history demonstrates that higher education has always been comprised of both public and private organizations. In fact, the National Association of Independent Colleges and Universities lists over 1700 private, non-profit institutions nationwide. They enroll 3.4 million undergraduate students and more than 5 million students total (NAICU, n.d.). While the number of private, nonprofit colleges is large, because they serve a smaller population, they do not represent an equally large percent of college attendees. In 2016, The Chronicle of Higher Education reported in its Almanac that the average enrollment at public institutions was almost four times that of a private, nonprofit college (Data from the 2016 Almanac, 2016).

Organizational theorists have debated the value of whether organization theory should be applied differently to public versus private organizations. Herbert Simon, a founding theorist, framed his work on all types of organizations. Rainey described Simon's work as being concentrated on general analyses of organizations with insights 
about organizational processes that apply across all types of organizations (Rainey, 2009, p. 60).

For this research and subsequent analysis, the application of organization theory was based mostly on public institutions. One could argue that a public university and a private, nonprofit university have similar missions-to educate the student without a focus on revenue generation; however, the same cannot be said about the for-profit, higher education institutions. For that reason, this research did not include private, forprofit organizations in this comparison but did include some private, nonprofit institutions. An unanswered question was whether the private, nonprofit institution is viewed as an organization that serves the public (for the general good) or if it serves only its trustees, who may or may not seek public good as a value of the institution's individual mission. While interesting, this question was not a primary consideration in this research; consequently, it remains unanswered in this writing, even though a small number of private, nonprofit schools are included in the research.

Both two- and four-year schools are public institutions. The Carnegie Classifications ${ }^{\circledR}$ defined associate’s colleges, typically two-year schools, as “institutions at which the highest level degree awarded is an associate’s degree” (Indiana University Center for Postsecondary Research, n.d.3, Carnegie basic classification description). These schools have many options for learning, but the basic offerings include applied associate's degrees, which are terminal, or associate’s degrees that serve as the first two years of a four-year degree. The Carnegie Classification ${ }^{\circledR}$ defines the four-year institutions more comprehensively because many traditional four-year schools offer not 
only baccalaureate degrees but also award master’s and doctoral degrees (Indiana University Center for Postsecondary Research, n.d.3, Carnegie basic classification description). This research focused on large four-year institutions, specifically those defined as doctorate-granting universities. Specific definitions are provided in the chapter describing the methods for the research.

\section{Shared Governance}

In its simplest form, shared governance is the way in which higher education is structured, operated, and managed-but it can mean so much more. Gary Olson described it this way:

... [I]t is a delicate balance between faculty and staff participation in planning and decision-making processes, on the one hand, and administrative accountability on the other. . . . Shared governance has come to connote two complementary and sometimes overlapping concepts: giving various groups of people a share in key decision-making processes, often through elected representation; and allowing certain groups to exercise primary responsibility for specific areas of decision making (Olson, 2009, pp. 33-35).

Olson's perspective on the overlapping concepts is accurate because in a distributed decision-making model, the specific areas of decision making are clear but are also promised through elected representation. In a more robust approach, Kezar and Eckel, leading authors on shared governance, provided a more artifact-based definition of governance:

At the broadest level, most theories assume that governance refers to the process of policy making and macro-level decision making within higher education. Governance has typically included scholarship on state boards, board of trustees, faculty senates, and student government. It is a multilevel phenomenon including various bodies and processes with different decision-making functions. Certain entities tend to have authority over 
specific kinds of decisions, such as faculty senates for curriculum or boards of trustees for budgetary issues (Kezar \& Eckel, 2004, p. 375).

This definition is more robust because it offers specific examples about the duties of the daily work of the actors in those roles and helps actors understand their role in the three-legged stool describing shared governance.

While in existence much earlier, the concept of shared governance was limited, mentioned little in books and articles until 1966 when a formal document, the Statement on Government of Colleges and Universities” was published (AAUP, 1967, rev. 1990). This was a joint statement by the American Association of University Professors (AAUP), the America Council on Education (ACE), and the Association of Governing Boards of Universities and Colleges (AGB). It attempted to capture the thoughts of many leaders in university governance, such as Clark Kerr, former president of University of California and former chair of the Carnegie Commission on Higher Education, yet offered guidance and direction for the growing number of institutions that might use these guidelines differently because,

... [C]ampus governance will vary according to the type, size, and sponsorship of the college or university. ... In effect, it urges maximum consultation and courtesy among the constituent groups and avoids laying out very clear boundaries of authority. So, naturally, there are ambiguities (Keller, 2001, p. 309).

This statement—hereafter noted as The Joint Statement— marked the first time facultyinvolved decision-making processes were penned jointly among organizations that supported faculty, administrators, and governing boards.

Kezar and Eckel (2004) alluded to the governance role being applied at the "macro-level”, but quickly the practical matters of operationalizing such institutional 
governance came into play on the actor level. Given the scenarios at Sunnyside State University, Happy Community College, and the University of Blissfulness, it is clear that the academic analyst plays a critical role in shared governance, and that role depends on the institutional type. Moreover, each role can prove unique and potentially challenging, contingent on the relationship between administration and faculty. Understanding the role of the academic analyst in shared governance has not been explored extensively, and the literature offered little guidance on navigating the role effectively.

The importance of the successful relationships between faculty and academic analysts can be summarized in an example showing how both faculty and academic analysts are involved in recording curriculum changes. Faculty play the role of curriculum development experts, and academic analysts are responsible for recording and implementing those changes, roles that Kisling summarized:

A review of curriculum changes and related processes used by an institution is typically don4ie periodically as part of the accreditation selfstudy process to ensure that there is appropriate faculty participation in the process, that the process is accomplished in a reasonable manner, and that the new curriculum is optimally designed to accomplish the mission of the institution. Registrars and curriculum managers care about tracking theses changes in order to ensure that they can be reflected accurately in catalog updates and in updates to course and student records in the institution's [student information system] (Kisling, 2016, pp. 20-21).”

These relationships may have more widespread consequences. Without academic analysts and faculty functioning as partners in shared governance, for example, accreditation bodies may ask whether the principles of accreditation required of the institution are being met. 


\section{Background of the Problem}

Academic analysts may play an important role in administrative decision making; how they impact shared governance seems critical even though it is not formally defined in the refereed literature on the topic. Terminology provided clues to exceptions. For instance, in some sources the term "administration” was used in lieu of the more common reference to the term "president”. In October 1966, for example, the ACE board stated that it "recognizes the statement as a significant step forward in the clarification of the respective roles of governing boards, faculties, and administrations” (AAUP, 1967, rev. 1990). This substitution of "administration" for "president” was notable because in shared-governance literature, typically the reference has been to governing boards, faculty, and the president. This switch was one of the listed insights to "administration" in the literature. The term administration is broad and could represent several different groups of staff, but who staff is and how they are represented in shared governance needed to be further evaluated.

In most cases, academic analysts report to an executive on the academic side of the house or, at the very least, serve in a unit that operates by supporting the academic mission of the institution. The phrase "academic analyst" also stems from other terminology in the literature that supports role theory and organizational design such as "symbolic analyst" and "street-level bureaucrat".

Scott defines role as:

[C]onceptions of appropriate goals and activities for particular individuals or specified social positions ... normative expectations of how the specified actors are supposed to behave ... In an organizational context, 
particular positions are defined to carry specified rights and responsibilities and to have varying access to material resources (Scott, 2001, p. 55).”

How the definition of academic analyst is crafted also creates the normative expectations of behaviors for this role and how it complements the other roles within the organization. Furthermore how the academic analyst is defined uniquely at each institution likely will impact how it influences and operates within the shared-governance model at each particular institution. Berger and Luckmann stated,

We can properly begin to speak of roles when this kind of typification [particular actions associated with particular actors to equal role creation] occurs in the context of an objectified stock of knowledge common to a collectivity of actors (1967, p. 9).

Role and role theory, therefore, has been the source to create a definition of academic analyst, based on the activities of an actor or the expectations of one.

In his body of work, Mintzberg offered multiple organizational models; each model shows power concentrated in a key area, different from the others; the five key components consisted of strategic apex, midline, operating core, technostructure, and support staff. The professional bureaucracy was one of five original models, and the remaining four models were called the simple structure, the machine bureaucracy, the divisionalized form, and the adhocracy (Mintzberg, 1993, p. 7). The academic analyst has roots in Mintzberg's roles of the technostructure analyst as well as of the professional administrator (Mintzberg, 1993, pp. 15, 199). Henry Mintzberg summarized a role in his technostructure similar to administrative analyst as "analysts existing to standardize the work of others, coordinating with others largely through mutual adjustment” (Mintzberg, 1993, p. 16). In his professional bureaucracy model, Mintzberg explained the role of the 
support staff as the professional administrator who "performs a series of roles that gives [the administrator] considerable indirect power in the structure” (Mintzberg, 1993, p. 199). This explanation balanced the reality that much of the direct power in this model belonged to the professionals in the operating core who "seek collective control of the administrative decisions that affect them” (Mintzberg, 1993, p. 197). The administrative analyst is a unique combination of these two actors - analyst and administrator-based on the professional bureaucracy model, wherein Mintzberg believes that universities function operationally. My research focus mainly was inspired by Mintzberg’s professional bureaucracy model.

The definition of administrative analyst was also derived from Robert Reich’s symbolic analyst role, which was described as actors that "solve, identify and broker problems” (Reich, 1991, p. 178) alongside other roles in the workforce. Reich described such roles as made of three main actor components: the symbolic analyst is the role where the new economy operates as compared to the more traditional roles in the workforce of the past, which were those of routine production services and in-person services (Reich, 1991, p.174).

Michael Lipsky introduced an additional perspective on the role of an administrative position charged with a responsibility that includes discretion around interpreting policy. Lipsky elaborated the role of the street-level bureaucrat. In the search for a term that better represented this particular analyst's work, similar characteristics to the street-level bureaucrat kept surfacing. According to Lipsky, a street-level bureaucrat is a "public service worker who interacts directly with citizens in the course of their jobs, 
and who has substantial discretion in the execution of her/his work” (Lipsky, 2010, p. 3). While not equivalent, administrative analysts and street-level bureaucrats carry some unique characteristics that seem to fit well with the technostructure role. Because a basic premise of the academic analyst role does not align with the technostructure (many of these actors are part of the operating core), the street-level bureaucratic role was eliminated as an exact match.

Both actors, the street-level bureaucrat and the academic analyst, find themselves in situations that Lipsky refers to as "situations too complicated to reduce to programmatic formats” (Lipsky, 2010, p. 15). This means that both a street-level bureaucrat and an academic analyst both end up with situations that are unique and potentially the first of their kind each time an encounter with a client occurs. For example, street-level bureaucrats are found walking into potentially dangerous environments as child welfare workers or probation officers. In another instance, academic analysts in an educational setting are being asked to review an exception completely unique to that student which may not occur again in the future. These situations have dramatically different environments yet similar expectations of the role. Lipsky offers additional support as to why discretion amongst street-level bureaucrats is needed, and it is that "the accepted definitions of their tasks call for sensitive observation and judgment (Lipsky, 2010, p. 15).” Without these necessary judgment calls, the similarity of those actors is diminished. And, while starkly different examples, they still display the reason for discretion at those levels and a commonality among the function of those roles. When describing the complexity of the work an analyst does, Scott provided 
“. . . acknowledgement at the outset that there is considerable overlap between the concepts of technology, technical system, task environment, and environment as these terms are employed by organizational analysts” (Scott, 2003, p. 231). Scott used a definition of technology to expand upon the technical tools and systems in order to reflect how the work is performed and what skills are needed to do it (Scott, 2003, p. 231).

The term administrative analyst could be applied broadly because of the inferences from the role described by Reich. However, the nuance of Mintzberg's interpretation in his professional bureaucracy model is what creates a difference between the administrative analyst role and the academic analyst role (Table 1 , row 1 ). The unique combination between Mintzberg’s technostructure analyst and the professional administrator in the support staff is unique to areas within higher education where shared governance exists because working directly with faculty (the operating core) is required. The operating core of the professional bureaucracy are "duly trained and indoctrinated specialists who have control over their own work" and often operate "outside of its own structure, in the self-governing associations its operators join with their colleagues from other Professional Bureaucracies” (Mintzberg, 1993, pp. 190, 192). It is the interaction with the operating core that sets apart the academic analyst role from the administrative analysts within an institution. While administrative analysts in the technostructure exist in many different areas of a higher educational institution, and support staff also work across the institution, academic analysts are limited to the pertinent work of shared governance because they also are so closely connected to the work of the operating core, which is the faculty. This additional relationship limits the actors in this categorical 
Table 1. Actors and their Level of Involvement in Shared Governance

\begin{tabular}{|c|c|c|c|c|c|}
\hline Types of Actors & $\begin{array}{c}\text { Technostructure } \\
\text { Analysts }^{\mathrm{a}}\end{array}$ & $\begin{array}{c}\text { Professional } \\
\text { Administrators }^{b}\end{array}$ & $\begin{array}{l}\text { Academic } \\
\text { Analysts }^{c}\end{array}$ & $\begin{array}{l}\text { Administrative } \\
\text { Analysts }^{d}\end{array}$ & $\begin{array}{c}\text { Level of } \\
\text { Involvement } \\
\text { in Shared } \\
\text { Governance }\end{array}$ \\
\hline $\begin{array}{l}\text { Registrars, } \\
\text { curriculum officers, } \\
\text { program } \\
\text { assessment } \\
\text { directors, } \\
\text { accreditation } \\
\text { officers, institutional } \\
\text { research officers } \\
\text { and directors of } \\
\text { teaching and } \\
\text { learning units }\end{array}$ & Yes & Yes & Yes & Yes & High \\
\hline $\begin{array}{l}\text { Directors of } \\
\text { classroom media } \\
\text { services, librarians } \\
\text { and distance } \\
\text { learning } \\
\text { administrators }\end{array}$ & Sometimes & Yes & Possibly & Yes & Medium \\
\hline $\begin{array}{l}\text { Student services, } \\
\text { auxiliary services } \\
\text { and administrative } \\
\text { services; directors of } \\
\text { student life } \\
\text { programs, campus } \\
\text { architects, budget } \\
\text { officers, human } \\
\text { resources managers } \\
\text { and information } \\
\text { technologists }\end{array}$ & Yes & No & No & Yes & Low \\
\hline
\end{tabular}

aDesigners, planners, technologists who analyze the effect of technical process for managers.

'Managers who determine the outcomes of analysts' work and propose the most effective solution to executives and faculty.

cOperations experts in academic units who analyze the effect of policy and its operational process for managers. dAnalysts who analyze the effect of technical processes on non-academic processes for managers.

framework: examples include registrars, curriculum officers, program assessment

directors, accreditation officers, institutional research officers and directors of teaching and learning units. 
Additionally, other providers of other academic services, such as directors of classroom media services, librarians and distance learning administrators, may meet the threshold for administrative analyst because they: 1) have the categorical reference of the technostructure analyst and 2) they operate as a professional administrator within the professional bureaucracy model (Table 1, row 2). Different from the described academic analysts, these positions may have more specific functionality of role, based on a narrow scope of work but a deeper impact on the policies of the institution within their functional area, that is, depth versus breadth. The second tier of positions had in common the close and directly related link to the academic affairs of the institution while maintaining their status of administrative analyst.

In Locus of Authority, Bowen and Tobin described the three areas of most critical involvement of faculty in shared governance: maintaining academic standards in admissions, curricular content, and student performance specifically, “protecting academic standards against all who would sully them. This responsibility should not change” (2015, p. 165). With this understanding of the faculty role in shared governance, it became clear which types of administrators worked closely with faculty on sharedgovernance issues. Moreover,

Although administrators and trustees at many colleges and universities have welcomed faculty participation in many areas of decision-making (and thus have given faculty the 'voice at the table' that they had long sought), there has been no wide-spread institutionalization of faculty authority outside the basic areas of faculty appointments/advancements and responsibility for maintaining academic standards (Bowen \& Tobin, 2015, p. 144). 
Bowen and Tobin reflected more on the limited role that faculty played outside of the main academic arenas in which they operated in a model of shared governance, and they supported the concept that administrative analysts in non-academic units have less interaction with shared governance.

Outside the academic analyst category but within the administrative analyst function, many positions abound in student services, auxiliary services and administrative services; directors of student life programs, campus architects, budget officers, human resources managers, and information technologists (Table 1, row 3). The fundamental difference is that these analysts operate at an arms-length distance from those who work more directly with academic affairs and the faculty senate on a regular basis. Nonacademic analysts are not immune from participating in shared governance, but the focus is on serving the administrative functions rather than the academic functions. For instance, in many cases, decisions made by executives to whom these administrative analysts report do not typically require the support or vote of the faculty senate. These are purely administrative decisions but that could depend on the shared-governance model operating at the institution.

Exceptions are intrinsic to this framework, generated through leadership by the faculty over time or a highly collaborative shared-governance model. For example, AAUP stated their interests as beyond the classroom in 1972 with a formal statement, The Role of the Faculty in Budgetary and Salary Matters, in an effort to provide guidance on their collective interests: (AAUP, 1972). 
Faculty are engaged in shared governance most extensively with an academic focus, but in limited environments they also have asserted their roles in more administrative functions at colleges and universities. No consistent approach prevailed for the latter, and most accrediting bodies did not spell out that kind of involvement as they have done with academic policy and standards. The Northwest Commission on Colleges and Universities (NWCCU) offered an example of this delineation in Standard Two of the accreditation rules. In section 2.A.30, Finance, the accreditors made it clear that the institution must involve management and the board in a process for oversight of finances yet no mention was made of faculty (NWCCU, n.d.). Some institutions may have chosen to involve faculty but Standard Two prescribed no mandate. On the other hand, in section 2.C, Education Resources, nearly all of the subcategories in this area mentioned faculty involvement in academics: topics ranged from transfer credit to admissions practices to learning outcomes (NWCCU, n.d.).

No one institution operates the same as the next, as Bowen \& Tobin observed:

The extensive opportunity for faculty to "have a say" in matters of all kinds is illustrated vividly by the list of no fewer than thirty-three standing faculty committees at Berkeley, which cover topics of every kind, including admissions, student life, educational policy, computing, the operations of the library, faculty awards, and university-emeriti relations. Patterns naturally vary across institutions, and there are also innumerable ad hoc committees (2015, p. 144).

These relationships between administrative analysts and faculty often reflected faculty involvement in all areas. Practitioners have observed more faculty involvement where academic analysts have supported academic functions and less faculty participation where administrative analysts have supported administrative functions. 


\section{Statement of the Problem}

Except for quite limited and relatively recent mention, the academic literature does not demonstrate that academic analysts are involved in shared governance; how this situation informs practice is troubling because it implies a hole in the literature and a gap between operational realities and supporting academic research. The concepts and the basic premise of shared governance in existence longer than 50 years is still the predominant approach to running public institutions, and it is still supported by most. The roles of trustees, faculty, and executive administrators (mainly presidents) in shared governance were clear in the literature and it created an expectation about each of the actors. The role of the academic analyst (mid-level and upper management) is limited.

It is unclear if this actor was purposefully scarce in the decision making structure, or was omitted by default, or the authors of the literature deliberately intended to imply the involvement of the academic analyst as a tentacle of the executive arm of shared governance. From the Statement on Government of Colleges and Universities, the structured reference only to the president, board, and faculty in The Academic Institution, sections 3 , 4, and 5, set up the framework for the literature to reference these areas (AAUP, 1967, rev. 1990).

Chait described the Statement as a policy “constituting a consensus among faculty, presidents, and trustees represented respectively by these three organizations (Chait, 2002, p. 301).” Most literature referenced these three groups and little else. Amy Zusman is an exception to this limited approach. While not providing details, Zusman referenced the three bodies involved in shared governance as trustees, administration, and 
faculty (Zusman, 2005, p. 147). An acknowledgment in the literature of the third leg of the stool being broader than the president was limited in coverage but also in depth of meaning.

In a guidebook on curriculum management for the American Association of College Registrars and Admissions Officers, Mathern offered this interpretation related to the role of academic analysts in shared governance:

The statement (Statement on Government of Colleges and Universities) specifies the roles of the governing board, president, and faculty. However, its explanation of how the day-to-day work of governance will be operationalized is somewhat less clear. For instance, "The faculty sets the requirements for the degrees offered in course, determines when the requirements have been met, and authorizes the president and board to grant the degrees thus achieved" (American Association of University Professors, 1966). Authority of the faculty and their authorization to the president and the board are clear and concise, but nowhere does it specify who is responsible for carrying out this work. That is where the complicated work of the office of the registrar really begins.

"The president shares responsibility for the definition and attainment of goals, for administrative action, and for operating the communications system that links the components of the academic community" (American Association of University Professors, 1966). The reference to administrative action could be construed as a directive to participate in governance and to help interpret and implement a convergence of the president's and the faculty's roles. The expectation is that the president will manage internal operations, while the registrar will manage internal operations on behalf of the president and help guide faculty when the lines between curriculum development and implementation blur. Ensuring that faculty maintain their role as owners of the curriculum within their academic units is paramount (Mathern, 2016, p. 4).

An opportunity is present for the academic analyst to operate using discretion and carve out a professional role in shared governance. This role in shared governance already exists but needs clarity around it because the literature does not reflect the demonstration of the work in the existing and longstanding, nationally accepted, shared-governance 
statement. Because of the absence of the administrative analyst in the shared-governance model, scant information has been accumulated about the relationship between faculty and academic analysts on areas where engagement does occur. It is in the office of the registrar where the faculty-authored and approved policy is applied to each and every student's record, thereby creating a unique role that the registrar plays as academic analyst. The registrar views the effect of such policy against thousands of student records, and the breadth of understanding of such impact is distilled into a representation that may only be viewed from that vantage point. Another example of a unique vantage point might be that of an institutional researcher who sees a culmination of data year after year on the same measurement. Until shared with and explained to other institutional leaders, the importance and benefit of such information might be understood only by the leader of such a unit, which is why the active role of the academic analyst can be beneficial to the institution as it relates to the role of shared governance.

\section{Purpose of the Study}

Research should determine if active involvement in shared governance by the academic analyst will improve the (shared governance) model and positively affect efforts to assist with the successful delivery of the institution's mission. Among the administrative staff in higher education, certain actors assist in maximizing efficiencies for faculty and students to positively influence equitable implementation of policies and curriculum from an institution-wide perspective. Such documentation and memorialization of how the academic analyst is involved in shared governance could contribute to the field in multiple ways. Findings learned from research on the role of this 
actor involved in shared governance could help shape the relationship that exists between administrators and faculty in the shared-governance model. This result would allow administration to rethink its role in shared governance and how it can best employ academic analysts and their skills and expertise in policy implementation.

Specifically, this research sought to determine the effect of the role of the registrar on the mechanistic functions of policy and curriculum implementation and to determine faculty perceptions that permit registrars to be actively involved in policy and curricular management as it relates to logistics and operations. By allowing the academic analyst active participation in the decision making process for policy and curricular management decisions that are mechanistic in nature, they can attempt to streamline the process and implement clear, equitable policies and rules for students and their academic experience. Examples include involvement in decisions regarding repeatability of courses, equivalency of courses, course designator naming conventions, withdrawal policies and other academic regulations or policies where the spirit and intent often get commandeered by implementation or functional limitations. Because registrars are seen as part of the administrative analyst group, specifically the academic analyst subgroup, the nature of the specific questions will focus on their work in the areas of academic policy and curricula management.

\section{Research Hypothesis}

The research was intended to measure perceptions about involvement in shared governance, what role the academic analyst plays, and how that role relates to curriculum management and academic policy. Ideally, results would indicate whether the academic 
analyst has a positive effect on student-based efficiencies such as time to graduation, ease of access to information that assists with registration, or less negative effects on a student's record because of the involvement. However, the focus of the research was to control for the different type of shared governance to determine if that influences perceptions of faculty about the involvement of academic analysts in curriculum management or academic policy. Specifically, the research question was: Does the level of involvement of an academic analyst in shared governance have an effect on curriculum management and academic policy while controlling for the shared-governance model practiced at that institution?

\section{Relevance of the Study}

The research may inform best practices about faculty preferences and successful outcomes that result from the work between registrars and faculty concerning policy development and curricula operations. Feedback from faculty about participation in curriculum management and policy development by academic analysts may be able to guide the broader conversation about the level of involvement in shared governance by all academic and administrative analysts.

One may argue that accomplishing goals is more about relationships than any formal structure, and regardless of the type of shared-governance model that exists, relationships will dictate how easy curriculum management can be to accomplish on a college campus.

Registrars can and should serve as strong partners within any academic governance model. The motivation for this involvement is not driven by self; rather, it is driven by the desire to provide the critical information and 
perspective that are based on the registrar's role in the institution. The registrar's work is to prove, at every opportunity, that the conversation includes deeper data, greater context, and more richness because the information the registrar has provided is of value to curriculum management decisions” (Mathern \& Pomerenk, 2016, p. 11).

Mathern and Pomerenk implied that building relationships was critical to ensuring that the academic analyst can successfully engage in shared governance with faculty.

One goal of the research outcomes was to be able to offer guidance to analysts based on the type of shared-governance structure within which one worked. Ultimately, that knowledge might enable one to use that approach toward developing relationships with faculty. Understanding the nuances of the shared-governance structure, the ability of academic analysts may improve to have favorable results on shared governance while working with faculty. Codifying, or at a minimum, formalizing, the structure for academic analysts should improve their ability to participate in shared governance in two ways.

In the first way, research that currently exists regarding this actor in the role of shared governance was limited. Recognition is quite limited with regard to their participation in the executive role; the literature was restricted to presidents, provosts, and in some cases, deans. By informing the literature in this arena, research not only may bring legitimacy to these actors and their role in shared governance, but it also may create an opportunity for a refereed discussion and debate about this topic. In the second way, a codified language to use with faculty or other academic leaders may encourage a construct to be created wherein people can best determine which responsibilities lie with whom. Instead of being imagined, such a construct might foster appropriate participation 
by academic and administrative analysts in governance using guidelines that have been created, tried, tested, and resiliently maintained through that process with their faculty partners. In addition to those standards, the language that codified the construct can be used as the dominant vocabulary of this new construct. Then, the need for discourse on this topic, with specific, appropriate language, may be able to increase the body of knowledge in this arena.

The outcomes of this research inform administrative analysts as a whole about which, if any, specific shared-governance model is best followed for improved efficiencies in their work with faculty. Specifically, positive contributions are likely in these areas:

1. Conflict resolution handled between academic analysts and faculty regarding curriculum management and logistics.

2. Best practices for academic code-switching in different environments, depending upon the stakeholders, to include interpreting the nuances of meetings and operating within the norms of that structure to achieve successful outcomes. Also, best practices imply being prepared to deliver the message to different types of audiences based upon their understanding of a topic.

3. Shared governance within the context of an organization's structure, including how to work successfully with faculty in shared governance. A possibility exists while working in the "white spaces" of the organizational chart to accomplish tasks by utilizing the relationships that fall in that "white space”. 
Whether the role of academic analyst fits into a tighter academic affairs structure or if the administrative analyst was used on a wider institutional capacity may not matter for the broader outcome of the research; the goal was to project the impact of a specific evaluation onto a broader context. What does the role of the registrar operating in a shared-governance model of the faculty senate teach us about the implications for other academic analysts and their ability to participate effectively in shared governance? Many roles in higher education could benefit from the same guidance on their involvement in shared governance. While not the point of this study, its outcome informed other academic analysts, and perhaps administrative analysts, on their role in shared governance and how to apply the approach with faculty. Because the center of the research was about registrars, an interest endured in what makes that role unique.

Perspective on this topic was included in a guidebook, published by The American Association of College Registrars and Admissions Officers (AACRAO). In chapter one, Mathern stated, “The Higher Education and Program Policy Council notes that shared governance came about because "faculty and professional staff are in the best position to shape and implement curriculum and research policy” (American Federation of Teachers, n.d., [AFT, n.d.], p. 4). Mathern then more fully elaborated:

It is important to understand why the role of the registrar in curriculum management matters. Until the inner workings of a student information system (SIS) and their impact on curriculum logistics are considered, the registrar's role in shared governance and curriculum management may not seem distinctive from those of other administrators. The office of the registrar is a distinct convergence of policy and practice; the impact of curricular decisions on students is clear. Two critical processes demonstrate this reality: course registration and degree clearance at the end of a student's degree program. 
A student's eligibility to register for a course may be based on success in previous courses (prerequisites), completion of course equivalencies (through transfer credit or on-site equivalencies), or past registration for similar coursework (repeatability). All of these scenarios_-plus many others_-affect a student's progress toward degree completion and often are at the discretion of faculty (who create the curriculum rules regarding prerequisites, equivalencies, and repeatability). Faculty involvement in curriculum management is standard and appropriate; in fact, it is an expectation of faculty at regionally accredited institutions. However, because faculty have a curricular and departmental focus, it may fall to the office of the registrar - the office that receives all departments' changes - to provide a broader perspective. Often, the registrar's office implements departmental decisions and witnesses the full impact on students' present and future academic experiences.

Degree clearance is the last step that separates a student from graduation. Although the faculty create programs of study and determine the academic requirements for earning degrees in those programs, the office of the registrar is often responsible for validating, on behalf of the faculty, that students have successfully completed their programs of study. Because the office of the registrar performs this function for hundreds or even thousands of students each year, its staff often see patterns that, if enhanced, could benefit more students and potentially increase graduation rates. Degree clearance is also an opportunity for registrars to serve faculty by sharing with them the valuable information and insights they obtain from their particular vantage point. Sharing information can help faculty streamline the curriculum management process and ensure that the institution does not impede students' ability to graduate. Registration and degree clearance demonstrate the value of registrars' administrative involvement in curriculum management (Mathern, 2016, p. 2).

As these examples suggest, certain factors make the relationship between the registrar and the faculty senate unique and worthy of evaluation and research.

\section{Conclusion}

While some of these approaches may seem simple—such as getting along with colleagues, listening, and building relationships on campus_-it is much more complex. The successful actor in those environments, as an academic analyst, can achieve improved efficiencies because of successful collaborations within a shared-governance 
model. Consequently, the theoretical foundations for this research on shared governance included both a review of organization theory as well as an analysis of role theory. Shared governance comprises intellects from very different philosophical camps, people whose perspectives are quite diverse on whether shared governance is still effective as a model for managing higher education. 


\section{Chapter 2: Review of the Literature}

\section{Introduction}

Literature was limited with regard to the role of the non-executive administrator in shared governance. Most often, the literature referred to the three main areas of shared governance as the faculty, boards, and the president (Birnbaum, 1999; AAUP, 1967). The first two were clear and defined bodies, but the last, the president, remained somewhat unclear. Some of the literature was relatively silent on the staff supporting the president; it was not clear if the literature purposely referenced only the president or if the literature implied there was a staff role. As a result, the question arose of the non-executive administrator's involvement in shared governance.

This research described the non-executive administrator as one of two roles, either an administrative analyst or an academic analyst. The research focused specifically on the academic analyst's involvement in shared governance. The terms administrative analyst and academic analyst to date have not been found in research; consequently, sources were not cited when defining or describing them. Understanding the role of the analyst in shared governance within higher education required the analysis of how to drill down into the specificities of each area.

\section{Search Description}

The literature review triangulated this topic by reviewing role theory, organization theory, and shared-governance theory (Table 2). Role theory spoke directly to the actors performing as academic analysts and faculty. Applicable roles and role theory have been less prevalent in current research, which meant that the literature review on role theory 
was more dated than the review of literature for organization theory. Organization theory provided background for how and why institutions were structured. The research was performed using organization theorists' work, from prior research, that supported higher education models as well as public organizations. Finally, shared-governance theory contextualized how these roles fit into the shared-governance model at institutions of higher education.

Table 2. Overlay of Literature Review Topics and Research

\begin{tabular}{|c|c|c|c|}
\hline Application & \multicolumn{3}{|c|}{ Topics } \\
\hline Literature review & Roles, role theory & Organization theory & Shared governance \\
\hline Correlating research & $\begin{array}{l}\text { Administrative analyst, } \\
\text { Academic analyst, } \\
\text { Registrar }\end{array}$ & $\begin{array}{l}\text { Higher education } \\
\text { institutions }\end{array}$ & Shared-governance models \\
\hline
\end{tabular}

Because shared governance also had several other terms that described similar work, the following terms were used when performing search functions for the most relevant literature: 1) shared governance, 2) governance, 3) faculty governance, and 4) shared governance and higher education. Much literature on shared governance focused solely on healthcare (specifically nursing), and limiting outcomes on that research was necessary.

\section{Definition of Terms}

Different actors can play the role of the administrative analyst in higher education. For the purposes of this research, “administrative analysts” was defined as "an administrator who functions and is responsible for analysis and implementation at an upper administrative level but is not an executive who reports directly to the provost or president”. Those staff members who directly reported to the provost or president, for the 
purposes of this research were considered executives, who provided separation from the administrative analyst. Executives tended to assign the work of the administrative analyst. Evaluation of systems and implementation of processes have been performed by administrative analysts in higher education after decisions were made either by faculty or by institutional executive leadership or both.

The academic analyst, a subcategory of the administrative analyst, is defined as a person who ensured that the operations of the system and the structures functioned while resolving problems related to the direct academic units of the institution. This academic analyst is unique from the administrative analyst, a broader actor for all of the institution, because the administrative analyst did not have a solely academic focus, rather their broader areas were working in finance, administration, or even research units.

These definitions melded the descriptions of other terms utilized by two authors who have contributed to the body of knowledge in this area, namely, Robert Reich and Henry Mintzberg. Reich’s symbolic analyst and Mintzberg’s control analyst of the technostructure provided the impetus for further discernment of the academic and the administrative analyst roles. The symbolic analyst is a critical thinker who solves problems (Reich, 2005) and "the control analysts of the technostructure serve to effect certain forms of standardization in the organization” (Mintzberg, 1993, p. 15).

\section{Role and Role Theory}

The administrative analyst position exists in many areas of higher education, but for this research, the focus is on academic analysts and shared governance. The purpose of the use of role theory in the evaluation of the academic analyst was to understand the 
construct first, and then with that understanding, better ascertain how the academic analyst could use their role as an actor in higher education to participate in shared governance at an influential level. Role theory, as defined by Bruce Biddle, is "a science concerned with the study of behaviors that are characteristic of persons within contexts and with various processes that presumably produce, explain, or are affected by those behaviors” (Biddle 1979, p. 4). Hindin, on the other hand, does not refer to role as a science. Rather, she discussed the debate over the meaning of role in role theory, and how it can be defined in three ways: a social position, behavior associated with a social position, or a typical behavior (Hindin, pp. 2007, 3959). Hindin posited that role can be interpreted as what someone is expected to do, how they act, or how others act in similar roles. Theorists in this field have differing opinions on which is best suited to define role, and Hindin summarized it this way, "while some agreement exists that the basic concerns of role theory are with characteristic behaviors, parts to be played, and scripts for behavior, theorists differ on whether roles are norms, beliefs or preferences (Hindin, 2007, p. 3960).” Through the lens of the academic analyst, it seems that role was a norm because the expectation of the position was that it functioned on standards that were somewhat formalized into tasks, less formalized from beliefs or preferences.

Both Biddle and Hindin listed the five types of role theory as: functional role theory, symbolic interactionist role theory, structural role theory, organizational role theory, and cognitive role theory. Organizational role theory examined role development in organizations and had a focus on role conflict (Biddle, 1986, p. 74). Role conflict was defined as "the concurrent appearance of two or more incompatible expectations for the 
behavior of a person” (Biddle, 1986, p. 82). Because the literature on shared governance focused on executives, boards, and faculty and the roles assigned to them as actors, academic analysts have been caught between faculty and executive leadership while expected to implement policies and regulatory requirements. The expectation has been to implement the shared-governance decision but without any authority or purview over it. This is a clear example of role conflict. Relative to the administrative analyst and its interactions toward work in higher education, certain other aspects apply to organizational role theory in addition to role conflict. Biddle called them "structural conditions that are thought to cause problems in social systems”: role ambiguity (a condition in which expectations are incomplete or insufficient to guide behavior), role malintegration (when roles do not fit well together), role discontinuity (when the person must perform a sequence of malintegrated roles) and role overload (when the person is faced with too many expectations) (Biddle, 1986, p. 83). Role ambiguity seemed to be the focus if assessing the reality that the expectation of implementing governance decisions may be difficult for academic analysts to do when they have not had a formal role to play as an actor in shared governance.

When evaluating the roles of academic analysts and their ability to be involved at the appropriate levels of shared governance, the concept of role conflict also arose as did the other problematic structural conditions. For example, the expectation was that an academic analyst must implement policy correctly but do so without the opportunity for input in the creation of it, or at a minimum, the ability to flex it as needed. 
Role malintegration did not appear to be problematic in this environment because a gap was apparent after decisions were made in shared governance and when they were implemented. It made sense for the academic analyst to perform that work; however, it was possible for role conflict, role ambiguity, and role overload to all come into play. Role overload was an obvious interpretation if an academic analyst was expected to implement shared-governance decisions while also expected to serve faculty, the president, and potentially even the board.

Robert Reich took a different approach in the discussion of role in the work force. He argued for involvement of the administrative analyst in the decision-making process during policy development and implementation. In The Work of Nations, Reich described the shift in the economy to a more internationally focused one (now fully engrained but still emerging at publication in 1991), and how this shift had dramatically changed the type of jobs that existed in the United States as well as how they were categorized. The U.S. Bureau of the Census uses the generic occupational groups from the 1950s that do not represent new workers that have developed in the last thirty to forty years. Reich provided three new categories of work that he described as emerging: routine production services, in-person services, and symbolic-analytic services (Reich, 1991, p. 174). While his writing explicitly excluded government workers (where he referenced education), this review applied his prototype to a university setting (Reich, 1991, p. 180).

Routine production services—jobs that include "repetitive tasks"—Reich described as "one step in a sequence of steps for producing finished products tradable in a world commerce ... whose virtues are reliability, loyalty and the capacity to take 
direction” (Reich, 1991, pp. 174-175). In higher education, the role of routine production service providers has grown now that work can be done remotely; examples include payroll processor, switchboard operator or computerized report processor. In-person services were similar to the routine production services with two caveats, "these services must be performed person-to-person . . . and they require workers who have a pleasant demeanor” (Reich, 1991, p. 176). These positions have become abundant in higher education, spanning from office greeter to food service provider to lab assistant to parking services attendant.

Reich’s last category, symbolic analytic services, was the main focus of his argument about the changing nature of work in the American political economy. This role included, “problem-solving, problem-identifying and strategic-brokering . . . with these skills traded worldwide” (Reich, 1991, p. 177). In higher education, examples included program evaluators, curriculum specialists, systems analysts, and university executives. Reich’s writing contributed partially as a source for the creation of the term “administrative analyst”, and specifically “academic analyst”, for the purpose of this research.

In 2005, Reich wrote an article that split the symbolic analyst role into two: the national symbolic analyst and the global symbolic analyst. The former being his original definition of symbolic analyst but now more articulately summarized as people educated to think critically and manipulate information to solve problems, and the latter being a subset of the former but operating globally and within an elite "club" that relied on relational capital (Reich, 2005). 
The differentiation of these two terms and the definition of their roles clearly supported the involvement of the academic analyst in shared governance. In his discussion on diffusion of ownership and control, Reich focused on the shift from power based on organizational-chart relevance to power based on high-value enterprise, where "the capacity to add value to the enterprise" is what counts and the "problem-solvers, identifiers or -brokers are allowed to exercise leadership” which means that these decisions “increasingly occur at subterranean levels” (Reich, 1991, p. 99). Essentially, by encouraging symbolic analysts to be a problem-identifiers, solvers, and strategy brokers, they could be allowed to participate in the shared-governance model and add value, which is where, Reich wrote, leaders emerge (Reich, 1991, p. 99). The role of the academic analyst as an actor who provides such support, which results in such actors becoming emerging leaders, demonstrated why role theory was so crucial to understanding how academic analysts could prove useful in shared governance.

Blau addressed role theory as it applied to two roles being examined in this research — the faculty and the administrator — by describing the similarities and the differences that these roles have in shared governance.

Academics have in common with professionals the insistence on exclusive authority over their own work, the demand for self-regulation without administrative interference, and the claim that the colleague group alone may set standards of specialized competence and judge the performance of individuals. These claims to professional autonomy and self-regulation create potential conflicts with the bureaucratic authority of administrators, since administrative and professional considerations are often at variance (Blau, 1973, p. 159). 
Blau implied that this tension between roles has had at its root the different purposes for which faculty and administrators serve in shared governance and further values the need of the three-legged stool in shared governance.

\section{Organization Theory}

Models of organization were interpreted differently depending upon the empirical setting in which they operated, but organization theory has been the foundation for all models. Organization theory helps rationalize, or at the very least, explain, why institutions were structured as they are. Organization as a construct of study emerged from many theorists; however, a major contribution occurred when Weber's analysis of bureaucracy was translated into English in the mid-1940s (Scott, 2003, p. 9). "Social structures created by individuals to support the collaborative pursuit of specified goals” was a basic definition of organization, yet they are so much more complex than that (Scott, 2003, p. 11).

Leavitt created a figure for an organizational model that included these components: social structure, participants, goals, and technology, and those all fit into a dotted-line box with environment on the outside, showing that while part of the organization and its existence, environment is not one of the internal elements (Leavitt, 1965, p. 1145).

One weakness of organizations that has come to be accepted was what Scott referenced as a common curse. "Resources cannot be devoted directly to goal attainment; some of the resources utilized by any organization must be expended to maintain the organization itself” (Scott, 2003, p. 11). For example, maintenance units might include 
payroll or facilities. In higher education, these services must be funded and supported to keep the mission of the institution made possible as a result of the work of the faculty, yet they do not provide direct support to the education of individuals. Different organizational types experience these weaknesses differently and at different costs depending on what the organization needs to support its maintenance.

The need for differentiating between public and private organizations has been somewhat contentious in the literature discussing organization theory. Although more recently, the authors have produced more readings in the literature that offer distinctions between the two. For instance, many of the founding theorists of organization theory did frame much of their writing around both. Herbert Simon is an example of that, discussing how, "it is hard to identify systematic differences in productivity and efficiency between profit-making, nonprofit, and publicly-controlled organizations” (Simon, 1991, p. 38). He addressed the topic of employee motivation and why that was not always a major difference either. Simon specifically stated, “ . . . organizations can be highly productive even though the relation between their goals and the material rewards received by employees, if it exists at all, is extremely indirect and tenuous” (Simon, 1991, p. 38). Interestingly, the bottom line of private versus public organizations was so different, particularly with higher education. Private organizations focused on making a profit such as the University of Phoenix but public organizations concentrate on shared governance. These models are drastically different, and therefore, asserting that no organizational differences exist between the two was a strong claim. 
However, Simon also argued that public institutions and nonprofits are just as efficient as private businesses despite different organization models. Hal Rainey on the other hand believed that it implied a lack of importance to the distinction between the public and private organizations (Rainey, 2009, p. 60). Rainey continued to show support for the idea that the distinction limited their importance by referring to studies that were unable to categorize organizations cleanly down those lines. Other differentiations were made: “. . . organizations’ tasks and functions can have much more influence on their characteristics than their status as public or private. A government owned hospital, for example, obviously resembles a private hospital more than it resembles a governmentowned utility” (Rainey, 2009, p. 61).

Using role theory, Rainey also articulated the connections between public and private organizations because the functional roles of the actors likely were the same. Not only did organizations located in difference sections perform the same functions, but so did the actors within those organizations (Rainey, 2009, p. 64). Theorists who maintained the idea that limited differences were present between public and private organizations could examine that idea during research to discover if institution type had an effect on the outcomes of the research. Results of current research indicated whether institutional type influenced outcomes.

\section{Types of Organizations}

Scott addresses three main types of organizations, namely, rational, natural, and open. Each type had the support of major theorists behind the dominant models, and their use contributed to the academy. 
Through the rational systems perspective, Scott saw organizations that were “collectivities oriented to the pursuit of relatively specific goals and exhibiting relatively highly formalized social structures” (Scott, 2003, p. 27). Scott also discussed founding authors Henry Fayol, who addressed administrative theory, and Frederick Taylor, who authored the scientific management approach, as theorists who found themselves in the rational systems camp with their formal social-structured approaches (Scott, 2003, p. 38). Scott described a natural systems approach as

... [C]ollectivities whose participants are pursuing multiple interests, both disparate and common, but who recognize the value of perpetuating the organization as an important resource. The informal structure of relations that develops among participants is more influential in guiding the behavior of participants than is the formal structure (Scott, 2003, p. 28).

This particular definition of a natural system explained some of the tenets that apply to an institution of higher education. For instance, multiple interests do not always align in higher education, such as undergraduate teaching and research or publishing requirements. These endeavors may not have been seen as aligned to support each other; however, as the definition articulated, their value resides in the importance of both to the success of the organization.

Natural systems are far more fluid, focusing on the organization as an arrangement that is supported by participants’ interests rather than formal structure. Both rational and natural systems were viewed as closed systems until the introduction of the open system, when further developments encouraged the viewing of such systems as open or closed depending upon the theory being applied. Open systems, wrote Scott, were "organizations [that] are congeries of interdependent flows and activities linking 
shifting coalitions of participants embedded in wider material-resource and institutional environments” (Scott, 2003, p. 29). The natural system was the most flexible of all organizations, and seemed to be the best fit for higher education institutions; however, these institutions also could be easily seen as open systems because interdependencies existed without a formal and required relationship between different departments within the institution. It also should be noted that within an organization, interpretation of the structures was based on three levels: social psychological (behavior of individual), organizational structure (units, structures, or groups, i.e., components) and ecological (operating within a broader context, i.e., the organization is just one of the many organizations in an ecosystem) (Scott, 2003, p. 17). As a result, the aim of the research was to use these three levels to understand better the effectiveness of shared governance in higher education. Social psychological was the role of the actor (academic analyst); organizational structure was the model of shared governance used as the particular institutions being surveyed; and ecological was the outcome of that relationship and any effect that it had to increase efficiencies for students or the university as a whole.

\section{Two Models: The School System and Mintzberg's Bureaucracy}

Robert Birnbaum articulated the differences in structures of organizations by discussing two systems within one empirical setting. One he called the Pool System and the other, the School System. Imagine the Pool System looking exactly like a pool table with balls, cue sticks, and formal boundaries around it; a closed system.

The School System was dramatically different with multiple layers of boundaries that did not restrict access, that is, an open system (Figure 1). The left arrow points to the 
technical subsystem and the right arrow points to the administrative subsystem (Birnbaum, 1988, p. 32). The visual displayed the loose coupling of the School System whereas the vision of a pool table was clearly a tight coupling of the actors within the organization (pool balls within the pool table). The loose coupling of the School System had boundaries that overlapped or shifted, based on the factors in the environment to highlight that the environment was the one element of an organization that was not internal. Birnbaum called these "environmental inputs" and listed many in the School System: students, alumni, citizens (Birnbaum, 1988, p. 33).

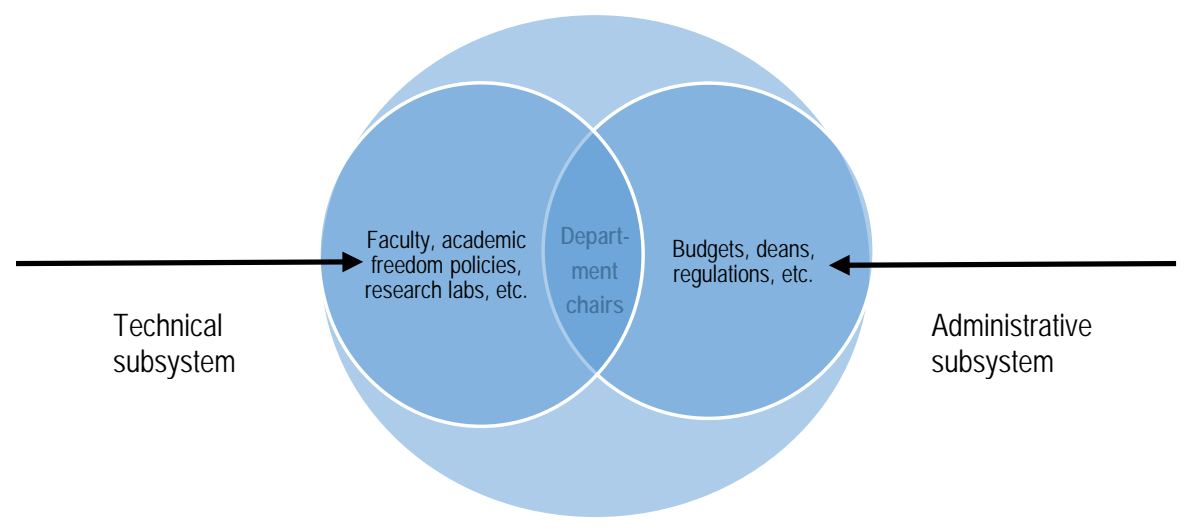

Figure 1. School system by Robert Birnbaum (Birnbaum, 1988, p. 32. Used by permission of John Wiley and Sons and Copyright Clearance Center.).

The School System included three parts that must operate within the system; the environment, which is outside of the organization, the administrative subsystem, and the technical subsystem both of which are inside the organization (Birnbaum, 1988, pp. 4142). How these parts interact between each other determines the looseness of the coupling. 
Birnbaum argued the values of both tight and loose coupling. The tightly coupled pool table was one that operated efficiently because the moving parts were firmly connected and could not have functioned without them operating in unison: the actors on a pool table were always visible and in play. Loosely coupled systems appeared to be mechanically inefficient, but those systems did not serve the machine bureaucracy, rather they served what Henry Mintzberg referred to as the "professional bureaucracy”. Consequently, loosely coupled systems may actually be viewed as efficient considering the environment and number of actors involved (Mintzberg, 1993, p. 189).

The School System model suggests that at least two things must be considered in designing an effective administrative system- the environment and the technical subsystem ... [the technical subsystem] describes the characteristic ways in which colleges and universities transform their inputs into outputs; these processes through which teaching, research and service are accomplished are the way the organization actually “does” its work (Birnbaum, 1988, p. 42).

Here, technical subsystem referred to the broadest sense of its meaning, not limited to technical processes. Scott called technology, "the work performed by an organization inclusive of hardware ... but also the skills and knowledge of workers” (Scott, 2003, p. 231). Multiple terms shared similar meaning. Technical subsystem from Birnbaum, technostructure from Mintzberg, and technology from Scott all represented similar concepts (Birnbaum, 1988; Mintzberg, 1993; Scott, 2003).

The School System closely resembled the Adaptive Structures model from organization theorists, Katz and Kahn. They applied the responsibility of adapting to a changing environment to the administrative subsystem. "These functions of planning, research, and development, which permit the organization to exploit a changing 
environment rather than to be exploited by it, are essentially the role responsibilities of the top leadership” (Katz \& Kahn, 1978, p. 88). The idea of the School System was that it had created a cybernetic institution. Cybernetic institutions “create feedback loops that tell it when things are going wrong” (Birnbaum, 1989, p. 241). This feedback allowed the technical subsystem and the administrative subsystem to use an adaptive function then modify activity and behavior “directed toward the survival of the organization” (Katz \& Kahn, 1978, p. 89). Katz and Kahn further explained, “ . . . structures [exist] that are specifically concerned with sensing relevant changes in the outside world and translating the meaning of those changes for the organization” (Katz \& Kahn, 1978, p. 55). That kind of activity was operating at either the organizational structure or the ecological level of the organization, based upon the type of environmental impact causing the adaptation. In higher education, the School System was Birnbaum's only feasible model of the two; the Pool System would not be effective. The Pool System was much better suited to the Machine Bureaucracy, which clearly did not represent higher education, as Mintzberg substantiates.

Between Birnbaum’s School System and Katz and Kahn’s Adaptive Structures model, it was easily possible to point out the role of the faculty in each; shared governance in these models, however, appeared in different ways. In applying the concept of shared governance from higher education to both of these models, shared governance appeared to be an action, not a thing. The feedback loop of a cybernetic institution appeared to be shared governance, meaning that the actual loop (exercise of reporting back between actors) was the governance. It is an intangible action, not an 
artifact, at which one can point. The existence of shared governance in Katz and Kahn appeared as the impact on an environment based upon the feedback. This impact on the environment could be different, depending on the work of the actors’ needs to adapt and modify behavior.

As Birnbaum, Scott, Katz and Kahn, and others were able to place the actor into the organization, the connection between role theory and organization became more evident. The ambiguity, malintegration, overload, conflict, and other role characteristics played out in each actor depending upon the organization type and its environment. Reich and Mintzberg both tied together succinctly the role of the actor and the organization model. Mintzberg did a more thorough job of this by evaluating five types of organizations and how actors affected each organization. Reich, on the other hand, had a narrower but much deeper application of the actor's role and its impact in an organization. In addition to the rationale Reich offered for involvement of the academic analyst in shared governance (acting as problem-identifier, problem solver, and strategy broker), the explanation of Mintzberg's effective organizational model and roles described the places where the administrative analyst was involved in the structure. His model, made of five basic parts, designated the roles of each unit (Figure 2). Mintzberg also bent and flexed it to show how his model could be adapted to many different types of organizations, based on the decentralization of power. 


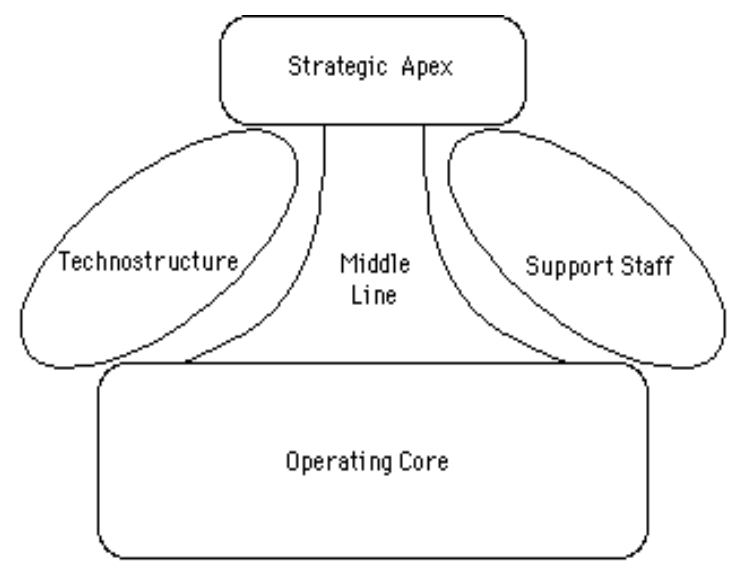

Figure 2. A rendition of the model from Mintzberg that shows the five basic parts of the organization (Mintzberg, 1993, p. 11. Used by permission of the author.).

Each area represented different roles within an organization. The operating core was made of "the operators who perform the basic work related directly to the production of products and services ... the operating core is the heart of every organization, the part that produces the essential outputs that keep it alive” (Mintzberg, 1993, p. 12). In higher education, without faculty teaching there would be no students to support the organization’s existence.

The strategic apex was where "the people charged with overall responsibility for the organization” existed; responsible for “ensuring that the organization serve[s] its mission in an effective way, and also that it serve[s] the needs of those who control or otherwise have power over the organization” (Mintzberg, 1993, p. 13). In higher education, this power resides in the president and provost plus their council or team and vice presidents who support the non-academic functions of the institution. They are 
responsible for the mission of the institution and for maintaining accreditation (and all compliance requirements) by ensuring the well-being and continuance of the institution.

The middle line was Mintzberg’s description of middle management. "Middle line managers with formal authority” (Mintzberg, 1993, p. 14) are responsible not only for managing the staff who report to them but also for the flow of information that must smoothly transfer between the operating core and the strategic apex. Department chairs, school directors, or even associate deans are perfect examples because they supervise or lead the actors who perform the core function of the institution and ensure that the mission directed by the strategic apex is being met by that operating core.

The technostructure housed "analysts who serve the organization by affecting the work of others. These analysts are removed from the operating work flow-they may design it, plan it, change it or train the people who do it, but they do not do it themselves" (Mintzberg, 1993, p. 15). This is the second source of information that created the definition of administrative and academic analysts for the purpose of this research. Higher education has required a slightly different definition than Mintzberg offered because the technostructure provides tools and efficiencies to support the operating core's ability to teach, but it does not design the teaching itself. Staff of the technostructure included functional experts in areas where positions existed, such as assessment coordinators, student information systems operators, technical analysts, or librarians.

At times, confusion existed between the actors in the technostructure and the final part of the Mintzberg organizational model, the support staff. Coincidentally, the empirical setting Mintzberg used in his summary of support staff was a university. He 
offered examples, such as departmental units like payroll, mail room, and residence living. Support staff “exist to provide support to the organization outside its operating work flow” (Mintzberg, 1993, p. 16). Differentiating between technostructure staff and support staff in his model, Mintzberg highlighted two areas in which support staff did not participate: 1) standardization of delivery and 2) analysis and recommendations. He stated, “They cannot be looked upon primarily as advice givers” (Mintzberg, 1993, p. 16). In the higher education setting, Mintzberg mentioned certain areas in which support staff do not participate, areas wherein the technostructure staff do participate and that performance by those actors was critical for the operating core to continue functioning. While the roles between the basic parts of this model are relatively clear, the sometimesconfused roles of the technostructure and the support staff can be delineated using those two areas as differentiated by Mintzberg.

Birnbaum and Mintzberg offered two different models that tend to complement each other when applied to a similar setting. The sophistication of Mintzberg's model showed some weaknesses in the School System and in its limited units of participants. Yet, the professional bureaucracy model from Mintzberg tended to shrink certain areas within his five parts. Suddenly, it began to look more like Birnbaum. More research has been devoted to Mintzberg; consequently, its applicability has been studied in depth in many empirical settings. When focusing solely on colleges and universities, however, it is believed that the difference is less than it first seemed. One feature of the School System was the visual reminder of the interplay between the technical subsystem, the administrative subsystem and the environment. Recognizing that department chairs (and 
other actors too) operate in both subsystems, the School System showed flexibility not visible in the professional bureaucracy model.

The School System offered great reverence to the environment as part of its ability to achieve homeostasis.

Environments can be stable or turbulent, so that some institutions may exist in worlds that look much the same year to year, while others constantly confront new and unexpected problems as enrollments suddenly decline or external agencies demand new and costly programs or reports ... the level of stability, homogeneity, clustering and munificence will affect the governance and management systems [of said institution] (Birnbaum, 1988, p. 43).

This recent impact of involvement from the growing interest in external factors on shared governance forced this balancing action. "The very nature of shared governance, of course, precludes unilateral action," but where is the distributed power going? "Less power remains on campus to distribute. The once almost impenetrable membrane between the campus and the larger society has thinned greatly” (Chait, 2002, p. 313). Gilley offered guidance on achieving such stabilization, “... states must unfetter institutions, allowing them to become entrepreneurial; and multi-campus governing boards must focus on strategic issues rather than attempt to micromanage their institutions” (Gilley, 1991, p. 100). Heeding Gilley’s advice would allow for more distancing (again) between the work of shared governance internally and the external society of which Chait warns.

Katz and Kahn assigned adaptation to the administrative subsystem. This placement implied that the strategic apex and the middle line needed to be involved in shared governance to achieve balance. The role of actors in the technostructure was not 
implicit, yet not excluded either, which highlighted the absence of the technostructure in the School System. Aspects of the technostructure may exist in all three areas- the technical subsystem, the administrative subsystem, and the overlapping area (department chairs) - yet it was not described anywhere. Focusing specifically on the professional bureaucracy model from Mintzberg offered perspective on why the technostructure was missing from the School System, thereby also excluded from shared governance. Mintzberg missed an opportunity to apply shared governance to his organizational structure in any of the five basic parts. Having done so, Mintzberg could have allowed for a more thorough review and enhancement of the professional bureaucracy, and that inclusion may have resulted in a sixth type in his typology of decentralization. This sixth type would not only have been effective as a tool for higher education but also for the healthcare field, wherein nursing and other areas use shared-governance models extensively.

The professional bureaucracy model was not necessarily an inaccurate representation of higher education even if gaps existed in the technostructure area. However, a weakness was noticed while evaluating the decentralization of power in Mintzberg’s model. Shared governance has strong involvement from faculty, administrators, and trustees that result in the support staff unit being smaller and the strategic apex being larger. In terms of configuring the model, this is a hybrid of Types A and $\mathrm{E}$ of the five types of decentralization (Mintzberg, 1993, p. 115), recognizing the large amount of control that the operating core has over their own work in educational institutions along with the involvement of the strategic apex. These combinations do not 
reflect the reference to Type E, which only mirrors the power in the operating core (Mintzberg, 1993, pp. 115, 190). While not a perfect reflection of Mintzberg's types, a hybrid graphic better demonstrated the importance of the strategic apex in Type A and the importance of the operating core in Type E (Figure 3). Placing these two images together with both heavy involvement on the strategic apex and on the operating core (imagine "big on top" and "big on the bottom") produced a more accurate sharedgovernance type in the professional bureaucracy model.

Birnbaum's two systems offered a closed and open systems comparative analysis that provided a salient view of organization theory for a particular empirical setting that was valuable and has informed research. The analysis allowed an opportunity for researchers to explore the best location for academic analysts to fit within the School System. Perhaps, the School System can be modified to reflect the work that seems to be missing from multiple approaches. This model from Birnbaum offered a clear view for how practitioners could view the effect of the environment on the work performed in higher education but also on the flexibility of the organization and the need for it to ebb and flow between the administrative functions and the technical subsystem. While a merge of Mintzberg's Types A and E allowed for a more practical description of a shared-governance model, it was not clear how easily the organization may be able to flex when 


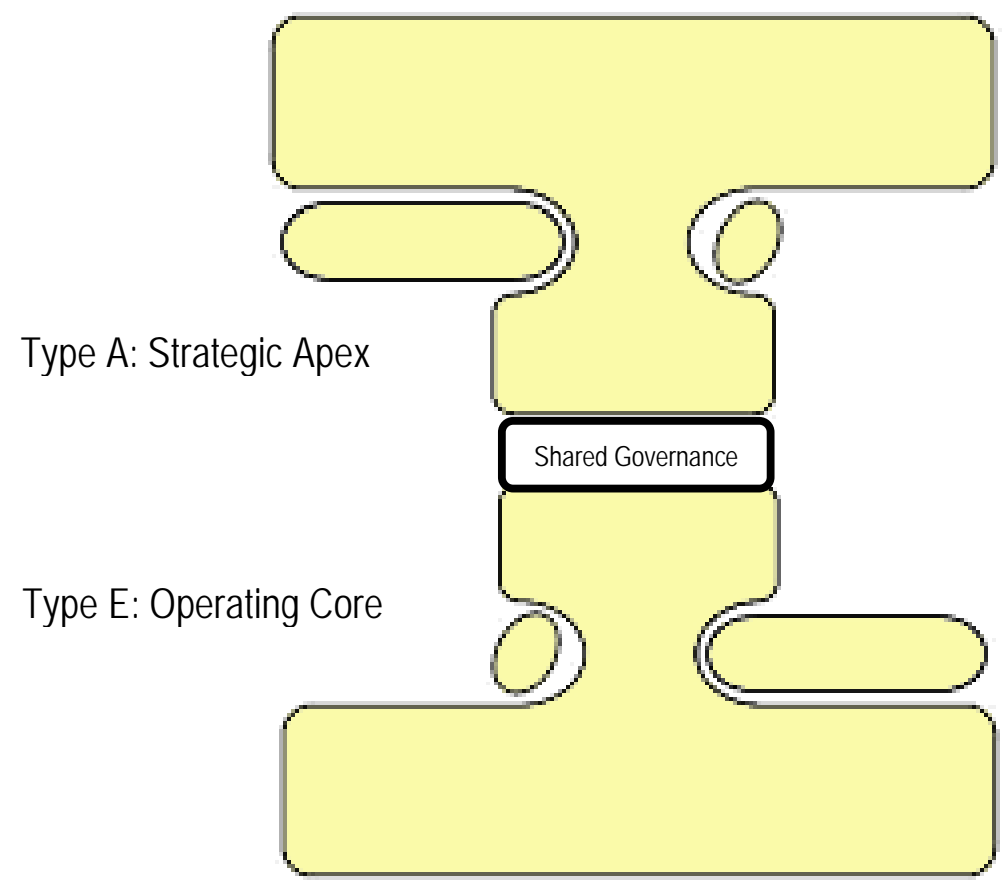

Figure 3. Contrast in importance of types of decentralization by Mintzberg, suggesting an accurate shared-governance model in the professional bureaucracy. (1993, pp. 115, 190. Used by permission of the author.).

allowing the operating core to lead the organization versus the strategic apex (as appropriate or needed).

Blau offered examples of how this can happen but does not articulate the cumbersome nature of accomplishing it.

University administrators rarely if ever tell faculty members what topics to cover in their classes or how to conduct experiments, and faculty members acknowledge that class schedules must be coordinated by administrators . . . but jurisdictions cannot always be neatly separated, and conflicts arise when they cannot be. A typical illustration of such an area of overlapping jurisdictions in academic institutions is the appointment of faculty members, which involves budgetary commitments that are administrative 
responsibilities and judgments of specialized competence that are professional ones (Blau, 1973, p. 159).

If the two segments of the organization both wanted to lead, it may prove more difficult to merge the decentralization models if there is not smooth and free flow between the administrative and technical functions. Understanding shared governance in this situation will help determine if an additional model can be proposed to the Mintzberg decentralization models, assuming higher education falls into the professional bureaucracy model (Mintzberg, 1993, p. 189).

Blau also described two models of the higher education organization, the bureaucratic model or the professional model. Conceptually, the large university was considered the bureaucratic, and the small college was believed to operate as a professional model. Blau did, however, point out that these stereotypes were not always true and referenced survey outcomes to support that assertion (1973, pp. 184-185). Blau's models still exist, but with the diversification of many institution types, these models are not as discreet as they had been in the past.

\section{Shared Governance}

Governance in higher education was defined by many authors, and many terms were used to define this concept. Subtle nuances were apparent among terms, yet the generality of the topic was met by most terms. Governance, faculty governance, shared governance, and shared authority were all terms that have been used interchangeably for the concept used to define the operational model by which an institution of higher education is run. This study used the term "shared governance" as the default 
terminology but may use "governance" interchangeably without inferring a new or different meaning.

Birnbaum defined governance as, "the term we give to the structures and processes that academic institutions invent to achieve an effective balance between the claims of two different, but equally valid, systems for organizational control and influence" (Birnbaum, 2004, p. 5). Kaplan called it, "the means and actions by which a collective entity decides matters of policy and strategy” (Kaplan, 2004, p. 23). The difference between these two was that the approach of Kaplan focused on the "collective entity,” and Birnbaum used a more divisive approach, calling for balance between two different but equal systems. Kezar, on the other hand, did not speak to the actors at all in her definition, rather, only the process. "Governance refers to the process of policymaking and macrolevel decision making within higher education” (Kezar, 2004, p. 36). Finally, Smith used the term "shared authority" and defined it in two parts. To share here meant, "to let someone else have or use a part of something that belongs to you." thereby implying that “ . . . authority over some realm is granted to more than one individual or group” (Smith, 2015, p. 25).

These definitions live on a continuum of characteristics (Figure 4). Process and actors make up the definitions, but not all authors found both in their interpretation of governance. 
Actors

Smith (2015)
Process

Birnbaum (2004) Kaplan (2004)
Kezar (2004)

Figure 4. Sources suggesting a continuum of governance characteristics

While Kezar was a strong contributor to the shared-governance literature, the governance definition she offered in this particular publication was limited and lacked a main characteristic of the requirements for governance to function. Smith's definition did the same. Birnbaum and Kaplan covered both characteristics but with dissimilarities on whether actors approached the work together or separately. This continuum of governance characteristics aligns with the importance of role theory in my research: the actors must be a critical part of the research when assessing the effectiveness of shared governance.

\section{Models of Shared Governance}

In a presentation given at Oregon State University, Kezar defined the different types of shared-governance models by their approach to making decisions: fully collaborative decision making, distributed decision making, and consultative decision making. She also summarized them:

Fully collaborative. The traditional model many call "collegial model of governance” wherein decisions were made jointly, and the goal was consensus. Distributed. The model wherein responsibilities among faculty, administration, and board were delineated and clear. 
Consultative. The communicative model wherein advice was sought from faculty and staff, but authority remained with the senior administration and the Board of Trustees (Kezar, January 15, 2015).

Dean Smith provided strong supplemental support to these three categorical definitions. His reference to "shared authority" covered both the fullycollaborative model and the distributed model because he stated that they are differentiated only by the amount of distribution of authority that takes place on each campus. His description appeared more like a continuum than two discreet models (Smith, 2015, p. 26). Smith’s definition of consultative model aligned well with Kezar’s description:

... [C]onsultative authority provides a group the opportunity to influence an administrator's decision, but it does not provide enfranchisement . . . [C]onsultative authority is associated with inherently limited power. Consultative influence depends on its function authority- its expertise in the object of the decision (Smith, 2015, p. 27).

These three models, defined by Kezar and supported by Smith, were critical to develop the assessment rubric of the research as discussed in chapter three.

Different types of institutions have tended to select different shared-governance models; likewise, it has not been guaranteed that all comparable institutions will align with the same model of shared governance. While not always the case, community colleges have most commonly opted for the consultative role, where the faculty have “advisory councils” and not "senate bodies”; governance here actively involved a consultative process. Moreover, in the best interest of the institution, the president has been expected to work hard and foster a strong relationship with the council, to approve 
most recommendations that come from such advisory councils. These councils often have had the right to a vote of no-confidence in their president (or dean) if the situation necessitated, a situation still considered "shared" governance even if there is no binding outcome. Additionally, most for-profit educational institutions also have established advisory councils but in a different format from those that occurred in a community college setting. One could wonder if they only existed because they must; regional accreditation bodies require faculty involvement in interests such as curricula, student success, and other academic policies (NWCCU, 2016).

Within public universities, all three models have been used, but by far the fully collaborative and distributed models are the most used, with some institutions creating a hybrid. Fully collaborative models have been difficult to operate all of the time because measured processes are required to seek involvement from all parties. A hybrid between the consultative and the distributed model was also a popular approach for institutions. The University of Virginia offered a clear example of the distributed-consultative combination. Their distribution of authority resided in degree creation and termination, but the collaborative decision-making process was still used for other educational matters that affected the university. This delineation was firmly written into the constitution and by-laws of their Faculty Senate Purpose Statement (University of Virginia, n.d.). Other public institutions have had quite different approaches: at the University of Minnesota the most authoritative senate body was the University Senate, made of representatives from faculty, student, civil service and the Professionals and Administrators Senates. Composed of a majority of faculty, the body represented all areas of the university and 
has had authority for decision making (University of Minnesota, n.d.). This University Senate demonstrated one of the most comprehensive approaches to shared governance and showed an example of administrative participation in faculty governance that was difficult to find in the literature. However, concerns were raised because the voice of the faculty was limited as a result of other representation.

Shared-governance Actors

The Statement on Government of Colleges and Universities was jointly formulated by the American Association of University Professors (AAUP), the American Council on Education (ACE), and the Association of Governing Boards of Universities and Colleges (AGB). Each association separately acknowledged the Joint Statement (ACE in October 1966; AAUP Council also in October 1966 with members endorsing it in April 1967; AGB in November 1966, and it was revised for gender-neutral language by AAUP in April). The Joint Statement described three pillars supporting shared governance: faculty, administrators, and trustees (AAUP, 1967, rev. 1990, accessed 2016). While those were the only three roles referenced as formal partners in shared governance, others affected governance at the college and university levels.

For example, the Joint Statement said:

When students in American colleges and universities desire to participate responsibly in the government of the institution they attend, their wish should be recognized as a claim to opportunity both for educational experience and for involvement in the affairs of their college or university (AAUP, 1967, rev. 1990, accessed 2016)).

The Joint Statement addressed the constructed roles of each formal group, and it recommended appropriate participation in the main functions of the institutions' 
responsibilities. Kezar and Eckel described the intent of the Joint Statement: “to clarify roles in campus governance among the Board, president, faculty, and students and illustrate mutual interdependence” (Kezar \& Eckel, 2004, p. 377). The role of the board in shared governance was broad with oversight responsibilities. Similarly, Lyall explained that, “Traditionally, boards of trustees (or regents) have served both to buffer the academy from direct political intervention and as advocates for the mission of the academy to the outside worlds of commerce and politics” (Lyall, 2001, p. 19). As a result, the role of the board in shared governance tended to be more removed from the roles of the president and the faculty.

The Joint Statement omitted legislators, (local, regional, and federal), yet active legislative involvement existed in governance of colleges and universities. Some institutional boards were government-run boards; in addition, federal and state mandates were becoming so infused in the operational work of an institution that it impinged on their shared governance. The requirements related to Title IV funding eligibility have become so restrictive that institutions were required to change policies to maintain compliance (Lederman, 2014). In states, mandates that forced participation were regularly offered to public institutions, often affecting institutional governance. Recently in Oregon, changed administrative rules resulted in tuition reduction for students who were veterans or their dependents by state statute (Oregon University System, n.d.). Kerr described this situation, which has been somewhat overwhelming for practitioners:

... [A]uthority within the university is now more circumscribed than ever before. There are more checks and balances by governments, by the courts, by faculty members and by students. In sum, there are more 
contradictory variables, more uncertainties, more checks and balances, and more possibly unwelcomed developments (Kerr, 2002, p. 12).

Regardless of the appropriateness of this involvement, outside agents have become involved. The Joint Statement in 1966 did not include this stakeholder; however, it did reflect all institutions, not just public, and the topic was not as relevant in 1966.

Several other actors or areas were excluded from the Joint Statement. One was the newly-emerging, for-profit institutions that marginally existed in 1966 . Their governance structure was dissimilar from traditional higher education; most of these schools were either privately held or operated on the stock market. However, this difference has seemed to be shrinking.

Chait referred to more traditional institutions:

Governing boards were, at one time, primarily honorific and ornamental assemblies of stellar citizens that added legitimacy and luster to institutions of higher education and provided a buffer against economic and political turbulence....[c]ustomers, corporations, and other constituents now expect and demand that boards 'take charge' and solve these problems. In turn, trustees, especially of state-supported institutions, feel more urgency and accountability to act (Chait, 2002, pp. 308-309).

Many board members have come from a business background where they "learned to govern actively as corporate directors” (Chait, 2002, p. 309); that style and philosophy was expected to spill into their role in shared governance. The Association of Governing Boards (AGB) warned of this in their Statement on Board Responsibility for Institutional Governance by recommending:

The board should establish effective ways to govern while respecting the culture of decision-making in the academy. Colleges and universities have many of the characteristics of business enterprises, and their boards are accountable for ensuring that their institutions are managed in accordance with commonly accepted business standards. At the same time, colleges 
and universities differ from businesses in many respects ...

[consequently,] Boards and presidents should plan reasonable time for consultative and decision-making processes (AGB, 2010, Board

Responsibility for Institutional Governance).

Some of these actors missing from the initial Joint Statement perhaps have been no more welcome today than then.

Another actor missing from the Joint Statement was that of collective bargaining units that represented different populations on campus, outside of faculty. The Joint Statement mentioned, ever so briefly, the faculty collective bargaining process as another means of academic government (AAUP, 1967, rev. 1990). However, non-faculty collective bargaining units existed (and still do) on many, but not all, college and university campuses across the United States. While they did not run contradictory to shared governance, they did bring complications. Lyall articulately explained why these collective bargaining units can complicate shared governance. "The mixing of collective bargaining, an essentially adversarial process, with shared governance, an essentially collegial process, further complicates the overall governance environment of research universities” (Lyall, 2001, p. 24). While the Joint Statement did not express the concerns complicating shared governance and collective bargaining, it appeared to be offered as an alternative to shared governance, which was not the reality. Lyall better described what actually occurred, a mixing of the two.

\section{Relevance of Shared Governance}

Kezar (2004) noted that multiple studies and research have alluded to a "problem" with the effectiveness of the governance structure in higher education (Dimond 1991, Benjamin \& Caroll, 1998). These studies listed many reasons why shared governance has 
been perceived as ineffective. Some said the system has not been responsive and agile enough, while others explained that external factors have been pushing governance away from thoughtful, education-based decision making. Authors such as Birnbaum and Tierney (Birnbaum, 1989; Birnbaum 2000; Tierney, 2000) offered extreme perspectives on this and raised the issues as if the future of shared governance were being debated (Kezar, 2004, pp. 35-36). Clearly, there are definite questions abound about the need for shared governance, and what it should look like in higher education today. One broad, sweeping question arose in nearly all literature about shared governance:

There is no doubt that, as its critics suggest, faculty participation in shared governance will have the effect of making it more difficult to change the programs and purposes of higher education. Whether this is a good thing or bad thing is a matter of ideology (Birnbaum, 2004, p. 20).

Among the more telling statements that highlighted the concern about the relevance of governance in today's educational systems, was from the Association of Governing Boards. "Many presidents, governing boards, and faculty members believe that institutional governance is so cumbersome that timely and effective decision making is imperiled; factionalism, distrust and miscommunication, and lack of engagement among the parties can impede the decision making process” (AGB, 2010, p. ii). Birnbaum challenged this idea, arguing that maybe it was not the role of the university to be quick to respond or have speed in the decision-making process (Birnbaum, 2004, p. 8). The concept questioned the validity of treating academic institutions as if they operated as a market. Gumport also has challenged whether institutions live in those definitions or if there is a continuum between social institutions and industry on which they sit (as cited in Birnbaum, 2004, p. 8). However, Hamilton indicated the reality of the power structure, 
that the board holds the authority. "The governing board and the administration can place appropriate time constraints on the faculty consultative process in light of the urgency of the issue at hand” (Hamilton, 2004, p. 101). So, while Birnbaum believed the responses did not need to be or should not be speedy, faculty may not have a choice to operate that way and still be considered an active player in shared governance.

The paramount complaint of shared governance, by any actor or bystander, was that it was not effective. That said, the concern was measured differently by each population. Kaplan described the two kinds of criticism that shared governance receives:

The first claims that academic governance has become too corporate and capitalistic and that decision-making models increasingly mimic the centralized powers of corporate management in the for-profit sector. The second criticism contradicts this view, arguing that shared governance is too arcane in its traditions and that it remains unresponsive to the economic pressures and demands of the modern world (Kaplan, 2004, p. 24).

Essentially, one argument was that shared governance needs to be less like corporate decision-making structures, and the other argument was that it must be more responsive and business-like in its decision-making structure. Both criticisms support the complaint that shared governance was not being effective, with two different interpretations of what effective means to the complainants.

Kaplan performed a study to effectively measure the outcomes of sharedgovernance decisions to determine if they were more aligned with supportive faculty measures based on more faculty involvement in decision making. The outcomes of this single study pointed to a lack of formal alignment; two outcomes were stressed:

First, structures of governance do not appear to account, in a significant way, for variance in outcomes among institutions of higher education. 
Second, where effects could be observed, they often ran counter to predictions based both on the self-interested behavior and conflicting interests of all groups, and on models of adversarial relations among faculty, boards, and administrators (Kaplan, 2004, p. 31).

He then suggested that "explicit forms of governance may not matter that much and that higher education outcomes might be more related to factors beyond structural arrangements” (Kaplan, 2004, pp. 31-32). This statement supported the notion that an academic analyst's ability to engage with faculty and to manage curriculum and policy outcomes effectively may not necessarily have been contingent on the governance structure. Instead, that role might have depended on the relationship development that some suggested.

An additional study, conducted in 1993 also reported concerns that faculty shared specifically. Katharine Lyall reported:

A national survey conducted by the National Center for Education Statistics in 1993 indicates that faculty in U.S. colleges and universities spend about $11 \%$ of their work time (about six hours per week) in committee meetings and other efforts that are part of the sharedgovernance procedures. The same survey indicates that faculty report getting less and less satisfaction from their participation in governance, as well (Lyall, 2001, p. 23).

This observation spoke to the relevance of the participation and the role in which faculty saw themselves as it related to shared governance. Interestingly, Lyall also referenced another trend, in addition to faculty getting less satisfaction from their governance involvement. This trend was to "extend shared[-]governance rights to non-faculty professional staff (in addition to faculty)" and how "faculty governance" had become "shared governance” as a result of this shift (Lyall, 2001, p. 23). She raised both issues as 
faculty questioned the relevance of shared governance at colleges and universities based on the actors who participate in such governance.

The actual relevance of shared governance can be measured by how a particular shared-governance philosophy (or, modus operandi, as such) helps support the mission of the institution. Larry Gerber has addressed one position of faculty defending the mission of the institution as if it were at risk:

In the case of higher education, a professional professoriate acting through the mechanisms of shared governance is potentially the last-line defender against the triumph of a narrowly utilitarian definition of the purposes of higher education that views students as customers and sees job training as the sole function of colleges and universities (Gerber, 2014, p. 166).

Relative to the shifting of the mission and the hope of salvaging the long-time approach to higher education, Gerber was right, and the professoriate must defend its role and its authority. Moreover, “The basic question to ask is not whether we want to make governance more efficient, but whether we want to preserve truly academic institutions. If the answer is affirmative, then shared governance is an essential precondition” (Birnbaum, 2004, p. 20). Therein, Birnbaum summarized how to maintain the relevance of higher education via shared governance.

Threats to Shared Governance

Unsure if the AGB statement (2010) was insinuating slow deliberations in the past or just was warning about changes in the tide, administrators faced one of the biggest challenges to the culture of shared governance in recent history: the push for results faster than expected historically. Many (particularly those with little higher education 
experience and a corporate background) thought of this sluggishness as a system fault.

Susan Lapworth said:

[T]he slow deliberation of Senates and Faculty Boards hinders an institution's ability to respond to a rapidly changing external environment and this raises tension between a cultural desire for consultation and consensus, and the necessity of speedy and complex decision-making (2004, p. 300).

Others argued that the benefits and power of shared governance came from the deliberation and thoughtful consideration by actors in the operating core, that is, faculty.

The Association of Governing Boards stated its support:

... [F]aculty are accorded significant responsibility for and control of curriculum and pedagogy. This delegation of authority has historically resulted in continuous innovation and the concomitant effect that American college curricula and pedagogy define the leading edge of knowledge, its production, and its transmission (AGB, 2010).

Among the three main actors, faculty involvement in shared governance was most at risk

as the changes emerged from the new approach to board and external involvement.

Greater levels of accountability, decreased funding, the increased cost of higher education, the increasing decentralization and departmentalization of academic areas, as well as other factors have made it increasingly impossible to maintain an effective system of shared decision making in higher education (Pope, 2004, p. 83).

Myron Pope was more forthright about the imminence of such changes.

The Joint Statement (AAUP, 1967, rev. 1990) listed the primary functions

afforded to faculty in their shared-governance roles:

- When an educational goal has been established, it becomes the responsibility primarily of the faculty to determine the appropriate curriculum and procedures of student instruction.

- The faculty has primary responsibility for such fundamental areas as curriculum, subject matter and methods of instruction, research, 
faculty status, and those aspects of student life which relate to the educational process.

- The faculty sets the requirements for the degrees offered in course, determines when the requirements have been met, and authorizes the president and board to grant the degrees thus achieved.

Birnbaum summarized the faculty roles in the Joint Statement by articulating three questions that faculty control: "Who should teach?” "What should be taught?” and "Who should be taught?” (Birnbaum, 1999, p. 327). The idea was that those general topics fell solely to the faculty without excluding them from participation at other levels like budgeting and planning. For example, Duderstadt observed:

While faculty governance continues to be effective and essential for academic matters such as curriculum development, faculty hiring, and tenure evaluation, it is increasingly difficult to achieve true faculty participation in broader university matters such as finance, capital facilities, and external relations (2002, p. 3).

Given the changes to involvement from the board and external actors, faculty involvement became a herculean effort rather than the standard procedure it once was, thereby a threat to faculty in shared governance and to their core competency, teaching.

The “take-charge” approach, decreasing response time, mandated regulations and competition from for-profit institutions reduced the deliberation time previously allotted for critical discussions amongst faculty, administrators, and trustees. These factors also indicated the concern about limiting the faculty role in shared governance. Budgetary constraints that affected the funding of faculty positions could have also altered their roles. As Zusman noted, "Shared governance may be undermined in the future as the percentage of faculty who are not permanent increases” (2005, p. 147), indicating that 
adjunct faculty also should have been seen as actors in shared governance. Independently, these shifts may have seemed inconsequential, but when compiled, the evidence indicated a serious threat to faculty participation in shared governance.

Finally, one neglected area of consideration was that of the administrative role. In much of the literature, the president was the only representation of the administrative voice. While not true in practice, literature was limited with regard to administrative actors beyond the president. The president (and respective staff) was responsible for managing internal operations, setting budgetary parameters, leading innovation, and initiating new ideas (AAUP, 1967, rev. 1990). The president's role had much discretion yet restrictions still existed. Discretion allowed for the creativity and innovation to flow — with funds to go along with it-yet constraints still occurred informally and formally. Informally, a vote of no confidence by faculty was the strongest limiting factor to experience. Formally, accreditation, state educational boards, federal regulations, and other legal factors limited the presidential discretion (Birnbaum, 1999 p. 327). Presidents were paid handsomely for dealing with these limiting constraints where finding success without tremendous struggle was rare. For example, Blau noted that "The basic power in major universities, too, is exercised by the board of trustees and the central administration, notwithstanding the extensive decentralization of authority over academic affairs to the faculty” (1973, p. 188). Finally, it is true that while restrictions existed, much of the power resided with the president and administration. 


\section{Values of Shared Governance}

Kezar wrote of the values that were required for successful shared governance, comparing their importance to the importance of the structures that support governance. Specifically, she discussed relationships, trust, and leadership (Kezar, 2004, pp. 39, 43). Myron Pope also supported the value of trust as being paramount to effective shared governance, and he mentioned trust among certain stakeholders: students trusting higher education, faculty trusting administrators, and trust in planning processes (Pope, 2004, p. 75). An additional value that Tierney and Minor brought to the discussion was that of communication. They referred to an unpublished manuscript by Lewis Mayhew, where he stated:

...-[I]n one sense the governance of the university is governance by conversation. Many of the seemingly critical matters, such as the form of the curriculum or even the size of the budget ... are the subject of thousands of hours of consultation and conversation before a final decision is ratified (Tierney\& Minor, 2004, p. 86).

Finally, authors implied an understanding that institutional culture must be considered a value of shared governance. It may be better described as a characteristic, but authors writing about shared governance have recognized that culture was also crucial to a successful shared-governance model, regardless of which (Pope, 2004; Tierney, 1988). Relationships, trust, leadership, culture, and communication seemed to surface as the key values required for shared governance.

A bold yet consistent assertion from Kezar was that the presence of these values was more critical than the selected type of shared-governance model. In fact, the literature on shared governance was somewhat split on this concept. Some authors moved 
toward the idea that the type of shared-governance model in use was less important than the values of shared governance used as long as some form of governance was in place by which faculty could exercise their expertise in curriculum. Essentially, these arguments debated Kezar's point on which is more important for shared governance, structures or values. While there must be shared governance, it could be possible that the choice of model was less imperative than the presence of a model. In the end, Kezar focused on the interpersonal dynamics of the president with the faculty as being essential (2004, p. 40). Examples of these pertinent values and their role in the success of the organization were found throughout the literature.

Tierney suggested that administrators who recognize the complexity of the shared-governance culture will be more successful and can "minimize the occurrence and consequences of cultural conflict and help foster the development of shared goals” (1988, p. 5). In addition, he wrote:

[A]dministrators are well aware that they can take a given action in some institutions but not in others. They are less of aware of why this is true. Bringing the dimensions and dynamics of culture to consciousness will help leaders assess the reasons for such differences in institutional responsiveness and performance. This will allow them to evaluate likely consequences before, not after they act (Tierney, 1988, p. 5).

Another example of values taking precedence over the type of shared-governance model was present when presidents spoke about the value of formal and informal communication with faculty, rather than about the structures. Peter Flawn, President Emeritus of the University of Texas at Austin, suggested such ideas. Urging presidents “not to remain aloof from faculty”, President Flawn also suggested that "the best way to maintain . . . cordial relations with faculty is to entertain them”, and he urged other 
presidents not to diminish the value in the communication with faculty because "the faculty and its quality, attitude, and support of the institution and its programs are what distinguish a first-class university from a run-of-the-mill institution” (Flawn, 1990, pp. 82-83).

Integration of Role Theory, Organization Theory, and Shared-governance Theory When Mintzberg applied his organization breakdown to an institution of higher education, he asserted that these institutions were categorized as the Professional Bureaucracy (Mintzberg, 1993, p. 194). The focus on the operating core (Figure 5 [base]), the faculty, as being most active, with a limited role for the remaining four basic parts of the organization (strategic apex [top], technostructure [left], middle line [center] and support staff [right]) supported the notion that the academic analyst was limited in that role of impacting outcomes related to shared governance with faculty. The operating core functioned as the largest and most dominant part of the organization in this model.

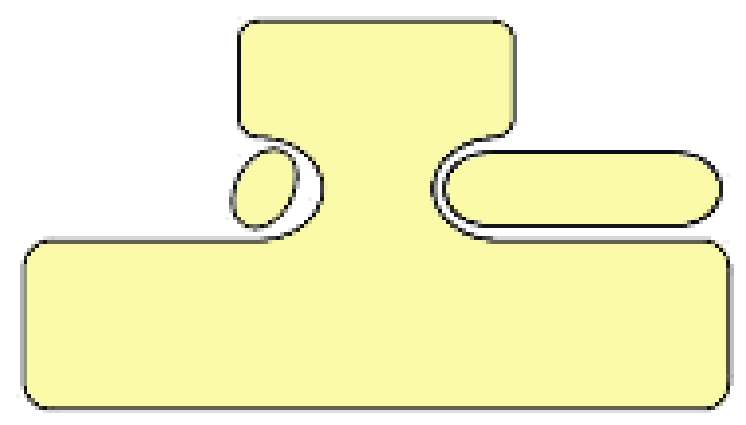

Figure 5. Mintzberg's professional bureaucracy model adaptation (Mintzberg, 1993, p.194. Used by permission of the author.).

Additionally, the perceived need for the academic analyst to be involved in shared governance-when the role was limited — exemplified Biddle's role conflict. These were 
other "structural conditions that cause[d] problems in social systems" such as role ambiguity, role malintegration, role discontinuity and role overload (Biddle, 1986, p. 83).

Biddle also suggested that other role theorists had described persons who experienced stress associated with positions or expected role as those who experienced role strain (Biddle, 1979; Goode, 1960; Marks, 1977; Merton, 1957; Snoek, 1966). Role strain likely existed anytime there was role conflict or malintegration. If academic analysts and faculty had a clear gap between the levels of involvement they believed should exist with the analysts and shared governance, it was likely that role strain existed. It was this relationship, the one between the faculty and the academic analyst, which was studied and evaluated.

Conclusion

To understand roles and role theory, it was necessary to comprehend the importance of the actors in higher education institutions, the organizations where the research took place. Clarity was provided by assessing how higher education institutions fit into the appropriate organization models so that a review of primary actors could be studied, academic analysts, in this environment, one of shared governance. Shared governance emerged from active roles within institutions that existed long before a national standard (and to some extent, language) was identified. The Joint Statement that directed most public institutions in the United States offered the language, guiding values, and standards that legitimized the work that many institutions were already performing or attempting. 
The different models of shared governance revealed the weaknesses of some institutions' involvement by faculty and administrators. The models helped articulate the types of involvement, but when the descriptions were overlaid with the Joint Statement, an unclear role still remained: that of the administrative bureaucrat. The role of the faculty existed in both, but their role was threatened by the rapidly changing involvement of the board and the external forces impacting institutions. "If any group is to take the lead in standing up for academic values . . . it must be the faculty, who must reassert their commitment to a broad conception of the professional rights and responsibilities” (Gerber, 2014, p. 169). The courageous declaration by the academy that needed to be made was one of authority regarding their model (shared governance) of doing business and why it worked for their industry (education) so as to remind the citizenry of it as a practiced, tested, and successful construct that can continue to be successful in future generations. 


\section{Chapter 3: Research Methods}

Introduction

This chapter outlines the methodology and procedures used to perform the research and evaluate specific questions that examined the hypothesis about the role of academic analysts in shared governance. The methodology includes a discussion of eleven topics: research design, research questions and hypothesis, definitions of terms, instrumentation, population, sample, contingencies, respondents, data collection, and data analysis. The chapter finishes with the topics addressing factors that restricted the study by covering the both assumptions as well as limitations of the study. The chapter ends with a brief conclusion.

\section{Research Design}

The research strategy was to develop a survey, select a population from a broad category of higher education institutions, and collect feedback from two types of respondents at the selected institutions. The intent of the survey was to collect both quantitative and qualitative data, a mixed methods approach. The quantitative data was collected using close-ended, multiple-choice questions, for both survey populations. The qualitative data included open-ended questions, for both survey populations. The qualitative data added context to the outcome of the analysis of the quantitative test, and it also offered new ideas that could not be validated in the quantitative analysis. Creswell argued that the Concurrent Triangulation Strategy should "weigh the methods equally", but it is difficult to guarantee that balance; many researchers do not attempt to do so (Creswell, 2009, p. 213). This survey was no exception. The qualitative data provided 
different evidence than the quantitative data, and it was not possible to weigh the responses from each method equally.

As part of the survey, basic questions were asked to determine shared-governance models in existence at the surveyed institutions. This data provided a baseline for assessment of the subsequent responses, and it was used to control for an accurate measurement of the outcome that the academic analyst had on curriculum management. The data gathering and assessment of this information occurred by offering definitions of three shared-governance models at the onset of the survey then asking respondents to identify the one that best fit their institution. This information was used as the control variable for the remainder of the survey questions.

\section{Research Questions and Hypothesis}

From a broad perspective, the hypothesis of this study focused on the actors involved in affecting curriculum management, based on the type of shared governance that existed at each institution. For example, when registrars are involved in curriculum management and a strong shared governance model existed at their institution, it appeared that two things were likely to occur. First, registrars have improved awareness about how curriculum changes impact students, and as a result, efficiencies for students occur. These efficiencies are likely in this situation because more informed decisions are made about how to set succinct curriculum rules and clear academic policies that limit negative impact on students. Consequently, in a model where shared governance respected active roles for all actors, the hypothesis was that academic analysts had more effect on the outcomes of curriculum management than in a model where active roles for 
all actors were not as valued. Specific to this study, the hypothesis narrowed dramatically. The research question specifically asked, “Does the level of academic analyst involvement in shared governance have an effect on curriculum management and academic policy while controlling for the shared-governance model practiced at that institution?”

This research question comprised three main areas, which covered the basic elements of a quantitative research question: the independent variable, the dependent variable, and the control variable. They were:

- $\quad$ shared governance (control variable),

- the level of involvement of the academic analyst (independent variable), and

- $\quad$ perceptions of improved curriculum management and academic policy (dependent variables).

Determination of these variables for this research question was drawn from definitions offered by both Simon and Burstein, and Creswell. Simon and Burstein defined the dependent variable as "the quantity or aspect of nature whose change or different states the researcher wants to understand (or explain or predict)" and the independent variable as "a variable whose effect upon the dependent variable you are trying to understand" (Simon \& Burstein, 1985, p. 26). The goal of this research was to understand the perceptions of improved curriculum management, based upon the effect of the level of involvement of the academic analyst, while controlling for the shared-governance model. Creswell described control variable as a "type of independent variable that researchers measure because they potentially influence the dependent variable . . . that need to be 
'controlled' so that the true influence of the independent variable on the dependent variable can be determined” (Creswell, 2009, p. 51). Shared governance acted as a control variable in this study so as to demonstrate if perceptions about curriculum management, based on the involvement of the academic analyst, were influenced by the different models of shared governance.

Ideally, from this research, the goal was to ascertain if academic analysts were involved in curriculum management, and, if so, if that level of involvement improved curriculum management and academic policy. The control variable, the sharedgovernance model, helped determine if this was more or less likely, based on the type of model at the institution. Thinking about it from a more structural perspective, allowed certain ideas to be mapped to the structure of the research as laid out in the instrumentation section of the chapter.

- Concepts. The idea that respondents believed that either registrars did affect curriculum management and academic policy or they did not.

- Constructs. The shared-governance model at each institution, the respondents' positions at each institution, and the institution type of each respondent.

- Measures. The determination of registrars' involvement; determination of perceived improved, curriculum-management outcomes for students; and determination of perceived improved academic policy for students. 


\section{Definition of Terms}

Because curriculum management was a critical, measured experience in the research, it was important to clearly define this term. Curriculum management had not been well defined by literature previously, and the ownership of such a definition was currently being juggled by authors with a vested interest, such as companies who owned curriculum-management software programs. The interpretations were vast, restrictive, and did not represent the intentions of this study. One example of a broader definition was provided by Nancy Howard, currently vice president, currIQunet (formerly Governet), a “global curriculum network” company. This company provides software for institutions who wish to have a workflow-based, approval process for their academic decisions to implement new, or update current, curriculum. Howard wrote, "Curriculum management is the process through which educators and administrators collaborate on the creation, development, design, review, approval, assessment, and refinement of learning content to achieve desired student outcomes” (Nancy Howard, personal communication [email], August 21, 2018). While the broad definition certainly covers the gamut of topics on curriculum, most educators have argued that curriculum creation, curriculum development, and curriculum design are all standalone terms and not a subset of curriculum management.

For the purpose of this research, “curriculum management” was viewed as the process by which the curricular operations and curricular logistics are negotiated or collaborated on and then implemented with the appropriate actors. The creation, development, and design were viewed wholly as the responsibility of the faculty with the 
topic expertise to create course outcomes, courses, and academic programs supported by such curriculum creation. The terms “curriculum operations” and "curriculum logistics” were interchangeable with “curriculum management” in this study. Instrumentation

This research evaluated survey responses from both quantitative and qualitative data looking for similarities and differences. The quantitative data were either answers to close-ended questions or responses to items on Likert scales in the survey to both types of respondents, registrars and faculty. Likert scales are a simple type of composite scale where respondents are presented with several items for which they either agree/approve or disagree/disapprove using a numbered scale. The scales are then scored in a simple sum (Simon \& Burstein, 1985, p. 219). The qualitative data were responses to openended questions in the survey from both respondent types.

The survey was split into four sections of data for collection. Several sections included close-ended questions, statements with Likert scales for responses, and openended questions. All statements and questions, including the demographic questions in section four, were optional responses on the survey. This option was set up purposefully in order to prevent a possible respondent from choosing to complete what they could versus not complete anything if they were unable to accurately respond to a particular question in the survey.

Section 1 (question 2) contained shared-governance models, including definitions, that respondents selected in order for the researcher to assign the shared-governance model at that institution. Utilizing a theoretical structure from Adriana Kezar, an a priori 
approach was employed with three different categorical types of shared-governance models. Two ways have been employed to classify research, either using a taxonomy structure or a priori. The taxonomy structure occurred when the data were sorted, then categories were constructed, to support the sorted groups. The a priori method was quite the opposite: categories were structured first, and the sorting happened using only those predetermined categorizations (Simon \& Burstein, 1985, p. 38). Each respondent from the institution selected the best definition from the predefined categories of sharedgovernance models.

In an effort to quantify a value regarding shared governance, an archetype (Figure 6) was initially designed as a possibility for measuring shared-governance models during the survey.

Figure 6. Shared-governance archetype proposed to measure decision-making authority of faculty

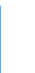

(1) Weak
(2) (3) Moderate
(4)

\section{Shared Governance}

However, the measurement archetype was not used during the survey; instead the definitions followed those of Adriana Kezar to summarize model types that were used. Respondents selected an appropriate shared-governance model, based on those definitions with regard to decision-making authority instead of based on the measurement archetype (Table 3) created as a possibility. The archetype depicted the strength of the 
model, based on the decision-making authority allowed in it. The units of strength were used later in the findings as the different shared-governance models are discussed.

Table 3. Definitions of Strength for Shared-governance Models by Decision-making Authority of Faculty

\begin{tabular}{lc}
\hline \multicolumn{1}{c}{ Decision Making Authority of Faculty } & \multicolumn{1}{c}{$\begin{array}{c}\text { Assignment of } \\
\text { Shared-governance Model }\end{array}$} \\
\hline $\begin{array}{l}\text { The faculty has no binding decision making authority in } \\
\text { decisions regarding both curriculum management decisions } \\
\text { and academic policy decisions. }\end{array}$ & Weak shared governance \\
$\begin{array}{l}\text { The faculty has binding decision making authority in } \\
\text { decisions regarding either curriculum management decisions } \\
\text { or academic policy decisions but not both. }\end{array}$ & Moderate shared governance \\
$\begin{array}{l}\text { The faculty has binding decision making authority in } \\
\text { decisions regarding both curriculum management decisions } \\
\text { and academic policy decisions. }\end{array}$ &
\end{tabular}

Section 2 (questions 3-15) contained statements and questions that measured the level of participation by the registrar in decisions about at least seven different academic policies or curriculum rules. These questions were asked and measured using three different methods: scaled responses, yes/no, and open-ended text fields. This section of the survey was identified as the independent variable of the research question. It was possible to measure these responses four ways: holistically in an aggregate format, separating them by the control variable, or using the shared-governance model, but also by running a statistical analysis utilizing all three variables.

Section 3 (questions 16-17) served as the third variable, the dependent variable in the research question. It contained statements and questions that measured the 
respondents’ perceptions about whether any effect had occurred on students from curriculum management and academic policy. These questions were asked using two different methods, a scaled response method and an open-ended text field. It was also possible to measure these responses four ways: holistically in an aggregate format, separating them by the control variable, or using the shared-governance model, but also by running a statistical analysis utilizing all three variables of the research question.

Section 4 (questions 19-24) contained questions about the respondents' basic professional demographics and how any of their authority gave agency to affect policies and involvement. It was critical to ask professional demographic questions of the survey participants at the completion of the study to ascertain if a connection existed between those demographics, the inductive research, or the open-ended questions that respondents answered. It was useful to compare and contrast the experience, such as years in the education field and level of highest degree attainment, with the insight offered about whether registrars had agency to influence policies and involvement. One question asked faculty and registrars if they had tenure. This was done with the intention of measuring if that authority shaped their responses.

Population

Drawing upon the definitions of population and sample as discussed by Simon and Burstein resulted in the selections chosen for this research study. These authors referred to the population as a universe, terms used interchangeably, but they believed universe has fewer confusing associations. Universe was "the collection of things or people from which you want to say that your sample was taken” (Simon \& Burstein, 
1985, p. 110). Sample was "the collection of observations for which you have data with which you are going to work” (Simon \& Burstein, 1985, p. 110). A sample comes from the universe or population, and a sample that was randomly chosen is one that is considered a "fair sample because each member of the population has an equal chance of being included” (Simon \& Burstein, 1985, p. 111).

The universe comprised all institutions listed in the Carnegie Classifications ${ }^{\circledR}$. The sample of institutions was created by utilizing the breakdowns as defined in the Carnegie Classifications of Institutions of Higher Education. The Carnegie Classifications ${ }^{\circledR}$ have been an industry standard for providing definitional differences between types of educational institutions.

Starting in 1970, the Carnegie Commission on Higher Education developed a classification of colleges and universities to support its program of research and policy analysis. Derived from empirical data on colleges and universities, the Carnegie Classification was originally published in 1973, and subsequently updated in 1976, 1987, 1994, 2000, 2005, and 2010 to reflect changes among colleges and universities. This framework has been widely used in the study of higher education, both as a way to represent and control for institutional differences, and also in the design of research studies to ensure adequate representation of sampled institutions, students, or faculty (Indiana University Center for Postsecondary Research, n.d.2, Carnegie basic classification description.).

Historically supported by the Carnegie Foundation, this classification was absorbed by the Indiana University Center for Postsecondary Research, effective January 2015. The classification still maintains its trademarked name, and there has been no formal statement on any future deviation from that structure (Lederman, 2014). Although the ownership of the commission changed hands, it remains the industry standard for this work. 
At the time of this research, the official Carnegie definition of doctoral universities was institutions that awarded at least 20 research/scholarship doctorates in 2013-14. Professional practice doctoral degrees (J.D., M.D., Pharm.D., Aud.D., DNP, etc.) were not counted for the purposes of this criterion. These categories were limited to institutions that were not identified as tribal colleges or special focus institutions (Indiana University Center for Postsecondary Research, n.d.1, Basic classification methodology). Categorically, doctoral universities were broken into three groups:

R1: Doctoral Universities- Highest research activity

R2: Doctoral Universities- Higher research activity

R3: Doctoral Universities- Moderate research activity (Indiana University Center for Postsecondary Research, n.d.1, Basic classification methodology).

For this research, a specific classification was used: public institutions defined as large, four-year institutions that were also classified as doctorate-granting universities with highest research activity, higher research activity, or moderate research activity. Based upon the most current data set at the time of research, which was updated in 2015, this sample of the population listed 196 universities that met the criteria. Sample

The basic concept of sampling is defined by Stephan and McCarthy as seeking knowledge or information about a whole class or similar objects (the population) but done via observation of some of that class or objects (the sample) and then extending the findings to the entire population (Stephan \& McCarthy, 1958, p. 22). Initially, the 
researcher intended to use a random sample for this research, specifically, a random, stratified sampling, wherein a sample of 50 randomly chosen universities would have been selected from the population of the 196 institutions that meet the population definition. Random stratified sampling occurs when "the population is first subdivided into two or more mutually exclusive segments, called strata, based on categories of one or a combination of relevant variables. Simple random samples then are drawn from each stratum, and these subsamples are joined to form the complete, stratified sample” (Singleton \& Straits, 1999, pp. 149-150).

Given the fact that section 1 of the survey immediately categorized respondents by their shared-governance models, it was critical to use a larger sample size initially so that categorical breakdown did not render the sample sizes too small to evaluate feedback. Consequently, this research utilized a purposive sample from a population, focusing on the entire population selected from the Carnegie Classification ${ }^{\circledR}$ and assuming that the response rate would limit the ability to analyze the data. Singleton and Straits defined purposive sampling as “a form of nonprobability sampling that involves the careful selection of typical cases or of cases that represent relevant dimensions of the population” (Singleton \& Straits, 1999, p. 564). This decision was made because it was important that respondents from all schools defined within the population had a chance to respond to the survey. Additionally, the selected respondents, both registrars and faculty with curriculum expertise, needed to have enough knowledge about the topic to respond to the questions accurately. 
The a priori model used by the respondents to select the appropriate shared governance definition was developed directly from the basic description of the three types of shared-governance models adapted from Adrianna Kezar. Listed earlier in chapter two, the three types were consultative, distributed decision-making, and fully collaborative. Definitions of faculty behavior (Table 4) were used by respondents to select the model that best indicated the shared governance at their institution. The depth and scope of the actors operating in the shared governance-model, and the decisionmaking nature of the body where the actor was employed, played a part in helping delineate the definitions clearly for respondents to choose the best model. Table 4. Sorting Rubric for Each Shared-governance Model by Behavior of Faculty

\begin{tabular}{|c|c|}
\hline Behavior of faculty & $\begin{array}{c}\text { Assignment of } \\
\text { shared-governance model }\end{array}$ \\
\hline $\begin{array}{l}\text { Faculty do not make decisions but do make } \\
\text { recommendations to other bodies, actors who } \\
\text { make the decisions. }\end{array}$ & Consultative \\
\hline $\begin{array}{l}\text { Faculty make binding decisions about specific } \\
\text { academic issues such as admissions } \\
\text { requirements, graduation requirements, academic } \\
\text { program requirements. }\end{array}$ & Distributed decision-making \\
\hline $\begin{array}{l}\text { Faculty make binding decisions about non- } \\
\text { academic topics such as budget, human } \\
\text { resources policies, or other administrative } \\
\text { functions not aligned with direct academic } \\
\text { outcomes. }\end{array}$ & Fully collaborative \\
\hline
\end{tabular}

\section{Respondents}

The survey questions informing the research question were targeted at a sample of two particular actors who were asked the same questions; these respondents were registrars and faculty. First, registrars acted as academic analysts, relative to their role in 
working with curricular decision-making bodies. Second, faculty acted as leaders of the institution's curricular decision-making body. As stated earlier, other academic analysts at educational institutions worked closely with faculty on many topics, but the research question narrowed to registrars specifically. Similarly, many faculty bodies worked with administrative analysts related to other areas of higher education, but the survey focused on curriculum management and the relationship between the faculty leaders of the curricular decision-making bodies and the office that implemented much of that work, the office of the registrar. When collecting the contact information for the two types of respondents, registrars and faculty leaders, information was gathered differently.

Gathering the name and contact information for the registrars was done in two ways. The American Association of College Registrars and Admissions Officers supplied their membership roster and the researcher was able to sort for the schools in the population and the sample. This sort successfully returned about $60 \%$ of the contacts for that respondent type. The remaining $40 \%$ or so was collected using basic search functions on institutional websites, employing keywords such as University Registrar, Registrar, Office of the Registrar, Registrar's Office. In rare cases, searching for the terms “registration” and "records” was required. This work was done relatively quickly and easily.

Faculty information-gathering required a different approach. One particular challenge was best determining who the faculty leader was of the particular, appropriate curricular decision-making body. Institutional websites first were searched for faculty senate offices, and then each committee of the faculty senate was reviewed for the 
appropriate committee name and description. This review-and-search process was often based on the structure at each institution surveyed, using basic information gathering and evaluating the summaries of the committee charges for each institution. As soon as the name of the committee was determined, it was necessary to collect the name and contact information for the chair of the committee. In the case that two people served as cochairs, the person with the most seniority on the committee (the soonest committee expiration date) was selected. If that information was not available, the researcher selected the first co-chair listed.

\section{Data Collection}

The researcher used a standard online survey tool, Qualtrics, for data collection. Survey design and development occurred and was tested by peers of the possible respondents. This process ensured that data collection was performed on a pilot test and that the survey questions and data collection methods were modified prior to the survey being distributed. Peer respondents offered useful feedback, and significant changes occurred as a result. This process required several iterations of the survey before completion, but only one of the iterations included peer-respondent feedback.

Upon successful completion of the pilot testing and modifications made to the research instrument, the researcher requested and received appropriate Institutional Review Board (IRB) approval from multiple institutions. According to the approved research agreement, the survey was administered after the IRB accepted revisions. The date of survey administration was February 22, 2018. The first reminder occurred on March 7, 2018, and the final reminder occurred on March 20, 2018. The survey included 
information about informed consent for participants who chose to engage in research. The survey remained open for 37 days, approximately ten days longer than had been anticipated. This was done because data collection proved to be slow, and the researcher chose to extend the length of the survey in an effort to increase participation.

\section{Quantitative Data Analysis}

The research performed on the survey data included examination of both qualitative and quantitative data sets. Quantitative data were analyzed to determine if the control variable, shared governance, had an effect on the ability of the independent variable, academic analyst, to influence the dependent variables, perceptions of improved curriculum management and academic policy. The statistical test performed to analyze the significance of the data was Fisher's Exact Test (RCT-CRAN, 2017). The researcher initially planned to run a standard Chi-square test on the data but upon evaluation of the data, the cell sizes were small enough that a standard Chi-square test would not yield appropriate results. In order to measure for statistical significance, Fisher's Exact Test was used.

Fisher's Exact Test works for all sample sizes, but it is mainly employed when sample sizes are small, and other tests of statistical significance may not yield results. Ramsey and Schafer defined Fisher's Exact Test as "the gold standard of testing tools for $2 \times 2$ tables ... It is exact in the sense that the $p$-value is based on a permutation distribution and requires no approximations” (Ramsey, 2002, p. 552). They further defined Fisher’s Exact Test as, “appropriate for any sample size, for tests of homogeneity or of independence” (Ramsey, 2002, p. 562). This definition served as the main 
difference between Fisher's Exact Test and the Chi-square test, which is an approximate test. Fisher's Exact Test is useful for studies when the sample was not random, a good fit for this study where a purposive sample was employed (Ramsey, 2002, p. 564).

Fisher's Exact Test was performed with the registrar input statements (seven of them) being run against the perceived impact statements (eight of them) while controlling for the shared-governance model (three of them). This resulted in the test being performed 168 times $(7 \times 8 \times 3)$. Results reported with a $p$-value of less than .1 would demonstrate significance.

\section{Contingencies}

While Fisher's Exact Test is effective on small sample sizes, in this research the use of multiple five-response scale sets which were then separated by shared-governance models caused many results to have zero values in multiple places. The researcher determined that to simplify the testing process, Likert-scale responses would be collapsed into smaller categories that created binary measurements such as Agree and Disagree or Yes and No instead of the larger scaled response key. There was no plan to perform the analysis in this fashion, but the data yielded results that required the creation of a contingency plan.

Qualitative Data Analysis

The qualitative data were analyzed for additional evidence to support further exploration of the hypothesis. These data were collected in three main categorical responses, and a basic content analysis was performed on those three categories to summarize the qualitative data and evaluate it against the hypothesis. The first categorical 
response was based on the follow-up questions about registrars' involvement in institutional policies, the independent variable. The second categorical response was based on the dependent variable, the respondents’ perceptions about the registrar's involvement having an effect on students. The final categorical response evaluated the registrars' own perceptions on how their authority gave them agency in these processes. Institutional Policy Questions

The survey asked a series of four questions about specific policies related to academic requirements and graduation requirements (questions 4-15). Respondents selected yes, no, or unsure. Each question had logic-controlled questions that only were asked based on the respondents answer: one question if the respondent answered yes and another question if the respondent answered no or unsure. The secondary questions were open-ended. Four policy questions, resulted in a series of twelve total questions, three for each policy, but each respondent was asked only two of those three questions, depending on the response to the first question in the series. The idea was to ascertain if the institution had such a policy and the role the registrar played in the process as well as if their role was helpful. If the institution did not have such a policy or the respondent was unsure, the idea was to ascertain how the registrar could have been involved in the process related to that topic. The four policy questions were:

- Does the institution have limitations on the number of credits/courses in an academic program that can be taken as "generic courses” such as research credit hours, independent studies, special topics, et al.? 
- Does the institution have a policy about how to define course equivalencies (two courses at the institution offering credit for the exact same outcomes) when modifying or creating a course?

- Does the institution have a policy about withdrawing from the university and any limitations this places on students?

- Does the institution have a policy about academic standing to ensure students are progressing toward the degree they are seeking? Note: this is not related to financial aid requirements for satisfactory academic progress; it is related to academic standing such as probation, warning, suspension, et al.

For each question, if the respondent answered yes, the follow-up question was, "What role does the Registrar play in the process? Please explain the level of helpfulness that comes from the role of the Registrar in the process.” If the respondent answered no or unsure, the follow-up question was, "Describe how you think the Registrar could be involved in the process.” Because the follow-up questions for all policy questions were the same, the evaluation of these questions required a standard protocol in order to measure responses.

The protocol for evaluation of these questions was as follows. The initial review of responses to these questions (Q4-15) was performed without controlling for the shared governance-model of the respondent. Because of the initial review of the responses, the following coding schemes were created:

- Information provider - the registrar offered information to the process for others to make a decision. 
- Managing a tool — the registrar managed a tool that assisted with the process for that policy.

- Involved - the registrar was actively involved in discussions around the process and policy.

- Committee participation - the registrar participated on a committee that made decisions related to the policy (ex-officio or voting membership).

- Input - the registrar provided input to the process.

- Helpful - the registrar was described as helpful to the process.

- Consultant — the registrar was consulted based on their expertise.

- Limited/none - the registrar had limited or no input into the process.

- Institutional knowledge - the registrar provided institutional knowledge to the process.

Respondents' answers were evaluated for these categorical themes and coded appropriately. The coding was not limited to one code per response; any and all appropriate codes were listed for each individual response. Not all responses received a code. If a response was too peripheral to the question or not applicable at all, it was not coded. All responses were then separated by shared-governance model, but the codified answers were reported both by shared-governance models and holistically.

\section{Registrar's Involvement and Impact to Students}

The study asked an open-ended qualitative question that served as a support question to a quantitative question (question 17). The quantitative question was about the perceived impact on students because of decisions related to curriculum management and 
academic policies. A series of statements about impact to students based on eight different policies or practices used a Likert scale to measure level of agreement about the impact to students. Following that series, an open-ended question asked, "Does the Registrar's involvement in curriculum management and academic policy impact students? Please explain your answer.” The evaluation of this question required a protocol to measure responses.

The protocol for evaluation of this question was as follows. Respondents’ answers were coded in three ways: Yes, No, and Somewhat. The determinations were made based on these criteria:

Yes-Coded if the statement used clear and affirmative language such as yes, absolutely, for the most part, positive impact, etc.

No-Coded if the statement used clear and affirmative language such as no, rarely, seldom, limited, not proactive, etc.

Somewhat—Coded if the statement openly used language stronger than seldom, limited but was not clear enough to measure as a yes response. This determination was generally made after a Yes or No response was determined to not be an appropriate categorization.

Next, the responses were coded by the shared-governance model type-consultative, distributed decision-making, and fully collaborative—so that comparisons could be made across the models. All coding on these questions was performed on paper, not in an electronic form, in an effort to easily color-code the work and make visualizations quick 
to interpret and easy to modify. It is possible to perform much of this work electronically, but it is more time consuming.

\section{Registrar's Authority and Agency}

The final question of the study was an open-ended qualitative question serving to discover the actors' ability to influence policies and registrar involvement at the institution (question 24). Using basic display logic, the final question only was asked if the respondents selected "Registrar" instead of "Faculty" (who plays a role in curriculum approvals or academic policy) to the question, "What is your main role at your institution?” Coding responses were created for evaluation of the respondents’ comments. An inductive approach was used to create the coding responses.

The initial review of responses to this question was performed without controlling for the shared-governance model of the respondent. As a result of the initial review of the responses, the following coding schemes were created:

- Years-The number of years of experience in the field gives agency.

- Institutional Knowledge-Institutional knowledge/history, institutional memory, memory, etc. gives the registrar agency.

- Education-The registrar's degree attainment (such as Ph.D. when working with faculty) gives agency.

- Multiple Institutions - Working for more than one institution and brought perspective depth from other places gives the registrar agency. 
- Implementation-The registrar serves as an expert in implementing policies, procedures, outcomes of institutional decisions and that expertise gives agency.

- Trust/Respect-The amount of respect and/or trust earned by the faculty and administration gives the registrar agency.

Respondents' answers were evaluated for these categorical themes and coded appropriately. The coding was not limited to one code per response; any and all appropriate codes were listed for each individual response. Not all responses received a code. If a response was too peripheral to the question or not applicable at all, it was not coded. Additionally, several responses contained thoughtful information but did not fit into a category. Some of those responses were shared as quotes. All responses were then separated by the shared-governance model, but the codified answers were reported both by shared-governance models and holistically.

Inductive Review of Qualitative Responses

A final perspective on the data collected from the open-ended questions was performed using an inductive content analysis to identify themes not otherwise found using a protocol that included categorization of comments by topical areas developed inductively. The purpose of this process was to look for emerging theories or themes from the textual responses that may have resulted in solidifying the hypothesis or finding an emerging new one. The textual responses in this analysis displayed via powerful statements from respondents showed such support. As described by Vaismoradi, et al., inductive content analysis is similar to thematic analysis, and both are used in cases 
where no previous studies deal with the phenomenon (Vaismoradi, et al., 2013, p. 401). However, Elo and Kyngäs further explained that inductive content analysis may be used in addition to when no previous studies deal with the phenomenon, if the phenomenon is fragmented (Elo and Kyngäs, 2008, p. 107). A final perspective on the value of inductive content analysis was that, in addition to using it to seek themes from data analysis, it also could be used to enhance the trustworthiness of research (Cho and Lee, 2014, p. 16). Another way to validate further the hypothesis topics was by the use of inductive content analysis for enhancing the trustworthiness of the research.

While shared governance theory is not new, it is a practice in higher education, and the evaluation of roles within shared governance is a body of literature that is extremely limited. Therefore, inductive content analysis for some of the open-ended questions in the survey was an appropriate review tool. This perspective was secondary to the formal protocols developed for the qualitative data, but it was still critical to the possibility of making further contributions to the literature on the subject of shared governance and the role of the registrar.

\section{Assumptions of the Study}

This research sought to inform the literature about the level of academic analyst involvement in shared governance. Specifically, it aimed to determine whether that involvement has more of an effect on the outcomes of curriculum management and academic policy based on the shared-governance model practiced at that institution. One goal was to apply the outcomes successfully onto broader generalizations about academic analysts and shared governance, using specific feedback from registrars and faculty 
regarding curriculum management and academic policy. Another goal was to advance knowledge about the perceptions of academic analysts’ involvement in shared governance.

If the perceptions resulted in positive findings, the qualitative feedback could be used for best practices about how to replicate this work with other academic analysts. If the perceptions were negative, the feedback could be used for either corrective action to make changes or to reevaluate how academic analysts should be involved in shared governance. Additionally, this survey sought to allow registrars the opportunity to offer their perspectives on the need for their involvement in shared governance; this had not yet been done in the body of literature at the time the survey was administered. The feedback from faculty was to inform if or how including the academic analyst's participation could successfully happen from the lens of faculty leaders in curriculum management and academic policy development. The current body of knowledge related to shared governance covered faculty, boards, and executives (specifically presidents), but the non-executive administrators were missing from the discussion. By surveying registrars and faculty about this topic, a contribution has been made to the sharedgovernance literature that allows for expansion of the discussion regarding the executive (president) role.

\section{Limitations of the Study}

This research was limited by the broader shift in shared governance that occurred. Several reasons caused this shift: one was an increased governmental involvement in public higher education; another was that institutions are (and have been) shifting toward 
the use of business models instead of educational models to drive their "business". Both of these factors could affect the ability of faculty and administrators to be as active in shared governance as they had been in the past or had hoped to be in the future. While unrelated to the relationship between registrars and faculty, because there may be fewer "seats at the shared-governance table", this could affect the ability to increase the sharedgovernance partnership between registrars and faculty.

\section{Conclusion}

This chapter described the research methods performed to successfully execute the study. The details of the research design, research questions and hypothesis set the stage for determining the next phases of the study. Subsequently, defining the population and the sample allowed for the development of a plan to collect responses from the stated population. The research methods section also described the instrumentation selected for the survey. The creation of the survey questions was also summarized. Data collection and analysis plans described both the qualitative and the quantitative research methods. Finally, assumptions about the research were described briefly, as were the concerns about the possible limitations of the study. 


\section{Chapter 4: Findings}

\section{Introduction}

The broad purpose of the research was to explore the role of administrative analysts and the part they play in shared governance with a specific focus on academic analysts and their involvement in curriculum management and academic policies. The primary hypothesis was that when registrars are involved in curriculum management and there is a strong shared-governance model, efficiencies for students occur because more informed decisions are made about how to set succinct curriculum rules and clear academic policies that limit negative impact on students. The research question specifically asked, "Does the level of academic analyst involvement in shared governance have an effect on curriculum management and academic policy while controlling for the shared-governance model at that institution?” To explore this hypothesis, a mixed methods survey was performed. Quantitative data was evaluated via close-ended survey questions and qualitative data was collected via open-ended survey questions. Both approaches served to explore the hypothesis equally but with completely different approaches to the data. The results answered the specific research question but also highlighted the many individual ideas shared about the role of the academic analyst in shared governance that could not be measured in a survey instrument with only closeended questions. Those results created the newest ideas for further research to be explored.

As stated in the research methods chapter, one attempt to test this hypothesis was performed using R and running Fisher’s Exact Test (RCT-CRAN, 2017). The test 
compared questions about the registrar's participation in decisions about academic policies to questions about perceived impact on students from curriculum management and academic policy decisions. Data was also evaluated in an effort to test and gauge the relationship between the shared-governance models and additional close-ended questions in the survey. Results shared represented the structured research question and the results of the hypothesis being tested but also the findings from additional views of the data that support the question.

The second attempt to explore and examine the hypothesis was performed through three different tabulations of open-ended questions using a structured protocol to review, categorize, and codify themes in the feedback. This evaluation was planned for ten different questions within the survey but resulted in being performed on six different questions, with feedback available on five questions. Results shared represented the perspectives of the respondents and served to further test the hypothesis by evaluating the categorical framework of the responses as they are testing against the research question.

The third and final review of the hypothesis was performed through an inductive review of the open-ended comments. This strategy was followed in an effort to find unique responses that articulated additional ways that the hypothesis was being tested and further explored. Additionally, it served as an opportunity to share unique outcomes that could result in uncovering new territory on the topic of shared governance and the role of the registrar in curriculum management. All three approaches (Table 5) to evaluating the hypothesis against questions in the survey served distinct roles in the exploration of the research question. 
Table 5. Hypothesis Tests and Outcomes

\begin{tabular}{|c|c|}
\hline Hypothesis test & Outcome \\
\hline Fisher's Exact Test & $\begin{array}{l}\text { Inconclusive results. Of } 168 \text { tests performed, } 8 \text { tests resulted in a p- } \\
\text { value of } .1 \text { or less, indicating few significant results. }\end{array}$ \\
\hline $\begin{array}{l}\text { Structured protocol to evaluate } \\
\text { open-ended questions directly } \\
\text { related to the hypothesis }\end{array}$ & $\begin{array}{l}\text { Positive results. The majority of the feedback, among all shared } \\
\text { governance models, demonstrated how registrars positively affected } \\
\text { student efficiencies. }\end{array}$ \\
\hline $\begin{array}{l}\text { Inductive review of open-ended } \\
\text { questions directly related to the } \\
\text { hypothesis }\end{array}$ & $\begin{array}{l}\text { Topical results. The outcomes produced four main topics worthy of } \\
\text { further research that were not previously covered in the literature or in } \\
\text { the profession as constructs known widely to practitioners. }\end{array}$ \\
\hline
\end{tabular}

\section{Survey Outcomes}

The use of the Carnegie Classifications ${ }^{\circledR}$ to determine the survey population resulted in 418 possible respondents: 209 registrars and 209 faculty curriculum leaders. After adjusting for logistics, the survey was sent to $91 \%$ of the possible respondents: $53 \%$ were registrars and $47 \%$ were faculty curriculum leaders. Among respondents, $38 \%$ initiated the start of the survey but only 27\% completed the survey questions (Table 6, row 2). Respondents with surveys started but not finished did have data included in the output when a question was answered fully and could be evaluated.

\begin{tabular}{|c|c|c|c|}
\hline Action & $\begin{array}{l}\text { Faculty } \\
\text { Curriculum } \\
\text { Leaders }\end{array}$ & Registrars & Total \\
\hline Emails Sent & 179 & 202 & 381 \\
\hline Surveys Started & 50 & 96 & 146 \\
\hline Surveys Finished & 32 & 71 & 103 \\
\hline Emails Bounced & 3 & 2 & 5 \\
\hline Duplicate Email & 1 & 0 & 1 \\
\hline
\end{tabular}

Registrars had nearly a ten percent higher response rate versus faculty curriculum leaders. This response rate did not come as a surprise because the researcher is an active registrar 
in the field, and peers likely recognized the name. This association potentially triggered more respondents. It is also possible that the topic was of greater interest to the registrars than to faculty curriculum leaders.

\section{Respondent Demographics}

The survey also collected basic demographics related to the respondents and included questions about the highest level of degree attained, number of years working in the field, the main role of the individual at the institution, whether the institution offers tenure for that role, and if so, whether the respondent had tenure.

\section{Level of Highest Degree Attainment}

Of the respondents, $49 \%$ had attained a doctoral degree, $48 \%$ had attained a master’s degree, and only 3\% had attained only a baccalaureate degree. Knowing that 50 respondents, at a minimum, had attained a doctoral degree means that at least twenty of them were registrars. This degree attainment for a specific role demonstrated that the role values the high level of education; a possible question for a future study would be to measure the degree attainment of registrars of the past versus the registrars today to measure if this demographic has changed over time. If it has, learning about why could be useful for the purpose of better understanding the role of the registrar in shared governance.

\section{Number of Years in Education Field}

Respondents selected the range of appropriate years they had been in the education field (Table 7). When controlling for the respondent's role, the split was generally the same between the registrar and the faculty. Most registrars are promoted 
(internally or externally) from a lower level registrar position, such as assistant or associate registrar, to the full registrar position. As a result, it is not uncommon to see that most registrars have more than ten years of experience in the education field. It is possible that the faculty respondents have more experience than one might expect since this survey was sent to faculty curriculum leaders, not just general faculty. This may mean that their ability to be involved in shared-governance matters such as curriculum management happens only after incurring experience at the institution. Further research would be required to validate this question.

Table 7. Number of Years in the Education Field

\begin{tabular}{|c|c|c|}
\hline \multicolumn{3}{|l|}{ Appropriate Range } \\
\hline (Number of Years) & Response & $\%$ \\
\hline $0-5$ & 0 & 0.00 \\
\hline $6-10$ & 4 & 4.00 \\
\hline $11-20$ & 29 & 29.00 \\
\hline $21-30$ & 42 & 42.00 \\
\hline $30+$ & 25 & 25.00 \\
\hline Total & 100 & 100.00 \\
\hline
\end{tabular}

\section{Registrars versus Faculty Curriculum Leaders}

Sixty-nine respondents said that their main role at the institution was that of registrar and 31 said that their main role was faculty (who plays a role in curriculum approvals or academic policy). Twenty-seven respondents stated that their institution offered tenure for their role and seventy-three said it did not. Of the twenty-seven respondents, twenty-two of them answered yes when asked if they had tenure. The number of registrar respondents with tenure was too low to report. 


\section{Shared-governance Models}

The first section of the survey asked each respondent to evaluate the definitions provided and then select the most appropriate shared-governance model used by their institution. Of the three options—consultative, distributed decision-making, and fully collaborative -107 respondents selected one of the three options. Consultative model was selected by 18 respondents, distributed decision-making was selected by 67 respondents and fully collaborative was selected by 22 respondents. This section was critical because it established the control variable for each respondent in the quantitative analysis using Fisher's Exact Test. Having such a large number of respondents select distributed decision-making was expected because it is a standard model for likeinstitutions. It was surprising, however, that among the institutions in the population selected for this survey, 18 universities did not have formalized decision-making authority allotted to the faculty for any of their academic decisions.

\section{Registrar's Input}

This section of the survey questioned each respondent about the extent to which the registrar participated in academic policy decisions. Seven discrete questions were supplied, asking respondents to answer, using a five-point Likert scale, where Not at all was equal to a value of 1 , and Always was equal to a value of 5 . The higher the average value for each statement, the more input from the registrar (Table 8). These data became the independent variable in the Fisher's Exact Test. 
Table 8. Input from the Registrar

\begin{tabular}{|c|c|c|c|c|c|c|c|}
\hline Question & & & & Resp & nses & & \\
\hline $\begin{array}{l}\text { decisions about the following } \\
\text { academic policies? }\end{array}$ & $\begin{array}{l}\text { Not } \\
\text { at all } \\
(1)\end{array}$ & $\begin{array}{l}\text { Rarely } \\
\text { (2) }\end{array}$ & $\begin{array}{l}\text { Some- } \\
\text { times } \\
(3)\end{array}$ & $\begin{array}{l}\text { Often } \\
(4)\end{array}$ & $\begin{array}{c}\text { Always } \\
(5)\end{array}$ & $\begin{array}{c}\text { Total } \\
\text { Response } \\
\end{array}$ & $\begin{array}{l}\text { Average } \\
\text { Value }^{\mathrm{a}}\end{array}$ \\
\hline $\begin{array}{l}\text { Setting up repeat rules for new } \\
\text { or modified courses when they } \\
\text { go through the academic } \\
\text { approval process. }\end{array}$ & 12 & 11 & 20 & 26 & 38 & 107 & 3.63 \\
\hline $\begin{array}{l}\text { Changing course } \\
\text { designators/subject codes. }\end{array}$ & 10 & 8 & 17 & 26 & 46 & 107 & 3.84 \\
\hline $\begin{array}{l}\text { Determining academic residency } \\
\text { requirements required for a } \\
\text { degree (not within the specific } \\
\text { program requirements). }\end{array}$ & 24 & 17 & 12 & 22 & 31 & 106 & 3.18 \\
\hline $\begin{array}{l}\text { Determining the minimum GPA } \\
\text { required for a degree (not within } \\
\text { the specific program } \\
\text { requirements). }\end{array}$ & 35 & 20 & 11 & 14 & 26 & 106 & 2.77 \\
\hline $\begin{array}{l}\text { Determining general education } \\
\text { requirements required for a } \\
\text { degree (not within the specific } \\
\text { program requirements). }\end{array}$ & 39 & 15 & 23 & 16 & 13 & 106 & 2.52 \\
\hline $\begin{array}{l}\text { Determining total credit hours } \\
\text { required for a degree (not within } \\
\text { the specific program } \\
\text { requirements). }\end{array}$ & 38 & 15 & 14 & 17 & 23 & 107 & 2.74 \\
\hline $\begin{array}{l}\text { Academic policies that impact } \\
\text { how academic history is } \\
\text { recorded on the student } \\
\text { academic transcript. }\end{array}$ & 3 & N.R.b & 12 & 26 & 66 & 107 & 4.42 \\
\hline
\end{tabular}

The average value was calculated by multiplying the number of respondents times the value for that response (i.e., 12 Not at all responses equal a value of 12 and 38 Always responses equal a value of 190), adding all five response totals and dividing it by the total responses for that statement.

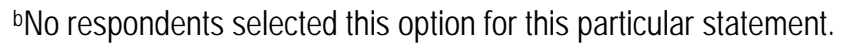

The average values displayed input from the registrar in order of relevance related to the work of a registrar’s office (academic transcripts, course creation, repeat rules, etc.). All of the academic policies listed (Table 8, column 1) come to a crossroads in the registrar's 
office during degree completion or end-of-term grade processing. However, the data in this section show that the role of the registrar in shared governance related to academic and curriculum policies was strongest when it involved direct relationships to the work of a registrar's office.

Additional evaluation of the input from the registrar demonstrated that when exploring the relationship between the type of shared-governance model and the amount of input from the registrar (Table 9), the respondents from the consultative sharedgovernance model stated the registrars were more involved than in either the fully collaborative or the distributed decision-making models. The consultative model was defined as less strong than the distributed decision-making model and the fully collaborative model.

This particular comparison between the models was interesting because while it revealed that the consultative model demonstrated the highest level of reported involvement, it also showed considerable fluctuation between shared-governance models on the same academic policy. The policy with the largest fluctuation was one related to degree requirements and GPA, something that is less relevant to the work of a registrar's office than some of the other policies evaluated. It cannot be ascertained from this evaluation if further study about the involvement of the registrar at institutions with consultative shared-governance models could show that their involvement was higher in all academic policies not limited to curriculum. 
Table 9. Registrars' Input by Shared-governance Model

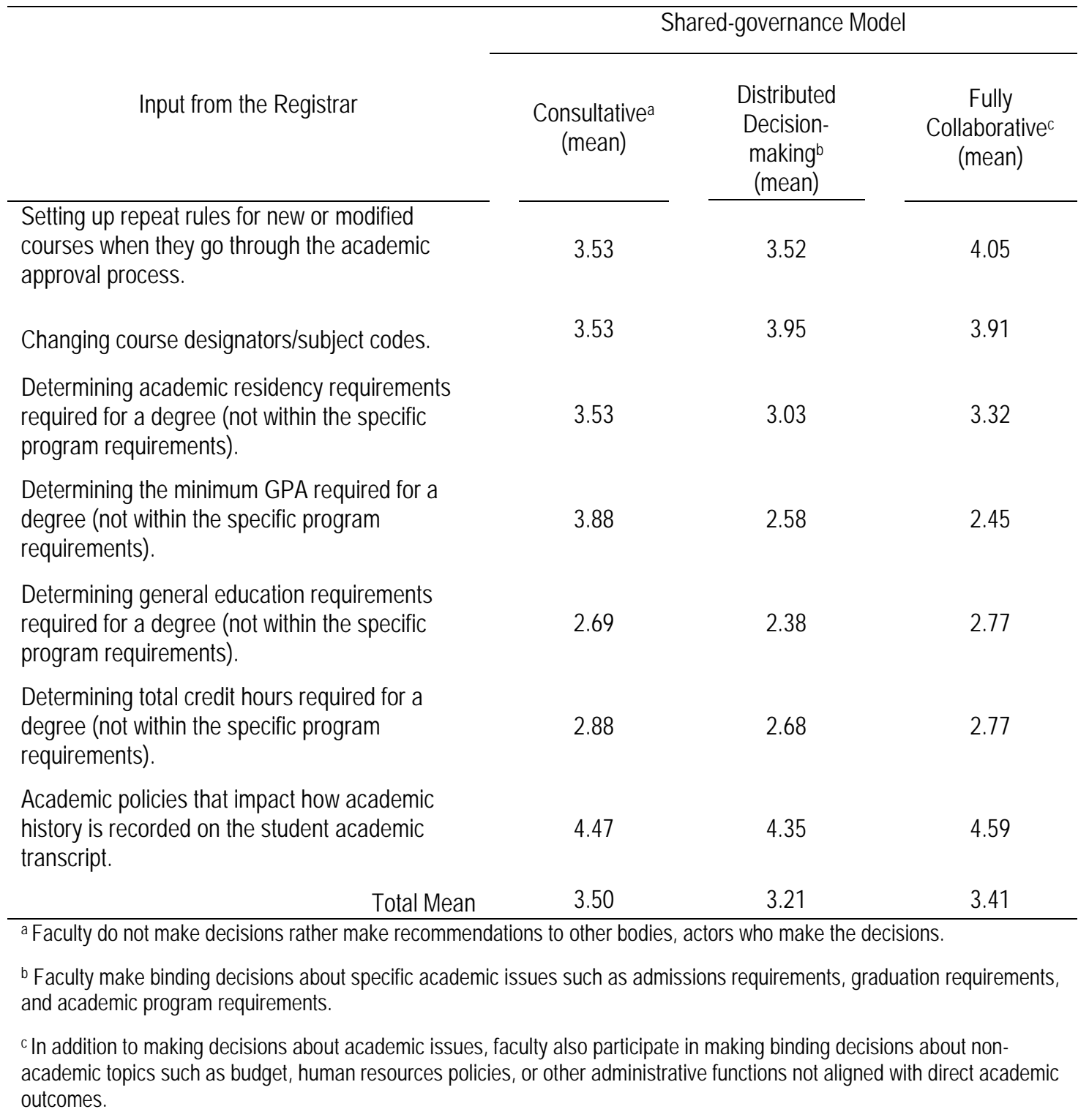

\section{Perceived impact on students}

This section of the survey measured any perceived impact on students from curriculum management and academic policy decisions. Respondents selected a response 
that corresponded to their level of understanding of the reality at their institution. Eight discrete statements were made asking respondents to identify the level to which they agreed with those statements. A five-point Likert scale was used where Strongly Disagree was equal to a value of 1 and Strongly Agree was equal to a value of 5. The higher the average value for each statement, the more the respondent perceived the statement impacted a student or group of students (Table 10). These data became the dependent variable in the Fisher's Exact Test.

The outcomes from this data were reassuring; more often than not, respondents perceived that students were not negatively affected in their progress toward graduation because of policies or curriculum rules. There were two exceptions; policies related to misadvising and to interpreting degree requirements using degree audit tools. These two areas should be investigated further because they demonstrated a result higher than both the mean (2.42) and the midpoint (2.5). 
Table 10. Perceived Impact on Students

\begin{tabular}{|c|c|c|c|c|c|c|c|}
\hline Perceived Impact Statement & \multicolumn{7}{|c|}{ Responses } \\
\hline $\begin{array}{l}\text { decisions. Please select the response that } \\
\text { corresponds with your understanding of the } \\
\text { reality at your institution. }\end{array}$ & $\begin{array}{l}\text { Strongly } \\
\text { Disagree } \\
(1)\end{array}$ & $\begin{array}{l}\text { Dis- } \\
\text { agree } \\
(2)\end{array}$ & $\begin{array}{l}\text { Un- } \\
\text { sure } \\
(3)\end{array}$ & $\begin{array}{c}\text { Agree } \\
\text { (4) }\end{array}$ & $\begin{array}{l}\text { Strongly } \\
\text { Agree } \\
\text { (5) }\end{array}$ & $\begin{array}{c}\text { Total } \\
\text { Response }\end{array}$ & $\begin{array}{c}\text { Average } \\
\text { Value }\end{array}$ \\
\hline $\begin{array}{l}\text { A student, or group of students, was negatively } \\
\text { impacted in their progress toward graduation } \\
\text { because repeatability rules had been set up in } \\
\text { such a way for a course that a student could take } \\
\text { the same course more than once for credit but } \\
\text { were only able to count one attempt toward } \\
\text { graduation requirements. }\end{array}$ & 29 & 37 & 13 & 15 & 6 & 100 & 2.32 \\
\hline $\begin{array}{l}\text { A student, or group of students, was negatively } \\
\text { impacted in their progress toward graduation } \\
\text { because an academic unit changed course } \\
\text { designators/subject codes on their courses, } \\
\text { students were uninformed and took the same } \\
\text { course more than once unknowingly because of } \\
\text { the new designator/title only to learn later of the } \\
\text { mistake. }\end{array}$ & 42 & 27 & 11 & 13 & 6 & 99 & 2.13 \\
\hline $\begin{array}{l}\text { A student, or group of students, was negatively } \\
\text { impacted in their progress toward graduation } \\
\text { because academic programs offer a series of } \\
\text { courses as generic offerings (i.e., special topics, } \\
\text { experimental courses) in lieu of sending the } \\
\text { courses through a curriculum approval process } \\
\text { and therefore limiting the number of those credits } \\
\text { that can count toward a student's degree. }\end{array}$ & 31 & 32 & 12 & 17 & 6 & 98 & 2.34 \\
\hline $\begin{array}{l}\text { A student, or group of students, was negatively } \\
\text { impacted in their progress toward graduation } \\
\text { because the course equivalencies set up when a } \\
\text { course was modified through the curriculum } \\
\text { approval process resulted in the student being } \\
\text { required to take a similar course again or risk } \\
\text { missing a small amount of course material } \\
\text { because of partial curriculum overlap. }\end{array}$ & 37 & 25 & 16 & 16 & 5 & 99 & 2.26 \\
\hline $\begin{array}{l}\text { A student, or group of students, was negatively } \\
\text { impacted in their progress toward graduation } \\
\text { because policy creation or modifications (such as } \\
\text { university withdrawal rules or academic standing } \\
\text { policies) negatively impacted students because } \\
\text { of changes that occurred to those policies. } \\
\text { Examples may include limiting the number of } \\
\text { university withdrawals or adding restrictions to } \\
\text { academic standing and how it may impact } \\
\text { whether or not a student is in good standing or } \\
\text { warning, probation or suspension }\end{array}$ & 35 & 40 & 8 & 10 & 6 & 99 & 2.11 \\
\hline $\begin{array}{l}\text { Students have difficulty graduating because they } \\
\text { do not understand what requirements are } \\
\text { expected of them. }\end{array}$ & 22 & 41 & 11 & 19 & 6 & 99 & 2.45 \\
\hline $\begin{array}{l}\text { Students need to see academic advisors for } \\
\text { questions about academic policies because the } \\
\text { policies are not clear. }\end{array}$ & 8 & 34 & 21 & 27 & 10 & 100 & 2.97 \\
\hline $\begin{array}{l}\text { Students have problems with interpreting degree } \\
\text { requirements through the use of a degree audit } \\
\text { tool. }\end{array}$ & 19 & 31 & 14 & 29 & 7 & 100 & 2.74 \\
\hline
\end{tabular}


Additional evaluation of the perceived impact on students demonstrated information when exploring the relationship between the type of shared-governance model and the perceived impact on students related to academic policy and curricular decisions (Table 11). The respondents from the fully collaborative shared-governance model stated they perceived that students have the least amount of difficulty than in either the consultative or the distributed decision-making models. The fully collaborative model was defined as a stronger shared-governance model than both the distributed decisionmaking model and the consultative model in Chapter Three. It was clear that the distributed decision-making model was carrying the weight of the mean, due to its size, and the other two shared-governance models both demonstrated less of a perceived impact. It begged the question about why the two opposite shared-governance models were similar in experience but the distributed decision-making model was different. Exploring Kezar's assertions about relevance of the engagement of actors versus the type of model in which the actors operate is worth further discussion. 


\section{Table 11. Perceived Impact on Students by Shared-governance Model}

\begin{tabular}{|c|c|c|c|}
\hline \multirow[b]{2}{*}{ Perceived Impact Statement } & \multicolumn{3}{|c|}{ Shared-governance Model } \\
\hline & $\begin{array}{l}\text { Consultative } \\
\text { (mean) }\end{array}$ & $\begin{array}{l}\text { Distributed } \\
\text { Decision- } \\
\text { making } \\
\text { (mean) }\end{array}$ & $\begin{array}{c}\text { Fully } \\
\text { Collaborative } \\
\text { (mean) }\end{array}$ \\
\hline $\begin{array}{l}\text { A student, or group of students, was negatively impacted in their } \\
\text { progress toward graduation because repeatability rules had been } \\
\text { set up in such a way for a course that a student could take the } \\
\text { same course more than once for credit but were only able to } \\
\text { count one attempt toward graduation requirements }\end{array}$ & 2.31 & 2.33 & 2.19 \\
\hline $\begin{array}{l}\text { A student, or group of students, was negatively impacted in their } \\
\text { progress toward graduation because an academic unit changed } \\
\text { course designators/subject codes on their courses, students } \\
\text { were uninformed and took the same course more than once } \\
\text { unknowingly because of the new designator/title only to learn } \\
\text { later of the mistake. }\end{array}$ & 2.19 & 2.17 & 1.71 \\
\hline $\begin{array}{l}\text { A student, or group of students, was negatively impacted in their } \\
\text { progress toward graduation because academic programs offer a } \\
\text { series of courses as generic offerings (i.e., special topics, } \\
\text { experimental courses) in lieu of sending the courses through a } \\
\text { curriculum approval process and therefore limiting the number of } \\
\text { those credits that can count toward a student's degree. }\end{array}$ & 1.94 & 2.45 & 2.14 \\
\hline $\begin{array}{l}\text { A student, or group of students, was negatively impacted in their } \\
\text { progress toward graduation because the course equivalencies } \\
\text { set up when a course was modified through the curriculum } \\
\text { approval process resulted in the student being required to take a } \\
\text { similar course again or risk missing a small amount of course } \\
\text { material because of partial curriculum overlap. }\end{array}$ & 2.19 & 2.19 & 2.33 \\
\hline $\begin{array}{l}\text { A student, or group of students, was negatively impacted in their } \\
\text { progress toward graduation because policy creation or } \\
\text { modifications (such as university withdrawal rules or academic } \\
\text { standing policies) negatively impacted students because of } \\
\text { changes that occurred to those policies. Examples may include } \\
\text { limiting the number of university withdrawals or adding } \\
\text { restrictions to academic standing and how it may impact whether } \\
\text { or not a student is in good standing or warning, probation or } \\
\text { suspension }\end{array}$ & 2.25 & 2.12 & 1.76 \\
\hline $\begin{array}{l}\text { Students have difficulty graduating because they do not } \\
\text { understand what requirements are expected of them. }\end{array}$ & 2.19 & 2.37 & 2.67 \\
\hline $\begin{array}{l}\text { Students need to see academic advisors for questions about } \\
\text { academic policies because the policies are not clear. }\end{array}$ & 2.94 & 3.03 & 2.76 \\
\hline $\begin{array}{l}\text { Students have problems with interpreting degree requirements } \\
\text { through the use of a degree audit tool. }\end{array}$ & 2.56 & 2.77 & 2.62 \\
\hline Total mean & 2.32 & 2.42 & 2.27 \\
\hline
\end{tabular}

a Faculty do not make decisions rather make recommendations to other bodies, actors who make the decisions.

${ }^{b}$ Faculty make binding decisions about specific academic issues such as admissions requirements, graduation requirements, and academic program requirements.

c In addition to making decisions about academic issues, faculty also participate in making binding decisions about nonacademic topics such as budget, human resources policies, or other administrative functions not aligned with direct academic outcomes. 


\section{Fisher's Exact Test Findings}

The sheer volume of responses created many small cell sizes when categorized into multiple, five-response scale sets, separated by shared-governance models. This was the main reason that Fisher's Exact Test was used in lieu of a standard Chi-square test. In an effort to further minimize that effect and increase the possibility of finding significance, the Likert scale responses were collapsed into smaller categories. The registrar input section was collapsed as follows: Not At All and Rarely became NO whereas Sometimes, Often and Always became YES. The range of the perceived impact section was also collapsed from Strongly Disagree, Disagree, Unsure, Agree, and Strongly Agree into: Strongly Disagree and Disagree became Disagree, Agree and Strongly Agree became Agree while Unsure remained its own category.

While controlling for the shared-governance model that each respondent selected relative to their institution, a Fisher's Exact Test was performed on each statement in the registrar's input section against each of the perceived impact statements (Table 12). The comparison of these two sections of the survey resulted in the Fisher's Exact Test being run 168 times; 56 times for each shared-governance model (Appendix B). 
Table 12. Fisher's Exact Test Distributions

\begin{tabular}{|c|c|c|c|}
\hline $\begin{array}{c}\text { Shared-governance } \\
\text { Model }\end{array}$ & $\begin{array}{l}\text { Registrar Input } \\
\text { Statements }\end{array}$ & $\begin{array}{l}\text { Perceived Impact } \\
\text { Statements }\end{array}$ & Total Tests \\
\hline Consultative & 7 & 8 & 56 \\
\hline $\begin{array}{l}\text { Distributed } \\
\text { decision making }\end{array}$ & 7 & 8 & 56 \\
\hline Fully collaborative & 7 & 8 & 56 \\
\hline
\end{tabular}

The data output supported the conclusion that not enough connection was found, related to the specific hypothesis, between the registrar's participation in decisions about academic policies and the perceived impact on students from curriculum management and academic policy decisions when controlling for the shared-governance model at each institution. Of the 168 tests performed, only 8 had a p-value of less than .1 (Table 13).

The first series of tests performed were answers from respondents who stated that their institution operated using a consultative shared-governance model. There were no outputs that showed a $p$-value of less than .1 in this test. The second series of tests performed were answers from respondents who stated that their institution operated using a distributed decision-making shared-governance model. Only four of the comparisons, of 56, showed a $p$-value of less than .1 in the output. The third series of tests performed were answers from respondents who stated that their institution operated using a collaborative shared-governance model. Once again, only four of the comparisons, of 56, showed a $p$-value of less than .1 in the output.

While eight different results from the many Fisher Exact Test's did turn out with a $p$-value of less than .1, the sheer number of tests performed meant that "the large number of comparisons, however, compounds the statistical uncertainty in the statements of 
evidence” (Ramsey, 2002, p. 149). Essentially this means that when that volume of tests were performed, it was likely that there would be some outliers. There are methods to adjust for multiple comparisons, but in doing so, the threshold for significance becomes much lower. Because of simultaneous inference, compound uncertainty can occur. “Compound uncertainty arises when many tests are considered simultaneously. The greater the number of tests performed, the higher the chance that a low $p$-value will be found for at least one of them, even in the absence of group differences. Consequently, the researcher is likely to find group differences that are not really there” (Ramsey, 2002, p. 160).

A summary table (Table 12) was constructed to list the eight tests of the 168 that did show a $p$-value of less than .1. While tempting to hope that these few output data were not showing a null hypothesis of the research, it was important to recognize that these data only represented $4.7 \%$ of the tests performed. Moreover, it was not likely to not have a null hypothesis from that small number of tests. Some of the responses displaying a $p$-value of less than .1 did cluster in certain sections of questions, which begged the question of a strong connection between certain topics raised in the research. Specifically, clustering occurred around the registrar input statement “determining academic residency requirements required for a degree (not within the specific program requirements)" and two perceived impact statements. These were "students have problems with interpreting degree requirements through the use of a degree audit tool” as well as "students need to see academic advisors for questions about academic policies because the policies are not clear.” It is uncertain if these clusters could legitimately 
challenge the concerns about simultaneous inference without further study. The sheer number of tests performed made it difficult to know if results demonstrating a $p$-value of less than .1 were legitimate or just a result of the volume of tests. However, the clustering of results, as demonstrated in Table 13, clearly suggest that the three areas listed above, are not random outcomes rather specific areas that need further hypothesis testing on those specific topics. 
Table 13. Significance

\begin{tabular}{|c|c|c|}
\hline $\begin{array}{l}\text { Registrar Input Statement } \\
\text { (Question \#) }\end{array}$ & $\begin{array}{c}\text { Perceived Impact Statement } \\
\text { (Question \#) }\end{array}$ & $\begin{array}{c}p- \\
\text { value }\end{array}$ \\
\hline \multicolumn{3}{|c|}{ Distributed Decision-making Shared-governance Model } \\
\hline $\begin{array}{l}\text { Setting up repeat rules for new or } \\
\text { modified courses when they go } \\
\text { through the academic approval } \\
\text { process. (3-3) }\end{array}$ & $\begin{array}{l}\text { Students have problems with } \\
\text { interpreting degree requirements } \\
\text { through the use of a degree audit tool. } \\
(16-4)\end{array}$ & 0.030 \\
\hline $\begin{array}{l}\text { Changing course } \\
\text { designators/subject codes. (3-3) }\end{array}$ & $\begin{array}{l}\text { Students have problems with } \\
\text { interpreting degree requirements } \\
\text { through the use of a degree audit tool. } \\
(16-6)\end{array}$ & 0.074 \\
\hline $\begin{array}{l}\text { Determining academic residency } \\
\text { requirements required for a degree } \\
\text { (not within the specific program } \\
\text { requirements). (3-3) }\end{array}$ & $\begin{array}{l}\text { Students have problems with } \\
\text { interpreting degree requirements } \\
\text { through the use of a degree audit tool. } \\
(16-7)\end{array}$ & 0.085 \\
\hline $\begin{array}{l}\text { Academic policies that impact how } \\
\text { academic history is recorded on the } \\
\text { student academic transcript. (3-4) }\end{array}$ & $\begin{array}{l}\text { Students have problems with } \\
\text { interpreting degree requirements } \\
\text { through the use of a degree audit tool. } \\
(16-7)\end{array}$ & 0.021 \\
\hline \multicolumn{3}{|c|}{ Collaborative Shared-governance Model } \\
\hline $\begin{array}{l}\text { Determining academic residency } \\
\text { requirements required for a degree } \\
\text { (not within the specific program } \\
\text { requirements).(3-1) }\end{array}$ & $\begin{array}{l}\text { A student, or group of students, was } \\
\text { negatively impacted in their progress } \\
\text { toward graduation because the course } \\
\text { equivalencies set up when a course } \\
\text { was modified through the curriculum } \\
\text { approval process resulted in the student } \\
\text { being required to take a similar course } \\
\text { again or risk missing a small amount of } \\
\text { course material because of partial } \\
\text { curriculum overlap. (16-8) }\end{array}$ & 0.082 \\
\hline $\begin{array}{l}\text { Determining academic residency } \\
\text { requirements required for a degree } \\
\text { (not within the specific program } \\
\text { requirements).(3-2) }\end{array}$ & $\begin{array}{l}\text { Students have difficulty graduating } \\
\text { because they do not understand what } \\
\text { requirements are expected of them. } \\
(16-8)\end{array}$ & 0.015 \\
\hline $\begin{array}{l}\text { Determining academic residency } \\
\text { requirements required for a degree } \\
\text { (not within the specific program } \\
\text { requirements). (3-3) }\end{array}$ & $\begin{array}{l}\text { Students need to see academic } \\
\text { advisors for questions about academic } \\
\text { policies because the policies are not } \\
\text { clear.(16-8) }\end{array}$ & 0.006 \\
\hline $\begin{array}{l}\text { Determining the minimum GPA } \\
\text { required for a degree (not within the } \\
\text { specific program requirements). } \\
(3-7)\end{array}$ & $\begin{array}{l}\text { Students need to see academic } \\
\text { advisors for questions about academic } \\
\text { policies because the policies are not } \\
\text { clear. }(16-8)\end{array}$ & 0.044 \\
\hline
\end{tabular}


All tests performed were planned comparisons; therefore, the individual confidence level needed to be controlled if any conclusions were to be drawn about those few results where the $p$-value was less than .1. Assuming there is further exploration to do on the hypothesis, using only a few of the scenarios would require additional tests or using the same tests but modifying the original hypothesis. For example, in reference to Table 12, the same hypothesis is not null when you only look at questions 3-1, 3-2, 3-3, 3-4, 3-7, 16-4, 16-6, 16-7, 16-8. Using limited questions to validate the hypothesis requires a new study with new questions. Otherwise, it is considered data snooping because the newly generated assumption could not have been made without looking at the data output from the initial research. Further, one cannot assume that the respondents would not respond differently if their set of questions changed.

Further research could be done about the role of the registrar in shared governance as it relates to degree audit tools, academic advising, and academic residency. Applying that level of specificity in a study to other actors who operate as academic analysts may make it more difficult to assume an implied connection in results. Even without the applicability, however, the research could provide telling and useful, important information to the registrar community as well as faculty curriculum leaders. Comparing the quantitative findings against the qualitative findings implied that complexities were related to the role of the registrar in curriculum management and academic policies but perhaps not isolated to specific shared-governance models. 


\section{Qualitative Research}

The qualitative research performed in the survey was extensive in nature and included a multitude of questions that not only sought to validate the research hypothesis but also sought to grasp a fuller picture of the issue. Open-ended questions were asked about specific policy questions. Then, a question to allow for some comparison between the quantitative test and a more blunt approach to the same outcome was posed by asking the question in an open-ended manner. Next, a question was asked that only registrars responded to related to their authority and their role. Finally, analysis performed inductively by evaluating some of the poignant quotes from the respondents served to provide informative ideas related to further exploration of the hypothesis.

\section{Specific Policy Questions}

Following the series of questions about the registrar's participation in decisions about a multitude of policies, four follow-up questions were asked about whether the institutions had specific policies in four different areas. Skip logic was used to ask a follow-up question based on the response. All four policy questions had high response rates when the respondents were asked close-ended questions that affirmed if the institution had the policy referenced in the question. In all four questions, however, no respondents provided additional information when they stated that the institution did not have a policy or they were unsure if the institution had a policy. The researcher affirmed that the survey skip logic was set up correctly, and it was not an error in the survey administration. Two possibilities may explain why this happened. The first was simply that no one chose to respond to the follow up question, a plausible explanation given that 
the number of respondents answering with a no or unsure response was small. The second possibility was that the question was poorly worded or misleading. The follow up question, "Describe how you think the Registrar could be involved in the process," was difficult to answer if the respondent believed there was not a process for which the registrar could be involved or they were unsure if there was a process. There was no way to find out which scenario occurred, but as a result of either possibility, no findings were available to evaluate.

Three of the four policy questions resulted in useful, open-ended responses. It became clear, though, that one question, related to withdrawing from the university, was misinterpreted enough by the respondents that the decision was made to not evaluate the qualitative data for meaningful analysis or even evaluate the yes, no, and unsure responses to the close-ended question. This question, "Does the institution have a policy about withdrawing from the university and any limitations this places on students?” was misguided, and it was clear that many respondents believed the question to be different than intended. The researcher chose to toss the question because of the perceived lack of clarity in the question that surfaced as a result of the inconsistent and confusing responses received. No analysis was performed on this question.

The three remaining questions were evaluated for both open-ended and closeended responses. These three questions included:

- Does the institution have limitations on the number of credits/courses in an academic program that can be taken as 'generic courses' such as 
research credit hours, independent studies, special topics, et. al. [sic]?

\section{(Table 14)}

- Does the institution have a policy about how to define course equivalencies (two courses at the institution offering credit for the exact same outcomes) when modifying or creating a courses? (Table 15)

- Does the institution have a policy about academic standing to ensure students are progressing toward the degree they are seeking? Note: this is not related to financial aid requirements for satisfactory academic progress; it is related to academic standing such as probation, warning, suspension, et. al. [sic] (Table 16)

The responses to all three questions were coded using the same themes because so much overlap appeared in the feedback from respondents, likely a result of the questions all being about academic policies. The categorical themes were: Information Providers, Managing a Tool, Involved, Committee Participation, Input, Helpful, Consultant, Limited/none, and Institutional Knowledge.

In the question about limitations on the number of "generic credits", 60/106 respondents answered yes to the question, 32/106 answered no, and 14/106 answered unsure. Segregated by shared-governance models, the results for consultative were 10/18 answered yes, 4/18 answered no, and 4/18 answered unsure. The distributed decisionmaking results were 35/66 answered yes, 21/66 answered no, and 10/66 answered unsure. The fully collaborative results were 15/22 answered yes and 7/22 answered no. 
Respondents did not always have a response coded, and a portion of respondents articulated more than one theme in their responses.

Table 14. Role of the Registrar by Shared-governance Model

\begin{tabular}{|c|c|c|c|c|}
\hline \multirow{2}{*}{$\begin{array}{l}\text { Question: } \\
\text { Does the institution have limitation on } \\
\text { the number of credits/courses in an } \\
\text { academic program that can be taken } \\
\text { as "generic courses" such as } \\
\text { research credit hours, independent } \\
\text { studies, special topics, et. al. [sic]? } \\
\text { What role does the registrar play in } \\
\text { the process? Please explain the level } \\
\text { of helpfulness that comes from the } \\
\text { role of the registrar in the process. }\end{array}$} & \multicolumn{4}{|c|}{$\begin{array}{l}\text { Shared-governance Model } \\
\text { (Number of Responses) }\end{array}$} \\
\hline & Consultative $^{\mathrm{a}}$ & $\begin{array}{l}\text { Distributed } \\
\text { Decision- } \\
\text { makingb }\end{array}$ & $\begin{array}{c}\text { Fully } \\
\text { Collaborative }^{c}\end{array}$ & Total \\
\hline Information Provider & 4 & 13 & 6 & 23 \\
\hline Tool Management & 1 & 3 & 0 & 4 \\
\hline Involved & 1 & 2 & 0 & 3 \\
\hline Committee & 1 & 6 & 5 & 12 \\
\hline None/Limited & 2 & 5 & 1 & 8 \\
\hline Helpful & 2 & 4 & 1 & 7 \\
\hline Consults & 0 & 3 & 3 & 6 \\
\hline Input & 0 & 0 & 0 & 0 \\
\hline Institutional Knowledge & 2 & 2 & 0 & 4 \\
\hline Totals & 13 & 38 & 16 & 67 \\
\hline
\end{tabular}

\footnotetext{
a Faculty do not make decisions rather make recommendations to other bodies, actors who make the decisions.

${ }^{\mathrm{b}}$ Faculty make binding decisions about specific academic issues such as admissions requirements, graduation requirements, and academic program requirements.

\begin{abstract}
c In addition to making decisions about academic issues, faculty also participate in making binding decisions about nonacademic topics such as budget, human resources policies, or other administrative functions not aligned with direct academic outcomes.
\end{abstract}

When evaluating the question with respect to the amount of registrar involvement in shared governance, respondents had two themes emerge in the question about the registrar's helpfulness in a process related to policy on limitation of courses/credits that can come from "generic courses” (Table 4). First, registrars were reported as being information providers by nearly $25 \%$ of the respondents (Table 14 ). More than $10 \%$ of respondents stated that the registrar, as an actor, was involved in committee work related 
to the topic. This was equally prevalent in all shared-governance models for this question except that registrars were not reported as involved in committee work at institutions that operated using a consultative model. This lack of involvement on committees may not conflict with the earlier reporting about the relationship between the type of sharedgovernance model and the perceived impact on students related to academic policy and curricular decisions. However, it was curious that institutions with a consultative model reported limited committee involvement for the registrar, but the perceived impact on students was lower than in the institutions with a distributed decision-making model. How the impact stays low without committee involvement was unknown.

In the question about defining course equivalencies, 58/102 respondents answered yes to the question, 31/102 answered no, and 13/102 answered unsure. Segregated by shared-governance models, the results for consultative were 7/17 answered yes, 4/17 answered no, and 6/17 answered unsure. The distributed decision-making results were 40/64 answered yes, 18/64 answered no, and 6/64 answered unsure. The fully collaborative results were 11/21 answered yes, 9/21 answered no, and 1/21 answered unsure. Respondents did not always have a response coded and a portion of respondents articulated more than one theme in their response.

When evaluating the feedback about the registrar's helpfulness in their policy on how the institution defines course equivalencies (Table 15), respondents had three top themes emerge. First, registrars were reported as being information providers and providing input by approximately 25\% of the respondents. Curiously, it was the 
Table 15. Role of the Registrar in Defining Course Equivalencies by Shared-governance Model

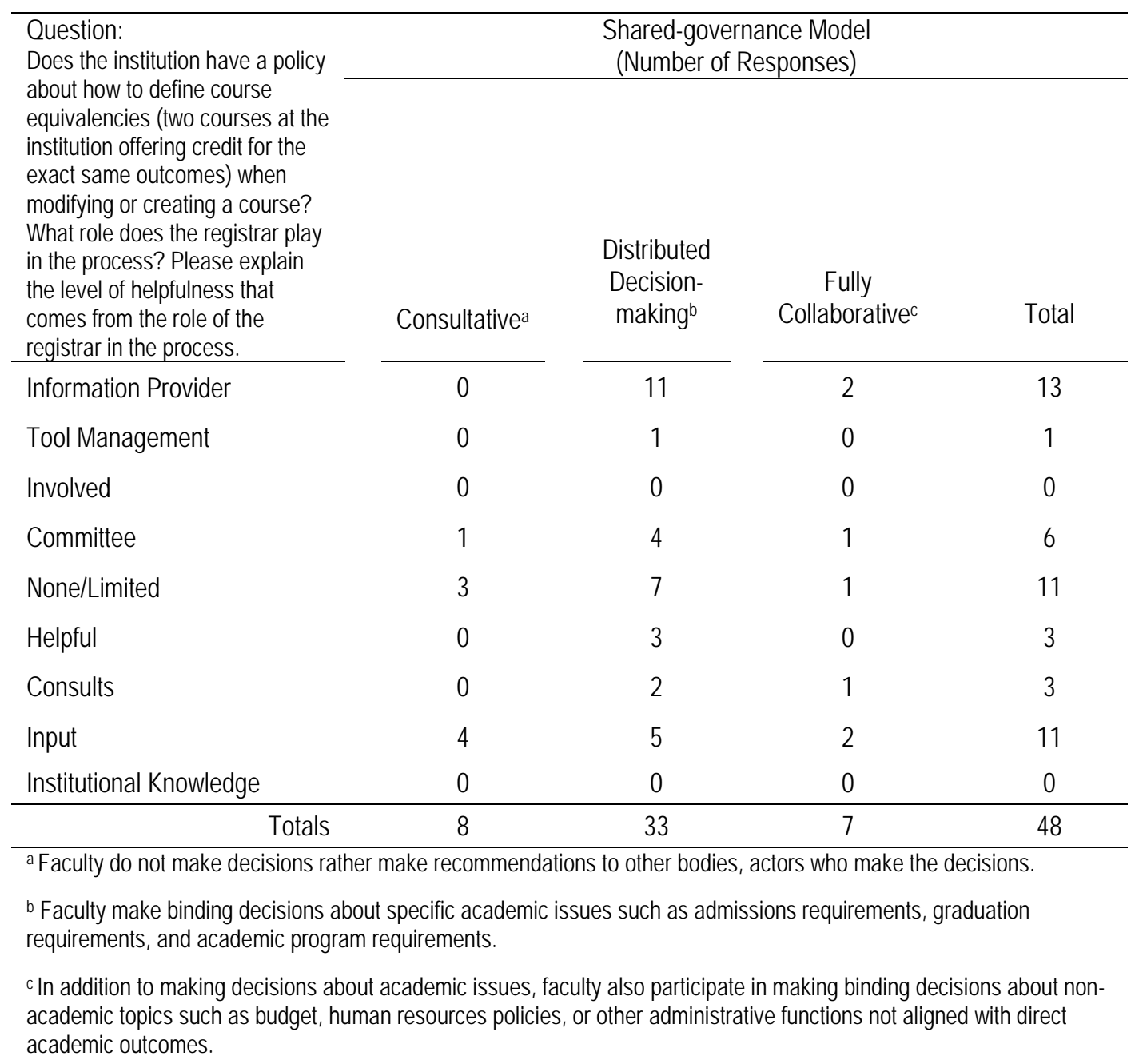

respondents who operate in a distributed decision-making model who make up a majority of those respondents. Approximately $10 \%$ of respondents stated that the registrar provided no or limited input. Both the consultative and the fully collaborative model respondents had very few themes with which they identified, an outcome considerably different than the respondents from institutions with a distributed decision-making model. In the question about policies on academic standing, 94/99 respondents answered yes to the question, 5/99 answered no, and no one answered unsure. Segregated by shared 
governance-models, the results for consultative were 16/17 answered yes and 1/17 answered no. The distributed decision-making results were 58/62 answered yes and 4/62 answered no. The fully collaborative results were all 20/20 respondents answering yes. Respondents did not always have a response coded and a portion of respondents articulated more than one theme in their response.

Considering the strong feedback from respondents stating involvement, it is interesting that no significance showed in the Fisher's Exact Test for any of the different shared-governance models. Given the high amount of feedback stating involvement, it would seem to be one area where significance might be displayed.

When evaluating the feedback about the registrar's helpfulness in their policy on academic standing to ensure students are progressing toward their degree, respondents had a clear sense that the registrars were involved in this process (Table 16). Nearly 60\% of the respondents stated involvement by the registrars. Interestingly, that is juxtaposed with the next top responses that approximately 14\% stated limited or no involvement. 
Table 16. Role of the Registrar in Students' Academic Standing by Shared-governance Model

\begin{tabular}{|c|c|c|c|c|}
\hline \multirow{2}{*}{$\begin{array}{l}\text { Question: } \\
\text { Does the institution have a policy } \\
\text { about academic standing to } \\
\text { ensure students are progressing } \\
\text { toward the degree they are } \\
\text { seeking? Note: this is not related } \\
\text { to financial aid requirements for } \\
\text { satisfactory academic progress; } \\
\text { it is related to academic standing } \\
\text { such as probation, warning, } \\
\text { suspension, et. al. [sic] What role } \\
\text { does the registrar play in the } \\
\text { process? Please explain the } \\
\text { level of helpfulness that comes } \\
\text { from the role of the registrar in } \\
\text { the process. }\end{array}$} & \multicolumn{4}{|c|}{$\begin{array}{l}\text { Shared-governance Model } \\
\text { (Number of Responses }\end{array}$} \\
\hline & Consultative $^{a}$ & $\begin{array}{l}\text { Distributed } \\
\text { Decision- } \\
\text { makingb }\end{array}$ & $\begin{array}{c}\text { Fully } \\
\text { Collaborativec }^{c}\end{array}$ & $\begin{array}{c}\text { Total } \\
\text { Responses }\end{array}$ \\
\hline Information Provider & 0 & 0 & 0 & 0 \\
\hline Tool Management & 1 & 0 & 0 & 1 \\
\hline Involved & 11 & 35 & 14 & 60 \\
\hline Committee & 3 & 4 & 3 & 10 \\
\hline None/Limited & 0 & 12 & 2 & 14 \\
\hline Helpful & 1 & 1 & 0 & 2 \\
\hline Consults & 0 & 1 & 0 & 1 \\
\hline Input & 1 & 0 & 0 & 1 \\
\hline Institutional Knowledge & 1 & 1 & 0 & 2 \\
\hline Totals & 18 & 54 & 19 & 91 \\
\hline $\begin{array}{l}\text { a Faculty do not make decisions rat } \\
{ }^{\mathrm{b}} \text { Faculty make binding decisions a } \\
\text { requirements, and academic progr }\end{array}$ & $\begin{array}{l}\text { ake recommend } \\
\text { specific academic } \\
\text { quirements. }\end{array}$ & $\begin{array}{l}\text { to other bodie } \\
\text { es such as adn }\end{array}$ & $\begin{array}{l}\text { tors who make th } \\
\text { ons requirements, }\end{array}$ & $\begin{array}{l}\text { sions. } \\
\text { lation }\end{array}$ \\
\hline
\end{tabular}

\section{Qualitative and Quantitative Results Compared}

The survey asked an open-ended qualitative question that served as a support question to a quantitative question. The quantitative question was about the perceived impact on students because of decisions made by choices related to curriculum management and academic policies. A series of statements about impact on students 
based on eight different policies or practices used a Likert scale to measure level of agreement about the effect on students. Following that series, an open-ended question asked, “Does the Registrar’s involvement in curriculum management and academic policy impact students? Please explain your answer.”

\section{Table 17. Effect of Registrars' Involvement on Students by Shared-governance Model}

\begin{tabular}{|c|c|c|c|c|}
\hline \multirow{2}{*}{$\begin{array}{l}\text { Question: } \\
\text { Does the Registrar's } \\
\text { involvement in curriculum } \\
\text { management and academic } \\
\text { policy impact students? }\end{array}$} & \multicolumn{4}{|c|}{$\begin{array}{l}\text { Shared-governance Model } \\
\text { (Number of Responses [\%]) }\end{array}$} \\
\hline & Consultative ${ }^{a}$ & $\begin{array}{l}\text { Distributed } \\
\text { Decision- } \\
\text { makingb }\end{array}$ & $\begin{array}{c}\text { Fully } \\
\text { Collaborativec }\end{array}$ & $\begin{array}{c}\text { Total } \\
\text { Responses }\end{array}$ \\
\hline Yes & $11(69 \%)$ & $33(67 \%)$ & $14(74 \%)$ & $58(69 \%)$ \\
\hline No & $1(6 \%)$ & $8(16 \%)$ & $3(16 \%)$ & $12(14 \%)$ \\
\hline Somewhat & $4(25 \%)$ & $8(16 \%)$ & $2(10 \%)$ & $14(17 \%)$ \\
\hline Total Responses (100\%) & 16 & 49 & 19 & 84 \\
\hline \multicolumn{5}{|c|}{ 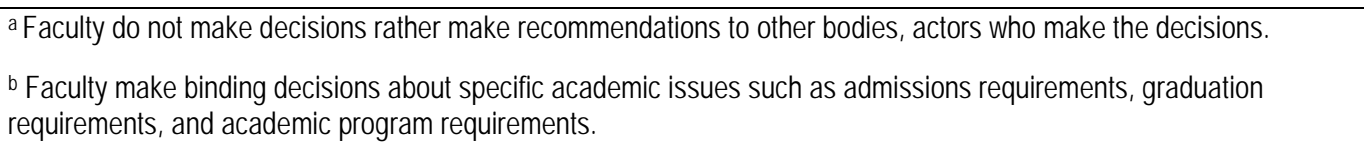 } \\
\hline
\end{tabular}

Two themes emerged when reviewing respondents' feedback about whether the registrar's involvement in curriculum management and academic policy impacts students (Table 17). A small number of respondents articulated why they had stated that the registrar did not impact students or why the impact was limited. However, a large number of respondents, consistent among all three shared-governance models, stated a clear role that the registrar plays in impacting students as it relates to academic policy and curriculum management, a global understanding of policy impact and how students 
would be affected. Described many different ways, the gist of the feedback in this area was that registrars understood the broader effect of a policy on all students, not just students within a particular academic unit or a particular college.

Additionally, comments were offered about how the role of the registrar was to help faculty understand possible negative implications. One respondent said, "One of the most important things a registrar on a curriculum committee can do is to stop well intentioned faculty from creating barriers for students”. Another respondent said, “[The Registrar] tries to think about the impact on the university as a whole and especially to students from other departments which may not be the top priority of the proposing department.” Registrars are at the crossroads of academic policy and student success. This confluence of the policy meeting the practical informed the perspective that registrars could see the broader impact because they were dealing with real instances regularly.

The second thread in the open-ended feedback from respondents to this question was about equitable applicability of policies for students. While less frequently reported, respondents who discussed this point made clear that it was important that a body at the institution worked to ensure fairness and consistency (Table 18). For instance, one respondent stated that the office of the registrar "applies the same standards to all departments to try and promote equity.” An additional comment was that the registrar's office "provides a perspective about equity in application of curriculum management and academic policy for all students that may get missed by looking only at a single academic school/college.” 
Table 18. Themes of Registrars' Impact on Students by Shared-governance Model

\begin{tabular}{|c|c|c|c|c|}
\hline \multirow{2}{*}{$\begin{array}{l}\text { Themes related to the } \\
\text { explanation of whether the } \\
\text { registrar's involvement in } \\
\text { curriculum management and } \\
\text { academic policy impact } \\
\text { students }\end{array}$} & \multicolumn{4}{|c|}{$\begin{array}{l}\text { Shared-governance Model } \\
\text { Number of Responses }\end{array}$} \\
\hline & Consultative ${ }^{a}$ & $\begin{array}{l}\text { Distributed } \\
\text { Decision- } \\
\text { making }\end{array}$ & $\begin{array}{c}\text { Ful } \\
\text { Collaborative }^{c}\end{array}$ & $\begin{array}{c}\text { Total } \\
\text { Responses }\end{array}$ \\
\hline $\begin{array}{l}\text { Global understanding of } \\
\text { policy impact }\end{array}$ & 7 & 23 & 5 & 35 \\
\hline Equity of policies for students & 1 & 3 & 1 & 5 \\
\hline Total Responses & 8 & 26 & 6 & 40 \\
\hline \multicolumn{5}{|c|}{$\begin{array}{l}\text { a Faculty do not make decisions rather make recommendations to other bodies, actors who make the decisions. } \\
{ }^{b} \text { Faculty make binding decisions about specific academic issues such as admissions requirements, graduation } \\
\text { requirements, and academic program requirements. }\end{array}$} \\
\hline
\end{tabular}

Both themes carried the idea that the registrar was one role, one office, where all students landed. Moreover, convergence of students from all colleges/schools resulted in the responsibility of the registrar to communicate about the broader impacts, the long-term effect of proposed policies, and the equity issues that could influence students as a result. Feedback showed that the registrar was maintaining the standards for the institution.

\section{Registrar Only Feedback}

The final question of the study was an open-ended qualitative question serving to find out about the actors' ability to make an impact on policies and registrar involvement at the institution. Using basic display logic, the final question was only asked if the respondents selected "Registrar" instead of "Faculty (who played a role in curriculum approvals or academic policy)" to the question "What is your main role at your institution?” The question was, "Please describe how, if any, of your authority (such as 
tenure, degree earned, and number of years in the field, or any other impacting factor) gives you agency toward the impact on the policies and Registrar involvement mentioned in previous sections of this survey.” The responses were coded into the following themes: Years, Respect, Institutional Knowledge, Multiple Institutions, Education, and Implementation (Table 19).

Of the respondents, 57 responded to the question. Segregated by sharedgovernance models, the result was 10 consultative responding, 35 distributed decisionmaking responding, and 12 fully collaborative responding. Respondents did not always have a response coded, a portion of respondents articulated more than one theme in their response, and the total responses reflected duplicated responses when respondents had more than one theme in their narrative. 
Table 19. Agency Derived from Registrars' Authority by Shared-governance Model

\begin{tabular}{|c|c|c|c|c|}
\hline \multirow{2}{*}{$\begin{array}{l}\text { Question: } \\
\text { How your (registrar only) } \\
\text { authority gives you agency } \\
\text { toward impacting policies and } \\
\text { involvement? }\end{array}$} & \multicolumn{4}{|c|}{$\begin{array}{l}\text { Shared-governance Model } \\
\text { Number of Responses (\%) }\end{array}$} \\
\hline & Consultative ${ }^{a}$ & $\begin{array}{l}\text { Distributed } \\
\text { Decision- } \\
\text { making }\end{array}$ & $\begin{array}{c}\text { Fully } \\
\text { Collaborativec }^{c}\end{array}$ & $\begin{array}{c}\text { Total } \\
\text { Responses }\end{array}$ \\
\hline Years & 6 & 17 & 8 & 31 \\
\hline Respect & 3 & 8 & 6 & 17 \\
\hline Institutional Knowledge & 1 & 6 & 1 & 8 \\
\hline Multiple Institutions & 1 & 5 & 0 & 6 \\
\hline Education & 1 & 8 & 1 & 10 \\
\hline Implementation & 1 & 2 & 1 & 4 \\
\hline Total Responses & 13 & 46 & 17 & 76 \\
\hline $\begin{array}{l}\text { a Faculty do not make decisions rat } \\
\text { b Faculty make binding decisions a } \\
\text { requirements, and academic progra }\end{array}$ & $\begin{array}{l}\text { nake recommend } \\
\text { specific academic } \\
\text { equirements. }\end{array}$ & s such as ac & $\begin{array}{l}\text { ctors who make th } \\
\text { ions requirements, }\end{array}$ & ation \\
\hline
\end{tabular}

A respondent from an institution who operated in a distributed decision-making shared-governance model stated, "I believe my best strength as a registrar is to understand my earned and given authority and not hesitate to use it. I use my gut and my experience to work through most issues fairly quickly; far less often do I drop my title and/or senate position into discourse, it's not needed.” Another respondent from an institution who operated in a distributed decision-making shared-governance model stated a lack of clarity about the question. It is possible that rather than a lack of clarity, it was perhaps a strong interest in the role of the registrar as an actor in shared governance to be purely subservient to the faculty. The respondent stated, “Not sure what you're 
getting at. Supporting faculty in decision making means a willingness and ability to do research and to present findings in an analytical manner.” This response is not representative of someone who appears to have an interest in learning from the “experienced opinion” of a registrar, rather this respondent wished to make a decision based on the information provided, not the perspective of the person providing the information.

From this research, it appeared that years in the field and being a respected peer definitely carried the most responses from respondents of all shared-governance models. Interestingly, no respondents specifically tied their input to the shared-governance relationship they operated within at their institution. Perhaps that was implicit in their experience and colored their responses, but no one specifically articulated that connection because of the structure on their campus in which they work. Instead, those registrars were allotted authority to be involved or affect policies. As a researcher who asserts this authority is at the heart of how registrars and other academic analysts operate as actors within an organizational structure, it was disheartening not to find any feedback suggesting such authority was on the minds of respondent registrars.

\section{Inductive Findings}

In addition to the tabulated responses of the qualitative feedback, quotations were selected because of the rich perspective that was added to the evaluation of the data. When asking the registrars how their authority gave them agency toward impacting policies and involvement, two quotations were worth sharing from respondents who operated at institutions where a fully collaborative, shared-governance model was in 
effect. One respondent talked about not only the authority but also the responsibility of the role, one of the few respondents who offered strong feelings on the responsibility in addition to the authority. This registrar stated:

In general Registrars at my institution remain in their position for an 8-10 year period, so the general perception is that they have positional credibility in that they would not be in the position if they were not competent. With that said the Registrar has an endless opportunity to integrate fully in many areas of the university, and it is essential that the Registrar does that. This collaborative approach broadens the influence of the Registrar, breaks down silos, and clearly demonstrate the Registrar's willingness to support the universities overall strategic goals. It is no longer sufficient for the Registrar to remain centrally focused on the operations with the Registrar's Office.

This response was seminal in the overarching hypothesis of the research. The focus of this message was to utilize the structural authority of the role to affect students' success (assuming that was a strategic goal of the university) through collaboration (read: shared governance). Another respondent stated, “I don’t think that the impact has been gained through authority but rather through relationship building and evidence and a track record of providing valuable information.” Both of these respondents talked about using their respect and authority awarded through competence to make an impact. The reference to no longer remaining focused on the operations with the registrars also speaks to the perspective that this actor (registrar) did work that broadly impacted the university, and that operational discussions needed to happen at the university level, not at a departmental level as it likely had been in the past. A respondent from an institution who operated in a consultative shared-governance model stated:

I would hope the position, regardless of the person in the position, justif[ies] a level of agency. Time is always helpful because you build on 
your knowledge but to be a registrar, you should already have some knowledge and experience. Understanding the political frame of your institution is critical to success. Success for you as a Registrar and for your institution.

Both the collaborative and the consultative model respondents shared messages about time in the position and relationship development as the most poignant comments in the feedback.

The respondents within a distributed decision-making model were not drastically different from the collaborative and consultative respondents, but their responses had a sharper focus on two areas. First, trust and respect for the role was interlaced with many respondents' answers. Even though a connection was expressed among those terms and time at the institution, the focus of the respondents' comments was about trust or respect that rises from the time, less so about the time as the sole reason for the trust and respect. Second, the respondents from this shared-governance model talked about how their expertise as a resource was a result of their diversity of experience from multiple institutions or connections to their colleagues at other institutions or from being engaged in professional organizations. Registrars shared insightful perspective about other schools' practices because other administrators often have risen from faculty roles, with the result that they have been at one or very few institutions due to the tenure structure. One respondent said,

Nearly twenty years in higher education, many working closely with curriculum development and maintenance at both state schools, as well as, private institutions of various size and student populations gives me a wide expanse of experience to inform the responsibilities I have in my role. 
This insight appeared to be appreciated when crafting policies or discussing options for changes to current policies at institutions where the distributed decision-making sharedgovernance model was intact. Yet, while it may also occur at the consultative and fully collaborative schools, it was not nearly as explicitly described in the feedback from the respondents.

Three specific quotations served as thought provoking and worthy of further exploration. All three related to the role of the registrar in curriculum management as well as to the broader view of all academic analysts and their relationship in shared governance and specifically with faculty. On the surface, the quotations appear to be discrete comments, but it might be possible to thread implied dependencies between them.

Quotation 1:

I have also learned over the years that my role is often to be "the heavy" for administrators and faculty who don't like a rule but understand why it needs to be applied. Not always, but often. Some staff and faculty will always seem me as rule-bound but the majority of the community expects and wants me to use my authority.

Quotation 2:

Having a long standing reputation as someone that upholds academic integrity I believe has had the most impact on my ability to impact academic policy and curricular change.

Quotation 3:

The doctoral degree in education leadership provided me with great tools and frameworks to analyze situations, but I don't think it provides me with much advantage with faculty. I think that institutional knowledge has been critical in my ability to "lead from behind".

Independently, these three quotations deserve further attention because they directly speak to the imperative role of the actor, the registrar, in shared governance. When 
thinking about the dependencies between these descriptions provided by three distinct respondents, a theme emerged about the ethics and values of the actor being described. The authority of the registrar to hold firm to rules, presumably for the good of the institution or student, and the fact that the actor does so, speaks to the commitment of these registrars to uphold academic integrity. When seen as the person in a compliance driven role, it becomes difficult to be seen as a proactive visionary; the implied expectation from "being the heavy" is to lead from behind and keep the institution on a steady course. No respondents used the term, but some of the responses read as if the role can serve as the moral compass for equitable administration of curricular and academic policies. This topic is worthy of further research. As it pertains to the first quotation, the firm belief of the respondent was that the community "wants [them] to use [their] authority”, which was a strong argument for the role of the registrar to have a formal role in shared governance. It was, at a minimum, worthy of further research but also worthy of discussion on campuses where this attitude exists.

\section{Summary}

Once again, the purpose of the research was to test the hypothesis that when registrars are involved in curriculum management and there is a strong sharedgovernance model, efficiencies for students occur because more informed decisions are made about how to set succinct curriculum rules and clear academic policies that limit negative impact on students. The research was performed using a mixed-methods survey with quantitative data collected via close-ended survey questions and qualitative data collected via open-ended survey questions. The quantitative analysis was measured 
directly against the hypothesis and the qualitative data was analyzed to further explore the hypothesis for any clarity about the topic. The four-section survey data was collected in an attempt to answer the following research question: "Does the level of academic analyst involvement in shared governance have an effect on curriculum management and academic policy while controlling for the shared-governance model at that institution?” Upon collection of the data, the software R was used to run Fisher's Exact Test (RCT-CRAN, 2017) on a purposive sample of registrars and faculty leaders at large, four-year, research institutions. Unfortunately, statistical results from the 168 Fisher Exact Tests performed demonstrated a null hypothesis for the research question. Controlling for the shared-governance model resulted in much smaller data cells forcing more limited test options to find significance. While a small number of test results showed significance with a $p$-value of less than .1, those results were likely due to compound uncertainty as a result of simultaneous inferences. Further exploration on the specific topic of the areas that resulted in significance is required if more conclusive decisions about the hypothesis can be drawn.

The qualitative research analysis included evaluating six open-ended questions on the survey, looking for categorical themes identified by using an a priori research protocol. These questions focused on learning more about (1) how registrars were involved in curriculum and policy decisions, (2) if they were helpful in those processes, (3) the respondents' perceptions about whether or not that involvement impacted students, and finally, (4) what agency registrars had, based on their authority, toward impacting policies. Respondents’ feedback was summarized into a categorical framework 
that listed the main themes heard through the responses. Those summaries were tabulated and sorted for each question. The opportunity to ask respondents if the registrar's involvement in curriculum management and academic policy impacts students resulted in a response that did not support the outcome of the Fisher's Exact Test. The quantitative test did not show significance in many tests, but the actual Yes/No/Unsure responses collected from respondents showed that more than two-thirds of the respondents, in all shared-governance models, do believe there is a connection between the actor's involvement in the policy and the impact on students. Further research is needed to better understand the conflicting outcomes. Finally, the evaluation of open-ended text responses for useful quotations that might bring new information to bear on the broader topic of the role of the registrar in curriculum management resulted in three specific quotations that deserved further evaluation and study. These quotations opened new conversations around how the role of the registrar is to act as the standard bearer, even when not appreciated, to keep leading the institution to stay on a steady and ethical course as it relates to students' records. 


\section{Chapter 5: Discussion \& Conclusions}

Introduction

This research addresses the gap in the current literature, specifically the role of the academic analyst in shared governance in higher education. Current literature on shared governance only covers three roles: president, faculty, and board of trustees with very limited mention of administration as a term interchangeable with president. By researching the role of the registrar in curriculum management, I believe it is possible to gain a better understanding of the role that academic analysts play in shared governance. In turn, this knowledge, when applied, can give other academic analysts and administrative analysts the ability to utilize a newly codified role in shared governance, both in the literature and in their everyday work.

Literature is extremely limited that speaks directly to the role of the registrar and curriculum management. The American Association of College Registrars and Admissions Officers (AACRAO) dedicated just twelve short pages to this topic when writing The Registrar's Guide: Evolving Best Practices in Records and Registration; only one chapter discussed this matter. The chapter included a basic overview of how the registrar operates within the curriculum structure and a basic guide to understand what resources a registrar should bring to the curriculum discussion. Laudeman stated, "The registrar has a threefold relationship to curriculum development: advisery [sic] (institutional history), shaping (data and benchmarking), and executing (policy watch and degree audit)" (2006, p. 19). The chapter also discussed the concept that curriculum, in that particular reference, also included important academic and policy issues (Laudeman, 
2006, p. 20). This aligns with the research performed and the relevance of the qualitative findings related to serving to provide institutional history and acting as an information provider.

\section{Summary of Research Questions and Methods}

This study examined the role of the registrar in shared governance by specifically asking: "Does the level of academic analyst involvement in shared governance have an effect on curriculum management and academic policy while controlling for the sharedgovernance model practiced at that institution?” The researcher explored multiple research questions as part of this broader hypothesis. These research questions investigated the effect of the registrar on student success when involved in curriculum management and academic policy administration; determined if the shared-governance model affected the registrar's involvement; clarified the level of helpfulness of the registrar in policy administration; and discovered what agency registrars believed to have because of their role's authority.

Respondents answered questions about their experience with registrars’ involvement in curriculum management and academic policies at their institution using both qualitative and quantitative questions in an online survey. All four sections of the survey questions were evaluated separately, but several sections were also analyzed together to attempt to determine significance between the variables. The researcher performed Fisher's Exact Test by comparing section two and section three, testing for significance, while controlling for shared-governance model. The researcher also evaluated three series of open-ended questions using qualitative research methods that 
included established protocols to find core themes in responses and then measure the frequency of these themes. The survey also asked questions about basic demographics of the respondents related to their positions at their institutions. Finally, an inductive review of the open-ended statements revealed quotations and ideas that also lead to new perspectives on the role of the registrar in curriculum management and academic policies. These forms of evaluation all played into the broader discussion about the role of the academic analyst in shared governance.

\section{Limitations of the Research}

This research contained numerous limitations that could affect the results of the study and the multiple methodological approaches used to evaluate the results. This section will explore these limitations and potential impact.

First, the purposive sample selected for this work relied on response rates, and unless the majority of the population responds, it is problematic to draw conclusions with high levels of confidence. In this study, while a large number of the population responded to the survey, significantly less faculty curriculum leaders responded than registrars. This resulted in not being able to compare responses between these two subpopulations, the faculty curriculum leaders and registrars.

The main point of the survey was to look beyond simple registrar involvement in curriculum management and academic policy to focus on the control variable for the research study - the shared-governance model. The researcher wanted to know if the shared-governance model had an effect on the input of the registrar in the topics of curriculum management and academic policy. This critical factor was self-reported by 
respondents at the beginning of the survey, based upon definitions provided in the text of the survey. These responses were not checked for accuracy; rather, it was assumed the respondents were able to provide an accurate selection of the shared-governance model at their institution from the definitions provided. All further survey responses were categorized and reported on by their shared-governance model selection. If the selection was incorrect, the categorization of responses was also incorrect and therefore could influence the methodological analysis of the data.

Finally, some questions were misinterpreted by a reasonable number of respondents. It is unclear if the questions were poorly worded or if not enough context was included in the questions, but the results did not reflect the intention of the questions or respondents opted to not respond at all to those questions. As this surfaced during the evaluation of the data, the researcher opted to disregard those questions and not perform analysis on them as they appeared incomplete.

\section{Discussion of Findings and Suggestions for Future Research}

In reviewing the definition of terms related to the study, the registrar position categorically fit into the role of an academic analyst. The academic analyst is a person who ensures that both operations of the system and its structures function while resolving problems related to direct academic units of the institution. The academic analyst is a subcategory of the administrative analyst, that is, a manager who functions and is responsible for analysis and implementation at upper administrative levels but is not an executive who reports directly to the provost or president. These definitions serve as the structural roles of the actor when interpreting the findings from the research. 
A review of the literature uncovered three theoretical frameworks used to inform the research. Role and role theory served to help define the actor, the academic analyst, in the larger context of the organization and how the actor operated within the sharedgovernance model. The specific study and research questions narrowed the role even further to the registrar. Organization theory served as the foundation for evaluating the structures used to complete work by actors in an organization. The literature differentiated public organizations from private and focused on Birnbaum’s School System as well as Mintzberg’s Professional Bureaucracy. Specifically in this research project, the organization structure was an educational institution and the academic analyst and faculty roles exist when completing tasks related to curriculum management and academic policy. Finally, shared-governance at higher education institutions served as the field of study to examine the delineation in how specific actors engage in a governance process and why it might be different at different institutions, such as ones with either binding versus non-binding shared-governance models. The way in which sharedgovernance theory is applied over the top of an organizational structure in higher education is unique to that field. Few industries like higher education use a sharedgovernance approach to decision making. As evidenced during the literature review, nursing was the only other field of relevance found in shared-governance literature. Role theory, organization theory, and shared governance were the three areas used as the lens from which the researcher framed the discussion about the role of the registrar in curriculum management and academic policy. 


\section{Shared-governance Models}

Three shared-governance models exist: consultative, distributed decision-making, and fully collaborative. Comparable institution types tend to have closer alignment to similar shared-governance models. For instance, community colleges are more likely to have the same shared-governance model in common than they would with a four-year, public institution with a high research focus. The study results showed approximately two-thirds of respondents indicated their model was distributed decision-making while the remaining nearly one-third of respondents listed either the fully collaborative or consultative models. In a large, four-year, doctoral-granting, research institution, it is surprising that 18 respondents stated their model type was consultative. This number is large given the type of institutions surveyed, and it is somewhat surprising that more than just a few reported that faculty do not have binding authority in any decisions at their institution, especially academic policy decisions. Rather, they play a consultative role. Most schools classified in this way by the Carnegie Classification ${ }^{\circledR}$ structure allow their faculty a more formal role in decision making. The consultative model more commonly operates at other types of institutions such as private, for-profit, or community colleges.

If a zero sum game approach is used in determining the total number of actors who can participate in the decision-making process, this approach could lead to more decision-making authority or involvement for registrars at those institutions in scenarios where faculty have less binding authority. Further evaluation of the institutions who operate using a consultative model is required to further explore the hypothesis about that specific question. Possible research questions to ask of employees in schools who operate 
using a consultative shared-governance model could include questions about the level of decision-making authority of the academic analysts or on the amount of participation that exists in the process (consultative approach) for the academic analysts. Another approach might ask broader populations such as executives and faculty how they feel about the more limited role of the faculty in a consultative shared-governance model. Other findings suggest that more exploration of the institutions that operate using a sharedgovernance model is needed.

\section{Input from the Registrar}

When reviewing the survey section about the input from the registrar, a basic comparison transpired to delineate the responses based on shared-governance models and which model had the most input from the registrar in their decisions about curriculum management and academic policy. Earlier in this text, models were described using a continuum of less strong and stronger (Figure 6 and Table 3). The model defined as less strong, the consultative model, had the highest mean score of the three models when measuring input from the registrar based on a compilation of responses to seven topics. The fully collaborative model, considered the strongest, had the second highest mean, and the distributed decision-making model had the lowest of the three. Contrary to logical assumptions, no connection was shown to exist between the consultative model being a less strong model and having a low amount of input by the registrar. In fact, the opposite was demonstrated. In addition, when the logic of the zero sum game theory is followed, perhaps the consultative model allows for more involvement by the registrar since it is less strong relative to faculty input. This is a possible future research question, to learn 
about the decision-making authority registrars have in consultative shared-governance models, with the hypothesis that registrars are more involved in decision making when faculty have less binding input.

A surprising area that needs more clarity and better understanding begged the question why did institutions with the distributed decision-making shared-governance model have the least amount of involvement by the registrar. No clear rationale could explain this (other than the zero sum game theory, which is untested), and it seems that in a model where the decision making is so clearly laid out, an official role would exist for input from the registrar. Such was not the case, and more feedback is necessary to understand why. Unfortunately, these questions cannot be answered through the same feedback mechanism used to perform further research on the consultative model. These are separate research questions for unique populations, requiring multiple studies. This was not information known to the researcher prior to doing the initial study. As a result, these study options are for future research built upon the research dataset collected from this study.

\section{Perceived Impact on Students}

Eight scenarios about policies affecting students were presented to the respondents in the survey, and they were asked to state their level of agreement (or not) to these scenarios. Two scenarios consistently had a significantly higher mean than the other six across all three shared-governance models. These scenarios were: students need to see an academic advisor because policies are not clear (2.97/5) and students have problems interpreting degree requirements using a degree audit tool (2.74/5). A score of 
five meant that the respondent agreed that the statement impacted the student. This result likely would not surprise many practitioners, because it is common for students to struggle with interpreting requirements and degree audits. It is also not surprising that this outcome is universal, relative to all three shared-governance models.

These particular questions become interesting when looking at the findings of the Fisher's Exact Test because, while the hypothesis was null overall, 8 of 168 tests showed significance, and six of those eight tests showing significance had these two questions involved in the comparison. Respondents that reported using the distributed decisionmaking shared-governance model had four tests that showed significance, and the dependent variable for all four of these tests was "students have problems interpreting degree requirements using a degree audit tool”. The respondents that reported that they used the collaborative shared-governance model also had two of four tests that showed significance, and the dependent variable was "students need to see an academic advisor because policies are not clear”. Institutions who reported that they use the consultative shared-governance model did not show significance in any correlation test. It is unclear what this means, but further studies could focus on whether the fact that the registrars have the most input at institutions with a consultative shared-governance model resulted in there being less confusion around degree audit requirements or policies not being clear.

In reviewing the significance of these tests, these two key areas show up as problematic and deserve further research. Paramount to student success was an understanding what was unclear about the policies and interpreting why degree requirements using a degree audit tool were causing respondents to perceive a negative 
effect on students. Asking these questions of actors in institutions from all three sharedgovernance models will benefit the research. Learning from respondents who operate using the consultative model about the reason why they do not perceive there to be any negative effects may tell institutions using other models how to reduce the perceived negative effect on students. Additionally, further exploration of the responses from the distributed decision-making and the fully collaborative models may explain why the perception persists of adversely affecting students. Understanding what respondents perceived to be working and what respondents thought did not work is useful in being able to affect change where it is needed.

Additionally, when looking specifically at the results of the Fisher's Exact Test, determining residency requirements for a degree also surfaced as a topic found to be an important independent variable. It was visible in both distributed-decision making and fully collaborative shared-governance models, appearing in four of the eight tests that resulted in significance where the $p$-value was less than .1 . When registrars have input in determining residency requirements for a degree, they may perceive negative impact on students as it relates to the following two dependent variables: having to see an advisor because requirements are not clear and having problems interpreting degree requirements using a degree audit tool. The correlation between this independent variable and the two dependent variables may explain to institutional actors organizational shortcomings with students. If any implications are to be drawn from the findings displaying significance, it is that further research needs to be performed on institutions with consultative sharedgovernance models. The goal is to determine why these schools believe that the perceived 
impact is less on their students, what they are doing to ensure students do not have a negative effect from the policies, and how having their registrars involved has contributed to student success. Additionally, survey questions or even targeted interview questions focused on these three specific topics with people at institutions where distributed decision-making and fully collaborative shared-governance models may help the practitioner better understand where the disconnect between these topics exists.

One peculiar result continues to surface through multiple tests that cannot be ignored: the consultative model displays the more positive showing in these evaluations. When controlling for shared-governance models, either through basic categorization and review or through a correlation test that controls for the model in the test, the consultative model is demonstrating that it has more registrar input, but it also does not show significance when looking for problematic areas that affect students. Too little testing on this area was done to draw conclusions about the hypothesis, but it is clear that further research should be performed to find out why.

One possible hypothesis, via a question that seems to be surfacing from the research, is that perhaps the more prescribed the engagement of the actors is, the more limited the involvement of the academic analysts may be. For example, when a model demonstrated that faculty can provide input but there are not binding ways in which to provide the input, more involvement from the academic analysts occurs because all actors have a more equitable opportunity to be involved in curriculum management and academic policy. When the model is prescribed but states that faculty is involved in nearly all decision making, less involvement of the academic analysts occur because the 
fully collaborative model is just that, fully collaborative. This leaves the most prescribed shared-governance model, the distributed decision-making model, as the area where academic analysts are involved the least, perhaps because each area of input is prescribed more formally. If any of these models operate on a zero-sum game approach, that could also speak to why registrars are reportedly less involved in models where faculty are more involved.

None of these possible topics were even known until this study’s initial research was performed, but the questions surfacing now are intriguing. They are worthy of focused research to further distinguish why the input of the registrars was higher at a consultative institution and why consultative institutions show no significance in any critical topical areas when controlling for the shared-governance model. The input of the registrar being valued higher at an institution with a consultative shared-governance model was not an expected outcome.

A tangential but interesting question to explore further is to learn if schools in this research population who operate using a consultative shared-governance model are just as successful in recruitment of faculty as their counterparts. Many faculty looking for full-time employment in academia may take whatever opportunities arise without too much discernment about the shared-governance model at their possible schools of employment. However, long-term recruitment of qualified faculty to positions may include more applicants who may exercise more discrimination in this area. By comparing their experiences to the majority of their peers at institutions where faculty are able to participate in binding decisions in at least some of the administration of the 
institution, if not all, their decisions about where to work may be affected. It is possible that a similar question could be asked of registrars seeking employment at other institutions.

\section{The Qualitative and Quantitative Perspectives Compared}

The comparison is incongruous between the output of the Fisher's Exact Test and the responses to the direct question about the registrar's involvement in curriculum management and academic policy impacting students. While the Fisher's Exact Test did not return significance in a majority of the tests, the basic question resulted in the opposite response. Clear and distinct validation occurred: over two-thirds of respondents to the question about whether or not registrar's involvement in curriculum management and academic policy impact students responded with a Yes response (69\%). This percentage demonstrated that the respondents felt strongly that the role of the academic analyst in shared governance is critical, even if the response did not control for the shared-governance model. A higher percentage of the respondents from the consultative and the distributed decision-making shared-governance models stated that the registrar's involvement did affect students. The hypothesis stated earlier about the less prescribed models having more involvement in the process than the more prescribed models is continuing to surface as a possibility. Adriana Kezar asserted that the relevance of the engagement of actors versus having a formalized shared-governance model in which the actors operate is what matters to have an effective shared-governance model (Kezar, 2004, p. 36). If the suggestions from this hypothesis are further studied, more can be 
learned about what happens when the roles and boundaries of the governance structure are less prescribed and how that affects the academic analyst's role in shared governance.

\section{Qualitative Outcomes}

The findings resulting from the qualitative research were rich and worthy of further exploration for many of the topics related to shared governance and the role of the academic analyst. First, insights were provided by themes that surfaced when asking about the engagement of the registrar in certain policies and the processes related to those policies. With approximately $60 \%$ of respondents stating there was involvement by the registrar, the topical themes supported those affirmative responses. The open-ended responses also reflected involvement through terms such as information provider, input, involved, etc. Both the response rates to the initial question and the follow-up comments provided by the respondents demonstrated clear support that registrars are involved in shared governance, but language is limited in the literature to support these findings.

A specific question was asked only of registrars about how their authority gives them agency in completing their work. This was a useful question because it allowed respondents to speak directly to why they believe they are effective in their work. The two most frequent responses were about the number of years one had in the field and being a respected peer on campus. While not direct, these types of responses do imply a connection to the question Kezar posed previously about the effectiveness of relationships and trust versus shared-governance structure. No respondent spoke directly about their campus structure as a factor in their ability to be involved or affect policies, but this connection was implied in that some respondents listed their formal committee 
assignments as part of their authority giving them agency to complete their work. Committee assignments are often, but not always, part of an institution's governance structure. Encouraging registrars to articulate this contribution and giving them the constructs by which they could describe that involvement as a formal actor in shared governance lent credence to their work as active players in the shared-governance structure on their campus. It also ensures a formalized role that honors the value of the work being performed, with particular reference to the critical nature of operating as the standards bearer for both consistency of policy across all academic units, preventing negative unintended consequences, and applying their lens of equity for all students.

\section{$\underline{\text { Inductive Results }}$}

Returning to two particular quotations referenced in chapter four help define what is unique about the findings from the respondents but also highlight two areas that deserve far more attention and research. While the statements only came from two respondents, the comments embody what seems to be underlying in other respondents' comments and what could be happening with academic analysts on campus right now, particularly registrars, and also curriculum officers and institutional researchers.

The first quotation addressed the concept of "leading from behind". The respondent stated:

The doctoral degree in education leadership provided me with great tools and frameworks to analyze situations, but I don't think it provides me with much advantage with faculty. I think that institutional knowledge has been critical in my ability to "lead from behind". 
This statement summarized what registrars do, both figuratively and literally. From a literal perspective, many respondents mentioned that it was often the role of the registrar to find a solution to a curriculum or policy problem after it had been decided. During implementation, the problem was realized and the registrar had to go back to the appropriate decision-making body and work from behind the decision to creatively come up with a solution by either working within the constructs of the new rule or amending it. The registrar was leading from behind. Some respondents articulated a desire or an appreciation for being brought into the discussion sooner, but only after it was realized that institutional knowledge existed from which the decision-making body could benefit. Perhaps not every registrar leads from behind but that language resonated with the many respondents' thoughts on seeing the effect on students, sometimes when it was too late. Application of this concept to other academic analysts, curriculum officers and institutional researchers, is only speculative, but worthy of discussion. Curriculum leaders are required to perform such tasks as ensuring academic units complete periodic, protocol-driven program reviews and ensure that assessment (both student and course) happens on a cyclical basis. These are accreditation standards and required of most institutions. Typically without formal authority over the units, curriculum officers must encourage and convince faculty departments to engage in these critical but timeconsuming tasks. These activities may technically have a spot in the job description of faculty, but such is often lost amongst the many day-to-day requirements like teaching, research, and advising students. In applying this same logic to institutional researchers, there are many projects for which they serve as information providers but must first 
persuade the engaged parties (faculty and administrators) to agree upon institution-wide definitions for said projects. Or, the institutional researcher may need to shepherd a wellintended group from letting the scope creep out of control on a time-sensitive or missioncritical project because of what data can be reasonably provided to ensure the work is done accurately.

Research possibilities for determining if academic analysts are truly leading from behind may be trickier than simply asking the question. If leading from behind is not actually affirmed or acknowledged by the recipients of the leadership, it would be difficult to ask explicit questions that result in a response that clearly states if it is occurring. Rather, the evaluation of new policy formation or policy modification in areas likely for academic analyst involvement would need to be evaluated to determine who was involved in the process, at what point in the process and which participants had an effect on the outcome of the policy. Asking all who participated in the policy development process is necessary to gain full insight. For example, asking each participant what the policy started as, what iterations of the policy existed, and how the policy got to its end stage. Additionally, participants' perspective would need to include what role they had in the process. This information could then be triangulated to determine if academic analysts were leading from behind in the process. This idea sketched here is just one way of learning about how, if at all, academic analysts lead from behind. The secondary, and more important question, is why that matters and if it brings value to the institution. Understanding whether an action is occurring is interesting but understanding if that action is useful is the point of the research. 
The second quotation of fundamental importance in the findings relates to valuing the role of the academic analyst. When asked how their (registrar) authority gave them agency toward impacting policies and involvement one respondent, said:

I have also learned over the years that my role is often to be "the heavy" for administrators and faculty who don't like a rule but understand why it needs to be applied. Not always, but often. Some staff and faculty will always seem me as rule-bound but the majority of the community expects and wants me to use my authority.

This kind of response speaks to the deliberate yet indirect need for the institution to have registrars operating as authority figures in certain realms and not only with students. While the respondent did not articulate specific examples, one might deduce that holding administrators, faculty, and students to the same standards between colleges for the enforcement of a policy might be one way in which this could be experienced in practice.

A quote from another respondent may shed light onto why it is important that the community expects registrars to use their authority. "Having a long standing reputation as someone that upholds academic integrity I believe has had the most impact on my ability to impact academic policy and curricular change.” Stating that their tenure in the role of registrar created their reputation of someone who "upholds academic integrity" is precisely why this role is expected to use their authority; serving as that standard-bearer for the policies set forth by the institution or the laws required to be upheld. It may not be the only reason for this expectation by the community to act as "the heavy", but it certainly validates authenticity behind the role.

Application of this particular concept, acting as an authority to enforce rules or policy, to other academic analysts is not hard to imagine. During the creation of 
curricular programs or courses, basic standards must be met, and while they may seem tedious to faculty or academic leaders at the time, they are typically in place to prevent programs from not meeting accreditation standards or other policies that adversely affect program requirements. Institutional researchers are, at times, asked for data cells that do not conform to the privacy standards for research or federal privacy laws for student data. Acting as the agent for the institution to protect itself from violating the law, the institutional research director may have to tell people no, including their boss, in the best interest of the institution's well-being. This unpopular, yet critical role, serves the institution to keep it compliant with policies or laws, but it is not formally recognized in the shared-governance roles.

All three academic analysts_-registrars, curriculum officers, and institutional research directors - face this challenge within the structure of shared governance for which no formal role has been established, codified, and respected for them. While the research did convey that some shared-governance involvement is reported via committee involvement, it was haphazard and inconsistent among the respondents. Additionally, some respondents stated their institutions offered a limited role for registrars in this arena, which alone serves as an impetus for a more formalized role. Changing the sharedgovernance narrative to include “administrators” as part of the three-legged sharedgovernance stool would be the best first step in codifying the role of these analysts. The role of the president was seminal in the discussion on shared governance as early as the 1960s, but expanding that unit to include their staff (administrators) should not be seen as a threat to that role, only as an asset that expands the meaning and value of the broader 
involvement. The adage that "words matter" should drive home the importance of why codifying the role of the academic analyst through this expansive use of the term administrator instead of president matters.

In terms of new revelations, this quotation about the "community expecting the registrar to use their authority” is perhaps the most useful piece of evidence to surface from the research. Not because it is a new concept; it seems that registrars and other academic analysts are used to hearing that they are often the referred to as the "no" people on their campus. Rather, this new revelation marks the first time the use of registrar authority was viewed as a formalized, authorized, and supported role that an institution not only needs but also values. That value measurement may be below the surface and may be degraded when not useful to the person attempting to complete work, but appreciation still existed for that rule-bound registrar who was being a barrier. This exciting topic could be studied for further exploration of the concept of this role. Possibilities include:

- asking (interviewing or surveying) registrars, curriculum officers, and institutional researchers at multiple institutions with carefully worded questions to learn about their perspective on serving as the "authority" for rule or protocol enforcement, or

- asking (interviewing or surveying) faculty and administrators if they experience these types of academic analysts (registrars, curriculum officers, institutional researchers) as rule-bound enforcers of policies that may seem arbitrary or not helpful in certain situations. 
Many other ways may be available to learn about this topic, but most important to the research is to find answers to several important questions. First, are the academic analysts portrayed in this light? If yes, does it bring value to the institution? If it does bring value, what kind? If it does not bring value, why do people still believe that the role using such authority exists?

This summary of findings and suggestions for future research only delves so far into the information from the qualitative and quantitative data obtained during the survey of faculty curriculum leaders and registrars. The areas surfacing as ripe for future research from the data points relate to two critical areas for practitioners. Both topics came out of asking respondents about the perceived impact on students. Respondents agreed that students need to see an academic advisor because policies were not clear, and students have problems interpreting degree requirements using a degree audit tool. Both of these topics have the possibility to serve as a barrier to students' ability to graduate. If respondents are stating a higher level of concern about these topics than others, it is imperative that further exploration occur so that clarity around policies improve, and students learn how to better interpret degree requirements using the degree audit tool. Further research could then inform practitioners about how to affect the success of students by taking action from the outcomes of how to improve those two areas for students. Finally, the two most poignant statements from inductive review were the comments respondents made about the community expecting and wanting the registrar to use their authority as well as the statement that registrars lead from behind. These 
statements have serious promise for influencing practitioners' work if further research supported those actions.

\section{Theoretical Summary}

The findings from the survey about the registrar and their role in decision-making validate the approach that Reich espoused regarding how decision-making happens among the symbolic analysts. Recall that Reich said decisions "increasingly occur at subterranean levels" when he referenced the shift of power from the organizational chart relevance to the brokers who are making decisions (1991, p. 99). The registrar may not sit at the top of the organizational chart, but survey respondents articulated why they are the appropriate actors to make decisions based on their vantage point within the institution: their ability to understand broader effects that policies and curriculum rules have on students. Many respondents expressed the need for the involvement of the registrar in decisions, supporting Reich’s idea of decisions occurring at subterranean levels.

The disjointed understanding of the role respondents thought that registrars should play in curriculum management and academic policy and the actual involvement that some were allotted addressed the organizational role theory that Bruce Biddle articulated. Specifically, these findings demonstrate a clear indication that role conflict exists among registrars, and the understanding of how they are involved in shared governance related to academic policy and curriculum management. As stated earlier, Biddle defined role conflict as, "the concurrent appearance of two or more incompatible expectations for the behavior of a person” (Biddle, 1986, p. 82). Respondents discussed the expectations of leading from behind — the idea that without the ability to be part of the decision-making 
parties, they were still expected to ensure successful implementations of academic policy and curriculum management. Additionally, the expectation was implied that one might have an ex-officio role on a committee but also need to ensure that the outcome for students was not negative. Actors expected to maintain responsibility without authority experience role conflict.

The survey findings validated the messiness of the organizational structures under which work is accomplished at higher educational institutions. The evaluation of two models of organizations within the organization theory literature that are most connected to the findings are the Birnbaum and Mintzberg models. These models become the crossroads where the organization theory and the empirical setting of shared governance operationalized at educational institutions meet. While Mintzberg’s professional bureaucracy model (Figure 3) had more clarity around the actors of the bureaucracy, Birnbaum's school system (Figure 1) reflected the openness for the free-flowing process between the actors. In the space within the circles, the shared-governance process can flow back and forth or in and out, until the actors involved in the roles within the system complete the work.

Comparatively, Mintzberg’s model (Figure 7) had such strong delineation between the roles that it is more difficult to imagine how the shared-governance process flows between the units. Each role is isolated into its own part of the organization, and 


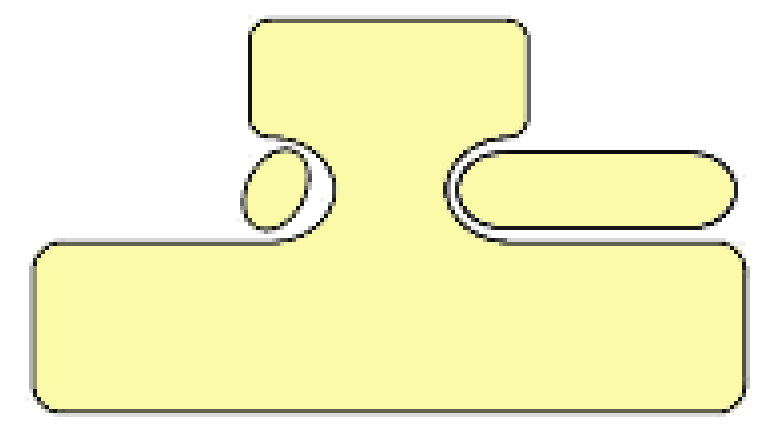

Figure 7.Type E: Operating core (Mintzberg 1993, p. 194. Used by permission of the author.).

no active movement occurs between them. Even without a visible exchange between the relationships of the actors in the professional bureaucracy that Mintzberg described, shared governance and process needs to be addressed.

It is the actors and the process interacting successfully that make shared governance effective. Neither Birnbaum nor Mintzberg have fully demonstrated that these two factors work together. The continuum displayed previously (Figure 4) showed authors (Smith, 2015; Birnbaum, 2004; Kaplan, 2004; Kezar, 2004) who focused on actors versus process; they also did not articulate how those two characteristics are both required for a successful engagement in shared governance. The findings of the research made it clear that both the actors and the process are important for a successful sharedgovernance experience, regardless of the model in operation at the institutions. Weak, moderate, or strong shared-governance types can all be effective if engagement is high and understanding is clear about how the actors work within the process. 
A better depiction (Figure 8) can be used to describe the relationship of the work; it shows the actors and processes as not diametrically opposed but as sitting on different axis points.

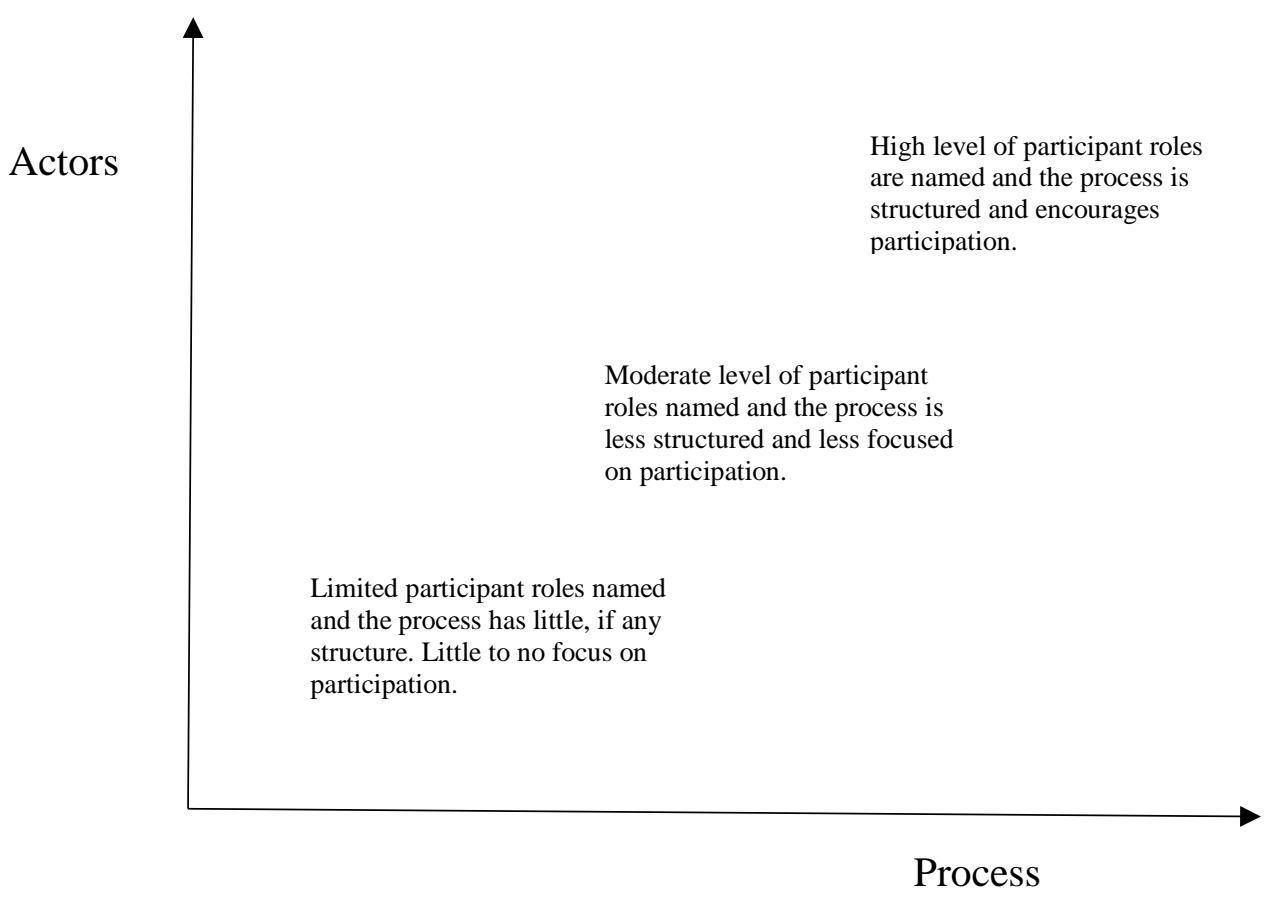

Figure 8. Actors and process in relationship for shared governance within organizations. Implications for Practice

Clearly, based on this research, academic analysts play a role in shared governance at educational institutions regardless of the type of shared-governance model in place at those institutions. Respondents articulated that the formalized structures that do exist for involving academic analysts often include governance committee membership (ex-officio or otherwise). Discussion of these roles that academic analysts play will help formalize their involvement at the institution. Once codified, further 
discussion must occur to shift the practical application back to the literature so it is reflected there. Currently, the shared-governance literature does not offer explicit reference to these structures as part of governance including the roles of the academic analysts.

Specific ideas for how to formalize roles into practice are identified for multiple types of academic analysts. Some ideas are applicable to any academic analyst, and some are specific to certain roles within an institution.

1. Faculty senate bodies can ensure that the language used in committee standing rules, role assignments, and committee charges include who is involved and why they are involved. Using these artifacts to articulate specific roles of the actors on the committees and why their role or /position is important in the particular committee work will bring language to bear in a practical sense for academic analysts to have their role codified in shared governance.

2. Registrars should produce informational reports for colleges and academic units to learn about their centralized perspective culling the implications of many units into one crossroads where students are affected by decisions that departments made without fully realizing the unintended consequences. The result is allowing registrars input into the curriculum logistics process prior to its passage and implementation. The input in the process should be codified.

3. Institutional research officers must educate faculty and academic unit leaders as to why there must be one authority for defining terms that require consistent 
measurement across colleges and the university in general. This authority should be codified into the shared-governance structures at the institution.

4. Curriculum officers need the authority to assist with standard measurements for the purpose of accreditation planning, any legislative reporting requirements, or other regulatory processes. While this particular example may require less nudging because of its regulatory nature, it still entails prodding or nudging to activate campus partners to buy-in to the activities required to complete the work. This role should be codified into the shared-governance structures at the institution.

Academic analysts who are involved in these activities can help turn out favorable results for the institution.

Registrars’ involvement will help ensure students are more successful; institutional researchers' involvement will help ensure the institution has comparable measurements of success rates for academic units across campus; and curriculum officers' involvement (and, in turn, critical engagement from faculty and administrators) can help ensure the institution meets its accreditation and regulatory requirements. It is possible that these valuable resources, the rich information and perspectives from the academic analysts, are being unintentionally isolated because a lack of understanding hinders how the engagement of the academic analysts can bring value to the sharedgovernance process. Institutions must be made aware of the resources on a broad scale. Practitioners and researchers must then publish these activities so that the shared- 
governance literature reflects its operationalized meaning in the empirical setting and not only a theoretical sense of how shared governance should work.

For example, the registrar's guide (Laudeman, 2006) produced by AACRAO is over twelve years old and the field changes quickly. A revised Registrar's Basic Guide was published in 2018, but it does not cover curriculum in the same depth of the original publication (Geyer, et al., 2018). In 2016, AACRAO published a book dedicated to curriculum management (referenced multiple times in Chapter 1), and it has been well received. All of these resources, however, should flow back to two major assessment tools created for registrars, and until this point, they have not. The Council for the Advancement of Standards in Higher Education (CAS) formalized a self-assessment guide for all programs and services. The most recent CAS self-assessment for registrar programs and services (2015) does not reference curriculum and the role of the registrar. In fact, even the earlier CAS standards for the registrar programs and services (Falkner \& Myers, 2012) are limited in what they state about curriculum. The second self-assessment tool is one produced by AACRAO. The book, AACRAO's Professional Development Guidelines for Registrars: A Self-Assessment, dedicates a chapter to academic policy, student academic records, transcripts, and grading processes, but it does not deliver assessment questions related to curriculum management and shared governance (Trombley, 2018, p. 83).

The two quotations from the results of the inductive analysis provide great insight for other academic analysts to engage with faculty and other administrative partners with the authority to act in the necessary ways. For instance, while "leading from behind" is a 
perfectly fine way to accomplish the task, feeling empowered to lead a policy conversation or process improvement is acceptable. Institutional partners may be helped to understand that it is appropriate for the role to lead the upcoming work, as they had done successfully in the past, using the examples wherein an academic analyst has led from behind and been successful.

The second quotation about the community wanting the registrar to use their authority even though they are simultaneously seen as rule-bound means that other academic analysts should feel empowered to do the same. The responsibility of some academic analysts to maintain the institutional standards is likely mandated due to compliance or regulatory requirements. Institutional Review Board administrators should not only feel confident in their decision to uphold standards, often to the chagrin of a researcher who may now have additional work to do, but those academic analysts should be praised, not chastised for holding the institution and its actors to those standards. The director of accreditation should be thanked for reminding academic units of their responsibilities to perform program reviews on a regular cycle. These reminders, and the academic unit's adherence to them, keeps the institution in good standing with their accreditors.

Not only should academic analysts begin to operate in this way if they are not already doing so, they should also do so with that support from the institution. The formalization of these roles by the president and the provost or chancellor offers backing for these analysts to do their best work. If that happens, rather than this work being seen 
as burdensome or laden with barriers, it becomes seen as the useful service to the institution that it is.

\section{Conclusions}

The goal of the research was to address the gap in the literature regarding the role of the academic analyst in shared governance in higher education and to further explore if the specific type of shared-governance model mattered. The survey findings made it clear that there is value in the registrar being involved in curriculum management and academic policy. A disparity existed between the qualitative and quantitative feedback related to specific research questions. This is interesting because the open-ended responses from the survey respondents articulated a need for registrar involvement in these roles while little significance was found when performing a Fisher's Exact Test on the data points. Perhaps this tells us that their involvement is critical regardless of the shared-governance model under which they operate, but it could also be telling us something as simple as the study itself did not ask the appropriate questions to display results that were easily comparable. The feedback from respondents analyzed using an inductive approach is enlightening and tells us where researchers can look next for understanding the role of the registrar in curriculum management.

The survey was limited by several factors, including how the initial delineation between shared governance model occurred as well as being able to effectively gain responses from a large enough population of the purposive sample. Practitioners in the field can move forward confidently by creating constructs within the current committee and governance structures that not only includes them in the process but also describes 
the value of the roles at different points of the process. Naming actors' roles in the process supports the structure that can then be codified into future literature. Future literature on shared governance should include a reflection that the three pillars of shared governance include more than the president, trustees, and faculty as well as an understanding of the importance of both the actors and the process. 


\section{References}

American Association of Collegiate Registrars and Admissions Officers (AACRAO). (2016). Curriculum management and the role of the registrar. W. Kilgore (Ed.). Washington, DC: Author.

American Association of University Professors (AAUP). (1967, rev. 1990). Statement on government of colleges and universities. Retrieved in 2016. Retrieved from http://www.aaup.org/report/statement-government-colleges-and-universities

American Association of University Professors (AAUP). (1972). The role of the faculty in budgetary and salary matters. Retrieved in 2016. Retrieved from https://www.aaup.org/report/role-faculty-budgetary-and-salary-matters

American Federation of Teachers (AFT). (n.d.). Shared governance in colleges and universities: A statement by the Higher Education Program and Policy Council. Retrieved March 16, 2016, from:

file:///C:/Users/New/Downloads/American\%20Federation\%20of\%20Teachers(1). pdfLe

Association of Governing Boards of Universities and Colleges (AGB). (2010, January 22). Board responsibility for institutional governance. Washington, D C: AGB. Retrieved from https://www.agb.org/sites/default/files/agbstatements/statement_2010_institutional_governance.pdf

Benjamin, R., \& Carroll, S. (1998) The implications of the changed environment for governance in higher education. In W. Tierney (Ed.), The Responsive University (pp. 92-119). Baltimore: Johns Hopkins University Press. 
Berger, P. L., \& Luckmann, T. (1967). The social construction of reality: A treatise in the sociology of knowledge. New York. NY: Doubleday Anchor. Available at http://perflensburg.se/Berger\%20social-construction-of-reality.pdf

Biddle, B. J. (1979). Role theory: Expectations, identities, and behaviors. New York, NY: Academic Press Inc.

Biddle, B. J. (1986). Recent developments in role theory. Annual Review of Sociology. 12, 67-92. https://doi.org/10.1146/annurev.so.12.080186.000435

Birnbaum, R. (1988). How colleges work: The cybernetics of academic organization and leadership. San Francisco, CA: Jossey-Bass, Inc.

Birnbaum, R. (1989). The cybernetic institution: Toward an integration of governance theories. Higher Education, 18, 239-253. https://doi.org/10.1007/BF00139183

Birnbaum, R., (1999). The dilemma of presidential leadership. In P. G. Altbach, R. O. Berdahl, \& P. J. Gumport, (Eds.), American higher education in the twenty-first century: Social, political, and economic challenges, (1 ${ }^{\text {st }}$ Ed.) (pp. 323-344). Baltimore, MD: The Johns Hopkins University Press.

Birnbaum, R. (2000). Management fads in higher education. San Francisco, CA: JosseyBass.

Birnbaum, R. (2004). The end of shared governance: Looking ahead or looking back. In W. G. Tierney \& V. M. Lechuga (Eds.), Restructuring shared governance in higher education (pp. 5-22). In M. Kramer (Series Ed.), New directions for higher education, Vol. 127. San Francisco, CA: Jossey-Bass, Inc. 
Blau, P. M. (1973). The organization of academic work. New York, NY: John Wiley \& Sons, Inc.

Blau, P. M., \& Scott, W. R. (1962). Formal organizations: A comparative approach. San Francisco, CA: Chandler Publishing Company. Available at https://www.questia.com/library/1434963/formal-organizations-a-comparativeapproach

Bowen, W. G., \& Tobin, E. M. (2015). Locus of authority: The evolution of faculty roles in the governance of higher education. New York, NY: Princeton University Press and ITHAKA.

Chait, R. (2002). The “Academic Revolution” revisited. In S. Brint (Ed.), The future of the city of intellect: The changing American university (pp. 293-321). Stanford, CA: Stanford University Press.

Cho, J. Y., \& Lee, E-H. (2014). Reducing confusion about grounded theory and qualitative content analysis: Similarities and differences. The Qualitative Report, 19(32), 1-20. Retrieved from https://nsuworks.nova.edu/tqr/vol19/iss32/2/

Council for the Advancement of Standards in Higher Education (CAS). (2015). CAS Selfassessment guide for registrar programs and services. Washington, DC: Author.

Creswell, J. W. (2009). Research design: Qualitative, quantitative, and mixed methods approaches. Los Angeles, CA: Sage Publications.

Data from the 2016 almanac. (2016, August 14). The Chronicle of Higher Education. Retrieved from https://www.chronicle.com/interactives/almanac-2016\#id=24_243 (by subscription or purchase of .pdf, \$19.00) 
Dewey, J. (1927). The public and its problems. New York, NY: Henry Hold and Company.

Dimond, J. (1991). Faculty participation in institutional budgeting. In R. Birnbaum (Ed.), Faculty in governance: The role of Senates and Joint Committees in academic decision making. New Directions for Higher Education (Series, No. 75). San Francisco, CA: Jossey-Bass.

Duderstadt, J. J. (2002, November 23). Governing the twenty-first century university: A view from the bridge. Lecture presented to Association for the Study of Higher Education, Sacramento, CA. Duderstadt lectures in the University of Michigan Archives, Deep Blue. Available at http://hdl.handle.net/2027.42/88751

Elo, S., \& Kyngäs, H. (2008). The qualitative content analysis process. Journa of Advanced Nursing, 62(1), pp. 107-115. https://onlinelibrary.wiley.com/doi/abs/10.1111/j.1365-2648.2007.04569.x

Falkner, T., \& Myers, B. (2012). The role of registrar programs and services: CAS Standards contextual statement. In D. I. Mitstifer (Ed.), CAS professional standards for higher education, (8 ${ }^{\text {th }}$ Ed.), (pp. 404-406). Washington, DC: Council for the Advancement of Standards in Higher Education. Most current version (10 ${ }^{\text {th }}$ Ed., print release March 2019; 2018 electronic version) available at https://www.cas.edu/store_product.asp?prodid=31

Flawn, P. T. (1990). A primer for university presidents: Managing the modern university. Austin, TX: University of Texas Press. 
Gerber, L. G. (2014). The rise and decline of faculty governance. Baltimore, MD: Johns Hopkins University Press.

Geyer, D., Schipporeit, K., Spaulding, L., \& Weber, D. (2018). Registrar's basic guide. Washington, DC: American Association of Collegiate Registrars and Admissions Officers.

Gilley, J. W. (1991). Thinking about American higher education: The 1990s and beyond. New York, NY: Macmillan Publishing Company.

Goode, W. J. (1960). A theory of role strain. American Sociological Review, 25, 483496. doi:10.2307/2092933

Hamilton, N. W. (2004). Faculty involvement in system-wide governance. In W. G. Tierney (Eds.), Competing conceptions of academic governance: Negotiating the perfect storm (pp. 77-103). Baltimore, MD: Johns Hopkins University Press.

Hindin, M. J. (2007). Role theory. In G. Ritzer (Ed.), The Blackwell encyclopedia of sociology (pp. 3959-3960). doi:10.1111/b.9781405124331.2007.x

Howard, N. (2018, August 21). Definition of curriculum management. Email (personal communication from vice president, product delivery and sales, currIQunet; www.currIQunet.com.).

Indiana University Center for Postsecondary Research. (n.d.1). About the Carnegie Classification. In: The Carnegie Classification of institutions of higher education, 2015 edition (spreadsheet).Retrieved in 2016. Retrieved from http://carnegieclassifications.iu.edu/ 
Indiana University Center for Postsecondary Research. (n.d.2). Basic classification methodology. In The Carnegie Classification of institutions of higher education 2015 edition. (n.p.) Retrieved in 2016. Retrieved from http://carnegieclassifications.iu.edu/methodology/basic.php

Indiana University Center for Postsecondary Research. (n.d.3). Carnegie basic classification description. In The Carnegie Classifications of institutions of higher education 2015 edition (n.p.) Retrieved in 2016. Retrieved from http://carnegieclassifictions.iu.edu/classification_descriptions/basic.php

Jupp, V. (2006). The SAGE dictionary of social research methods. London, England; Thousand Oaks, CA; New Delhi, India: Sage Publications. doi:http://dx.doi.org/10.4135/9780857020116

Kaplan, G. E. (2004). Do governance structures matter? In W. G. Tierney \& V. M. Lechuga (Eds.), Restructuring shared governance in higher education (pp. 2334). In M. Kramer (Series Ed.), New directions for higher education, Vol. 127. San Francisco, CA: Jossey-Bass.

Katz, D., \& Kahn, R. L. (1978). The social psychology of organizations ( ${ }^{\text {nd }}$ Ed.). New York, NY: John Wiley \& Sons, Inc.

Keller, G. (2001). Governance: The remarkable ambiguity. In P. Altbach, P. Gumport, \& D. Johnstone (Eds.), In defense of American higher education (pp. 304-322). Baltimore, MD: Johns Hopkins University Press. 
Kerr. C. (2002). Shock wave II: An introduction to the twenty-first century. In S. Brint (Ed.), The future of the city of intellect: The changing American university (pp. 123). Stanford, CA: Sanford University Press.

Kezar, A. (2004). What is more important to effective governance: Relationships, trust, and leadership or structures and formal processes? In W. G. Tierney \& V. M. Lechuga (Eds.), Restructuring shared governance in higher education (pp. 3546). In M. Kramer (Series Ed.), New directions for higher education, Vol. 127. San Francisco, CA: Jossey-Bass.

Kezar, A. (2015, January 15). Shared governance for effective campus leadership. President's \& provost's lecture series. Lecture conducted at Oregon State University, Corvallis, OR.

Kezar, A., \& Eckel, P. D. (2004). Meeting today’s governance challenges. The Journal of Higher Education, 75(4), 371-398.

https://doi.org/10.1080/00221546.2004.11772264

Kisling, R. (2016). Accreditation and assessment considerations. In AACRAO, Curriculum management and the role of the registrar (pp. 19-28). Washington, DC: AACRAO.

Lapworth, S. (2004). Arresting decline in shared governance: Towards a flexible model for academic participation. Higher Education Quarterly, 58(4), 299-314. https://doi.org/10.1111/j.1468-2273.2004.00275.x 
Laudeman, K. (2006). The registrar and curriculum development. In B. Lauren (Ed.), The registrar's guide: Evolving best practices in records and registration (pp. 19-30). Washington, DC: AACRAO.

Leavitt, H. J. (1965). Applied organizational change in industry: Structural, technological and humanistic approaches. In J. G. March (Ed.) Handbook of organizations (pp. 1144-1170). Chicago, IL: Rand McNally.

Lederman, D. (2014, October 9). Carnegie Classifications, Via Indiana. Inside Higher Ed. Retrieved from https://www.insidehighered.com/news/2014/10/09/indiana$\underline{\text { lumina-boost-take-over-carnegie-classifications }}$

Lipsky, M. (2010). Street-level bureaucracy: Dilemmas of the individual in public services. New York, NY: Russell Sage Foundation.

Lyall, K. C. (2001). Recent changes in the structure and governance of American research universities. In W. Z. Hirsch \& L. E. Weber (Eds.), Governance in higher education: The university in a state of flux (pp. 17-25). London, UK: Economica, Ltd.

Marks, S. R. (1977). Multiple roles and role strain: Some notes on human energy, time, and commitment. American Sociological Review, 42, 921-936. doi:10.2307/2094577

Mathern, R. (2016). Defining the role of the registrar in curriculum management. In W. Kilgore (Ed.), Curriculum management and the role of the registrar (pp. 2-7). Washington, DC: AACRAO. 
Mathern, R., \& Pomerenk, J. (2016). The importance of relationships and how to build them. In W. Kilgore (Ed.), Curriculum management and the role of the registrar (pp. 9-17). Washington, DC: AACRAO.

Merton, R. K. (1957). The role-set: Problems in sociological theory. British Journal of Sociology, 8, 106-120. PDF Stable URL: http://links.jstor.org/sici?sici=00071315\%28195706\%298\%3A2\%3C106\%3ATRPIST\%3E2.0.CO\%3B2-7

Mintzberg, H. (1993 [1983]). Structure in fives: Designing effective organizations. Upper Saddle River, NJ: Prentice Hall, Inc.

Morse, J. M. (1991, March/April) Approaches to qualitative-quantitative methodological triangulation._Nursing Research. 40(2), 120-123. Available at. https://journals.lww.com/nursingresearchonline/Citation/1991/03000/Approaches to_Qualitative_Quantitative.14.aspx

Northwest Commission on Colleges and Universities (NWCCU). (n.d.) Standard TwoResources and capacity. In Standards for accreditation (pp. 2-13). Retrieved in 2018. Retrieved from http://www.nwccu.org/wpcontent/uploads/2016/12/Standards-for-Accreditation.pdf

Olson, G. A. (2009, July 23). Exactly what is "shared governance”? The Chronicle of Higher Education, 55(42), pp. A33-A35. Retrieved from https://www.chronicle.com/article/Exactly-What-Is-Shared/47065

Oregon University System. (n.d.). Veterans' benefits. Retrieved on January 20, 2014. Retrieved from 
https://web.archive.org/web/20150314231839/http:/ous.edu/studentscounselors/prospective-students/college-costs

Pope, M. L. (2004). A conceptual framework of faculty trust and participation in governance. In W. G. Tierney \& V. M. Lechuga, (Eds.), Restructuring shared governance in higher education (pp. 75-84). In M. Kramer (Series Ed.), New directions for higher education, Vol. 127. San Francisco, CA: Jossey-Bass.

National Association of Independent Colleges and Universities (NAICU). (n.d.) About private colleges. Retrieved in 2018. Retrieved from https://www.naicu.edu/research-resources/private-colleges-factfile

Rainey, H. G. (2009). Understanding and managing public organizations, San Francisco, CA: Jossey-Bass.

Ramsey, F. L. 2002. The statistical sleuth : A course in methods of data analysis. $2^{\text {nd }}$ Ed. by Fred L. Ramsey with Daniel W. Schafer. Australia ; Pacific Grove, CA : Duxbury/Thomson Learning.

R Core Team. (1999-2012). R: A language and environment for statistical computing [Reference Index, version 3.5.1, July 2, 2018]. Vienna, Austria: The R Foundation for Statistical Computing. Stable URL: https://cran.r-project.org/doc/manuals/r$\underline{\text { release/fullrefman.pdf }}$

R Core Team-Comprehensive R Archive Network (RCT-CRAN). (2017). $R$ [Software version 3.4.3.]. Vienna, Austria: The R Foundation for Statistical Computing. Retrieved (201x) from https://ftp.osuosl.org/pub/cran/ 
Reich, R. (1991). The work of nations: Preparing ourselves for 21st century capitalism. New York, NY: Random House.

Reich, R. (2005, December 8). The new rich-rich gap. Newsweek (n.p.) (2006 Special Ed.). Stable URL: http://www3.cis.gsu.edu/dtruex/courses/IB8710/Articles/ReichNew-Rich-Rich-Gap-Newsweek-Issues-2006.pdf

Scott, W. R. (2001). Institutions and organizations. Thousand Oaks, CA: Sage Publications.

Scott, W. R. (2003). Organizations: Rational, natural and open systems. Englewood Cliffs, NJ: Prentice Hall.

Simon, H. A. (1991). Organizations and markets. Journal of Economic Perspectives, 5(2), 25-44. https://www.jstor.org/stable/1942684

Simon, J. L., \& Burstein, P. (1985). Basic research methods in social science ( ${ }^{\text {rd }}$ Ed.). New York, NY: Random House, Inc.

Singleton, R., \& Straits, B. C. (1999). Approaches to social research ( ${ }^{\text {rd }}$ Ed.). Oxford: Oxford University Press.

Smith, D. O. (2015). Understanding authority in higher education. Lanham, MD: Rowman \& Littlefield.

Snoek, J. D. (1966). Role strain in diversified role sets. American Journal of Sociology, 71(4), 363-372. https://doi.org/10.1086/224125

Stephan, F., \& McCarthy, P. J. (1958). Sampling opinions: An analysis of survey procedure. New York, NY: John Wiley \& Sons, Inc. 
Tierney, W. G. (1988). Organizational culture in higher education. Journal of Higher Education, 59(1), 2-21. doi:10.2307/1981868

Tierney, W. G. (2000). Critical leadership and decision making in a postmodern world. In C. Brown (Ed.), Organization and governance in higher education, (5 ${ }^{\text {th }}$ Ed.). Boston, MA: Pearson Custom.

Tierney, W. G., \& Lechuga, V. M. (Eds.). (2004.) Restructuring shared governance in higher education. In M. Kramer (Series Ed.), New directions for higher education, Vol. 127. San Francisco, CA: Jossey-Bass .

Tierney, W. G., \& Minor, J. T. (2004). A cultural perspective on communication and governance. In W. G. Tierney \& V. M. Lechuga (Eds.), Restructuring shared governance in higher education (pp. 85-94). In M. Kramer (Series Ed.), New directions for higher education, Vol. 127. San Francisco, CA: Jossey-Bass.

Trombley, E. (2018). Academic policy, student academic records, transcripts, and grading processes. In J. Ferguson, M.-J. Caro, \& T. Drueke, (Eds.), AACRAO’s professional development guidelines for registrars: A self-assessment (pp. 83122). Washington, DC: AACRAO.

University of Minnesota. (n.d.). University Senate constitution. Retrieved from https://drive.google.com/file/d/0BwYKgI1XNObyT19veWFtV1VJMjQ/view through University Senate constitution, bylaws, and rules at http://usenate.umn.edu/university-senate/university-senate-constitution-bylawsand-rules 
University of Virginia. (n.d.). Faculty Senate, constitution and by-laws. Retrieved from http://facultysenate.virginia.edu/content/about

Vaismoradi, M., Turunen, H., \& Bondas, T. (2013). Content analysis and thematic analysis: Implications for conducting a qualitative descriptive study. Nursing and Health Sciences, 15, 398-405. https://doi.org/10.1111/nhs.12048

Zusman, A. (2005). Issues facing higher education in the Twenty-first Century. In P. G. Altbach, R. O. Berdahl, \& P. J. Gumport, (Eds.). American higher education in the twenty-first century: Social, political, and economic challenges, (2nd Ed.) (pp. 109-148). Baltimore, MD: The Johns Hopkins University Press. 


\section{The Role of the Registrar in Curriculum Management and Shared Governance}

\section{Start of Block: Study Consent}

Q1 Title of Research Study: The Role of the Registrar in Curriculum Management and Shared Governance

This study is being conducted by: Rebecca Mathern, a doctoral candidate in the Portland State University Hatfield School of Government, under the direction of faculty advisor, Dr. Craig Shinn.

Why am I being asked to take part in this research study? You have been identified as either a registrar or faculty leader involved in curriculum at your institution. Your institution is part of the survey population (large, research institution as categorized by the Carnegie Classification).

Please read the following document and ask any questions before you participate in the study.

What is the purpose of the study? The purpose of this study is to determine if registrars' involvement in curriculum logistics and curriculum management have a positive impact on student success while accounting for shared governance model at the institution.

What is the time commitment and timeline of the study? The study includes four short sections of survey questions with several open-ended questions for you to provide responses and comments. This survey will take approximately 15 minutes and will be administered online via Qualtrics. The survey will open in February 2018 and it is anticipated the survey will close in March 2018.

How do I qualify to participate? In order to participate in the study, you must verify you satisfy the following criteria: Are a Registrar or faculty leader in curriculum work at a four-year institution Work at a large (more than 10,000), doctoral degree granting university (at least 20+ degrees awarded yearly) with research activity (highest, higher or moderate research activity). All defined by the Carnegie Classifications in 2015.

Do I have to take part in the study? Your participation is entirely voluntary, and you may change your mind or quit participating at any time, with no penalty; however, your 
assistance would be greatly appreciated in making this a meaningful study. Should you choose to participate, we would appreciate your participation in all questions to provide the most accurate and comprehensive data for the study.

What will I be asked to do? If you agree to participate, we would ask that you be a part of this brief survey to express your opinions and ideas concerning the registrar's role in curriculum management and logistics. You will be asked to respond to statements using a Likert scale for levels of agreement as well as some Yes/No, close ended questions. You will also have the opportunity to include comments and perceptions about the topic. All possible respondents will have the opportunity to see the outcome of the survey.

Who will have access to the information I provide? Only the researcher and faculty advisor will have access to the responses. All responses from the survey instrument will be kept strictly confidential even though no names are collected during the data collection or reporting process. All research records will be accessed via a password protected storage device and the researcher's access to the survey instrument is also password protected. Records will be retained for at least three years beyond the conclusion of the study, per IRB requirement.

What are the potential risks? The primary risk of the study is possible breach of confidentiality, as, through the participants' names will not be collected, there is a possibility that the statements by the participants could be associated back to them due to the limited nature of the population. It is not possible to identify all potential risks in research procedures, but all reasonable precautions to minimize any known risks have been performed. No monetary compensation is provided for participation.

Who do I contact if I have questions or concerns? If you have any questions about this study, please contact me at 503.754.4778 or rebecca.mathern@oregonstate.edu or contact my faculty advisor, Dr. Craig Shinn at 503.725.8220 or shinnc@pdx.edu.

What are my rights as a research participant? You have rights as participant in research. If you have questions about the rights of human participants in research, or to report a problem, you may contact the PSU IRB (Human Subjects Research Review Committee) at 503.725.2227 or via email at hsrrc@pdx.edu.

Waiver of Written Consent. After reading the above, by clicking to continue this survey, you are verifying that you have read the above information, meet the qualification criteria, and consent to participate in this study.

I consent to participate. (1) 
Q2 All regionally accredited academic institutions have some type of shared governance model by which they operate. This is required because regional accrediting bodies require some form of faculty participation in, at a minimum, curriculum development. The following descriptions of shared governance models are summarized from a presentation offered by Adriana Kezar, professor for Higher Education at the University of Southern California. Please select the mode that best describes the shared governance at your institution.

Consultative- Faculty do not make decisions rather make recommendations to other bodies, actors who make the decisions. (1)

Distributed decision making- Faculty make binding decisions about specific academic issues such as admissions requirements, graduation requirements, and academic program requirements.

Fully collaborative- In addition to making decisions about academic issues, faculty also participate in making binding decisions about non-academic topics such as budget, human resources policies, or other administrative functions not aligned with direct academic outcomes. (3) 
Q3 To what extent does the Registrar participate in decisions about the following academic policies?

Not at all

(1)

Setting up repeat rules for new or modified courses when they go through the academic approval process. (1)

Changing course designators/subject codes. (2)

Determining academic residency requirements required for a degree (not within the specific program requirements). (3)

Determining the minimum GPA required for $a$ degree (not within the specific program requirements). (4)

Determining general education requirements required for $a$ degree (not within the specific program requirements). (5)

Determining total credit hours required for a degree (not within the specific
Rarely (2) Sometimes

(3)

Often (4) Always (5) 
program

requirements). (6)

Academic policies that impact how academic history is recorded on the student academic transcript. (7)

Q4 Please select the response that best fits your institutional policy.

Does the institution have limitations on the number of credits/courses in an academic program that can be taken as 'generic courses' such as research credit hours, independent studies, special topics, et. al.?

Yes (1)

No (2)

Unsure (3)

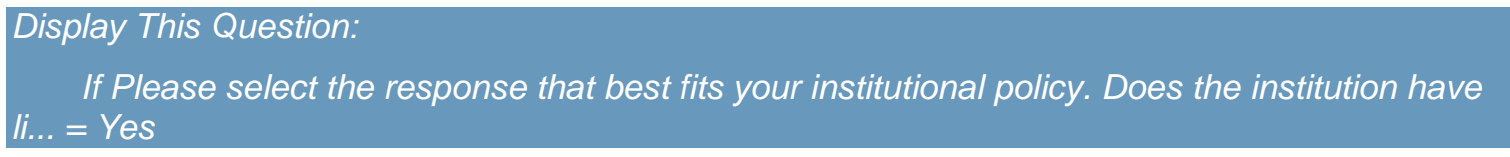

Q5 What role does the Registrar play in the process? Please explain the level of helpfulness that comes from the role of the Registrar in the process. 


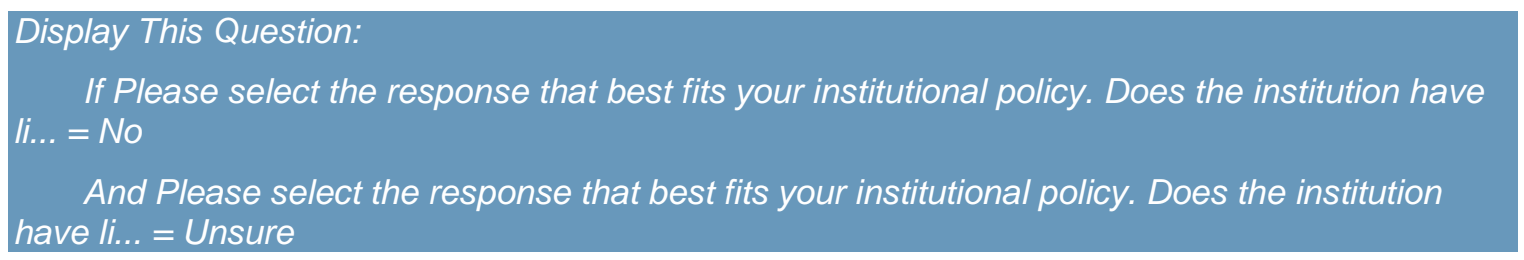

Q6 Describe how you think the Registrar could be involved in the process.

Q7 Does the institution have a policy about how to define course equivalencies (two courses at the institution offering credit for the exact same outcomes) when modifying or creating a course?

\section{Yes (1)}

No (2)

Unsure (3)

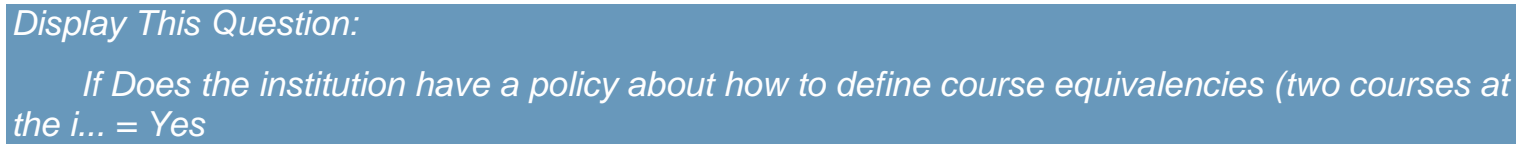

Q8 What role does the registrar play in the process? Please explain the level of helpfulness that comes from the role of the Registrar in the process. 


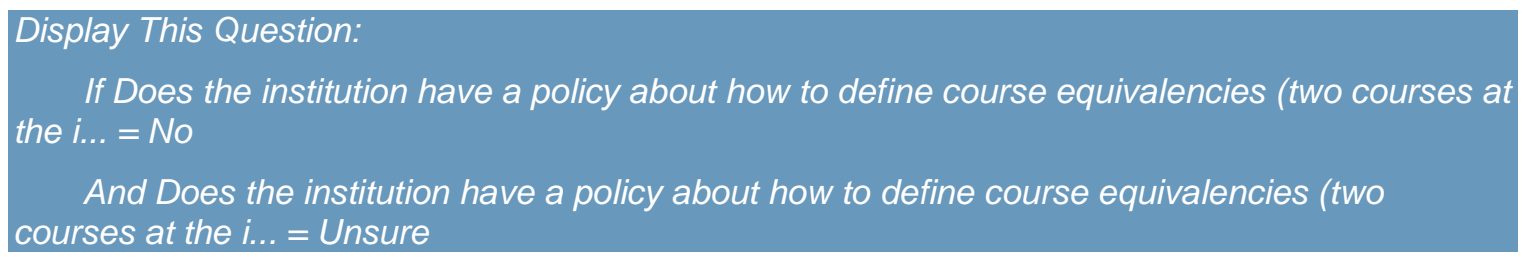

Q9 Describe how you think the registrar could be involved in the process.

Q10 Does the institution have a policy about withdrawing from the university and any limitations this places on students?

Yes (1)

No (2)

Unsure (3)

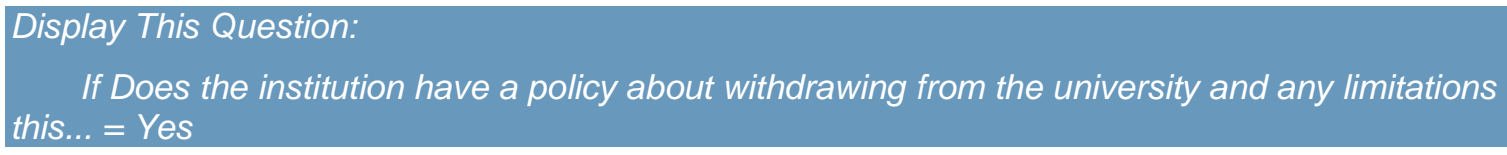


Q11 What role does the Registrar play in the process? Please explain the level of helpfulness that comes from the role of the Registrar in the process.

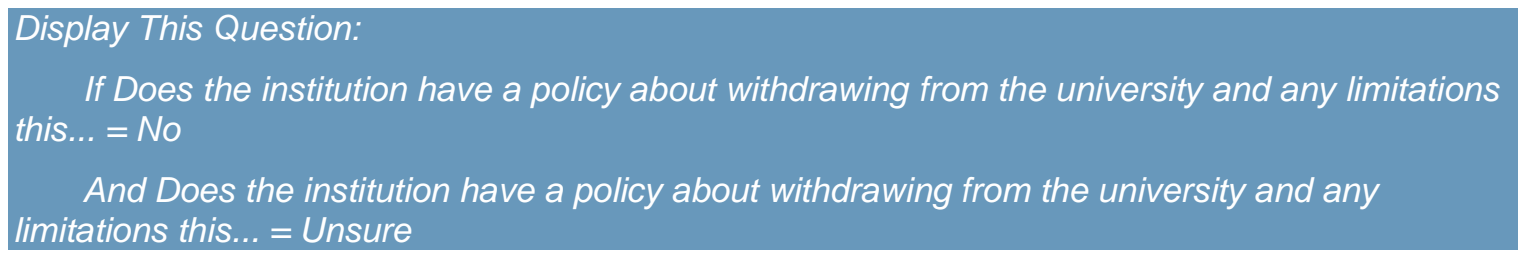

Q12 Describe how you think the Registrar could be involved in the process. 
Q13 Does the institution have a policy about academic standing to ensure students are progressing toward the degree they are seeking? Note: this is not related to financial aid requirements for satisfactory academic progress; it is related to academic standing such as probation, warning, suspension, et. al.

\section{Yes (1)}

No (2)

Unsure (3)

\section{Display This Question: \\ If Does the institution have a policy about academic standing to ensure students are progressing tow... = Yes}

Q14 What role does the Registrar play in the process? Please explain the level of helpfulness that comes from the role of the Registrar in the process.

\section{Display This Question: \\ If Does the institution have a policy about academic standing to ensure students are progressing tow... = No \\ And Does the institution have a policy about academic standing to ensure students are progressing tow... = Unsure}

Q15 Describe how you think the Registrar could be involved in the process. 
End of Block: Shared Governance

Start of Block: Perceptions about impact 
Q16 The following series of statements are to measure any perceived impact on students from curriculum management and academic policy decisions. Please select the response that corresponds with your understanding of the reality at your institution.

Strongly

Disagree

(1)
Disagree

(2)
Unsure (3) Agree (4)
Strongly

Agree (5)

A student, or group

of students, was

negatively impacted

in their progress

toward graduation

because

repeatability rules

had been set up in

such a way for a

course that a student

could take the same

course more than

once for credit but

were only able to

count one attempt

toward graduation

requirements. (1)

A student, or group

of students, was

negatively impacted

in their progress

toward graduation

because an

academic unit

changed course

designators/subject

codes on their

courses, students

were uninformed and

took the same

course more than

once unknowingly

because of the new

designator/title only

to learn later of the

mistake. (2)

A student, or group

of students, was 
negatively impacted in their progress toward graduation because academic programs offer a series of courses as generic offerings (ie special topics, experimental courses) in lieu of sending the courses through a curriculum approval process and therefore limiting the number of those credits that can count toward a student's degree. (3)

A student, or group of students, was negatively impacted in their progress toward graduation because the course equivalencies set up when a course was modified through the curriculum approval process resulted in the student being required to take a similar course again or risk missing a small amount of course material because of partial curriculum overlap. (4)

A student, or group of students, was negatively impacted in their progress toward graduation because policy creation or 
modifications (such as university withdrawal rules or academic standing policies) negatively impacted students because of changes that occurred to those policies.

Examples may include limiting the number of university withdrawals or adding restrictions to academic standing and how it may impact whether or not a student is in good standing or warning, probation or suspension. (5)

Students have difficulty graduating because they do not understand what requirements are expected of them. (6)

Students need to see academic advisors for questions about academic policies because the policies are not clear. (7)

Students have problems with interpreting degree requirements through the use of a degree audit tool. (8) 
Q17 Does the Registrar's involvement in curriculum management and academic policy impact students? Please explain your answer.

\section{End of Block: Perceptions about impact}

\section{Start of Block: Respondents' basic demographics}

Q18 The following questions are to collect some brief demographic information about the each survey respondent.

Q19 What is the highest degree you attained?

Baccalaureate (1)

Masters (2)

Doctoral (3) 
Q20 Select the appropriate range for the number of years in the education field.
$0-5(1)$
$6-10(2)$
$11-20(3)$
21-30 (4)
$30+(5)$

Q21 What is your main role at your institution?

Registrar (1)

Faculty (who plays a role in curriculum approvals or academic policy) (2)

Q22 Does your institution offer tenure for your role?

Yes (1)

No (2)

\section{Display This Question:}

If Does your institution offer tenure for your role? = Yes

Q23 Do you have tenure?

Yes (1)

No (2) 


\section{Display This Question:}

\section{If What is your main role at your institution? = Registrar}

Q24 Please describe how, if any, of your authority (such as tenure, degree earned, and number of years in the field, or any other impacting factor) gives you agency toward the impact on the policies and Registrar involvement mentioned in previous sections of this survey.

\section{Display This Question: \\ If Title of Research Study: The Role of the Registrar in Curriculum Management and Shared Governance... =}

Q25 Thank you for considering this survey. 
Appendix B: Fisher's Exact Test Results: Analysis of Survey on Shared

Governance and Curriculum Management

\section{Preliminaries}

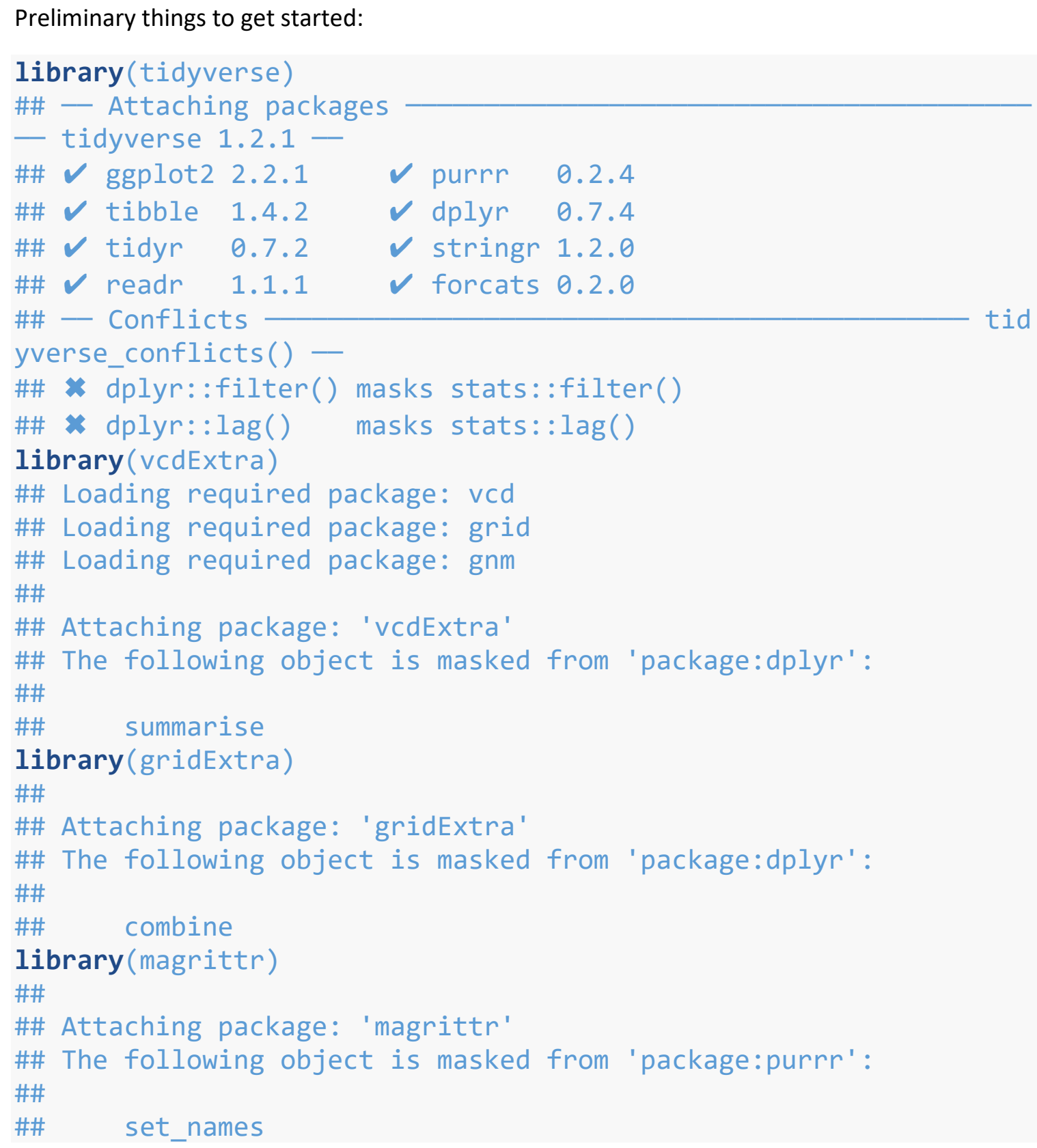




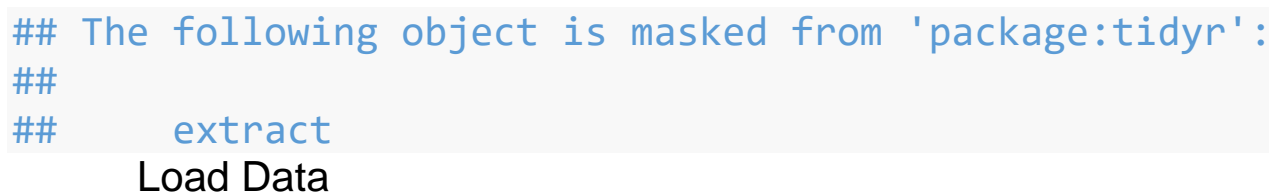

Load the data into $R$ and take a look at a few things:

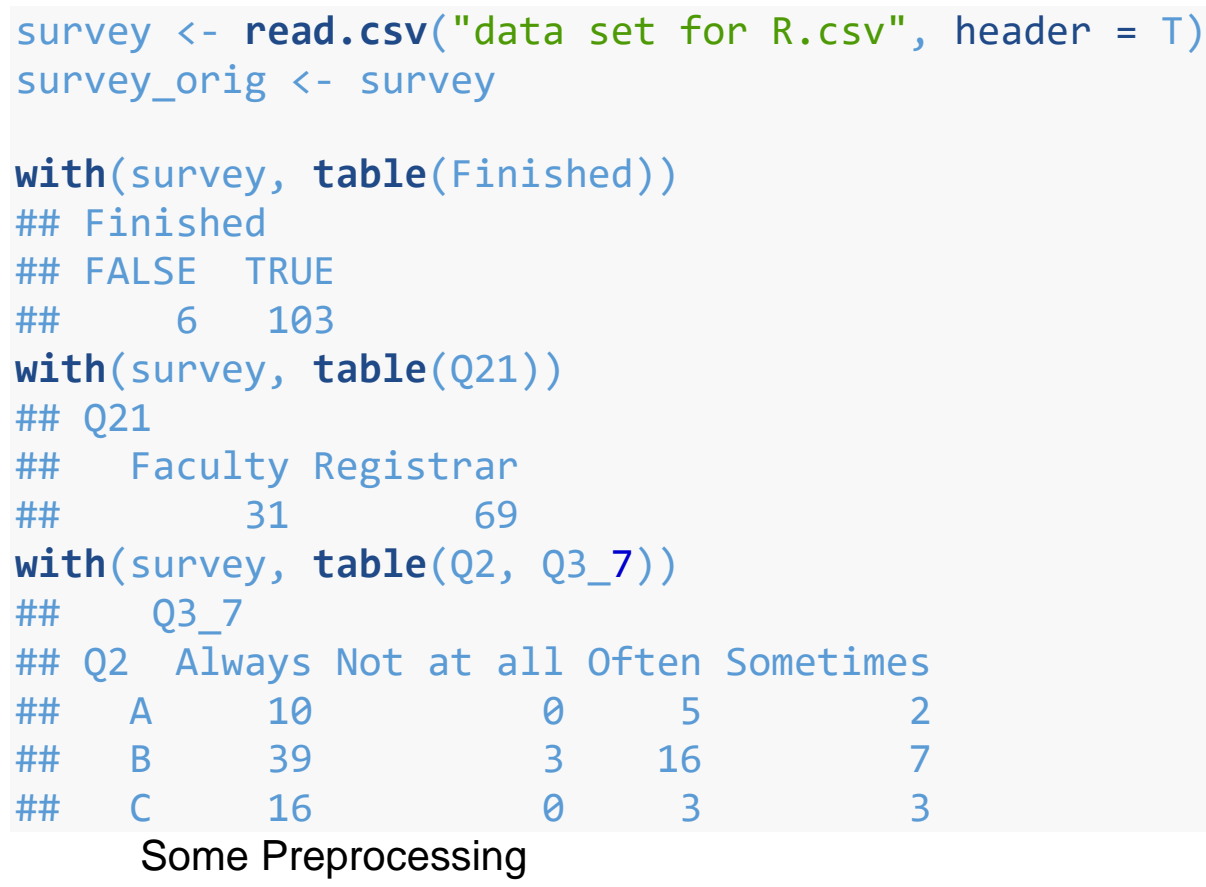

1. R sorts the answers to survey questions alphabetically rather than in Likert scale order, so the following chunk of code reorganizes the survey data.frame to reflect the Likert scale orderings of questions Q3-1 through Q3-7 and Q16-1 through Q16-8.

survey\$Q3_1 <- factor(survey\$Q3_1, levels = c("Always", "Often", "Sometimes", "Rarely", "Not at all"))

survey\$Q3_2 <- factor(survey\$Q3_2, levels = c("Always", "Often", "Sometimes", "Rarely", "Not at all"))

survey\$Q3_3<- factor(survey\$Q3_3, levels = c("Always", "Often", "Sometimes", "Rarely", "Not at all"))

survey\$Q3_4<- factor(survey\$Q3_4, levels = c("Always", "Often", "Sometimes", "Rarely", "Not at all"))

survey\$Q3_5<- factor (survey\$Q3_5, levels = c("Always", "Often", "Sometimes", "Rarely", "Not at all"))

survey\$Q3_6 <- factor(survey\$Q3_6, levels = c("Always", "Often", "Sometimes", "Rarely", "Not at all"))

survey\$Q3_7<- factor(survey\$Q3_7, levels = c("Always", "Often", 
"Sometimes", "Rarely", "Not at all"))

survey\$Q16_1 <- factor(survey\$Q16_1, levels = c("Strongly Agree", "Agree", "Unsure", "Disagree", "Strongly Disagree"))

survey\$Q16_2 <- factor(survey\$Q16_2, levels = c("Strongly Agree", "Agree", "Unsure", "Disagree", "Strongly Disagree")) survey\$Q16_3 <- factor (survey\$Q16_3, levels = c("Strongly Agree", "Agree", "Unsure", "Disagree", "Strongly Disagree"))

survey\$Q16_4 <- factor (survey\$Q16_4, levels = c("Strongly Agree", "Agree", "Unsure", "Disagree", "Strongly Disagree")) survey\$Q16_5 <- factor (survey\$Q16_5, levels = c("Strongly Agree", "Agree", "Unsure", "Disagree", "Strongly Disagree"))

survey\$Q16_6 <- factor(survey\$Q16_6, levels = c("Strongly Agree", "Agree", "Unsure", "Disagree", "Strongly Disagree")) survey\$Q16_7 <- factor(survey\$Q16_7, levels = c("Strongly Agree", "Agree", "Unsure", "Disagree", "Strongly Disagree"))

survey\$Q16_8 <- factor(survey\$Q16_8, levels = c("Strongly Agree", "Agree", "Unsure", "Disagree", "Strongly Disagree"))

2. We want to perform $\chi$-squared tests, but the tables are really sparse, so I suggested collapsing over different response categories:

** For the answers to the Q3 set of questions, we'll collapse Always, Often and Sometimes into Yes and Rarely and Not at all into No.

** For the answers to the Q16 set of questions, we'll collapse Strongly Agree and Agree into Agree; Disagree and Strongly Disagree into Disagree and leave Unsure.

\#\# Q3 set of questions

survey\$Q3_1 <- with(survey, fct_collapse(Q3_1, Yes = c("Always", "Often", "Sometimes"), No = c("Rarely", "Not at all"))) survey\$Q3_2<- with(survey, fct_collapse(Q3_2, Yes = c("Always", "Often", "Sometimes"),

$$
\text { No = c("Rarely", "Not at all"))) }
$$

survey\$Q3_3 <- with(survey, fct_collapse(Q3_3, Yes = c("Always", "Often", "Sometimes"),

$$
\text { No }=\mathbf{c}(\text { "Rarely", "Not at all"))) }
$$

survey\$Q3_4 <- with(survey, fct_collapse(Q3_4, Yes = c("Always", "Often", "Sometimes"),

$$
\text { No = c("Rarely", "Not at all"))) }
$$

survey\$Q3_5 <- with(survey, fct_collapse(Q3_5, Yes = c("Always", "Often", "Sometimes"),

No $=\mathbf{c}($ "Rarely", "Not at all")))

survey $\$ Q 3 \_6<-$ with $\left(\right.$ survey, fct_collapse $\left(Q 3 \_6\right.$, Yes = c("Always", 
"Often", "Sometimes"),

$$
\text { No }=\mathbf{c}(\text { "Rarely", "Not at all"))) }
$$

survey $\$$ Q3_7 <- with(survey, fct_collapse(Q3_7, Yes = c("Always", "Often", "Sometimes"),

$$
\text { No = c("Rarely", "Not at all"))) }
$$

\#\# Q16 set of questions

survey\$Q16_1 <- with(survey, fct_collapse(Q16_1, Agree = c("Agree ", "Strongly Agree"),

ly Disagree"),

$$
\text { Disagree }=\mathbf{c}(\text { "Disagree", "Strong }
$$

Unsure $=$ "Unsure"))

survey\$Q16_2 <- with(survey, fct_collapse(Q16_2, Agree = c("Agree ", "Strongly Agree"),

ly Disagree"),

Disagree $=\mathbf{c}($ "Disagree", "Strong Unsure = "Unsure"))

survey\$Q16_3 <- with(survey, fct_collapse(Q16_3, Agree = c("Agree ", "Strongly Agree"),

ly Disagree"),

Disagree $=\mathbf{c}($ "Disagree", "Strong Unsure = "Unsure"))

survey\$Q16_4 <- with(survey, fct_collapse $($ Q16_4, Agree $=\mathbf{c}($ "Agree ", "Strongly Agree"),

ly Disagree"),

Disagree $=\mathbf{c}($ "Disagree", "Strong Unsure $=$ "Unsure"))

survey\$Q16_5 <- with(survey, fct_collapse(Q16_5, Agree = c("Agree ", "Strongly Agree"),

ly Disagree"),

Disagree = c("Disagree", "Strong Unsure = "Unsure"))

survey\$Q16_6 <- with(survey, fct_collapse(Q16_6, Agree = c("Agree ", "Strongly Agree"),

ly Disagree"),

Disagree $=\mathbf{c}($ "Disagree", "Strong Unsure = "Unsure"))

survey\$Q16_7 <- with(survey, fct_collapse(Q16_7, Agree = c("Agree ", "Strongly Agree"),

ly Disagree"),

Disagree $=\mathbf{c}($ "Disagree", "Strong Unsure $=$ "Unsure"))

survey $\$ 016 \_8<-$ with $\left(\right.$ survey, fct_collapse $\left(016 \_8\right.$, Agree $=\mathbf{c}($ "Agree 
", "Strongly Agree"),

ly Disagree"),

$$
\text { Disagree }=\mathbf{c}(\text { "Disagree", "Strong }
$$

$$
\text { Unsure = "Unsure")) }
$$

3. Now, we want to create three separate data.frames, one for each of the three insitution types, A, B, C:

surveyA $<-$ subset (survey, $Q 2==" A "$ )

surveyB <- subset (survey, Q2 == "B")

surveyC <- subset (survey, Q2 == "C")

Note: there now appear to be three answers to Q3 that are NA...need to cross-check this with the original data.

\section{Data Analysis}

First, I built a function that takes as input a data.frame, cross-tabulates all of the Q3 questions with all of the Q16 questions and outputs a p-value from a Fisher's exact test.

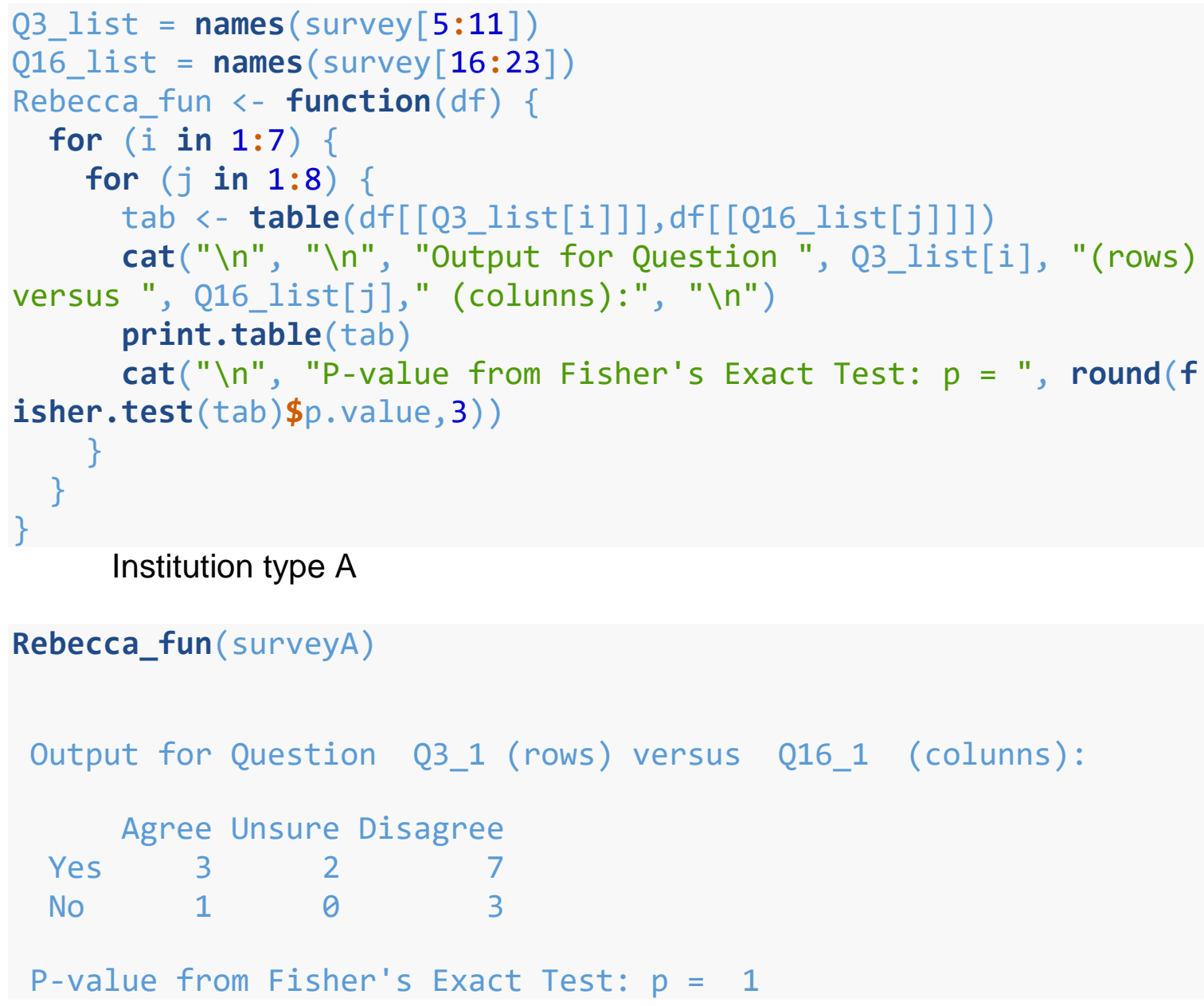




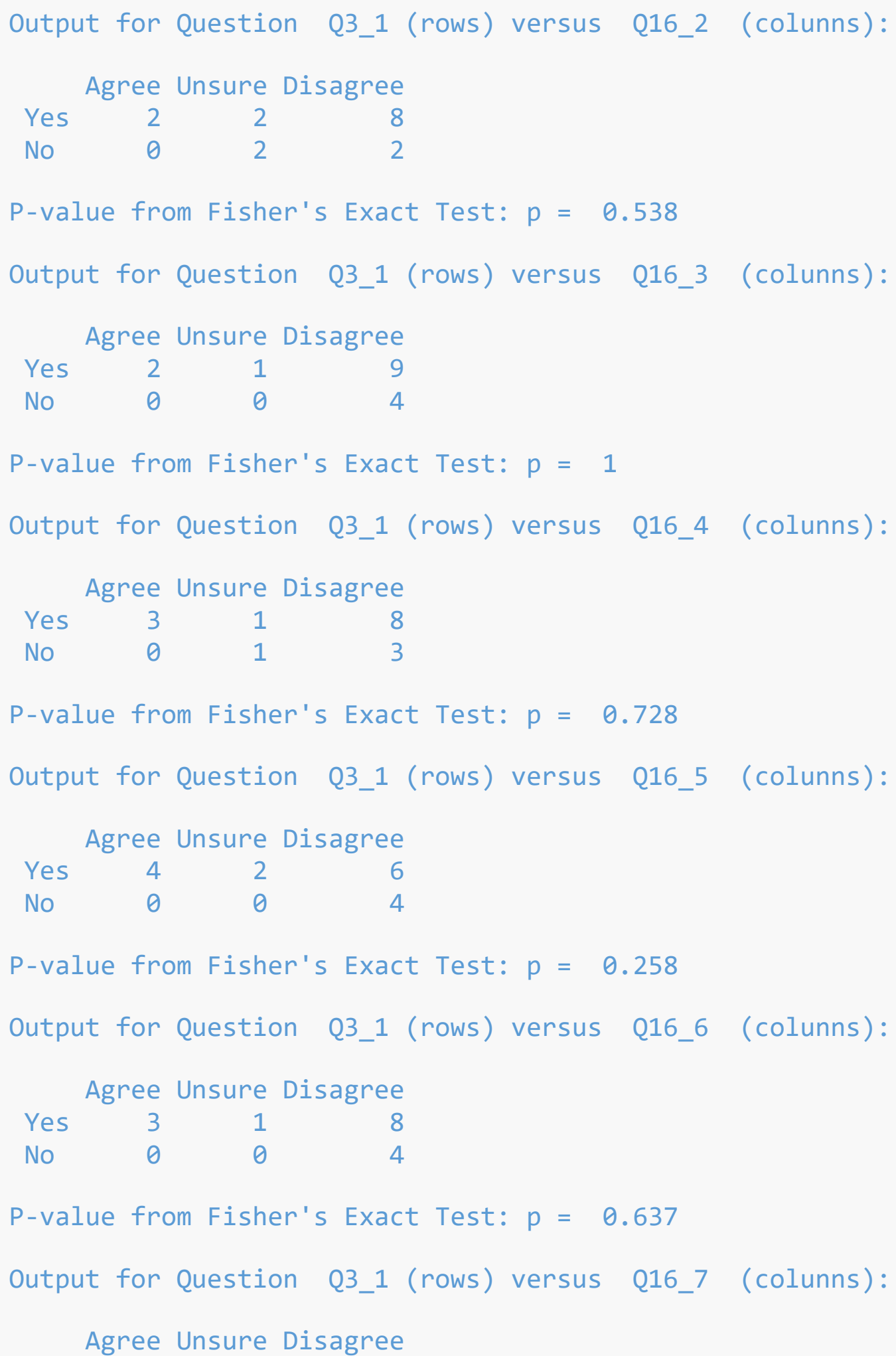




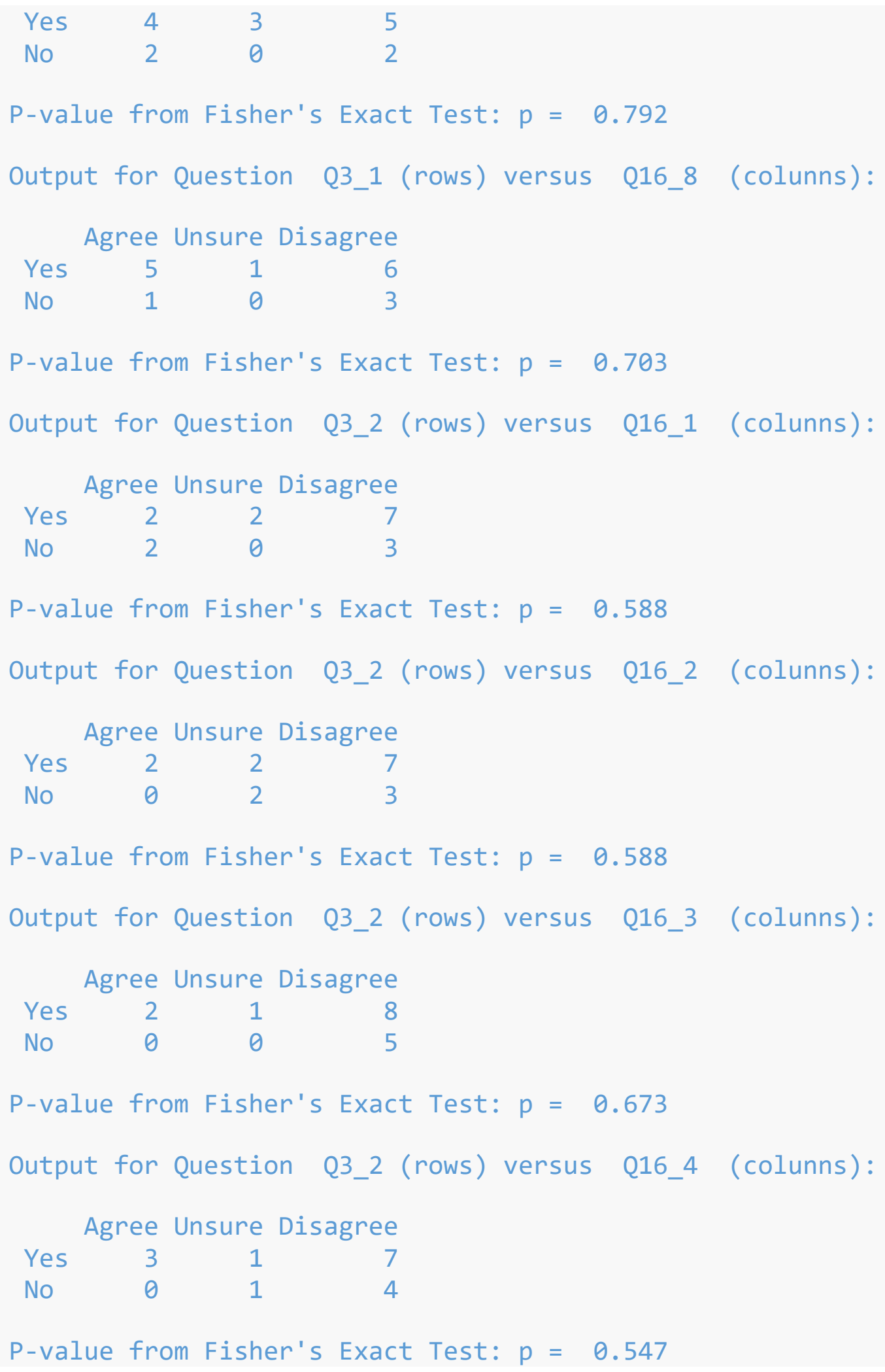




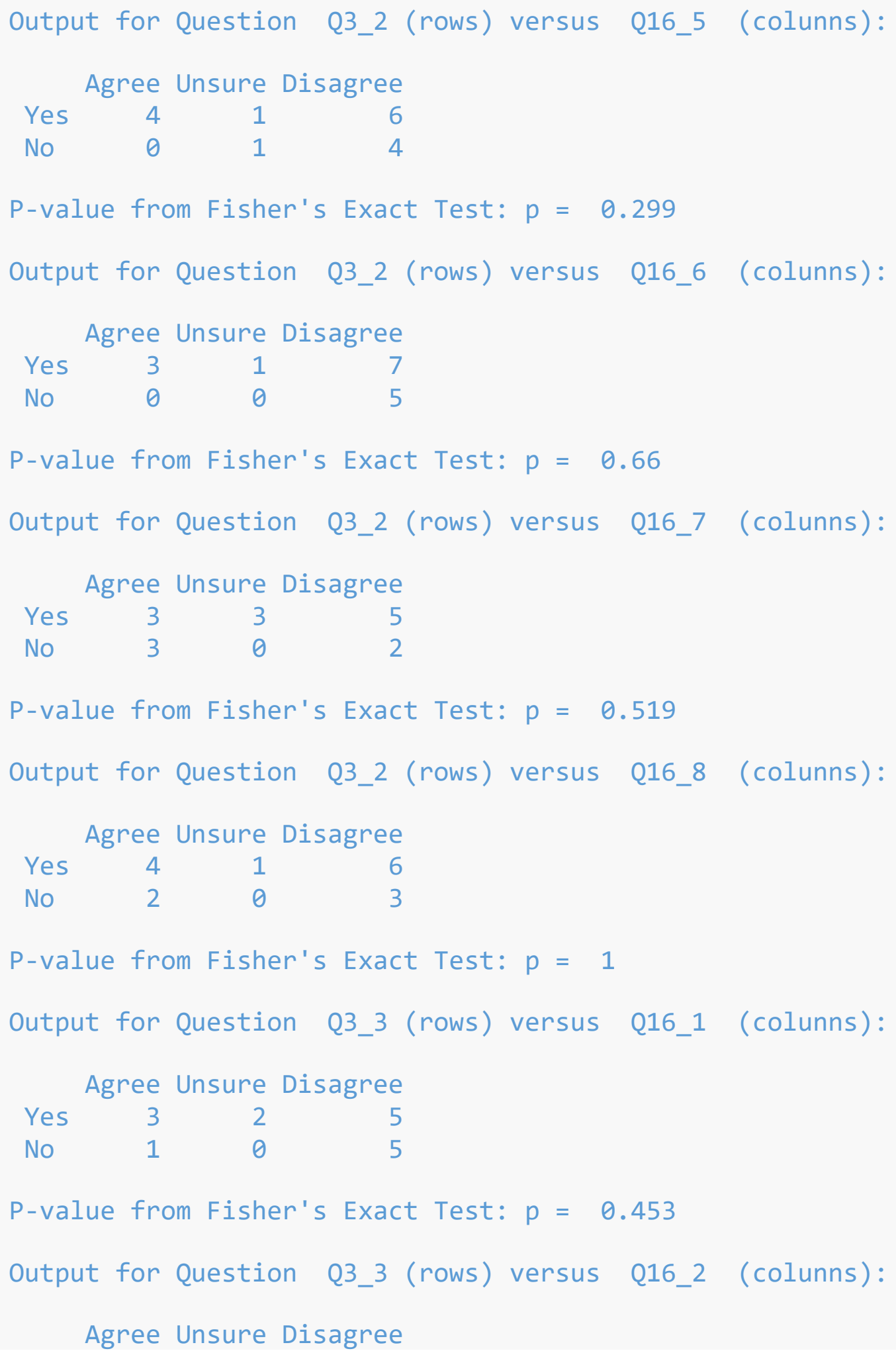




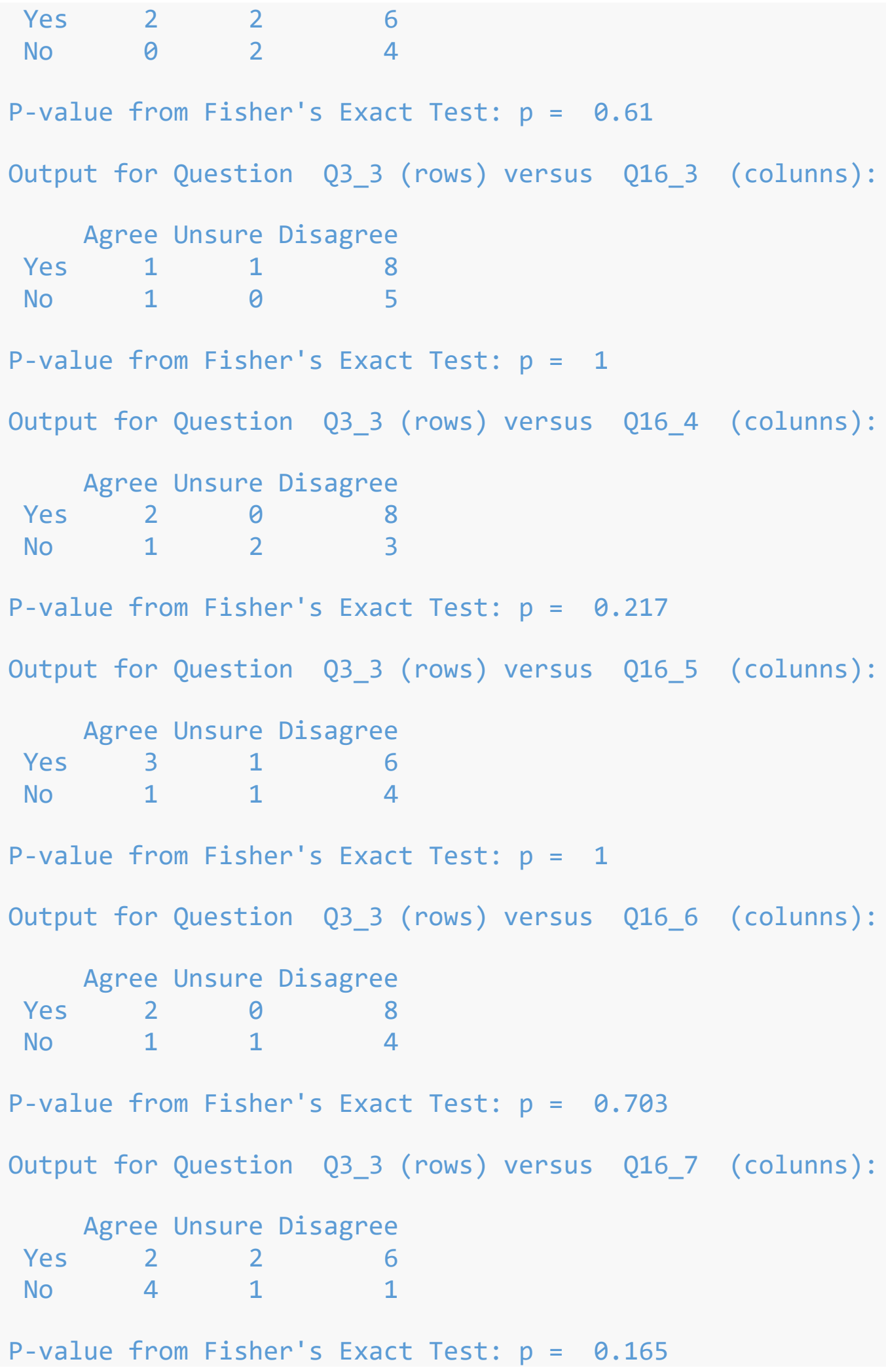




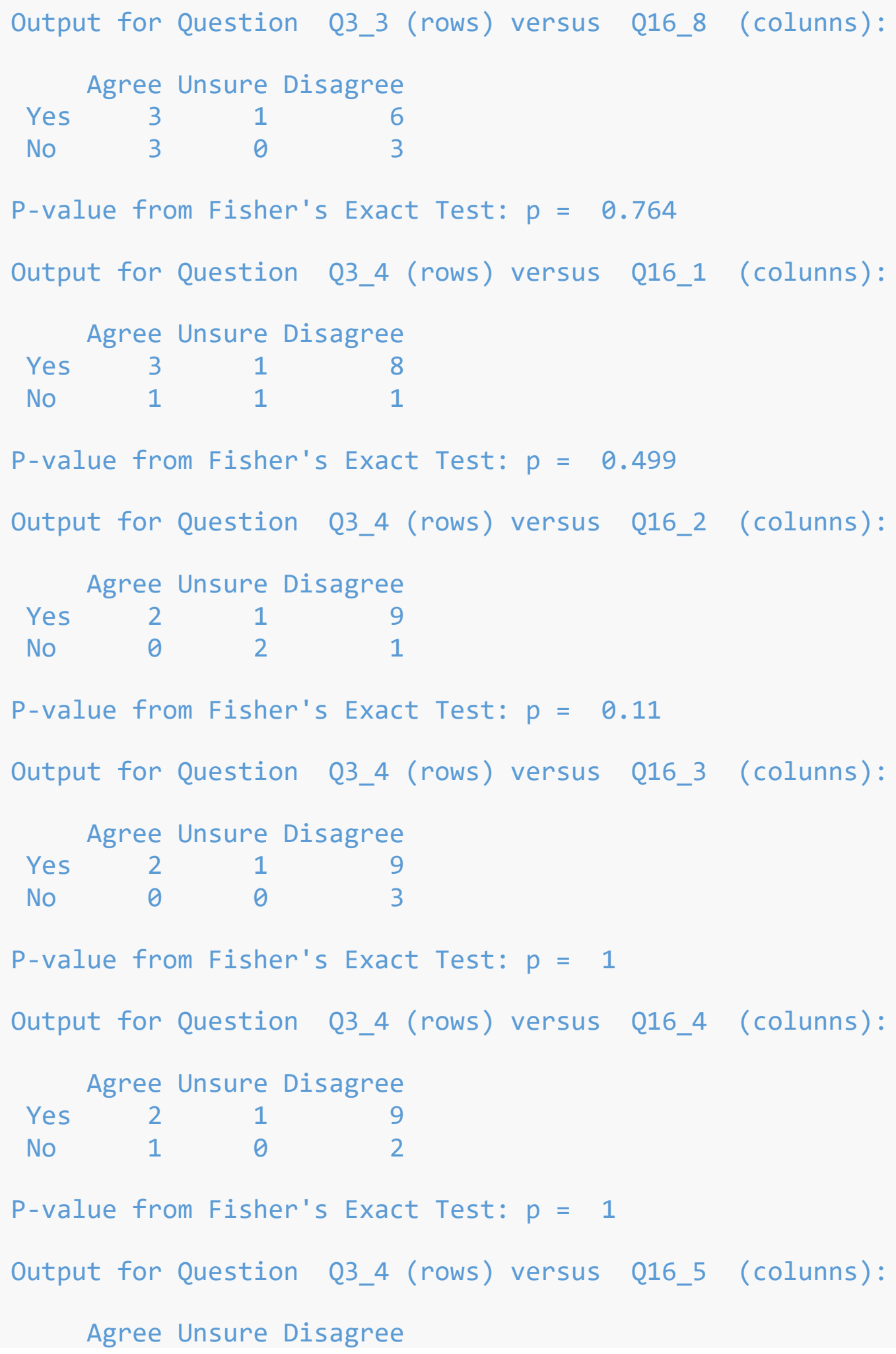




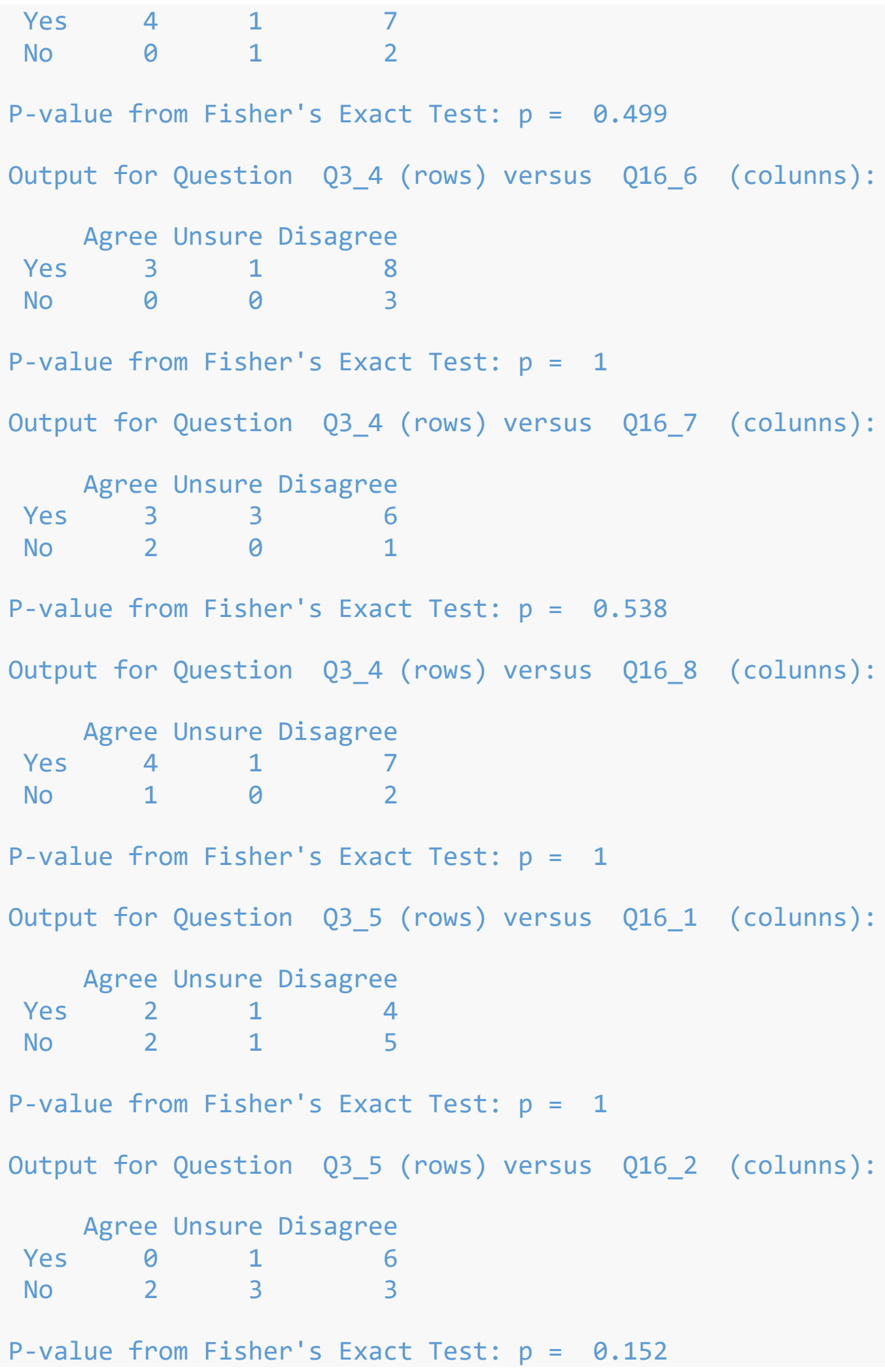




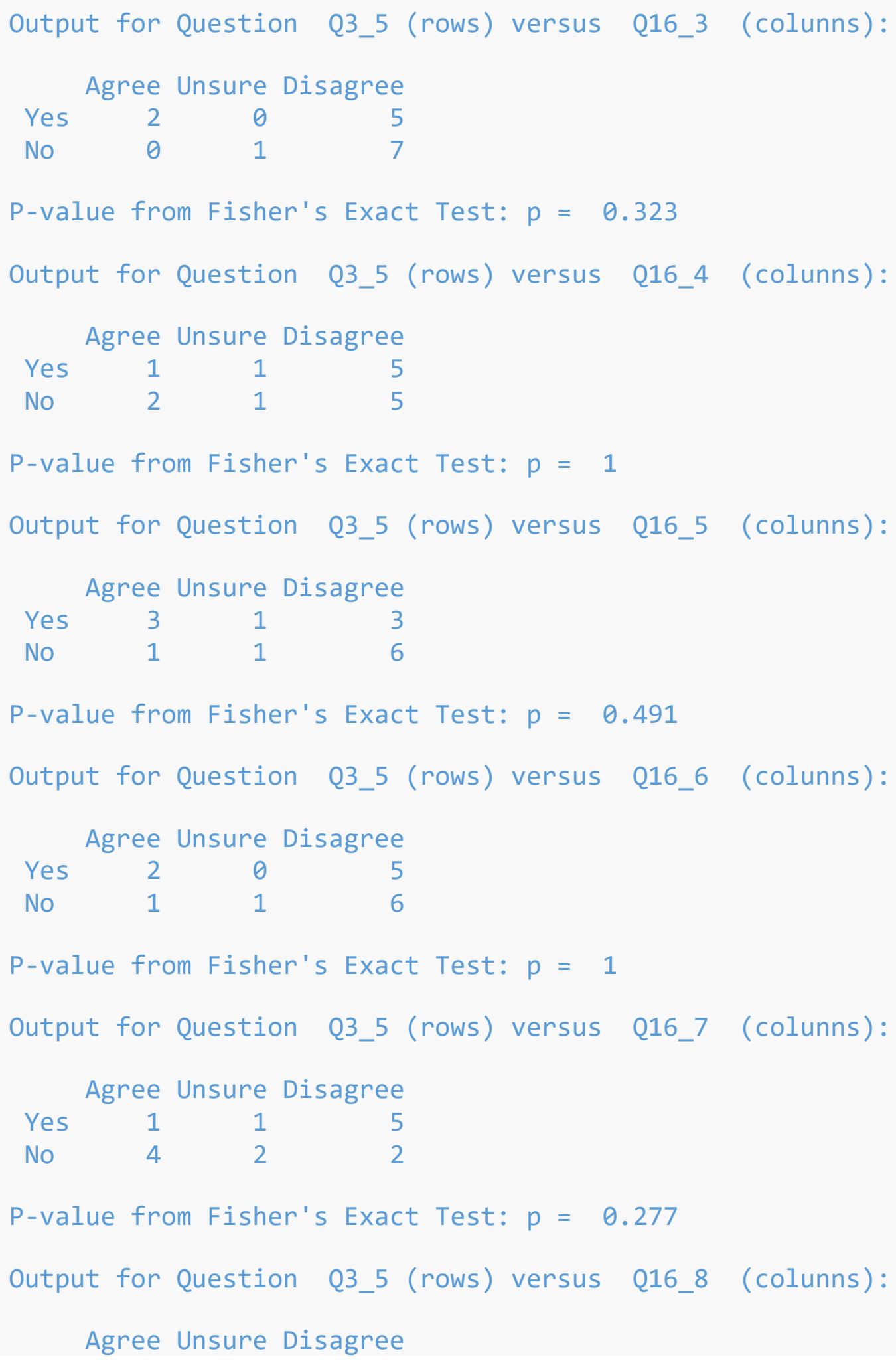




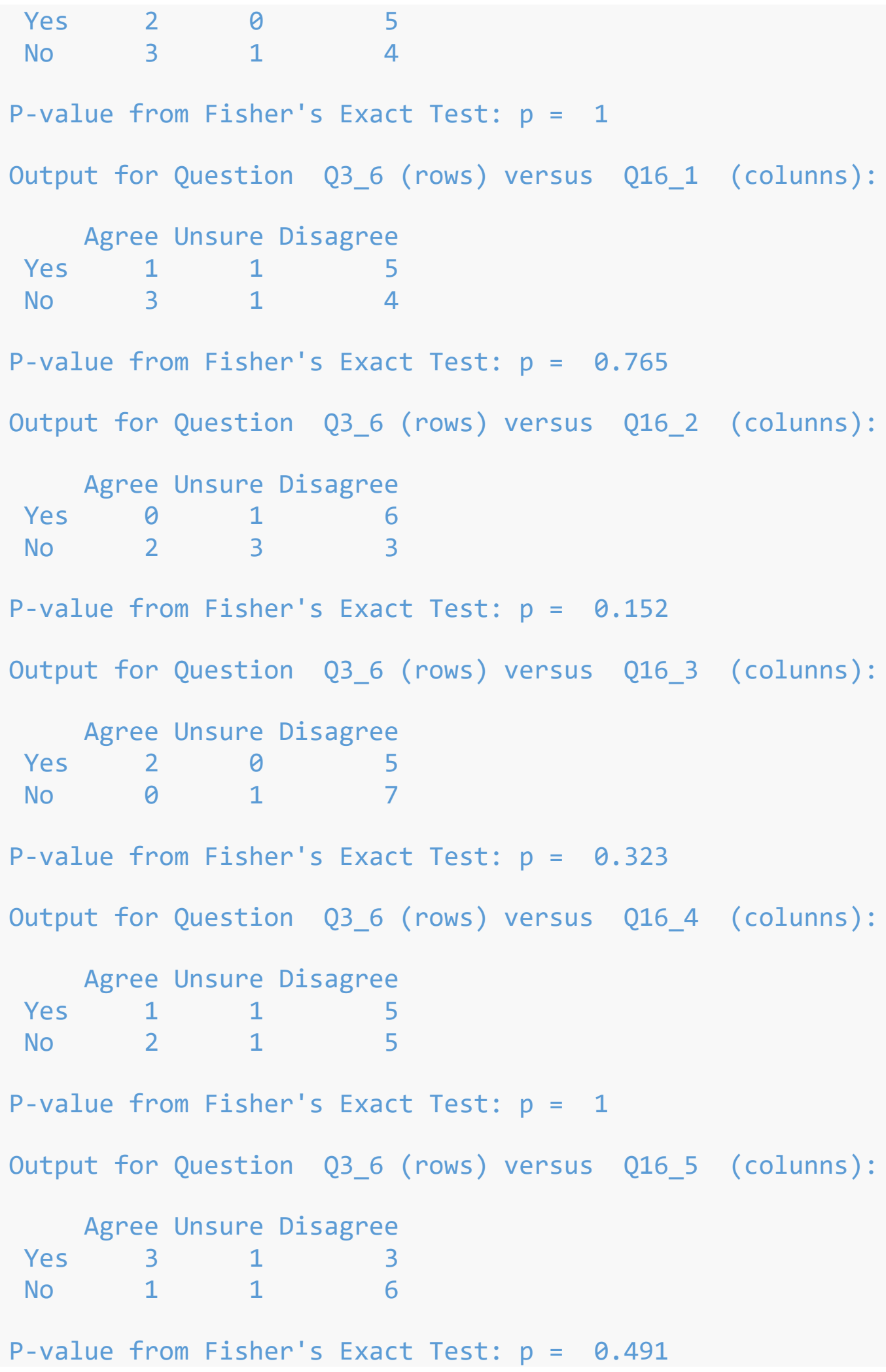




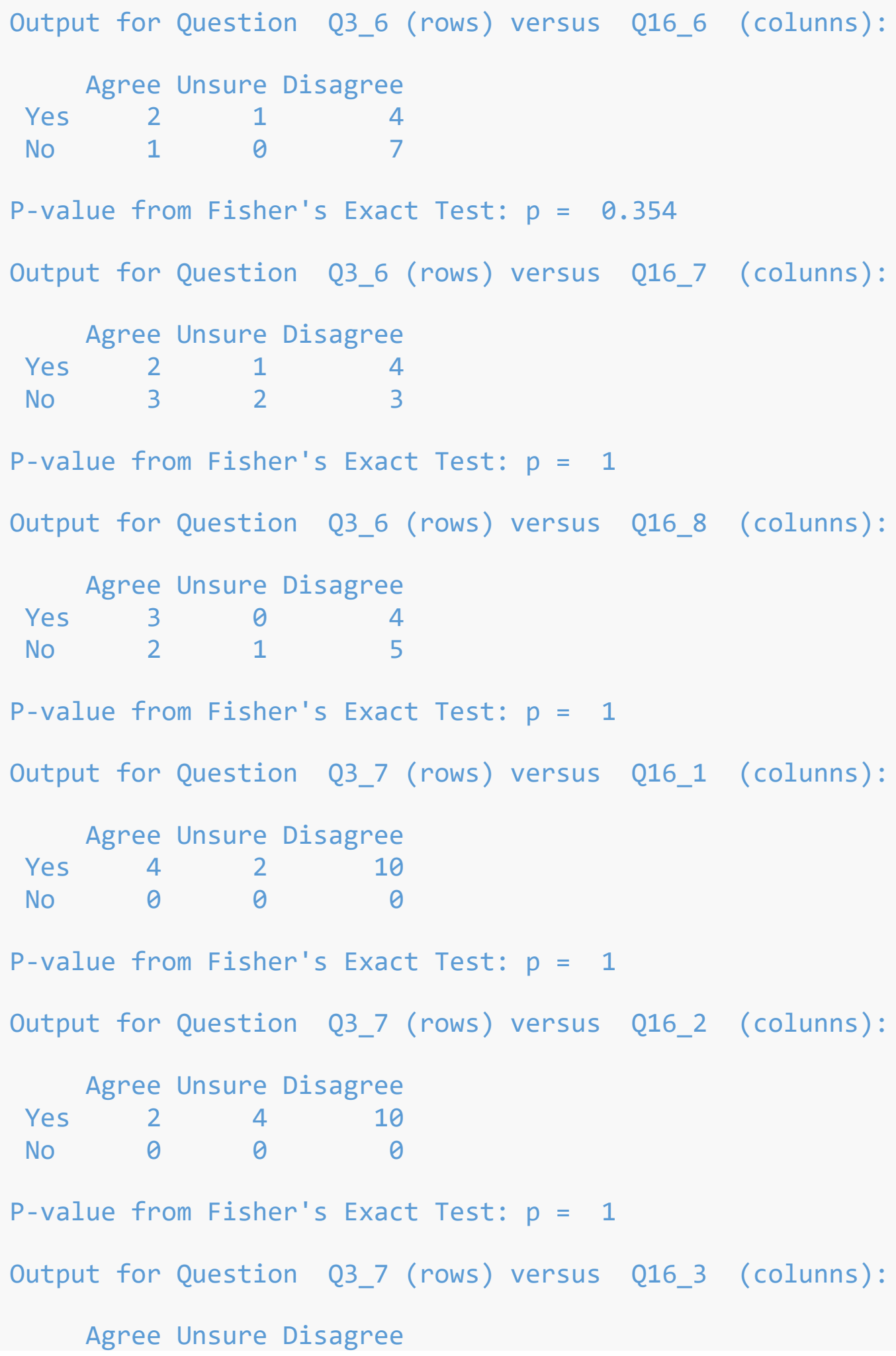




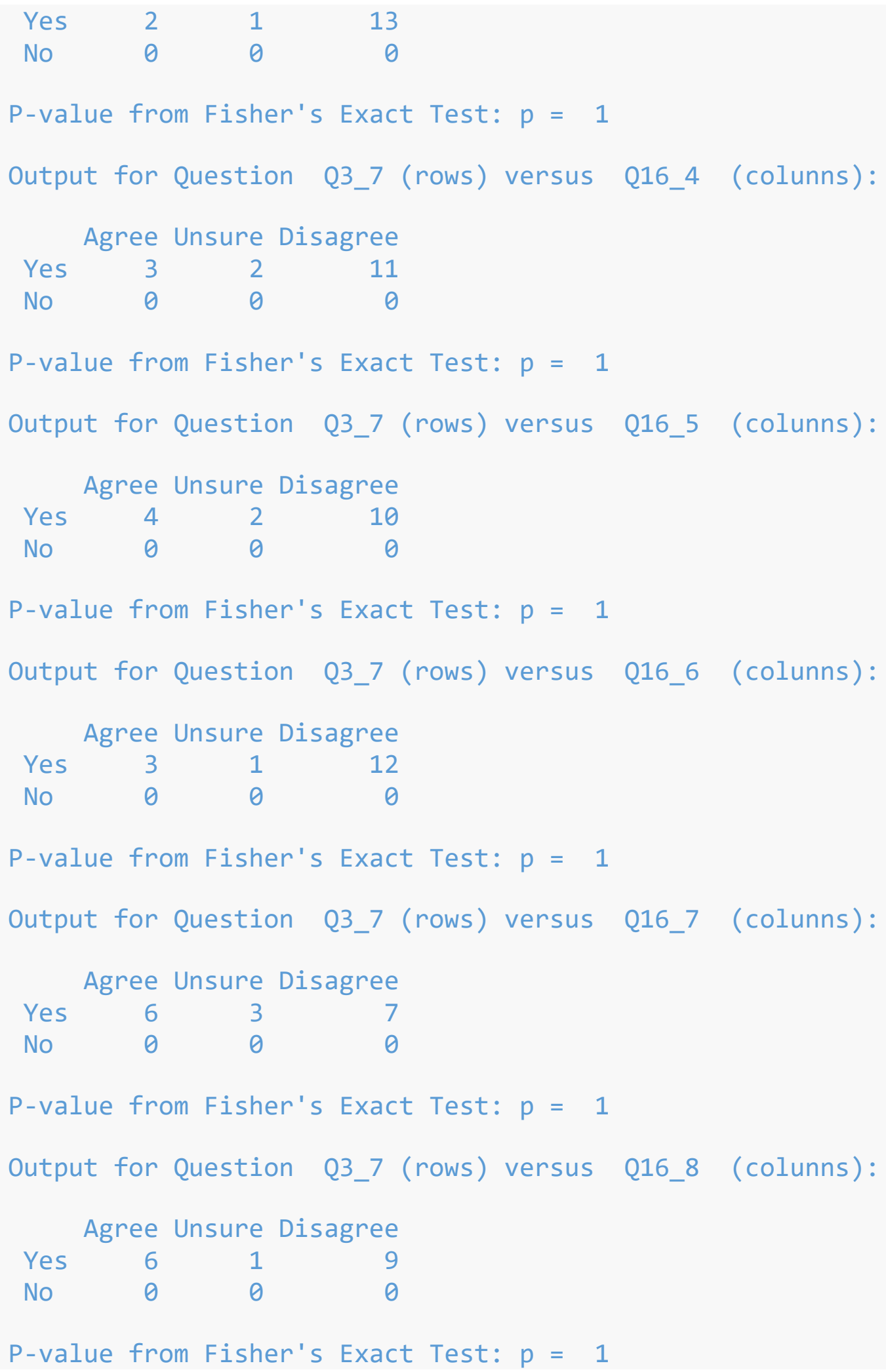




\section{Institution type B}

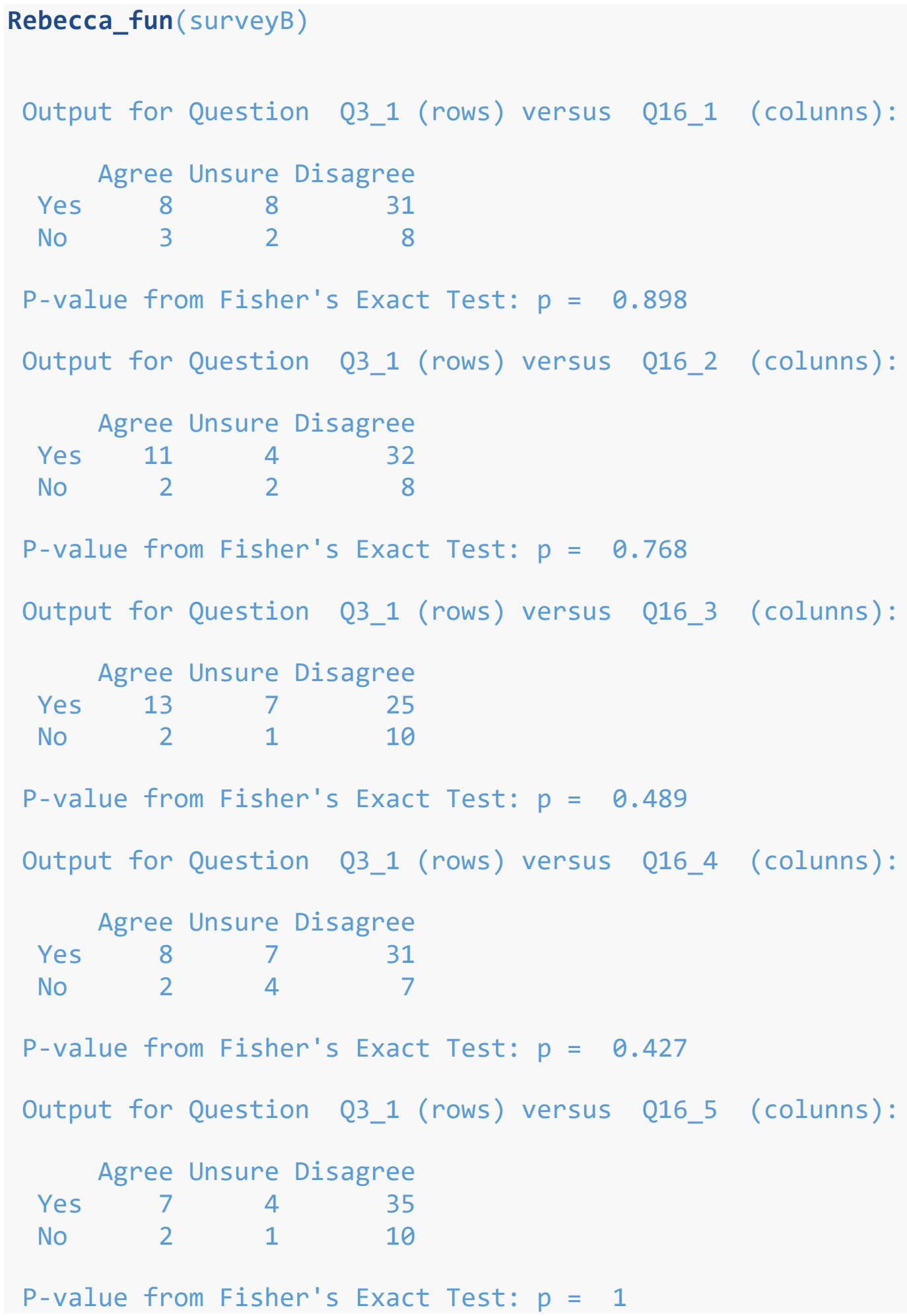




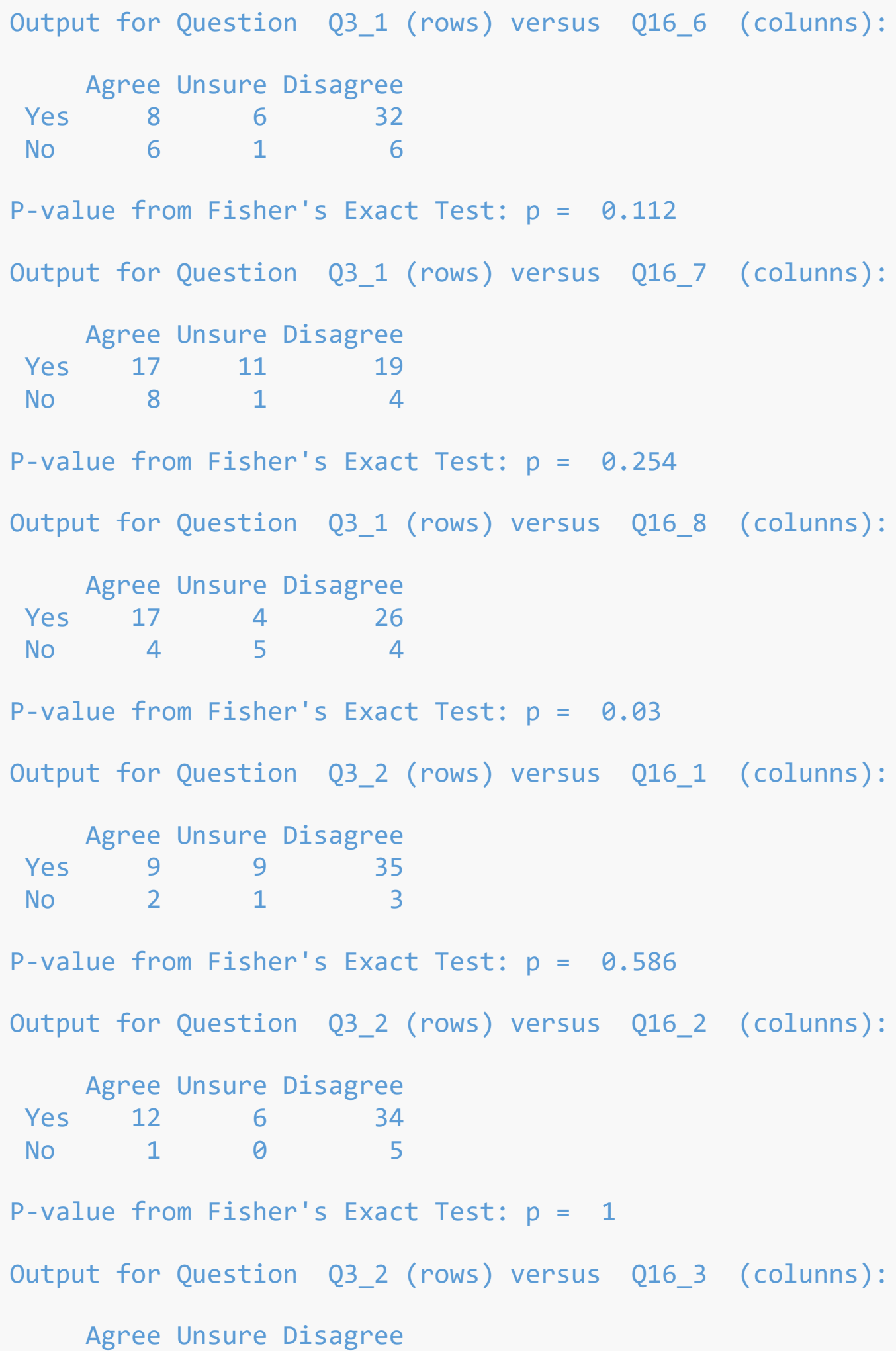




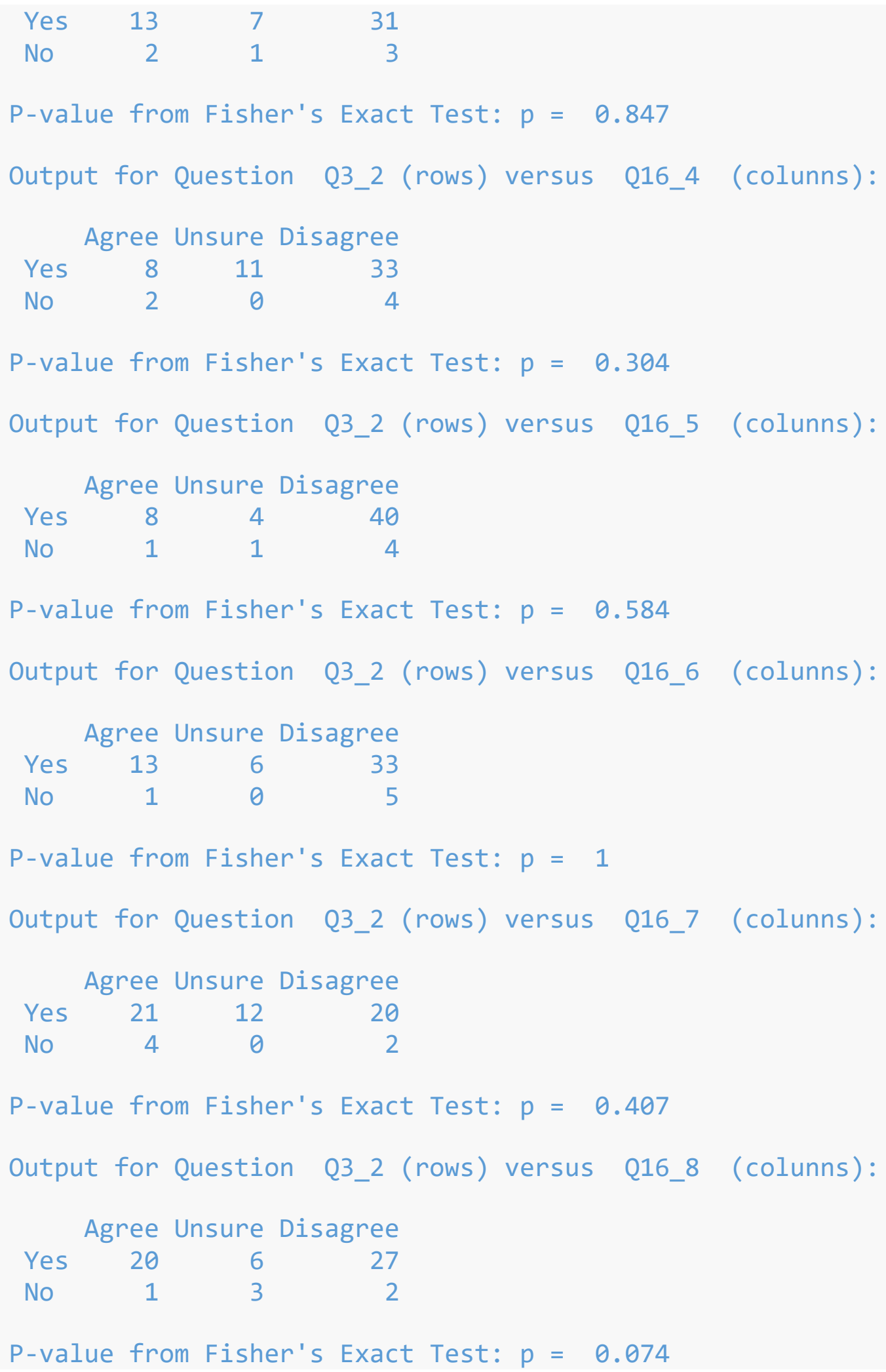




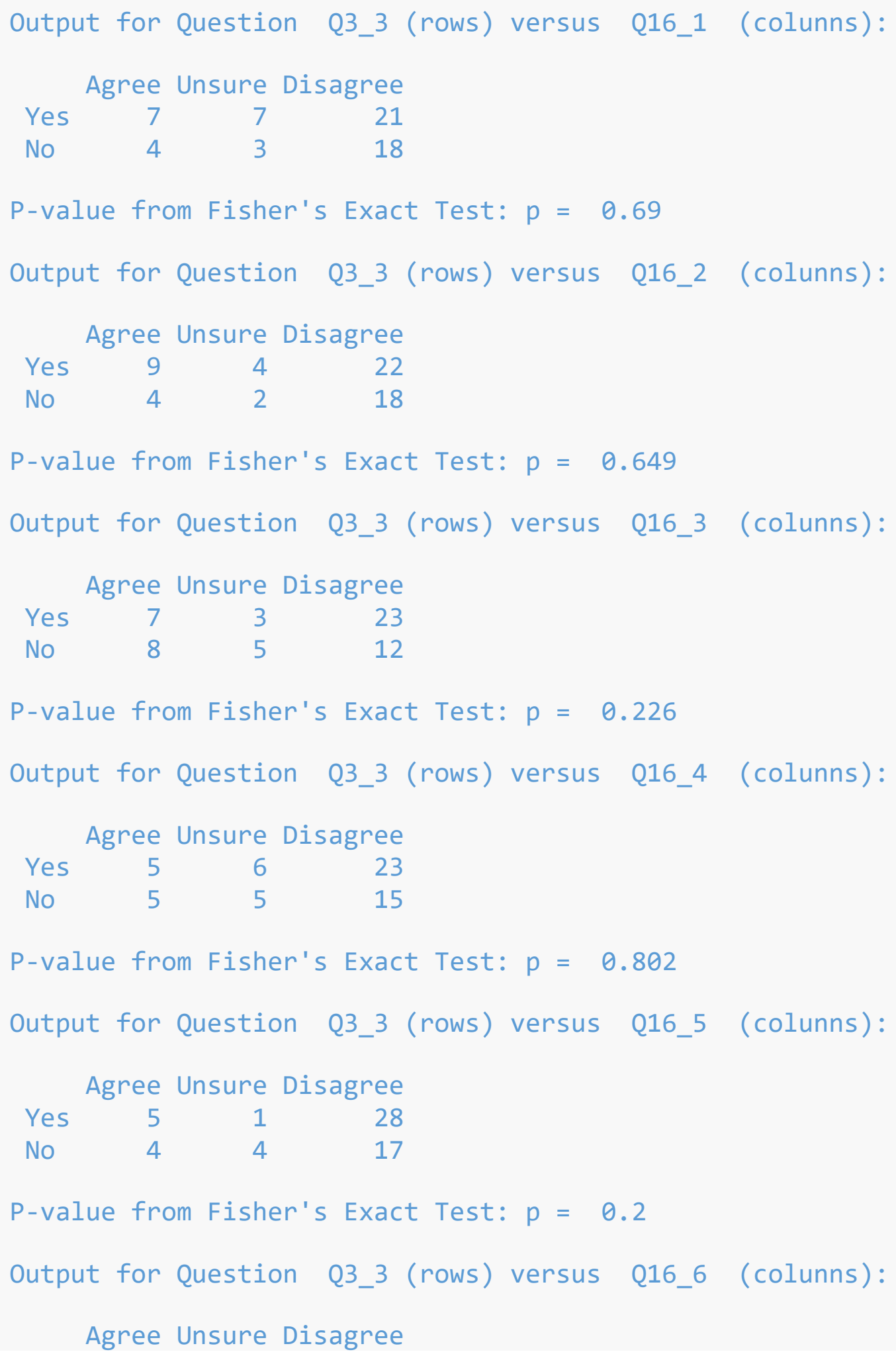




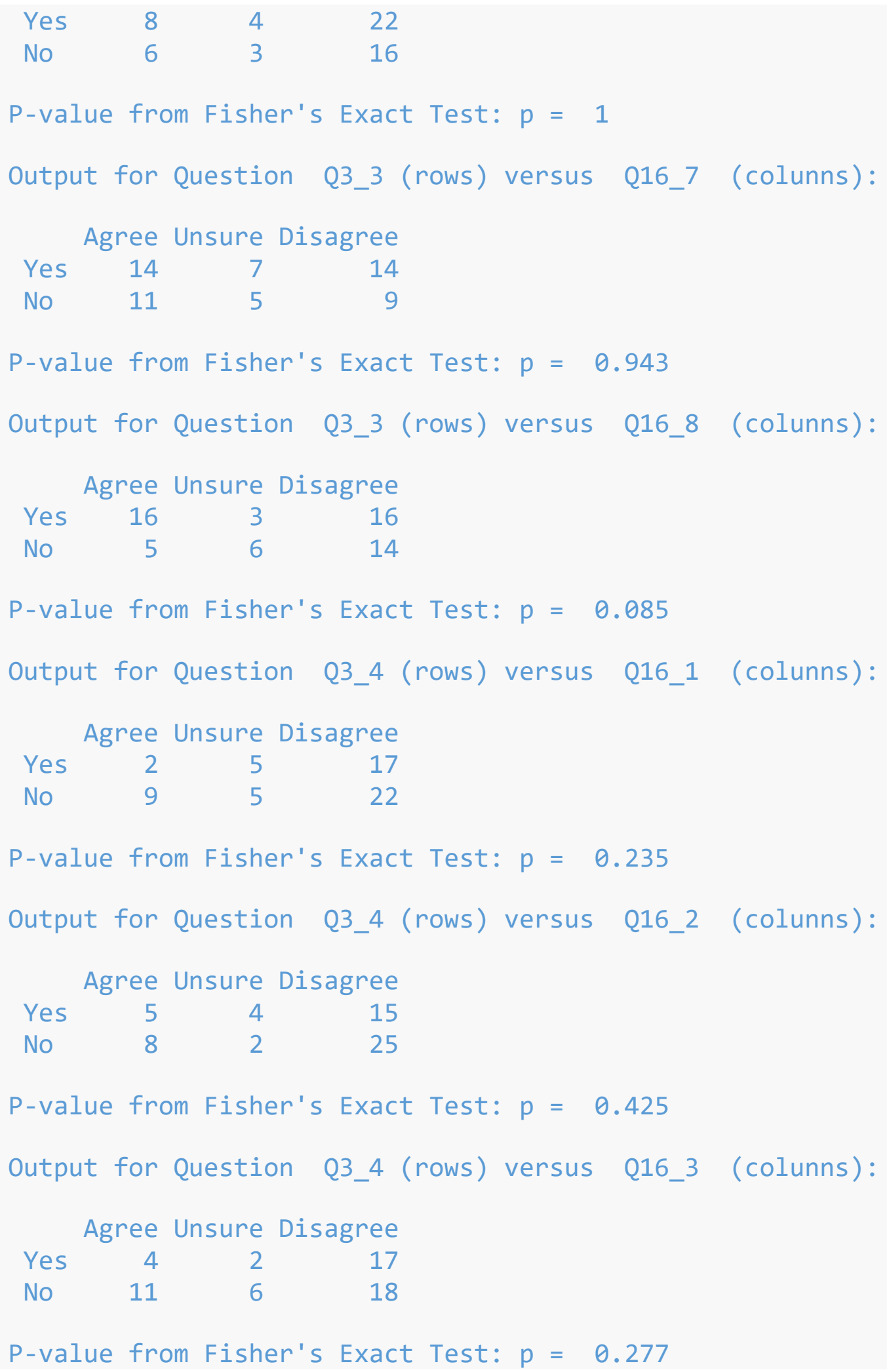




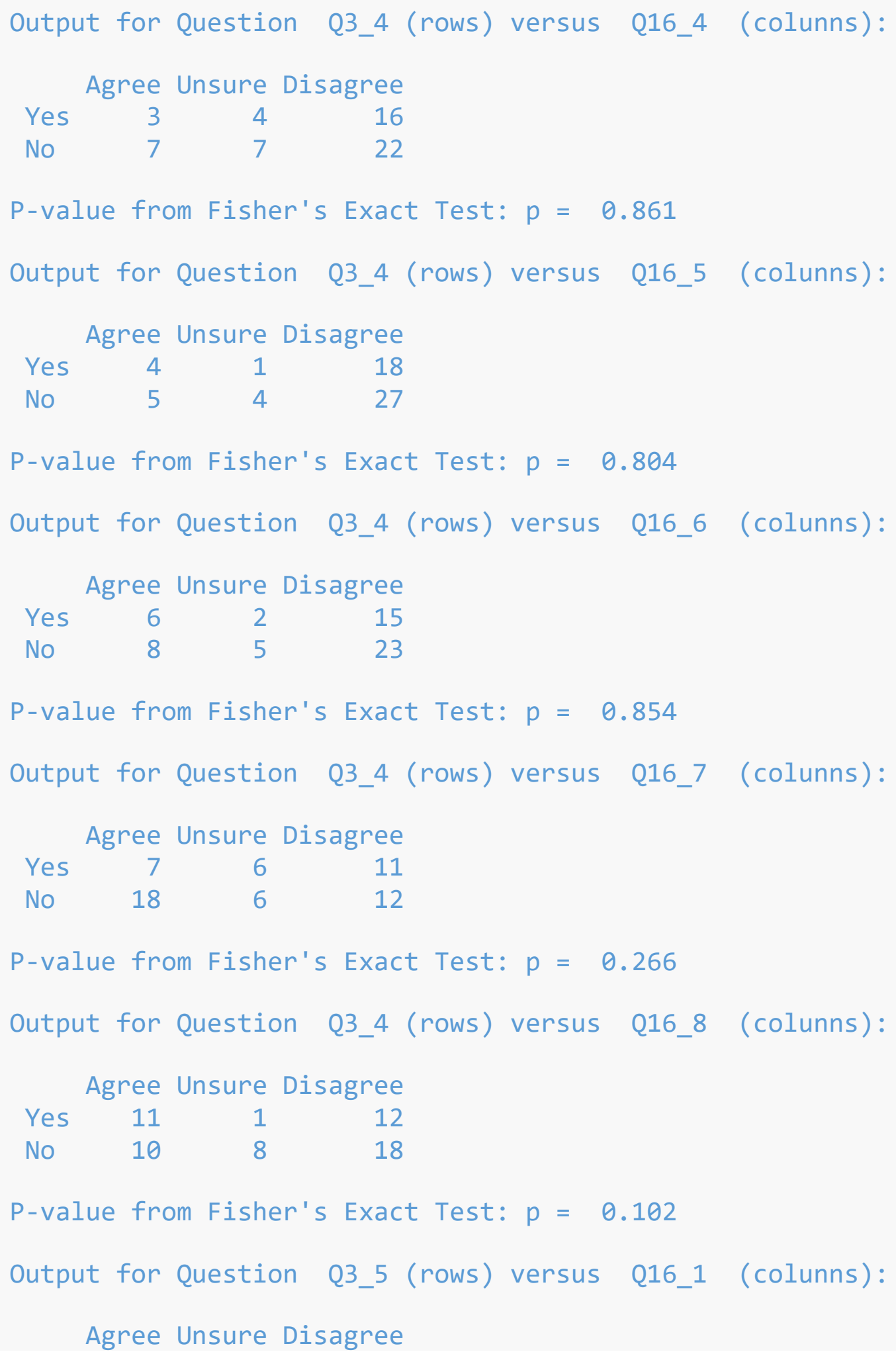




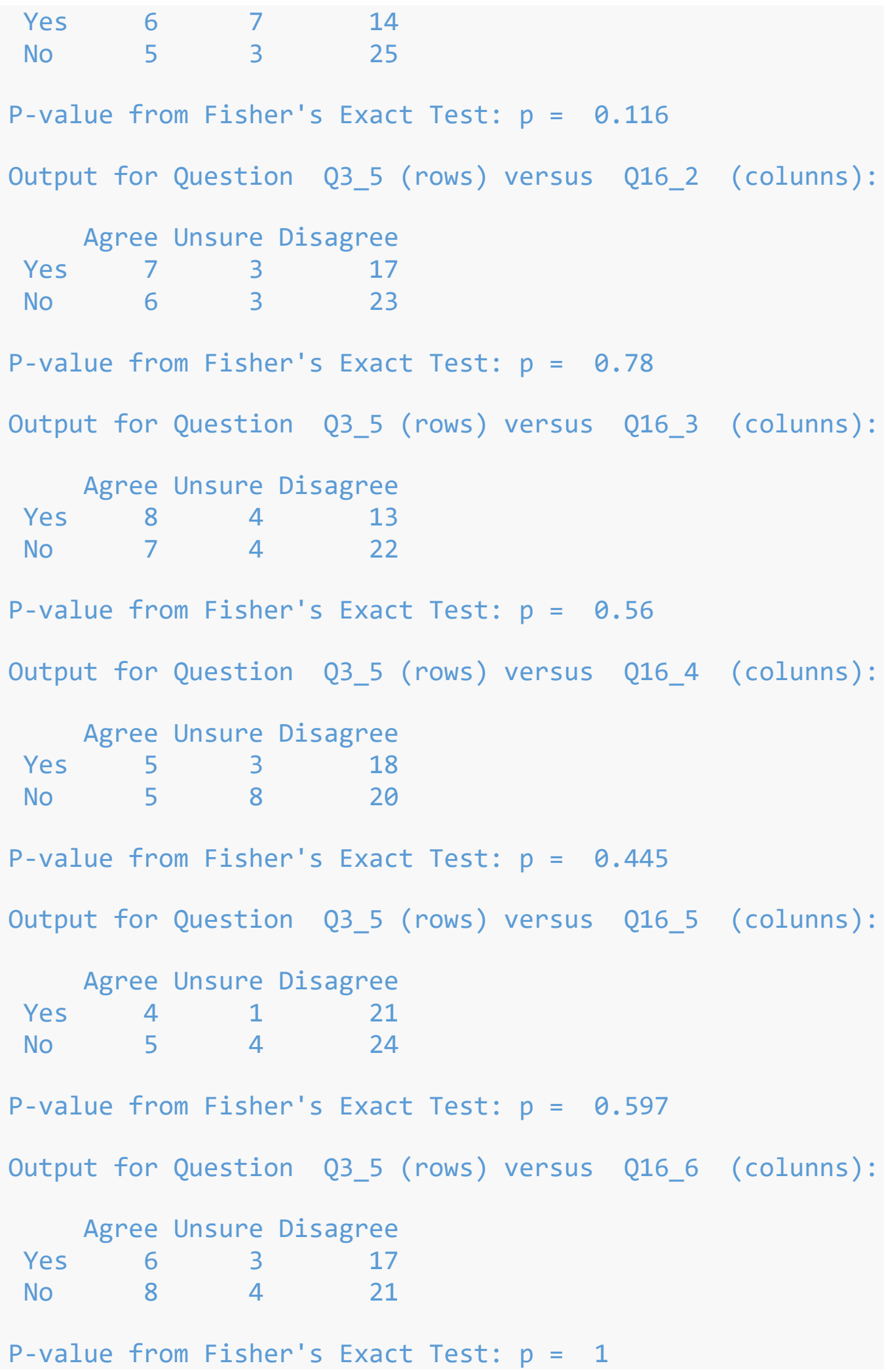




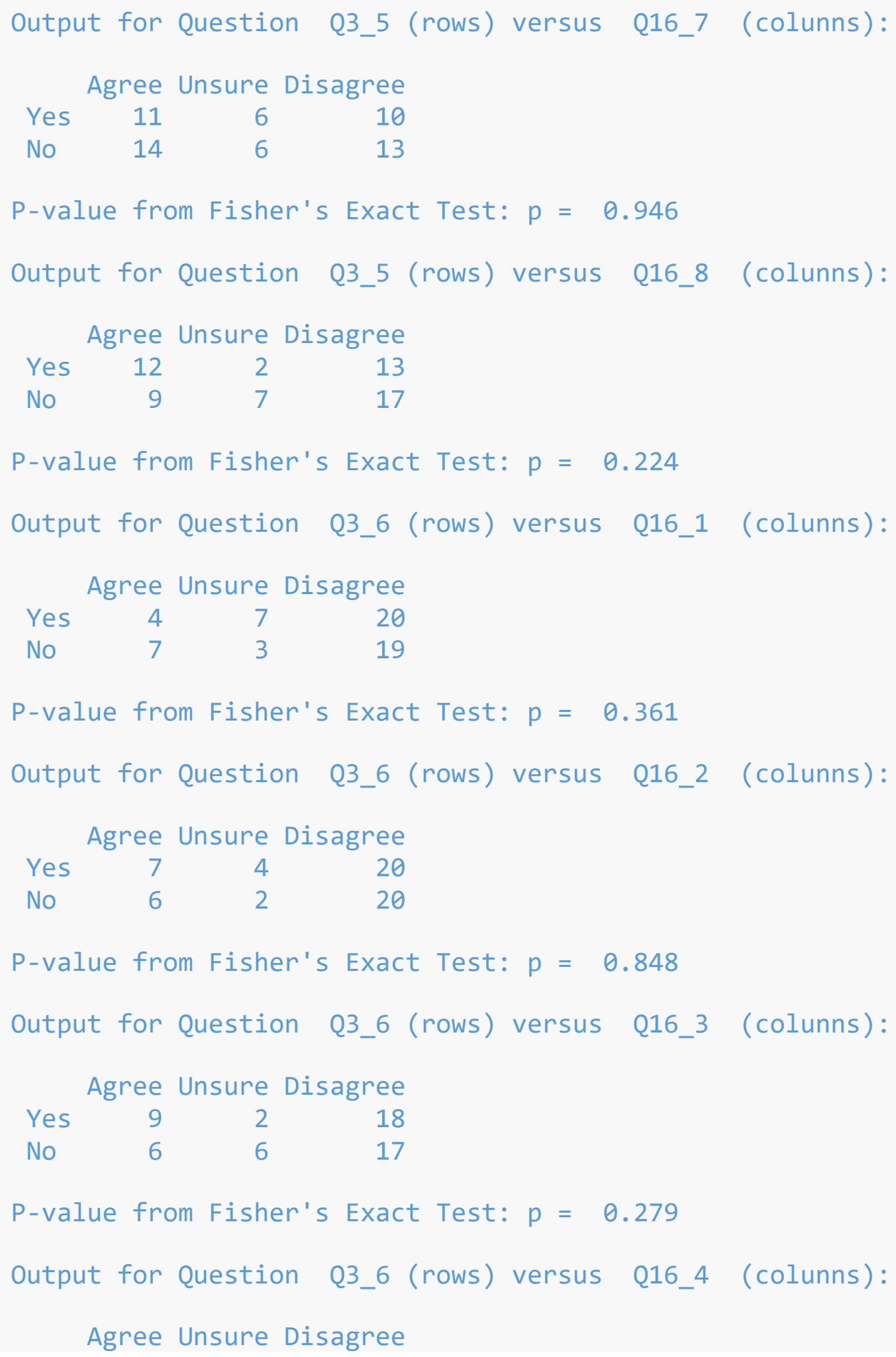




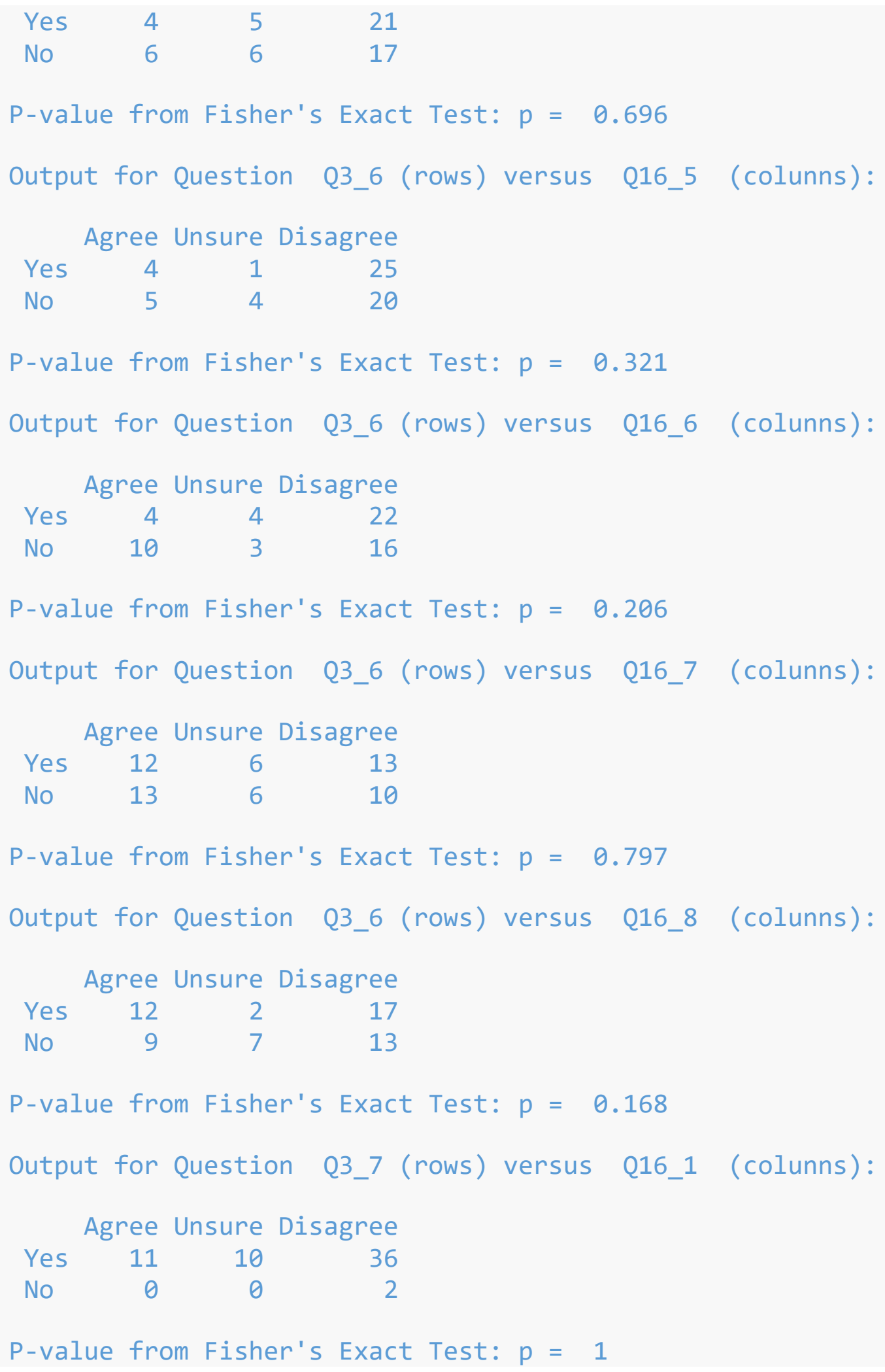




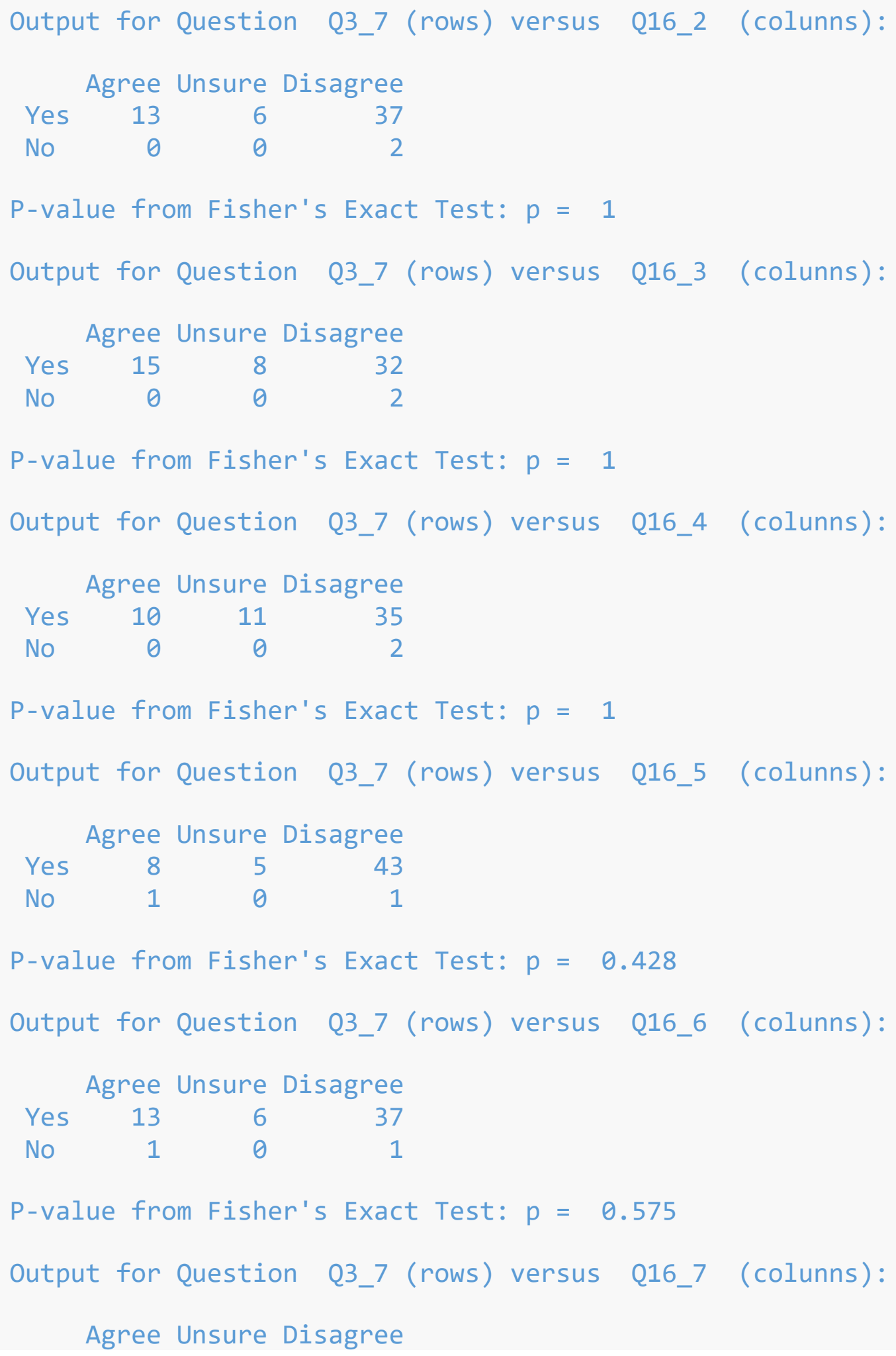




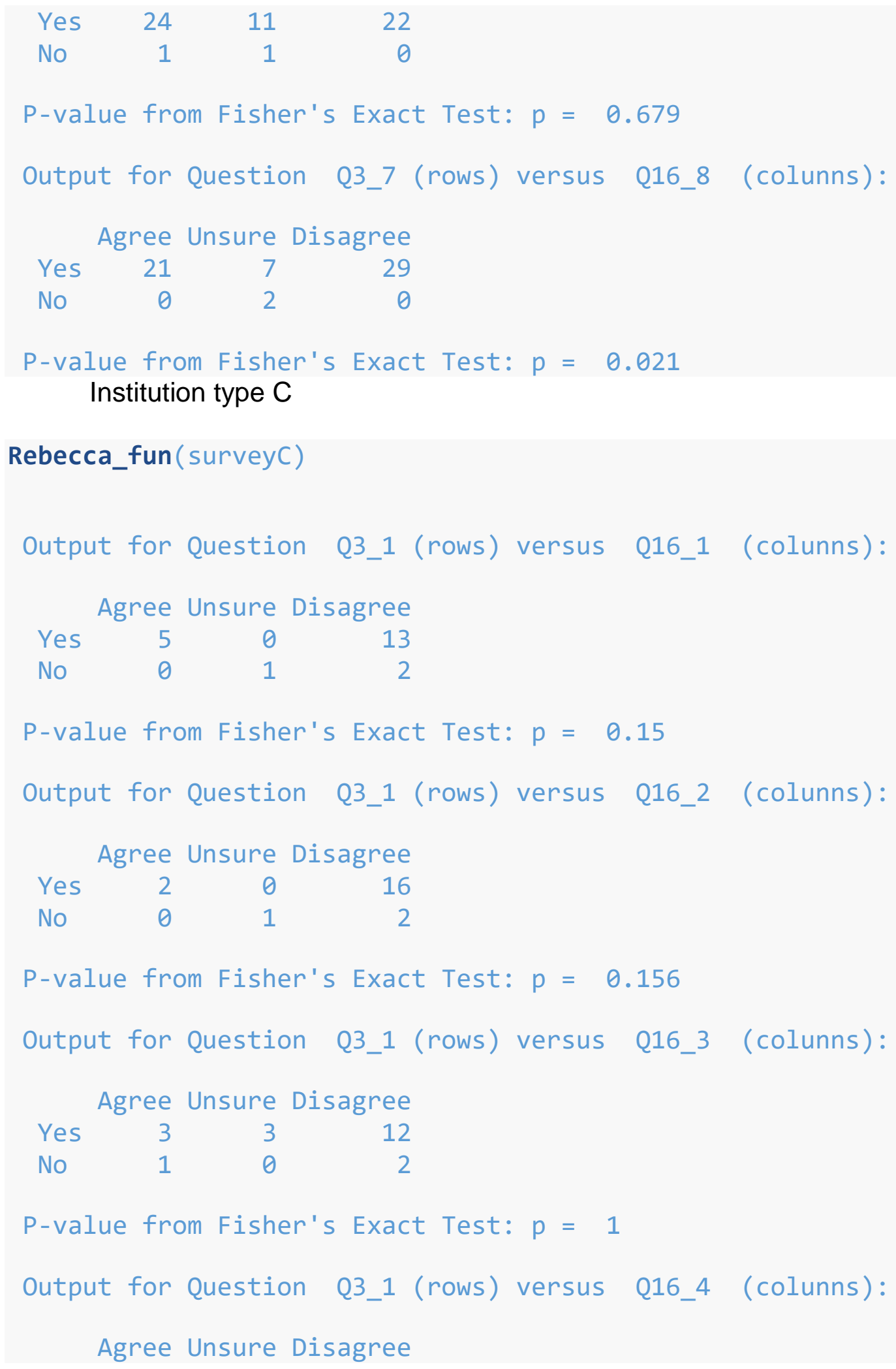




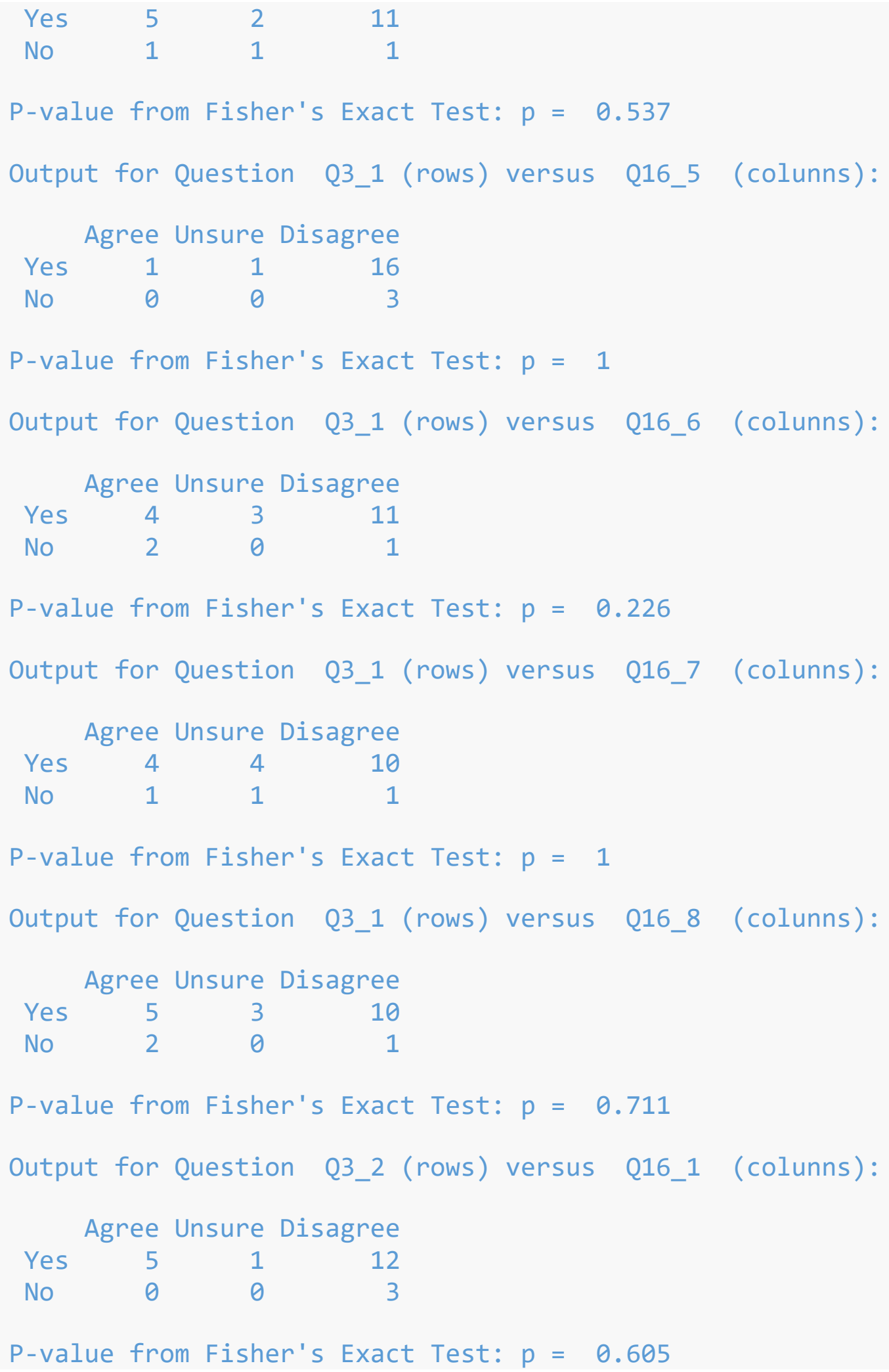




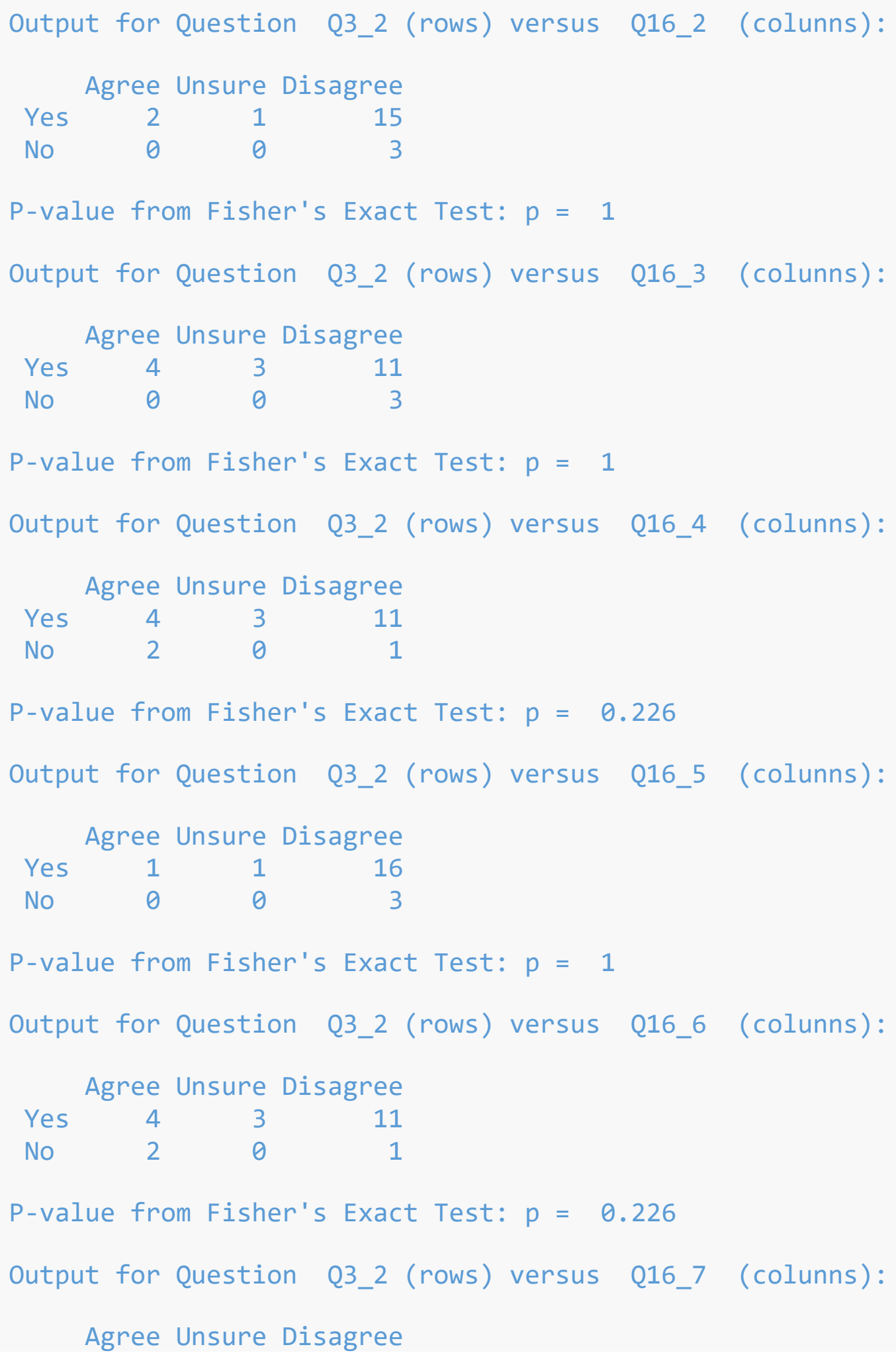




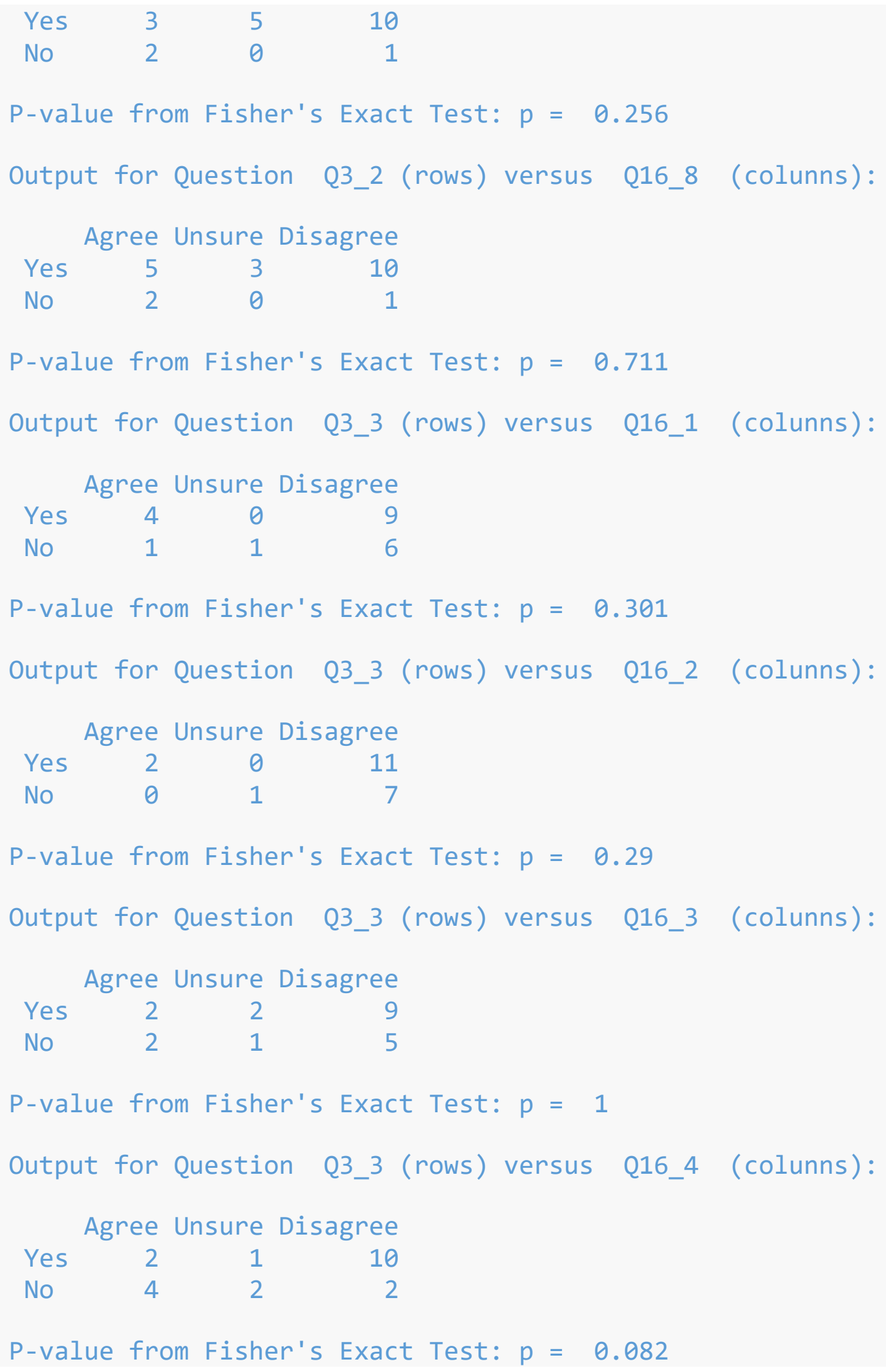




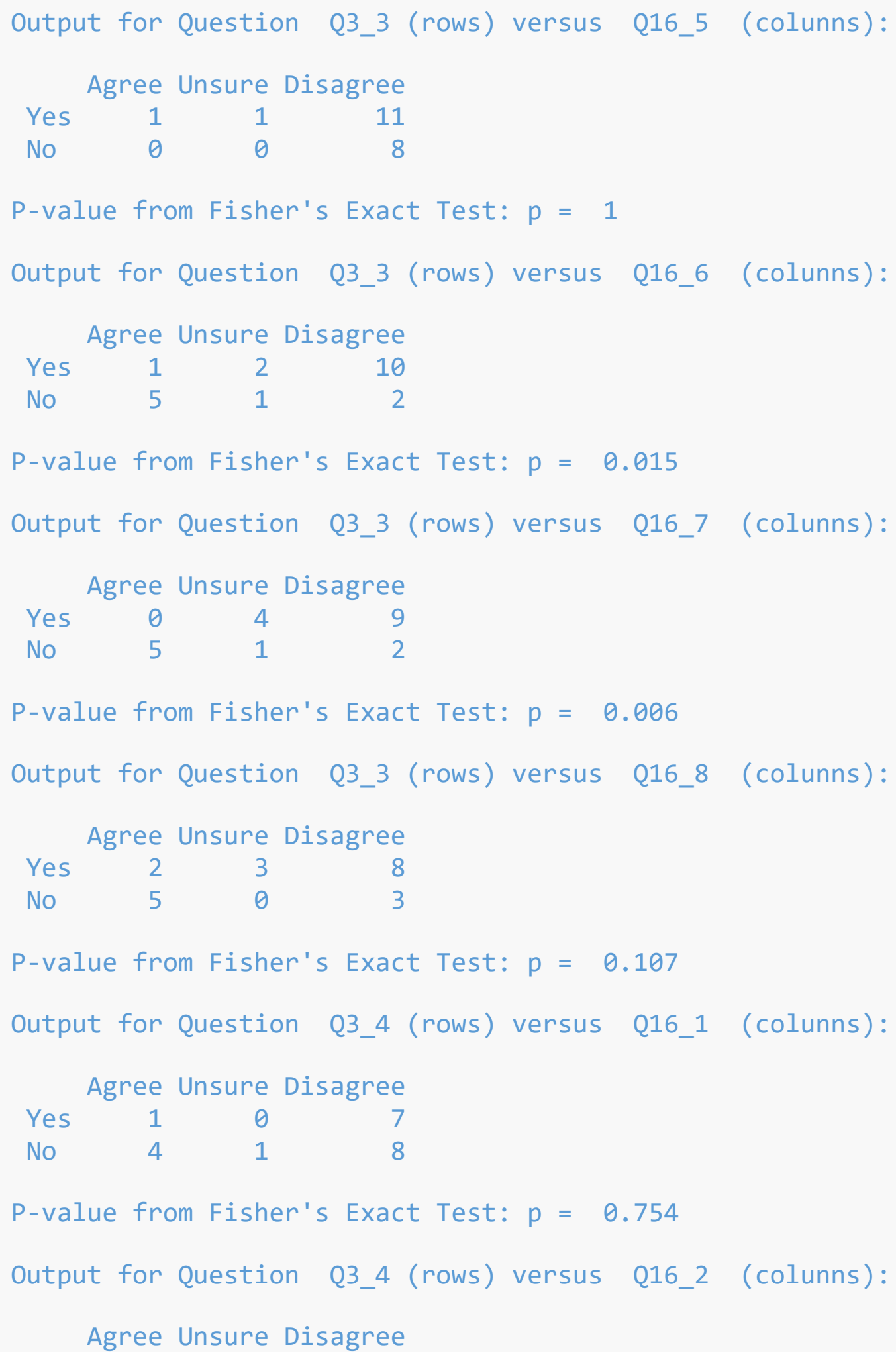




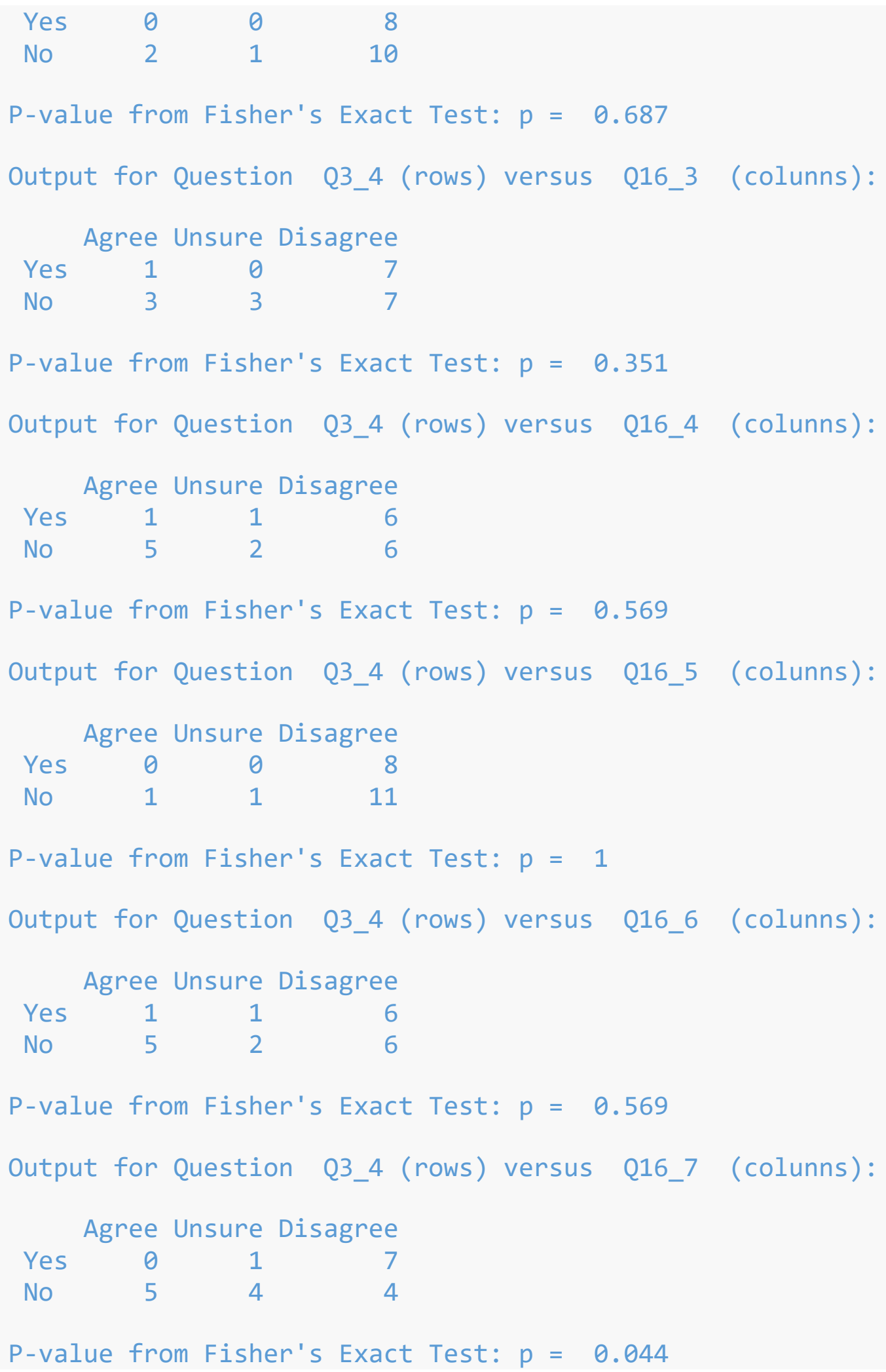




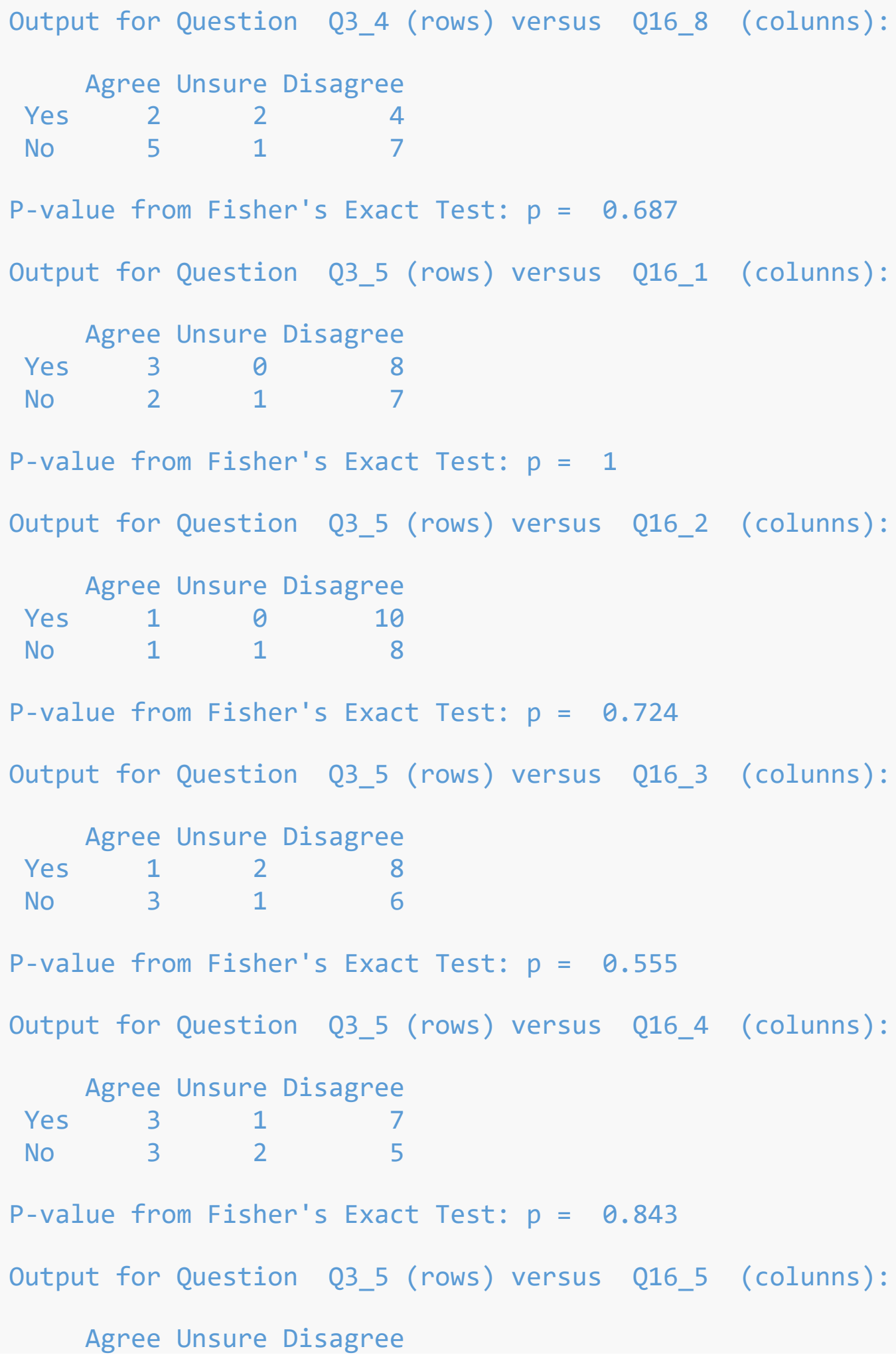




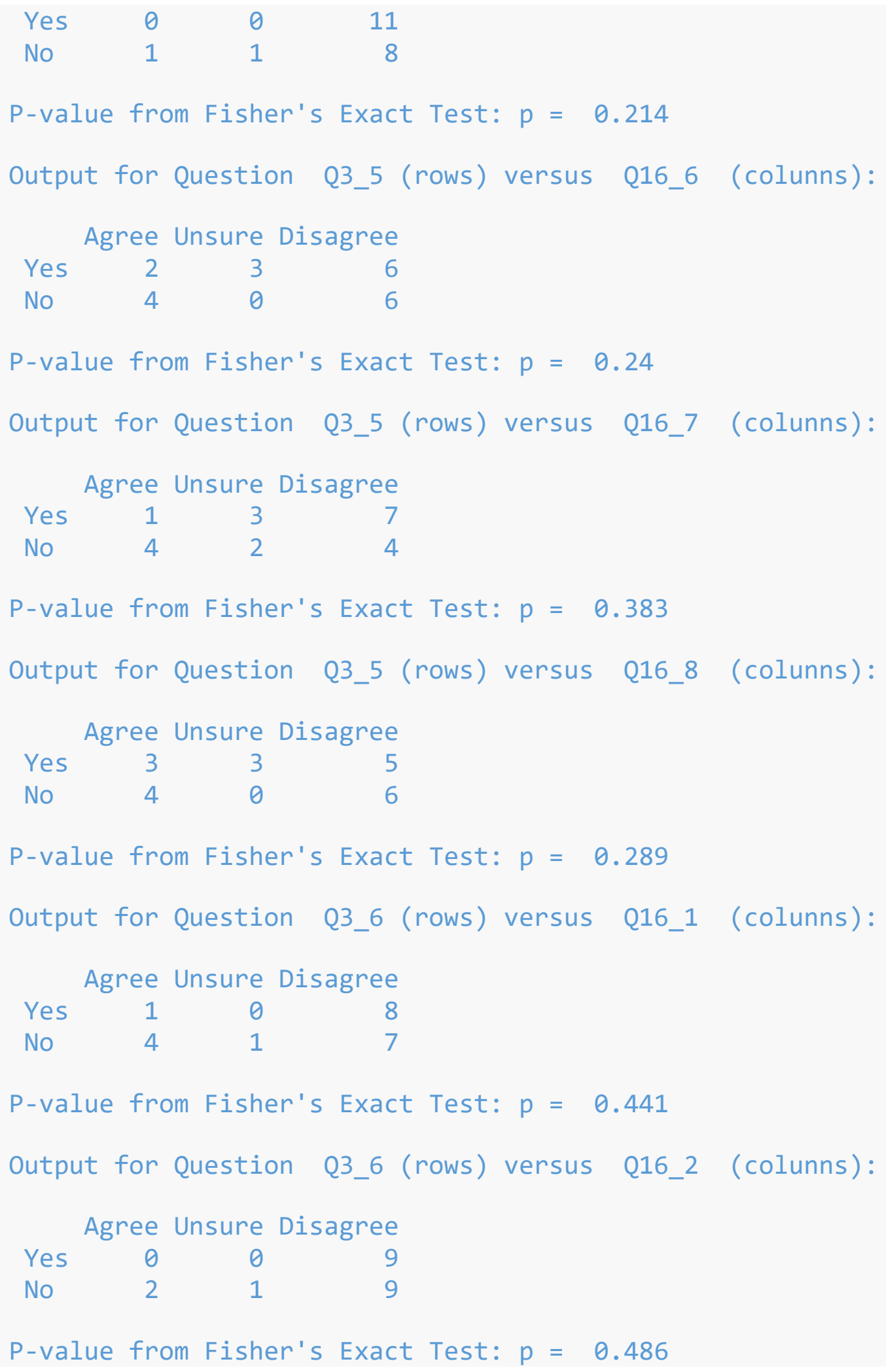




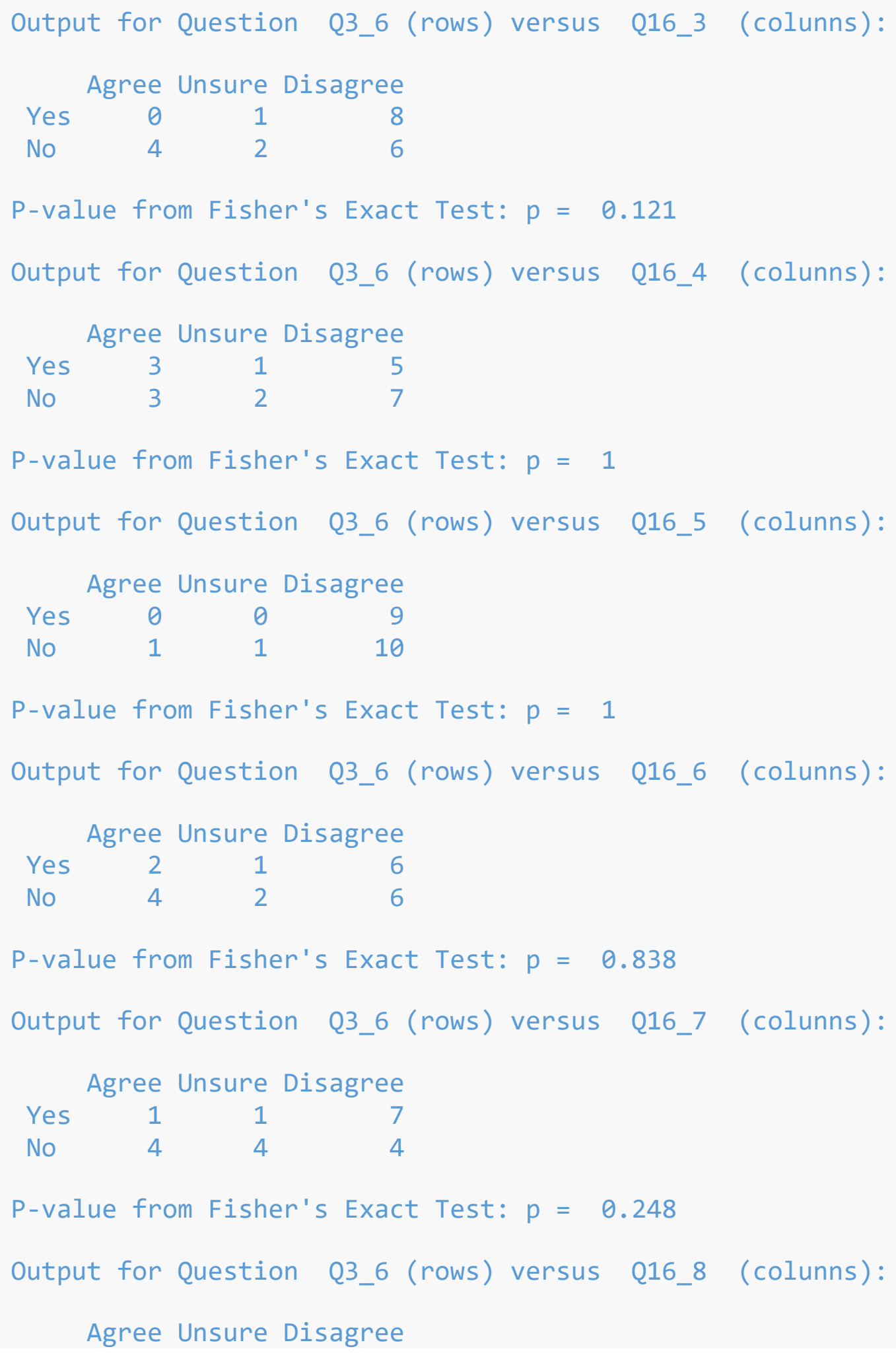




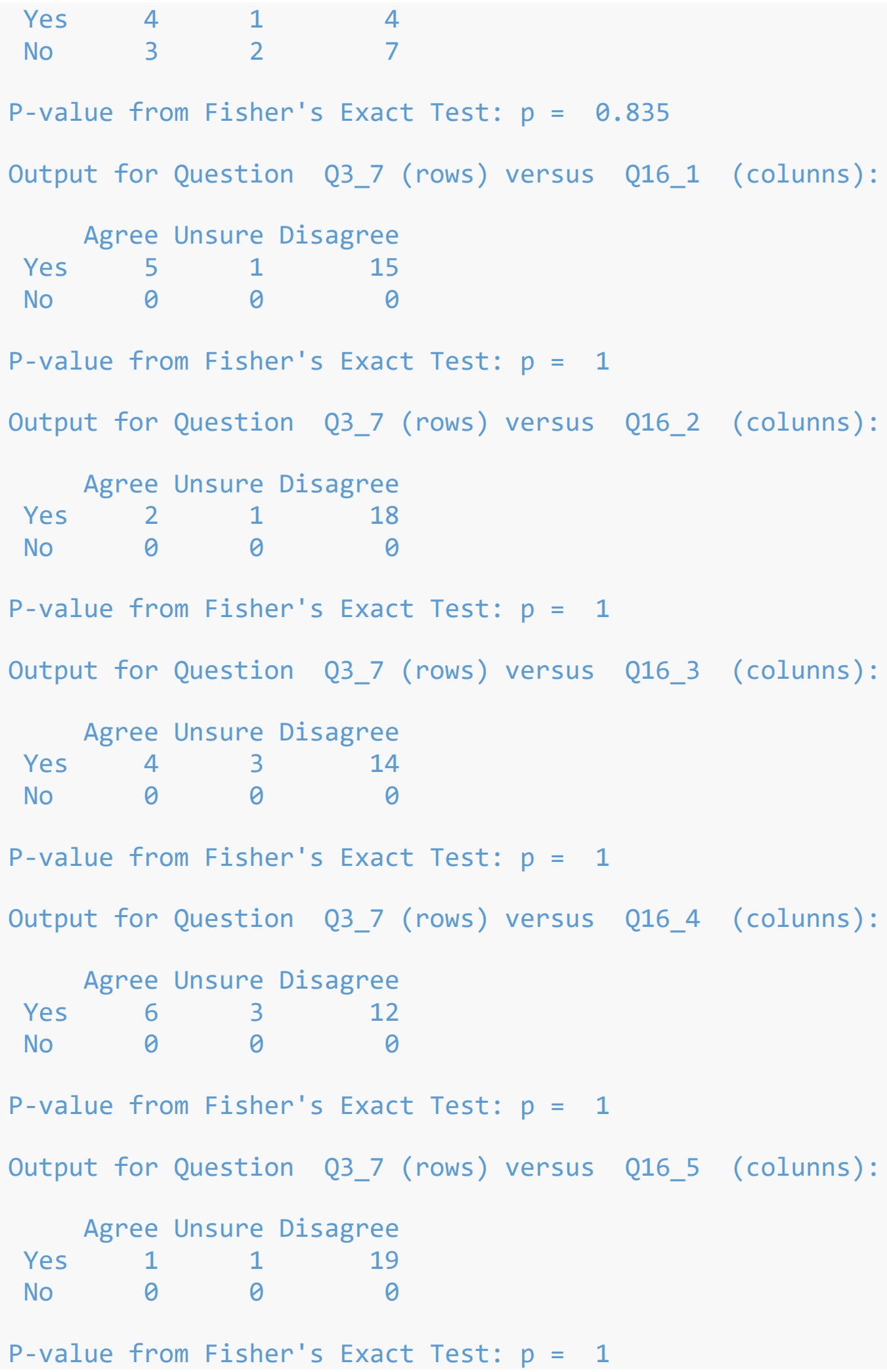




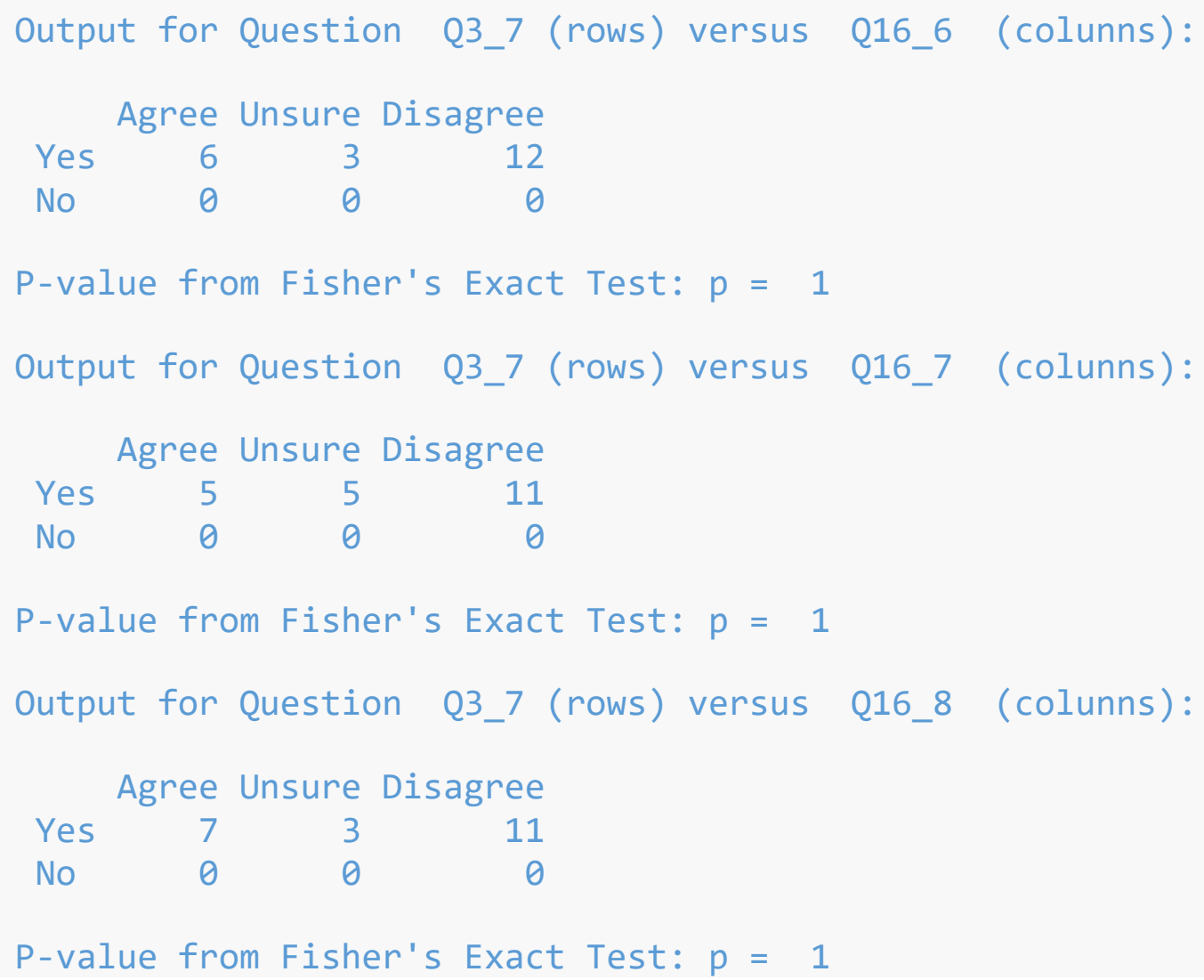




\section{Appendix C: Raw Data Results from Survey}

Q3 - To what extent does the Registrar participate in decisions about the following academic policies?

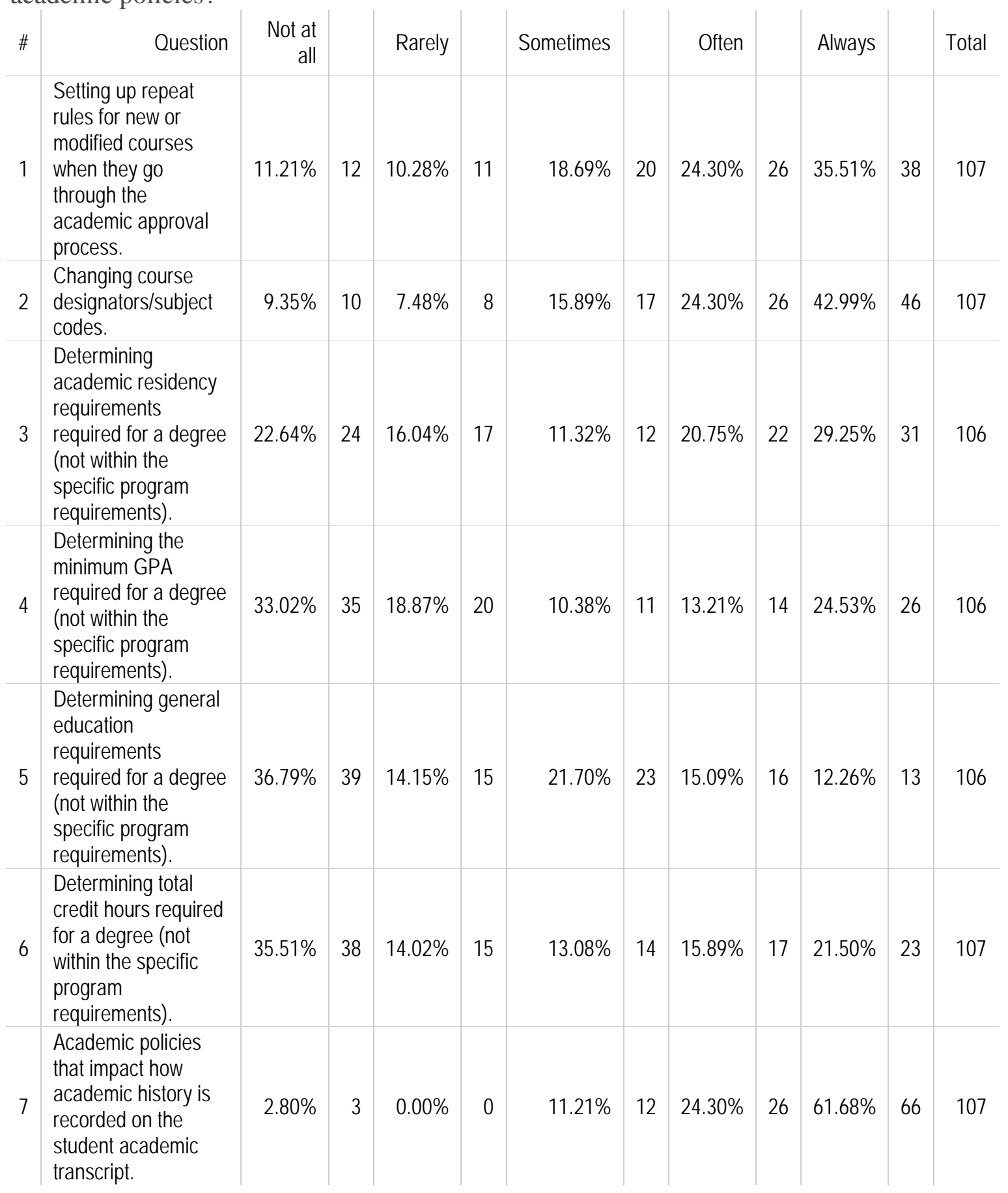


Q4 - Please select the response that best fits your institutional policy. Does the institution have limitations on the number of credits/courses in an academic program that can be taken as 'generic courses' such as research credit hours, independent studies, special topics, et. al.?

\begin{tabular}{r|c|c|r}
$\#$ & Answer & $\%$ & Count \\
\hline 1 & Yes & $57.80 \%$ & 63 \\
\hline 2 & No & $29.36 \%$ & 32 \\
\hline 3 & Unsure & $12.84 \%$ & 14 \\
\hline & Total & $100 \%$ & 109 \\
\hline
\end{tabular}

Q7 - Does the institution have a policy about how to define course equivalencies (two courses at the institution offering credit for the exact same outcomes) when modifying or creating a course?

\begin{tabular}{r|c|c|r}
$\#$ & Answer & $\%$ & Count \\
\hline 1 & Yes & $56.19 \%$ & 59 \\
\hline 2 & No & $29.52 \%$ & 31 \\
\hline 3 & Unsure & $14.29 \%$ & 15 \\
\hline & Total & $100 \%$ & 105 \\
\hline
\end{tabular}

Q10 - Does the institution have a policy about withdrawing from the university and any limitations this places on students?

\begin{tabular}{|r|c|c|r}
$\#$ & Answer & $\%$ & Count \\
\hline 1 & Yes & $87.25 \%$ & 89 \\
\hline 2 & No & $6.86 \%$ & 7 \\
\hline 3 & Unsure & $5.88 \%$ & 6 \\
\hline & Total & $100 \%$ & 102 \\
\hline
\end{tabular}


Q16 - The following series of statements are to measure any perceived impact on students from curriculum management and academic policy decisions. Please select the response that corresponds with your understanding of the reality at your institution.

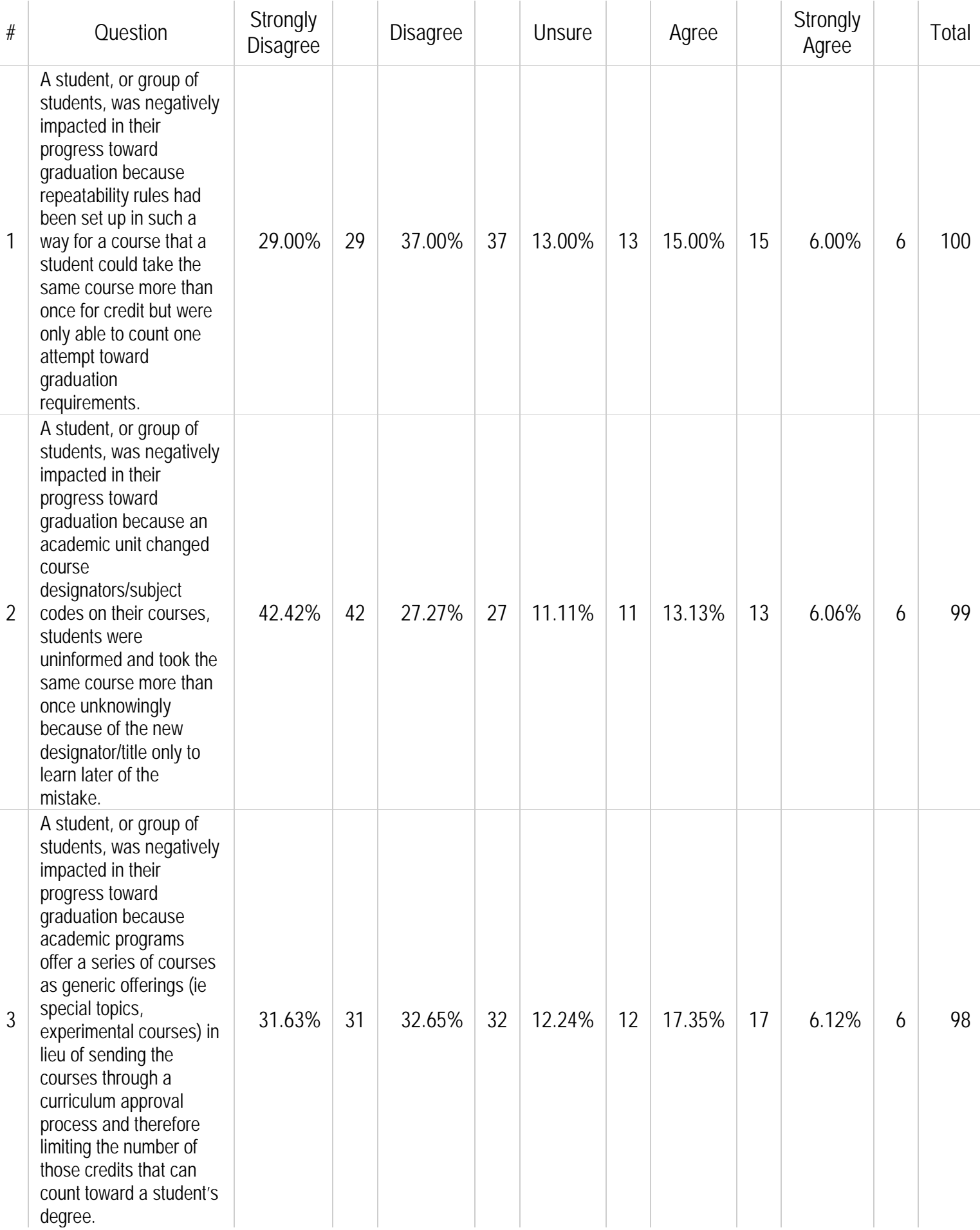


A student, or group of students, was negatively impacted in their progress toward graduation because the course equivalencies set up when a course was modified through the

4 curriculum approval process resulted in the student being required to take a similar course again or risk missing a small amount of course material because of partial curriculum overlap.

A student, or group of students, was negatively impacted in their progress toward graduation because policy creation or modifications (such as university withdrawal rules or academic standing policies) negatively impacted

5 students because of changes that occurred to those policies. Examples may include limiting the number of university withdrawals or adding restrictions to academic standing and how it may impact whether or not a student is in good standing or warning, probation or suspension. Students have difficulty graduating because they

6 do not understand what requirements are expected of them. Students need to see academic advisors for

7 questions about academic policies because the policies are not clear.

Students have problems with interpreting degree

8 requirements through the use of a degree audit tool.

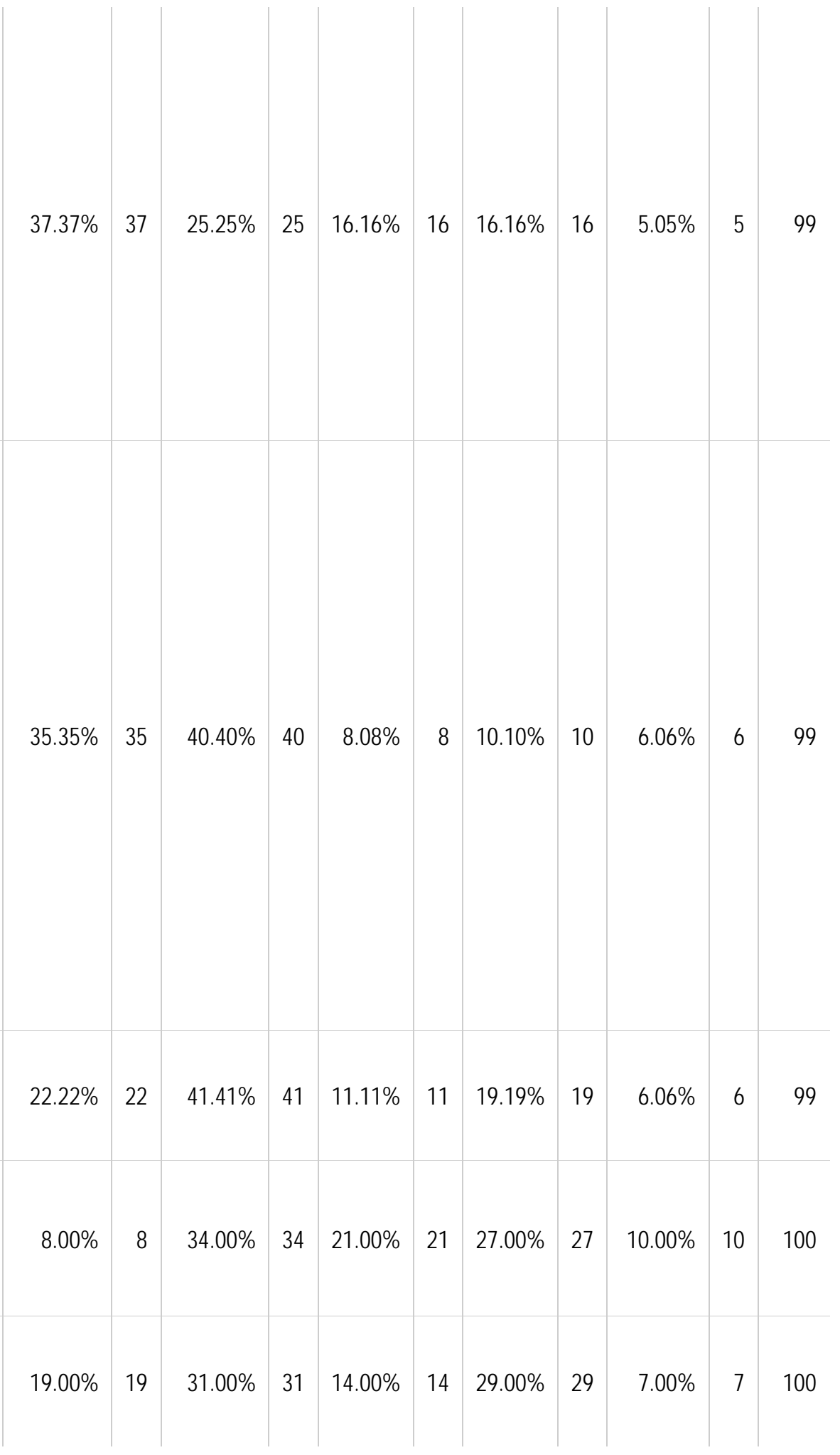


Q19 - What is the highest degree you attained?

\begin{tabular}{r|c|r|r}
\hline$\#$ & Answer & $\%$ & Count \\
\hline 1 & Baccalaureate & $3.00 \%$ & 3 \\
\hline 2 & Masters & $48.00 \%$ & 48 \\
\hline 3 & Doctoral & $49.00 \%$ & 49 \\
\hline & Total & $100 \%$ & 100 \\
\hline & & &
\end{tabular}

Q20 - Select the appropriate range for the number of years in the education field.

\begin{tabular}{r|r|c|r|}
\hline$\#$ & Answer & $\%$ & Count \\
\hline 1 & $0-5$ & $0.00 \%$ & 0 \\
\hline 2 & $6-10$ & $4.00 \%$ & 4 \\
\hline 3 & $11-20$ & $29.00 \%$ & 29 \\
\hline 4 & $21-30$ & $42.00 \%$ & 42 \\
\hline 5 & $30+$ & $25.00 \%$ & 25 \\
\hline & Total & $100 \%$ & 100 \\
\hline
\end{tabular}

Q21 - What is your main role at your institution?

\begin{tabular}{r|r|r|r}
\hline$\#$ & \multicolumn{1}{|c|}{ Answer } & $\%$ & Count \\
\hline 1 & Registrar & $69.00 \%$ & 69 \\
\hline 2 & Faculty (who plays a role in curriculum approvals or academic policy) & $31.00 \%$ & 31 \\
\hline & Total & $100 \%$ & 100
\end{tabular}


Q22 - Does your institution offer tenure for your role?

\begin{tabular}{c|c|c|c|}
\hline$\#$ & Answer & $\%$ & Count \\
\hline 1 & Yes & $27.00 \%$ & 27 \\
\hline 2 & No & $73.00 \%$ & 73 \\
\hline & Total & $100 \%$ & 100 \\
\hline
\end{tabular}

Q23 - Do you have tenure?

\begin{tabular}{r|c|c|r}
$\#$ & Answer & $\%$ & Count \\
\hline 1 & Yes & $81.48 \%$ & 22 \\
\hline 2 & No & $18.52 \%$ & 5 \\
\hline & Total & $100 \%$ & 27 \\
\hline
\end{tabular}




\section{Appendix D: Birnbaum Permission (Figure)}

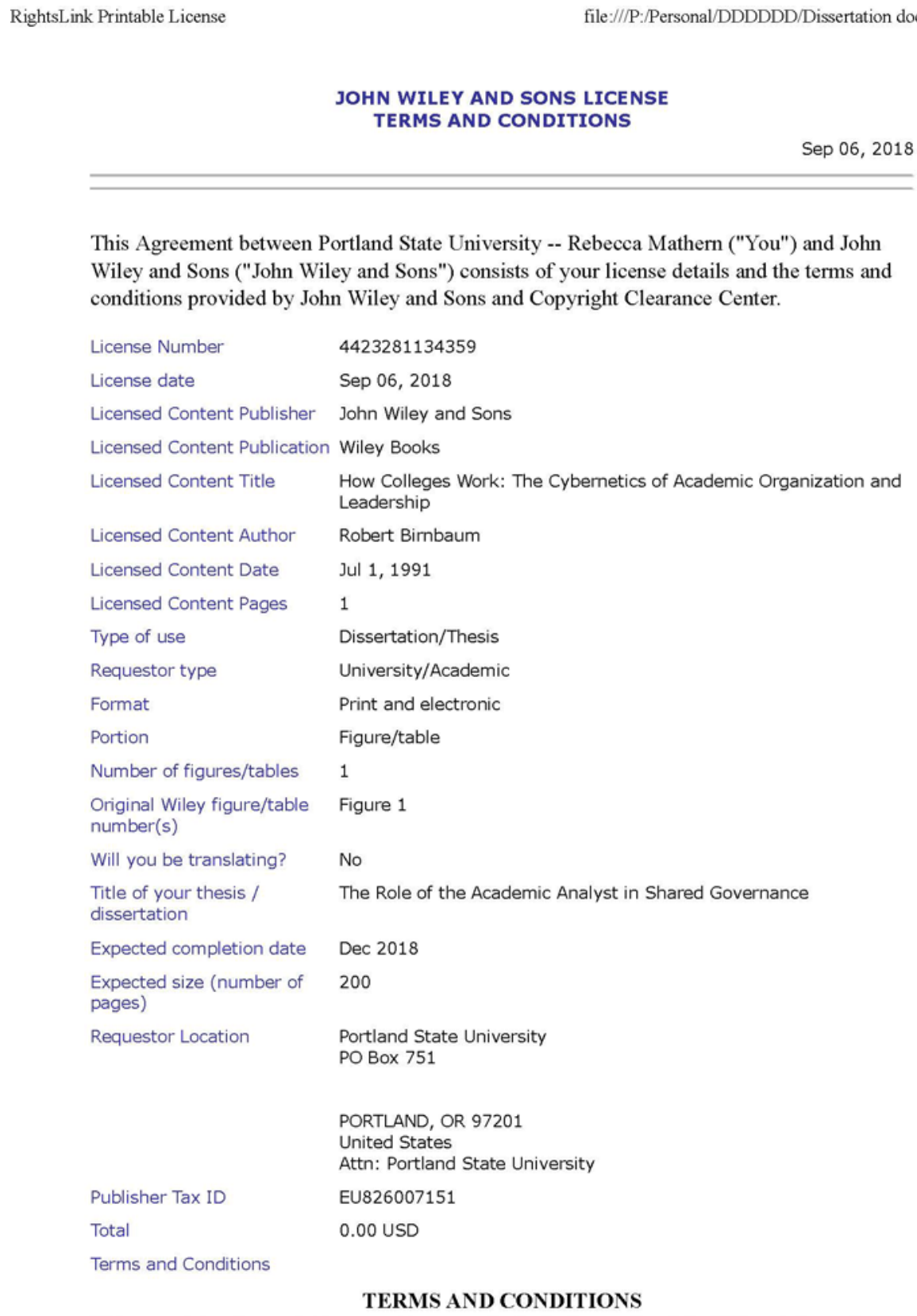

This Agreement between Portland State University -- Rebecca Mathern ("You") and John Wiley and Sons ("John Wiley and Sons") consists of your license details and the terms and conditions provided by John Wiley and Sons and Copyright Clearance Center.

This copyrighted material is owned by or exclusively licensed to John Wiley \& Sons, Inc. or one of its group companies (each a"Wiley Company") or handled on behalf of a society with 
which a Wiley Company has exclusive publishing rights in relation to a particular work (collectively "WILEY"). By clicking "accept" in connection with completing this licensing transaction, you agree that the following terms and conditions apply to this transaction (along with the billing and payment terms and conditions established by the Copyright Clearance Center Inc., ("CCC's Billing and Payment terms and conditions"), at the time that you opened your RightsLink account (these are available at any time at http://myaccount.copyright.com).

\section{Terms and Conditions}

- The materials you have requested permission to reproduce or reuse (the "Wiley Materials") are protected by copyright.

- You are hereby granted a personal, non-exclusive, non-sub licensable (on a standalone basis), non-transferable, worldwide, limited license to reproduce the Wiley Materials for the purpose specified in the licensing process. This license, and any CONTENT (PDF or image file) purchased as part of your order, is for a one-time use only and limited to any maximum distribution number specified in the license. The first instance of republication or reuse granted by this license must be completed within two years of the date of the grant of this license (although copies prepared before the end date may be distributed thereafter). The Wiley Materials shall not be used in any other manner or for any other purpose, beyond what is granted in the license. Permission is granted subject to an appropriate acknowledgement given to the author, title of the material/book/journal and the publisher. You shall also duplicate the copyright notice that appears in the Wiley publication in your use of the Wiley Material. Permission is also granted on the understanding that nowhere in the text is a previously published source acknowledged for all or part of this Wiley Material. Any third party content is expressly excluded from this permission.

- With respect to the Wiley Materials, all rights are reserved. Except as expressly granted by the terms of the license, no part of the Wiley Materials may be copied, modified, adapted (except for minor reformatting required by the new Publication), translated, reproduced, transferred or distributed, in any form or by any means, and no derivative works may be made based on the Wiley Materials without the prior permission of the respective copyright owner.For STM Signatory Publishers clearing permission under the terms of the STM Permissions Guidelines only, the terms of the license are extended to include subsequent editions and for editions in other languages, provided such editions are for the work as a whole in situ and does not involve the separate exploitation of the permitted figures or extracts, You may not alter, remove or suppress in any manner any copyright, trademark or other notices displayed by the Wiley Materials. You may not license, rent, sell, loan, lease, pledge, offer as security, transfer or assign the Wiley Materials on a stand-alone basis, or any of the rights granted to you hereunder to any other person.

- The Wiley Materials and all of the intellectual property rights therein shall at all times remain the exclusive property of John Wiley \& Sons Inc, the Wiley Companies, or their respective licensors, and your interest therein is only that of having possession of 
and the right to reproduce the Wiley Materials pursuant to Section 2 herein during the continuance of this Agreement. You agree that you own no right, title or interest in or to the Wiley Materials or any of the intellectual property rights therein. You shall have no rights hereunder other than the license as provided for above in Section 2. No right, license or interest to any trademark, trade name, service mark or other branding ("Marks") of WILEY or its licensors is granted hereunder, and you agree that you shall not assert any such right, license or interest with respect thereto

- NEITHER WILEY NOR ITS LICENSORS MAKES ANY WARRANTY OR REPRESENTATION OF ANY KIND TO YOU OR ANY THIRD PARTY, EXPRESS, IMPLIED OR STATUTORY, WITH RESPECT TO THE MATERIALS OR THE ACCURACY OF ANY INFORMATION CONTAINED IN THE MATERIALS, INCLUDING, WITHOUT LIMITATION, ANY IMPLIED WARRANTY OF MERCHANTABILITY, ACCURACY, SATISFACTORY QUALITY, FITNESS FOR A PARTICULAR PURPOSE, USABILITY, INTEGRATION OR NON-INFRINGEMENT AND ALL SUCH WARRANTIES ARE HEREBY EXCLUDED BY WILEY AND ITS LICENSORS AND WAIVED BY YOU.

- WILEY shall have the right to terminate this Agreement immediately upon breach of this Agreement by you.

- You shall indemnify, defend and hold harmless WILEY, its Licensors and their respective directors, officers, agents and employees, from and against any actual or threatened claims, demands, causes of action or proceedings arising from any breach of this Agreement by you.

- in No eVENT ShaLl WILEy or its LicENSORS be LIABLE TO you OR ANY OTHER PARTY OR ANY OTHER PERSON OR ENTITY FOR ANY SPECIAL, CONSEQUENTIAL, INCIDENTAL, INDIRECT, EXEMPLARY OR PUNITIVE DAMAGES, HOWEVER CAUSED, ARISING OUT OF OR IN CONNECTION WITH THE DOWNLOADING, PROVISIONING, VIEWING OR USE OF THE MATERIALS REGARDLESS OF THE FORM OF ACTION, WHETHER FOR BREACH OF CONTRACT, BREACH OF WARRANTY, TORT, NEGLIGENCE, INFRINGEMENT OR OTHERWISE (INCLUDING, WITHOUT LIMITATION, DAMAGES BASED ON LOSS OF PROFITS, DATA, FILES, USE, BUSINESS OPPORTUNITY OR CLAIMS OF THIRD PARTIES), AND WHETHER OR NOT THE PARTY HAS BEEN ADVISED OF THE POSSIBILITY OF SUCH DAMAGES. THIS LIMITATION SHALL APPLY NOTWITHSTANDING ANY FAILURE OF ESSENTIAL PURPOSE OF ANY LIMITED REMEDY PROVIDED HEREIN.

- Should any provision of this Agreement be held by a court of competent jurisdiction to be illegal, invalid, or unenforceable, that provision shall be deemed amended to achieve as nearly as possible the same economic effect as the original provision, and the legality, validity and enforceability of the remaining provisions of this Agreement shall not be affected or impaired thereby. 
- The failure of either party to enforce any term or condition of this Agreement shall not constitute a waiver of either party's right to enforce each and every term and condition of this Agreement. No breach under this agreement shall be deemed waived or excused by either party unless such waiver or consent is in writing signed by the party granting such waiver or consent. The waiver by or consent of a party to a breach of any provision of this Agreement shall not operate or be construed as a waiver of or consent to any other or subsequent breach by such other party.

- This Agreement may not be assigned (including by operation of law or otherwise) by you without WILEY's prior written consent.

- Any fee required for this permission shall be non-refundable after thirty (30) days from receipt by the $\mathrm{CCC}$.

- These terms and conditions together with CCC's Billing and Payment terms and conditions (which are incorporated herein) form the entire agreement between you and WILEY concerning this licensing transaction and (in the absence of fraud) supersedes all prior agreements and representations of the parties, oral or written. This Agreement may not be amended except in writing signed by both parties. This Agreement shall be binding upon and inure to the benefit of the parties' successors, legal representatives, and authorized assigns.

- In the event of any conflict between your obligations established by these terms and conditions and those established by CCC's Billing and Payment terms and conditions, these terms and conditions shall prevail.

- WILEY expressly reserves all rights not specifically granted in the combination of (i) the license details provided by you and accepted in the course of this licensing transaction, (ii) these terms and conditions and (iii) CCC's Billing and Payment terms and conditions.

- This Agreement will be void if the Type of Use, Format, Circulation, or Requestor Type was misrepresented during the licensing process.

- This Agreement shall be governed by and construed in accordance with the laws of the State of New York, USA, without regards to such state's conflict of law rules. Any legal action, suit or proceeding arising out of or relating to these Terms and Conditions or the breach thereof shall be instituted in a court of competent jurisdiction in New York County in the State of New York in the United States of America and each party hereby consents and submits to the personal jurisdiction of such court, waives any objection to venue in such court and consents to service of process by registered or certified mail, return receipt requested, at the last known address of such party.

\section{WILEY OPEN ACCESS TERMS AND CONDITIONS}

Wiley Publishes Open Access Articles in fully Open Access Journals and in Subscription 
journals offering Online Open. Although most of the fully Open Access journals publish open access articles under the terms of the Creative Commons Attribution (CC BY) License only, the subscription journals and a few of the Open Access Journals offer a choice of Creative Commons Licenses. The license type is clearly identified on the article.

The Creative Commons Attribution License

The Creative Commons Attribution License (CC-BY) allows users to copy, distribute and transmit an article, adapt the article and make commercial use of the article. The CC-BY license permits commercial and non-

Creative Commons Attribution Non-Commercial License The Creative Commons Attribution Non-Commercial (CC-BY-NC)License permits use, distribution and reproduction in any medium, provided the original work is properly cited and is not used for commercial purposes.(see below)

\section{Creative Commons Attribution-Non-Commercial-NoDerivs License}

The Creative Commons Attribution Non-Commercial-NoDerivs License (CC-BY-NC-ND) permits use, distribution and reproduction in any medium, provided the original work is properly cited, is not used for commercial purposes and no modifications or adaptations are made. (see below)

\section{Use by commercial "for-profit" organizations}

Use of Wiley Open Access articles for commercial, promotional, or marketing purposes requires further explicit permission from Wiley and will be subject to a fee.

Further details can be found on Wiley Online Library http://olabout.wiley.com/WileyCDA Section/id-410895.html

\section{Other Terms and Conditions:}

\section{v1.10 Last updated September 2015}

Questions? customercare@copyright.com or +1-855-239-3415 (toll free in the US) or +1-978-646-2777. 


\section{Appendix E: Mintzberg Permission (Figure)}

Mathern, Rebecca

\section{From:}

Sent:

To:

Subject:
Henry Mintzberg, Prof. <henry.mintzberg@mcgill.ca>

Friday, July 27, 2018 5:47 AM

Mathern, Rebecca

Re: Permission request for use of organization diagrams and figures

Permission granted Rebecca.

$\mathrm{H}$

From Henry Mintzberg's phone. Probably dictated, so please excuse any errors. www. mintzberg.org

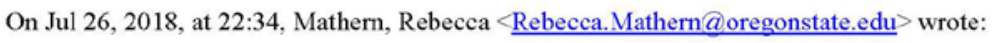

Hello Dr. Mintzberg,

Thank you for the very speedy response. Of course, I should have included the figures initially, my apologies.

All figures listed below come from your Structure in Fives book (1993 edition).

1. Parts of the Organization diagram ( $p 11)$

2. Type A of Decentralization (p115) - big apex and little core

3. Type $\mathrm{E}$ of Decentralization ( 190$)$ - big core and little apex

4. Professional Bureaucracy adaptation (p194) - big support and little technostructure

Your theory is core to my literature review for my dissertation on shared governance. I would be so appreciative of your permission to display and reference your figures in my writing.

I look forward to hearing from you.

Warmest regards with utmost appreciation (and pleasant shock of hearing from the ACTUAL Henry Mintzberg),

Rebecca

Rebecca Mathern

Associate Provost and University Registrar

Oregon State University

rebecca.mathern@oregonstate.edu

<image001.gif>

From: Henry Mintzberg, Prof. <henry.mintzberg@mcgill.ca>

Sent: Thursday, July 26, 2018 7:09 PM

To: Mathern, Rebecca <Rebecca.Mathem@oregonstate.edu>

Subject: Re: Form submission from: Contact 
Sure R, but you should really say which figures these are.

$\mathrm{H}$

From Henry Mintzberg's phone. Probably dictated, so please excuse any errors. www.mintzberg.org

On Jul 26, 2018, at 20:21, Rebecca Mathern via Henry Mintzberg 〈henry.mintzberg@mcgill.ca $>$ wrote:

Submitted on Thursday, July 26, 2018 - 20:21

Submitted by anonymous user: 128.193 .8 .218

Submitted values are:

Name: Rebecca Mathern

Email: rebecca.mathern@oregonstate.edu

Subject: permission for use of figures from Structuring in Fives book

Message:

Hello,

I'm inquiring about the use of multiple figures from the Structuring in Fives

book. I am currently writing my dissertation and Mintzberg models are core to

my literature review of theory. APA standards require that permission be

obtained from either the author or the publisher and I'm attempting to take

care of that.

I work at Oregon State University (Corvallis, OR, USA) but am attending Portland State University in the Public Administration and Policy program (Portland, OR, USA).

If possible, could someone please send a written notice to me allowing for the use of several figures from that book for the purpose of my dissertation that I may use in my bibliography and appendix? Of course, all sources will appropriately cited using the APA standards.

Many thanks in advance for your assistance,

Rebecca Mathern

rebecca.mathern@oregonstate.edu

503.754 .4778

The results of this submission may be viewed at:

http://www.mintzberg.org/node/236/submission/1388 


\section{P Pearson}

Sep 10,2018

Rebecca Mathern

PORTLAND STATE UNTVERSTTY

BUSINESS AFFAIRS OFFICE

P.O. BOX 951

PORTLAND, OR 97207

Dear Rebecca Mathern,

This letter is in response to your request letter dated Sep 6, 2018 for permission to reproduce content from the book STRUCTURE IN FIVES DESIGNING EFFECTIVE ORGNIZATION, 1st Ed. by MINTZBERG, HENRY, ISBN $013855479 \mathrm{X}$

We are sorry, but we must deny your request as Pearson no longer holds the copyright. In this regard, please reach out to the author directly for the required permission.

Unfortunately, we do not have any further information and can therefore not be of any further assistance herein

Sincerely,

Gaynor Thomas

Global Permissions Granting Analyst
Permissions

4th Floor, Auto Atlantic

Comer, Hertzog Boulevard \&

Heere ngracht

Cape town, 800

South Africa

USAPemissions@peasoncom

PE Ref \# 206442 